\title{
Corporate Entrepreneurship, Strategy Formulation, and the Performance of the Nigerian Manufacturing Sector
}

\author{
SEGUN OMISORE
}

A thesis submitted in partial fulfilment of the requirements of the University of East London for the degree of Doctor of

Philosophy 


\section{DEDICATION}

This thesis is dedicated to my brother, Otunba Iyiola Omisore, in appreciation of his encouragement and support throughout the research journey. I am also dedicating the thesis to our late mother, Emilia Adejola Omisore. Most importantly, glory belongs to God almighty for His grace, mercy and kindness every step of the way. 


\section{ACKNOWLEDGEMENTS}

I would like to acknowledge the following individuals for their role, which led to the successful completion of this programme. My Director of Studies, Professor Sonny Nwankwo, who consistently guided the development of the direction of this study even with his busy schedule. My supervisor, Dr Nnamdi Madichie is appreciated, for reviewing and commenting on numerous drafts of this thesis, His critical comments have been very useful and, indeed, instrumental to the successful completion.

Generally, my entire team of supervisors in the persons of Professor Sonny Nwankwo, Dr Nnamdi Madichie, and Dr Qingan Angus Huang, have undoubtedly contributed to making this thesis a much stronger research output following their constructive criticisms over the years.

I would also like to acknowledge my father, David Olajide Omisore, whose fatherly support, advice, and words of encouragement went a long way in strengthening me psychologically as I battled with the odds a project of this magnitude. He cannot be thanked enough.

I also wish to acknowledge friends and family members too numerous to mention. Let them be assured that words are not potent enough to show my heartfelt, profound gratitude to them for their support and encouragement, which proved resourceful in the course of writing this thesis. 


\section{ABSTRACT}

Corporate entrepreneurship is a process that encourages formulating and implementing new ideas, taking risks, and creating new ideas to start new businesses. It is associated with innovation, which results in entrepreneur wealth and adds value for an organisation and the customers that buy the products.

The Nigerian manufacturing sector has been underperforming in the past decade with numerous firms in the sector operating at less than $30 \%$ of initially installed capacity. Despite various industrial transformation programmes initiated by the successive governments to boost manufacturing outputs, most firms in this sector do not seem to have made any significant progress in response. Reasons for this underperformance is arguably due to the misalignment between 'externally-driven' policies and the 'internal processes' within the individual firms of various sizes.

To explore and unravel the undercurrents impelling the seeming strategyenvironment misalignment, this study takes a recourse to the strategic management literature. It draws from the intersectionality of strategy-environment congruence and the attendant moderating effect on performance. In order to drill down to conceptual specifics, it builds on the 3 Cs framework (competence, commitment and co-ordination) initially propounded by Jha and Iyer (2007). Based on a sample of 32 manufacturing firms and leaning on the qualitative methodological approach (using interpretative phenomenological analysis), the study sought to gain situated, contextual, insights into the perceptions of the phenomenon as demonstrable in the strategic configuration. It interrogated respective processes of strategy formulation and implementation in the degree to which they are moderated by the contending environmental variables and the cumulative impact on corporate performance. This is the level of analysis at which corporate entrepreneurship behaviour, in terms of both antecedents and consequences, profoundly manifests itself; mirroring management behaviour, sensitivity and predilections towards environmental scanning capabilities. The sample of firms was drawn from firms of varying sizes in four geopolitical zones of Nigeria - South West, South East, South, and North Central.

Results indicate profound ambivalences in the nature of the operating environment and the signals emitted there from which, in turn, truncates entrepreneurial behaviours of firms. Essentially, negative perceptions of the environment militated against strategic coherence, thus adversely impacting corporate performances. Essentially, the eclectic 3Cs paradigm holds strong explanatory as well as diagnostic force in explicating the setbacks of the Nigerian manufacturing sector. The analytical prism is a novelty and offers tremendous latitude for sketching out appropriate turnaround intervention strategies. 


\section{CONTENTS}

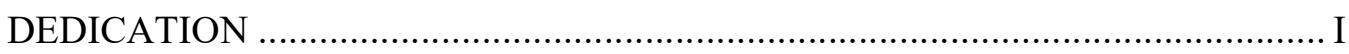

ACKNOWLEDGEMENTS ........................................................................... II

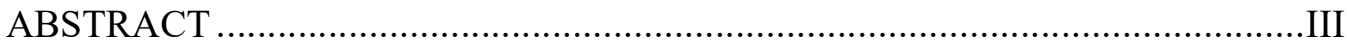

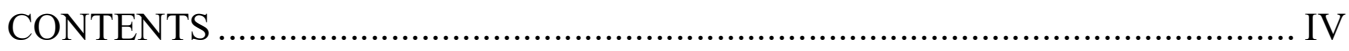

LIST OF APPENDIXES ..............................................................................

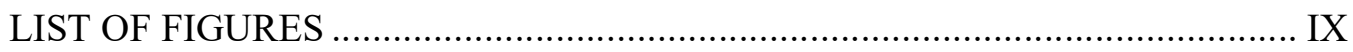

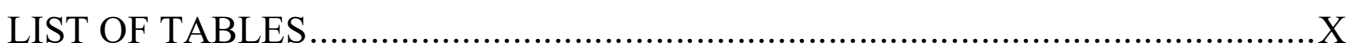

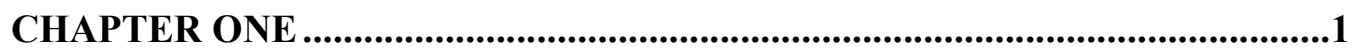

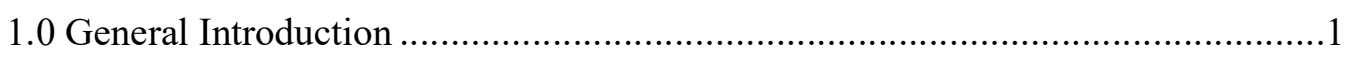

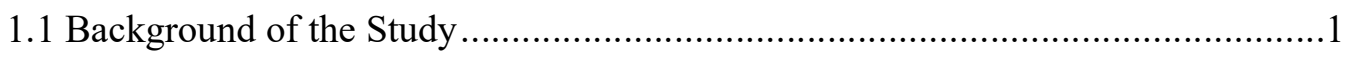

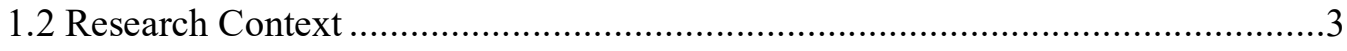

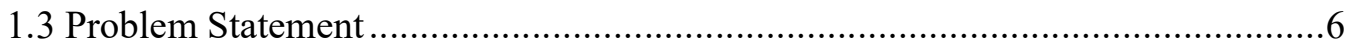

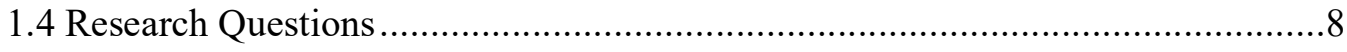

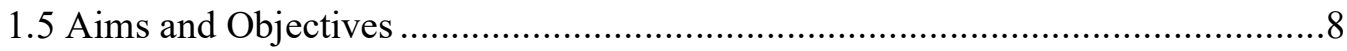

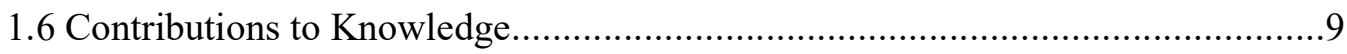

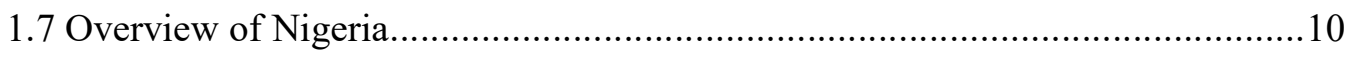

1.7.1 The Macroeconomy...................................................................... 11

1.7.2 Employee Performance and Redundancies ......................................... 13

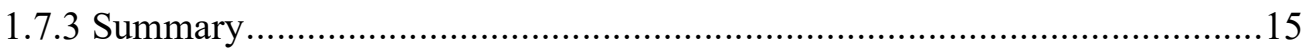

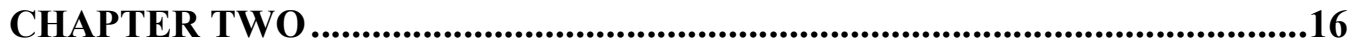

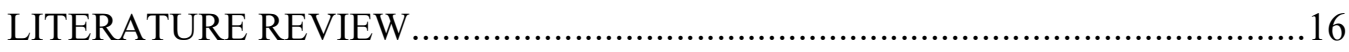

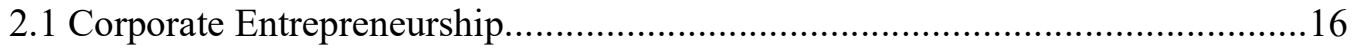

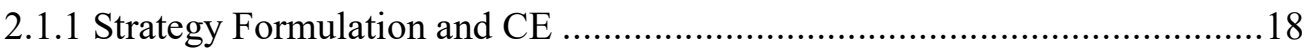

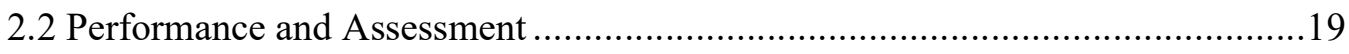

2.3 Conventional Models of Strategies and Organisational Performance Nexus ......21

2.4 Competence, Commitment, Coordination, and Organisational

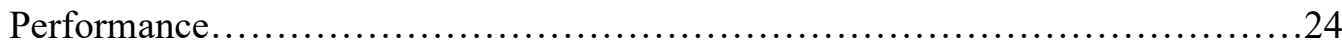

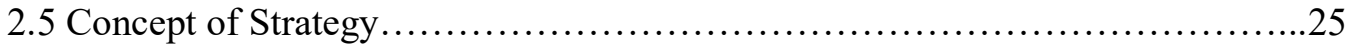

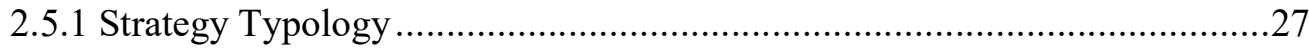

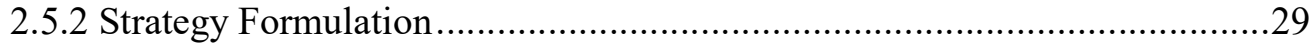

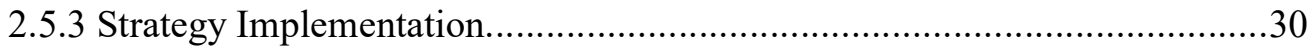

2.5.4 Strategic Management and Dynamic Environments ................................. 31 
2.6 Competence, Commitment, Coordination and Environments $(3 \mathrm{Cs}+\mathrm{E}) \ldots \ldots \ldots 33$

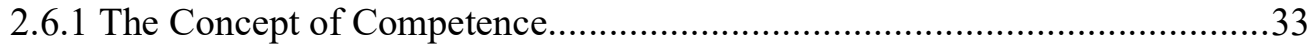

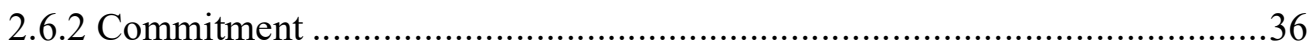

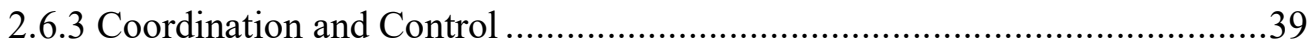

2.6.4 Strategic Management and Coordination .................................................41

2.6.5 Environmental Factors and Strategy .................................................42

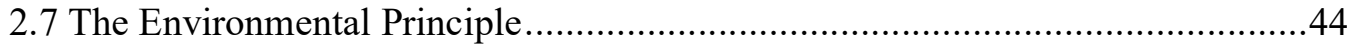

2.7.1 The Transition Period: Reorientation and Shock ........................................44

2.8 Managing Strategy in a Turbulent Business Environment...............................45

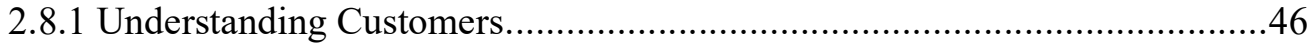

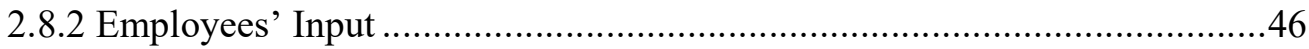

2.8.3 Collaborative Relationships and Environments .......................................46

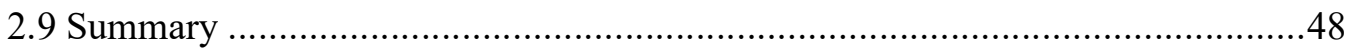

CHAPTER THREE .................................................................................5

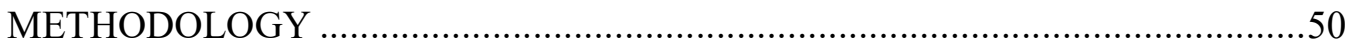

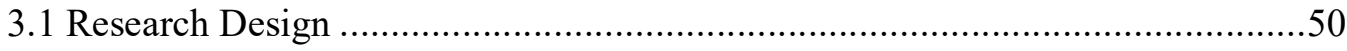

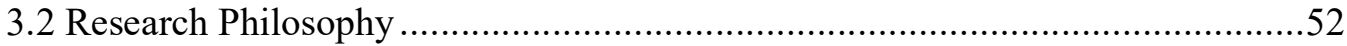

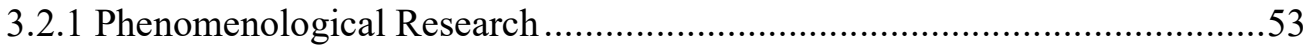

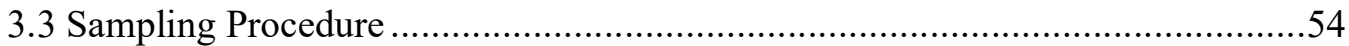

3.4 Guidelines for Saturation and Sample Size .....................................................55

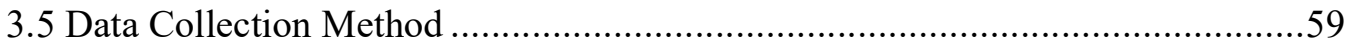

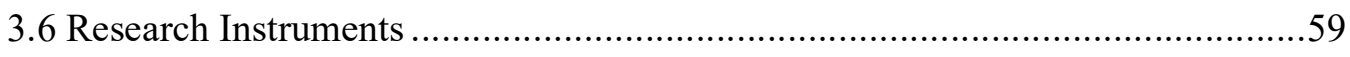

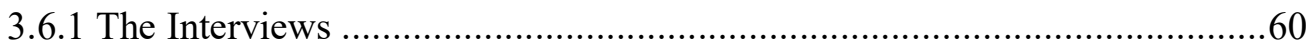

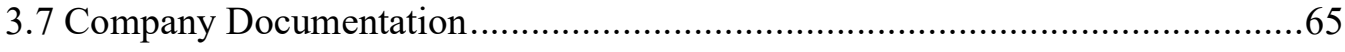

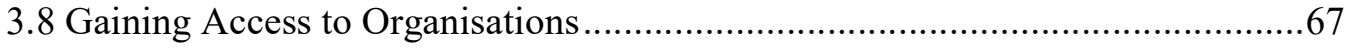

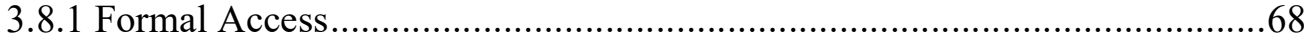

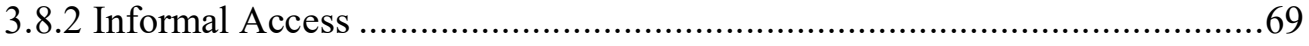

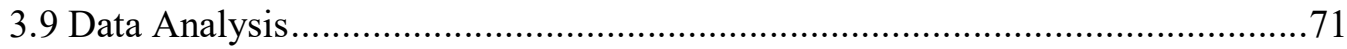

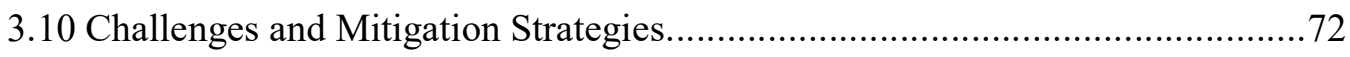

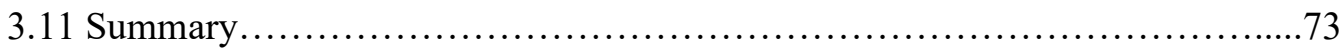

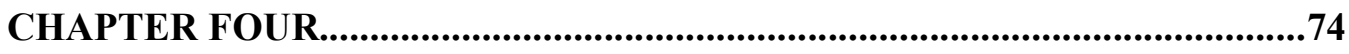

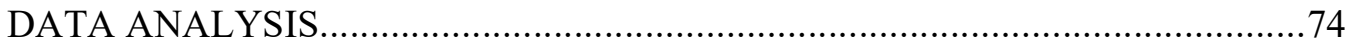

4.1 Auto and Auto Part Manufacturing Firms.................................................. 74

4.1.1 Innoson Vehicle Manufacturing Company Limited .................................75 
4.1.2 Ibeto Group (Union Auto Parts Manufacturing Company) ........................77

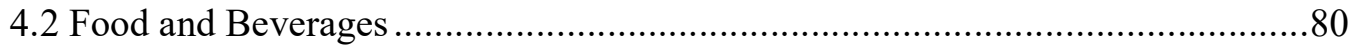

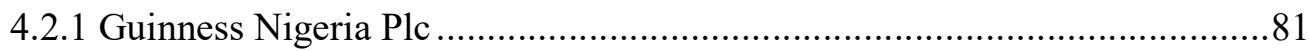

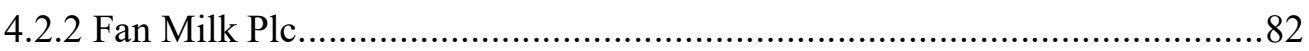

4.2.3 Notre Dame Industrial Company Limited ..............................................8 83

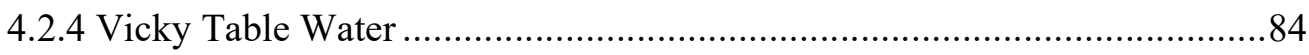

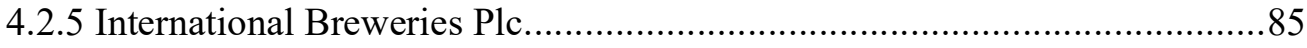

4.2.6 Nigerian Bottling Company Limited......................................................86

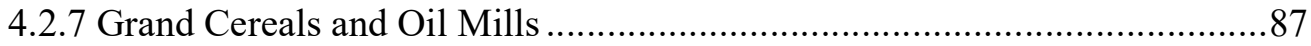

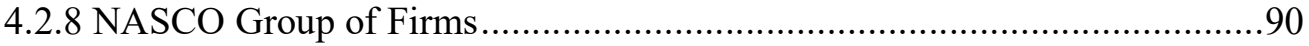

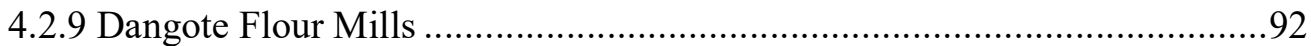

4.2.10 Multi Bond Venture, Awe, Oyo.........................................................93

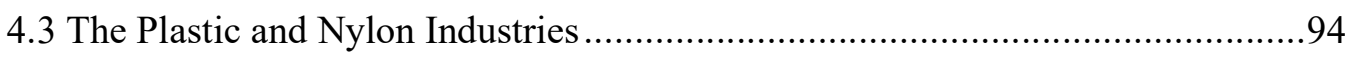

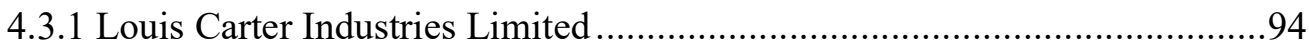

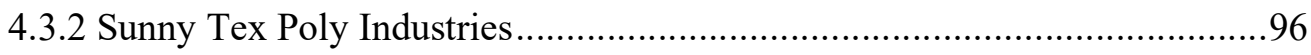

4.3.3 I.C. MASCOT Nigeria Limited, Benin City ............................................97

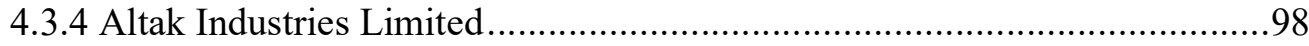

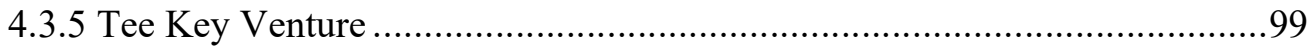

4.3.6 Crown Park, Polythene, and Plastic Bottles ...........................................100

4.3.7 Citico Plastic Industrial Limited .............................................................. 100

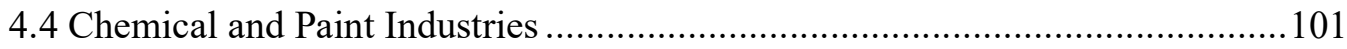

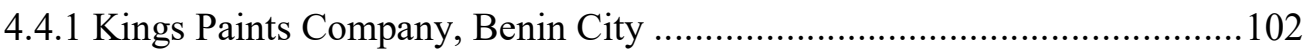

4.4.2 Anyi Solid Chemical Industries (Paint)................................................ 104

4.4.3 Bond Chemical Industry, Oyo ........................................................ 104

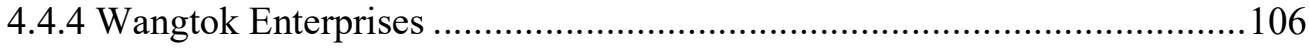

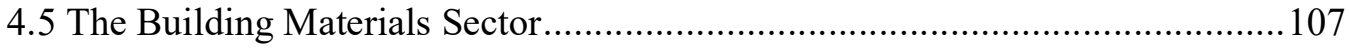

4.5.1 Hentsco Group of Company, Sapele ...................................................... 107

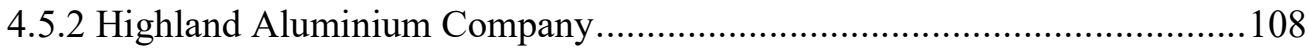

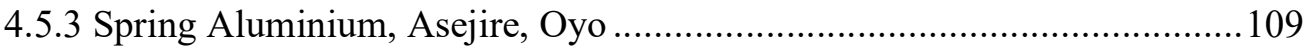

4.5.4 Holdent International Limited................................................................110

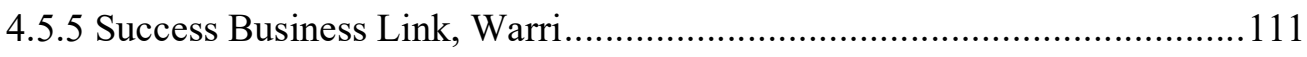

4.6 Iron and Steel Sector............................................... 112

4.6.1 Iron and Steel Nigeria Limited ....................................................... 112

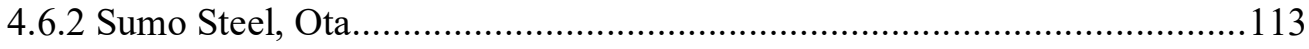




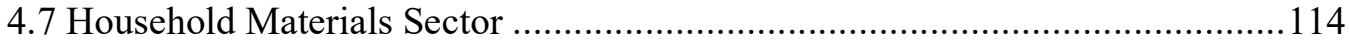

4.7.1 Yinka Oba Foam Nigeria Limited...................................................... 114

4.7.2 Divine Grace Business Enterprises .........................................................116

4.8 Competence, Commitment, Coordination (3Cs) and Performance ...................116

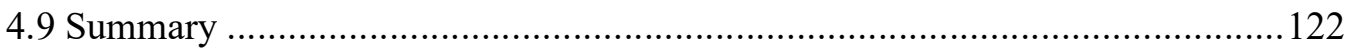

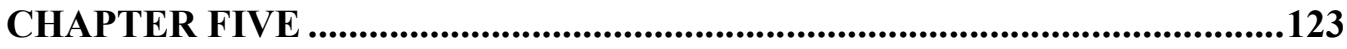

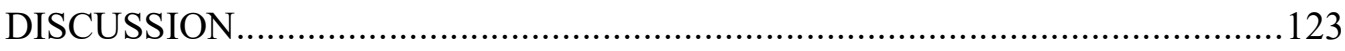

5.1 Competence, Commitment, and Coordination ........................................... 125

5.2 Mitigating Role of the External Environmental ............................................. 129

5.3 Geopolitical, and Socio-Cultural Influences on the 3C's .............................. 135

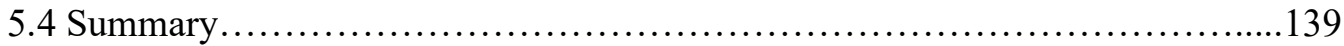

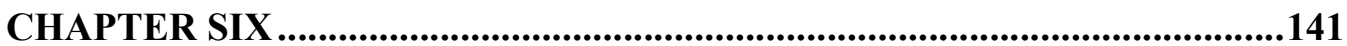

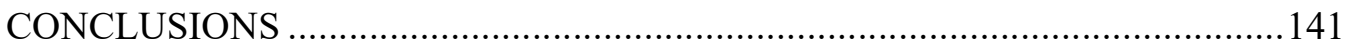

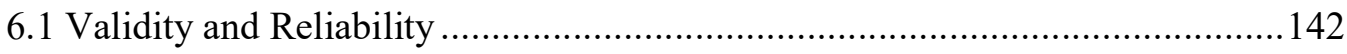

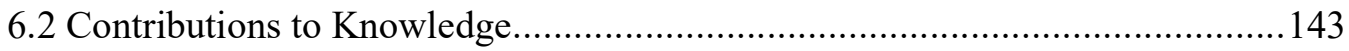

6.3 Limitations of the Research and Future Research Directions ..........................146

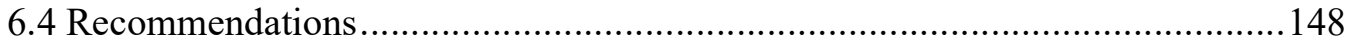

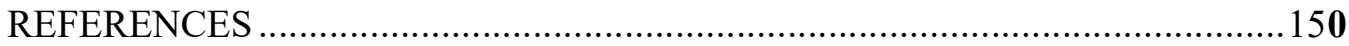

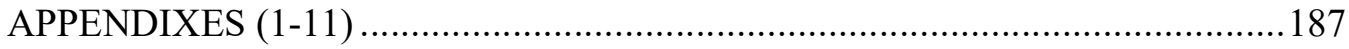




\section{LIST OF APPENDIXES}

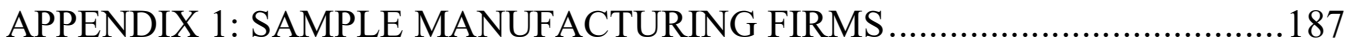

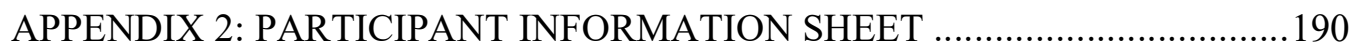

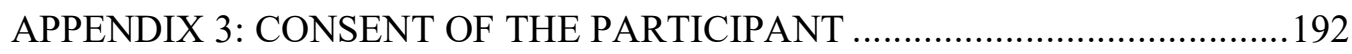

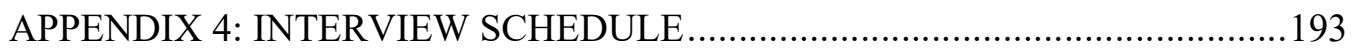

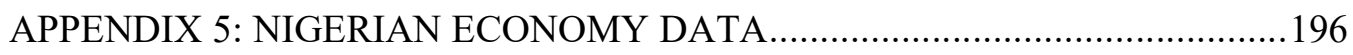

APPENDIX 6: EASE OF DOING BUSINESS RANK IN 2015 AND 2017.......... 197

APPENDIX 7: CONVENTIONAL MODELS OF STRATEGIES .........................198

APPENDIX 8: BACKLOG OF ALLOWANCES/SALARIES IN NIGERIA ........202

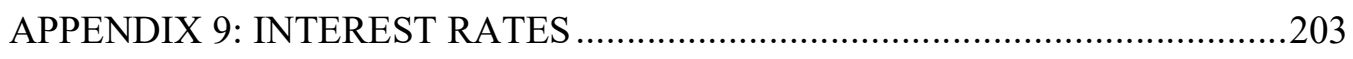

APPENDIX 10: RESPONDENTS' NAMES AND DATE VISITED ....................204

APPENDIX 11: EXTERNAL ENVIRONMENTAL ISSUES .............................207 


\section{LIST OF FIGURES}

Figure 1 Competence's contribution to the strategy formulaton process................117

Figure 2 Commitment's contribution to the strategy formulation process...............118

Figure 3 Coordination's contribution to the strategy formulation process..............119

Figure 4 Effects of environmental (geopolitical and socio-cultural) issues.............120

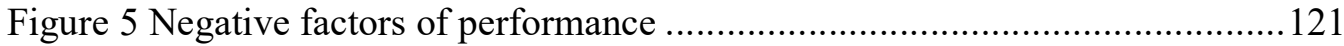

Figure 6 Positive factors of performance......................................................... 122 


\section{LIST OF TABLES}

Table 4.1 Auto and Auto Parts Manufacturing Firms ..........................................74

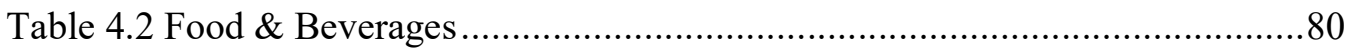

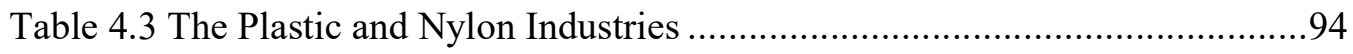

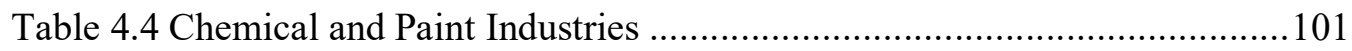

Table 4.5 The Building Materials Sector ........................................................ 107

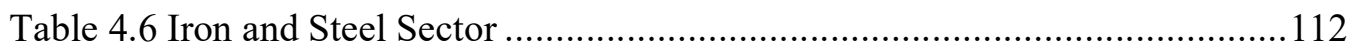

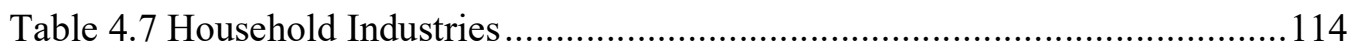

Table 5.1 Socio-Demographic Characteristics of Respondents ........................... 124

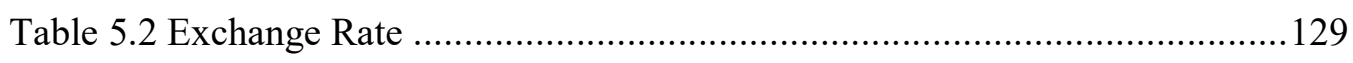

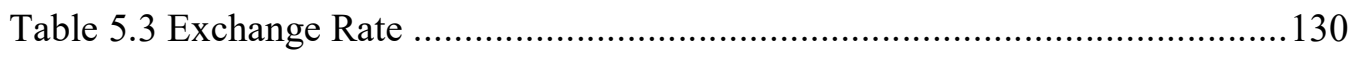

Table 5.4 Firm Closures by Geopolitical Zone (Ranked by Number)....................137 


\section{CHAPTER ONE INTRODUCTION}

\subsection{General Introduction}

Overview: This thesis is split into six chapters. Chapter One provides a broad overview of the study, i.e. it discusses the research context, problem statement, research question, objectives, and contribution to knowledge and provides an overview of Nigeria's situation, including the macro economy, labour system, and infrastructure. Chapter Two discusses in full the review of relevant and critical literature and provides the conceptual foundation and theory upon which the research was conducted. The principle behind this is to critically analyse previous research and call attention to the trends that have emerged. The research questions and objectives are covered in the literature review. It also provides definitions and descriptions of strategy (competence, commitment, coordination, and environment), corporate entrepreneurship, and organisational performance. Finally, it discusses the gap and addresses the shortfalls in the previous literature.

The philosophical assumptions of the research methodology are discussed in Chapter Three, which discloses the methods used in evaluating all samples, the data collected, and the method of analysis. Chapter Four reveals the study's findings and discusses the strategies and organisational performance of the 32 firms. Analyses on the findings in Chapter Four are presented in Chapter Five. Additional findings and theoretical models also emerge in this chapter. The study's significant review shows how the findings and theories developed are related to the existing research, thereby demonstrating an understanding of what was already known.

Chapter Six concludes the study, reflecting upon the unique problems facing the Nigerian manufacturing sector as evidenced by the sampled firms. The contributions of the study are also highlighted in this chapter alongside the study's limitations, and future research directions. Finally, both managerial and policy implications are also discussed.

\subsection{Background of the Study}

According to the Central Bank of Nigeria (CBN, 2016), the manufacturing, construction, and banking sectors constitute the primary sector in Nigeria and contribute to the gross domestic product (GDP) - although to a lesser extent than the 
extractive industry such as the oil sector. Stakeholders in the manufacturing sector have pointed out major stumbling blocks ranging from putrefying infrastructure, to inadequate electricity supply, and inappropriate financing. For example, 121 firms of different sizes that were surveyed by UNIDO (United Nations Industrial Development Organization) in 2010 provided information on the volatile electricity supply for an average of three days a week. The average access for large firms was 3.4 days a week, compared with 2.6 days for smaller firms. The performance of the manufacturing sector has been low, with a $4 \%$ average contribution to the GDP in Nigeria (CBN, 2016). Furthermore, according to the Federal Ministry of Finance, (2004) over $60 \%$ of business projects failed, $60 \%$ of them were not performing, and another $10 \%$ had no project on the ground. The government policy is to provide an enabling environment for the growth of industries and the economy, both of which influence national competitiveness.

However, beyond the challenge of inadequate infrastructural development, it is essential to analyse the input of business strategy, corporate entrepreneurship, and the working environment in the achievement of corporate goals. Paradoxically, in Nigeria, there is limited research that pulls together the discourse of corporate entrepreneurship, manufacturing sector performance, and strategy formulation and implementation. These have long been identified as challenging areas for business owners, chief executives and entrepreneurs (Phan et al., 2009). It is necessary, therefore, to get a sense of the issues and/ or challenges, with a view to suggesting avenues for better performance of the Nigerian manufacturing. As a consequence, this study explores antecedents and consequences of strategy formulation and corporate entrepreneurship problems in Nigeria - a key agenda of the government of the country (World Economic Forum, WEF - African Competitiveness Review, 2011).

Despite the strides made by numerous governments to bring about economic development driven by the manufacturing sector, there is still a lot of work to be done in this area. Like its African counterparts, however, Nigeria faces a range of institutional and environmental challenges. One of the most prevalent has to do with the stifling the business environment coupled with the lack of security for property and persons, lack of a functioning infrastructure (social and financial), policy continuity, political instability, and the rule of law. These factors have had negative effects to varying degrees on strategy formulation/ implementation, corporate 
entrepreneurship, and organisational performance. Evidently, strong institutions and contextually-sound strategies are required for the effective performance of organisations (Fafchamps, 2001; Aaron, 2000, Nwankwo and Richards, 2004) - not the least those in the manufacturing sector.

The emerging focus on a strategy formulation configuration should inform the understanding of the complex interplay between 'development traps' and the difficulty of corporate entrepreneurship and organisational performance. National economic performance is associated with specific institutional features (WEF, 2011). Institutional transition is a problem facing African businesses, comparable to those noticeable in many other emerging economies (Decker, 2010). It should be noted that the reform programmes did not consider this fundamental connection. However, recent studies have contributed to the knowledge by showing more understanding about institutional factors and how they interact to create new conditions (Nwankwo, 2011). Opportunities and threats to businesses are, indirectly or directly, these new conditions in which corporate entrepreneurship must be taken into account in the formulation and implementation of strategy.

\subsection{Research Context}

Structurally, the Nigerian economy can be classified into three main sectors, namely, 'primary/agriculture and natural resources; secondary-processing and manufacturing; and tertiary/services sectors' (Sanusi, 2010, p.16). The industrial sector comprises modern enterprises with less than 10 employees in microenterprises mainly located in the informal sector. The agricultural sector is an admixture of subsistence and modern farming, but it neither achieves its traditional roles of providing enough raw material needs for agro-allied industries, nor enables substantial surpluses for export, or feeding the population.

Indeed, the contribution of the agricultural sector to total GDP of the country has declined over the decades since independence. For example, while in the first decade of independence (i.e. 1960-1970), the dominant position of the GDP was $55.8 \%$, and in 1971-1980 the GDP was reduced to $28.4 \%$, before rising to $32.3 \%$, 34.2\&, and 40.3\% during the decades 1981-1990, 1991-2000 and 2001-2009, respectively $(\mathrm{CBN}, 2016)$. The fall was not because a strong industrial sector was

displacing agriculture but largely because of low productivity, owing to the 
dominance of peasant farmers and their reliance on rudimentary farm equipment and low technology.

The industrial sector is comprised of manufacturing, mining (including crude petroleum and gas), and electricity generation. Despite these efforts, however, the Nigerian manufacturing sub-sector, which is predominantly made up of large, medium, and small enterprises as well as cottage and handcraft units, has been grossly under-performing, with many of the firms operating at less than $30 \%$ of their initially installed capacities due to harsh operating conditions (Manufacturers Association of Nigeria, 2014). In order to provide a picture of the state of the Nigerian manufacturing sector, statistics have reported on different variables, such as the ease of doing business (Doing Business Database, 2017), the contribution of the primary sector, the corruption index, and the success rate of businesses. For instance, out of 183 countries ranked on ease of doing business by the World Bank's Doing Business 2010 report, Nigeria was dropped to the $125^{\text {th }}$ place in 2010 , from the $120^{\text {th }}$ in 2009 (World Bank, 2010, 2018).

Arguably, the general business environment may not be as benign as those of most developed economies, but it is equally the case that the group of enterprises, which the nation expected to lead the transformation, appear to have poorly executed their strategy formulation processes (Okpara, 2011). This brings into focus the nature of the link between strategy, corporate entrepreneurship, and the business environment on the one hand, and performance on the other. Against this background, the purpose of this study is to explore the interconnection between the process of strategy formulation (antecedents) and performance (consequences) in the context of corporate entrepreneurship, with a focus on the Nigerian manufacturing sector.

Despite spirited efforts made to boost manufacturing output and various policy regimes, the manufacturing sector has not made any significant contribution to the growth of the economy. The contribution contracted to $38.6 \%$ in the 1990 s and further to 29.4\% during 2001-2009 (World Bank, 2010). These numbers arguably belie the poor contribution of the manufacturing sub-sector to aggregate output in Nigeria compared with its peers in say Ghana (Davies \& Kerr, 2017) and Kenya (Heshmati \& Rashidghalam, 2018).

Indeed, the contribution of the manufacturing component has on average been below $5 \%$ in the last two decades. Even the relatively high contribution of the oil 
sector to the industrial sector contribution has been largely driven by crude production rather than by the associated 'core industrial' components like refining and petrochemicals. The contribution of wholesale and retail trades and services has remained stable, while that of building contribution rose sharply from $5.3 \%$ in the 1960 s to $8.3 \%$ in the 1970 s but fell consistently thereafter to $1.8 \%$ during $2001-$ 2009. During, and some few years after, the Structural Adjustment Programme (SAP), the main manufactured exports were textiles, beer and stout, cocoa butter, plastic products, processed timber, tyres, bottled water, soap, and detergents, as well as iron rods. However, some of these products have disappeared from the export list owing to a poor enabling environment.

As Oyelola et al. (2013) reported, the challenges of Nigerian manufacturing warrant further investigation considering that, in 2009, over 800 manufacturing firms closed shop. The statistics of such closures emerged from a survey conducted by the Manufacturers Association of Nigeria (MAN) that revealed that a total of 834 manufacturing firms closed operations over the past decade due to inability to cope with the challenges of high overhead costs and an unfriendly business environment (Sanni, 2018; Obisi, Samuel \& Ilesanmi, 2018). There were also causes such as an epileptic power supply and multiple taxes (including public convenience fees, sewage and refuse disposal fees, customary burial ground permit fees, religious establishment permit fees, signboard and advertisement fees, and radio and television license fees, other than radio and television transmitters), which resulted in a huge cost of doing business. The closure of these enterprises further compounded the already bad state of unemployment in the nation. In terms of firm performance, the 2002 Annual Report and accounts of the MAN indicated that $60 \%$ of all manufacturing firms in the country were ailing, 30\% had gone burst and the capacity utilisation was at an all-time low of 25\% (MAN, 2002, CBN Quarterly Economic Review, 2010).

This was the case across most of the sub-sectors. For example, the General Secretary of the National Union of Textile, Garment, and Tailoring Workers of Nigeria (NUTGTWN) cited a classic illustration of the Nigerian textile sub-sector. He reported that it was on the verge of extinction, with fewer than $10 \%$ of the over 250 textile firms that existed between 1997 and 2005, had operated at less than 20\% capacity (Vanguard, 2005). Not surprisingly, these firms had folded up by 2007 due to inefficient production (The Report Nigeria, 2010). The question thus arises as to 
what role strategy formulation, and implementation can play in mitigating the performance of the manufacturing sector in Nigeria. In the next section the argument would be built with a view to justifying the need for a study of this nature.

\subsection{Problem Statement}

While the subject of corporate entrepreneurship has been long identified as being fundamental to Nigeria's economic growth, it has equally faced enormous challenges (Dugguh, 2013) and thereby prompting a need to investigate the complex interplay between observable manufacturing 'development traps' and the challenge of strategy formulation in manufacturing firms.

Entrepreneurship in Africa faces challenges that are not altogether dissimilar to those observable in many other emerging and/or developing world economies but are nevertheless made more severe by the 'prevalence of institutional transitions' that are context-specific (Nwankwo, 2011; Madichie, Mpofu \& Kolo, 2017; Madichie and Nkamnebe, 2010; Igwe et al., 2019). This means that there is a close correlation between specific institutional features and national economic performance. However, early 'experiments' with economic reform programmes largely neglected this fundamental connection. Although some studies (e.g. Economic Affairs, 2012) have provided incremental additions to knowledge, they have also shown that much more understanding of the embedding institutional factors and how they interact to create new conditions is needed. These 'new' conditions, either directly or indirectly, represent threats and opportunities to businesses and must be considered in strategy formulation to promote enterprise development.

There have been very limited theoretical or empirical explorations of strategy formulation in the context of corporate entrepreneurship and firm performance research in Nigeria. A few discernible attempts from the extant literature (e.g. Dhliwayo, Van Vuuren and Fletcher, 2011) concerned aspects of strategy planning (such as perception of innovation management, environmental scanning, decisionmaking, and performance). Such studies tended to adopt a fixed ontological perspective, leaving a severe gap not only in the knowledge of the moderating factors of strategy but also of the process itself.

Similar outcomes are equally evident in other studies (e.g. Cobbold and Lawrie, 2006; Tervio, 2008), highlighting a lack of reflexivity and appropriate contextualisation of the issues at hand. Furthermore, there are hardly any studies that 
have sought to map the connection between the antecedents (the strategic configurations of corporate entrepreneurship) and manufacturing firms' performance outcomes - not the least, in the context of Nigeria. Consequently, these studies provide two key impetuses for the current study.

First, the strategy-environment congruence-a conceptual angle that has been applied in the evaluation of how specific environments impact strategy, strategic actions, and performance (Onyeonoru, 2003; Minniti and Moren, 2010; Khanna and Palepu, 2010). Second, the eclectic paradigm proposed by Jha and Iyer (2007), configurating the $3 \mathrm{Cs}$ has been appropriated and mapped against the strategycorporate entrepreneurship nexus in this study. Although originally developed as a project management construct and applied to the construction sector, model and/ or framework provides a new an arguably appropriate framework to guide and direct this study.

Probing the literature further, it is worth acknowledging that the study by Chandler and Hanks (1994a) referred to the environment as a parsimonious model of venture performance that incorporates individual founder, firm, and environmental characteristics. These authors went on to talk about "competence" as a key component/ moderating variable in venture performance based on a sample of 155 manufacturing firms in North-western Pennsylvania in a developed world context. Similarly, the intersection between competence and commitment has been explored in the literature. For example, Erikson (2002, p.275) made a connection with commitment as part of entrepreneurial capital, 'a multiplicative function of entrepreneurial competence and entrepreneurial commitment'.

While the contention of Jha and Iyer (2007) might have been focused on project management in the construction sector, the $3 \mathrm{Cs}$ outlined in their study and reflected in its title are equally transferable to a deeper understanding of the competitiveness of manufacturing firms. For one, commitment is related to the entrepreneurial capital discussed by Erikson (2002), and coordination is equally pertinent to organisational success and strategy implementation (Noble, 1999). As for competence, besides the construct of core competence in the strategy literature (Markides and Williamson, 1994; Coyne, Hall and Clifford, 1997; Prahalad and Hamel, 2003; 2006). Indeed, Chandler and Hanks (1994a; 1994b) touched upon founder competence and the environment, as well as on capabilities. 
From this subject position, it could be speculated that the problem of strategy formulation in Nigeria is entangled with the peculiar institutional features of the business environment in the country. Furthermore, based on a synthesis of prior research (e.g. Sawyer et al., 2000; Erondu and Sharland, 2002; Phan et al., 2009; Dauda, Akingbade and Akinlabi, 2010), it could be inferred that corporate entrepreneurs' approaches to strategy formulation in Nigeria have tended towards peoples' commodification and ritualisation. This has probably resulted in the poor performance of the corporate sector in Nigeria (see Osuagwu, 2002; Onyeonoru, 2003) and why environmental scanning (i.e. strategic management) have been described as arduous endeavours (Glynn, 1993; Warren, 2011).

\subsection{Research Questions}

This study poses the following research questions as follows:

1. How is the process of strategy formulation in the context of Nigeria's corporate entrepreneurship causatively linked to corporate underperformance?

2. Can a model be developed based on the interconnections between the $3 \mathrm{Cs}$ (competence, commitment, co-ordination) in relation to strategy formulation, corporate entrepreneurship, and organisational performance?

3. To what extent do the $3 \mathrm{Cs}$ and the environment influence corporate entrepreneurship and organisational performance (attributions of success or failure)?

\subsection{Aims and Objectives}

Based on the research questions posed in the previous section, the main research objectives are stated as follows:

1. To determine the effect of geopolitical and the socio-cultural influences on the $3 \mathrm{Cs}$, as well as the degree to which these dimensions contextually moderate strategic configurations and corporate performance.

2. To develop a model based on the interconnections between the $3 \mathrm{Cs}$ that will determine the effects in relation to strategy formulation, corporate entrepreneurship, and organisational performance.

3. To establish the extent to which $3 \mathrm{Cs}$ and the environment influence corporate entrepreneurship and the attributions of organisational performance. 


\subsection{Contributions to Knowledge}

The main preoccupation of this study is to explore the intersection of the $3 \mathrm{Cs}$ not only as causal factors but also an approach to mitigate the effects the turbulent corporate environment as contextualized with Nigeria. The contextual focus is germane when considered alongside the expected role of the manufacturing sector in the nation's economic development goals and a lift-off from the ascription as one of the poorest countries of the world. Essentially, understanding the lacklustre performance of the Nigerian manufacturing sector affords a solid base and, indeed, the key to unravelling the poverty of the Nigeria state, albeit from the economic standpoint. This integrative view proffered by this study is arguably novel in the sense that both theoretical and practical implications are highlighted for the future growth trajectory of the Nigerian manufacturing sector and the key players within the sector, whether small, medium, or large enterprises.

A further contribution, from a theoretical lens, is the appropriation and extension of the 3Cs framework espoused by Jha and Iyer (2007), in the context of an adjacent field (i.e. construction) being extrapolated to the discourse of strategy formulation and corporate entrepreneurship performance in the manufacturing sector of Nigeria. In a way, this approach has extended the repertoire of analytical lenses for explicating the nature and interconnectedness of environmental factors. From a practical/policy standpoint, the study develops a set of tools to equip managers to better understand the main dimensions of strategy formulation and implementation in a decentralised manner as opposed to the conventional 'commander model' in order to enhance corporate performance in a more sustainable manner (see Craven et al., 2008). In the light of these points, three key pointers need to be highlighted.

First, through an investigation of stakeholders' competence, emphasis is placed on entrepreneurs' and employees' knowledge, skills, and experience. These are identified as better performance indices in appreciating the dialectic link between strategy formulation and implementation, corporate entrepreneurship, and manufacturing sector performance - a dimension that seems absent in the extant literature. Second, the study explores the theoretical significance of strategic management and its congruence with the business environment with the view of establishing the effects of the commitment of employees' competence and coordination of organisations and the requisite environment (business and political) within which these can be successfully exploited. Thirdly, the study analyses 
coordination into two parts, notably, decentralised systems (a situation in which people across the organisation are encouraged to experiment with their inputs and identify new ideas and more innovative approaches) and the centralised system where the directors or CEOs set the strategy for a company (Tervio, 2008). This is a considerable move-away from the deterministic approach prevalent in the general literature.

By investigating different manufacturing outfits of various sizes and across four geopolitical zones in Nigeria, deeper insights have been gained through comparing and contrasting the interactions of organisational strategy formulation and implementation within the existing environmental constraints in the Nigerian manufacturing sector. Thus, this study has uncovered that the relationship of stakeholders' $3 \mathrm{Cs}$ and organisational performance is the key to failure or success. Furthermore, it provides a clearer understanding of the relationship between strategy formulation, corporate entrepreneurship, and organisational performance, as well as the relationship between environments (geopolitical and socio-cultural), influences on stakeholders' $3 \mathrm{Cs}$, and their influences on corporate entrepreneurship performance.

This study finds that the $3 \mathrm{Cs}+\mathrm{E}$ of stakeholders lie together at the heart of performance and success of strategic configurations in corporate entrepreneurship. It also revealed hybrid and ambivalent positions guiding and constraining the corporate entrepreneurship ecosystem and implications for the development (or underdevelopment) of corporate entrepreneurship in Nigeria.

\subsection{Overview of Nigeria}

Prior to independence, Nigeria was a three-way federation consisting primarily of Northern, Eastern, and Western regions. This explained the cultural and political differences among the country's three main tribal groups, including the HausaFulani, the Yoruba, and the Igbo/Middle Belt region, who constituted the majority of the population in the Northern, Western, and Eastern regions, respectively. Major factors that have driven the business climate in Nigeria are the issues of values, beliefs, and culture. This was affirmed by the words of the President-General of the National Union of Civil Engineering, Construction, Furniture, and Wood Workers, 
Adeoye (2005). He challenged economic rationalism by referring to the cultural and political set-up of the Nigerian economy, which has shaped the nature of businesses.

Nigeria has over 250 separate ethnic groups and languages, has been adduced as the largest population in Africa (about 170 million), as it accounts for $47 \%$ of West Africa's population, and is the $8^{\text {th }}$ most populous country in the world (Corporate Nigeria Guide, 2010). In principle, by cultural heritage, Nigeria is one of the world's most ethnically diverse societies. However, since the 1960s, the Nigerian political climate has been characterised by turbulence, with a history of more than 30 years of dictatorial rule compared to democracy. While a minority sect of the population, who are more apparent in remote areas, adheres to traditional religions, there have been political cleavages running along the major ethnic and religious divides (Corporate Nigeria Guide, 2010).

The reflections of continuous fraudulent activities have been equally evident in the manner in which government properties and corporations have been managed. For example, according to official statistics published in November 2003, it was revealed that a government carrier owned 25 aircraft in 1983; this dwindled to 3 in 1999 and then to none by 2005 due to bankruptcy. Additionally, between 1983 and 1999, some US\$400 million airline funds were mismanaged. It was stated that several senior officials, including two former ministers, sold government property, such as two aircraft, without authorisation (National Independent, 2003). In 2014, the Ministry of Finance discovered 3,000 ghost workers on its payroll. Then-finance minister Okonjo-Iweala, in an audit process in 2004 that was targeted at bringing about reforms and sanity to the public-service system, discovered that her ministry had fake pensioners. The audit revealed that not only did the ghost workers continue to receive promotions, they even retired. The minister strived to close huge loopholes in the ministry through which unscrupulous civil servants siphoned off the government's money.

\subsubsection{The Macroeconomy}

In the period between 2005 and 2010, the Nigerian economy was the second largest in sub-Saharan Africa after South Africa, with an average GDP growth of $6.4 \%$ (IMF, 2014). However, in 2014, just before the economic recession of 2015 Nigeria was ranked as the largest economy in Africa using the nominal GDP (CBN, 2016). 
According to reports, in 2016, it was reported that Nigeria, with its large natural resources, Nigeria was the $22^{\text {nd }}$ largest economy in the world with $41 \%$ of Africa's GDP (CBN, 2016), and accounted for Africa's largest gas reserve and the $7^{\text {th }}$ globally, and the $10^{\text {th }}$ oil producer and $4^{\text {th }}$ oil exporter in the world (NEMA, 2011).

Considering the deep mangrove swamps and creeks that characterise Nigeria's $800 \mathrm{~km}$ coastline, where most of the country's oil and gas reserves are found, opportunities for the exploration of bitumen, natural gas, and crude oil have accounted for over $85 \%$ of export earnings in Nigeria (Robson, 2005).

Despite the rapid growth of the oil sector in the 1970s, the agricultural sector accounts for about $40 \%$ of Nigeria's economic activity and provides both informal and formal jobs for most of the population. Nevertheless, there has been a paradoxical experience in agricultural outputs and return patterns in Nigeria. Specifically, the financial returns via farming have eroded over the years, and the country, a large net exporter of agriculture produce at independence in 1960, has now become import-dependent in this regard. Historically, in the 1960s, large quantities of natural resources like palm oil and kernel, timber, rubber, cocoa beans, groundnuts and cotton were exported. Since the early 1990s to date, only a smaller scale of rubber, cocoa, and palm products have been being exported to any notable degree (The Report Nigeria, 2013).

The government has made efforts to revitalise the agricultural sector with limited success due to factors such as the inadequate distribution of fertilisers, lack of investment interest, lack of political will and ability, grossly inefficient commodity boards, and so on (The Report Nigeria, 2013). Market-oriented reforms were introduced to increase both the food crops and export production and check the ailing import-dependent economy. These changes could be possible by removing pricefixing marketing boards and lifting the ban on the export of certain agricultural commodities (Economist Intelligence Unit, 2012).

While there have been clamours and a host of activities directed towards economic diversification from a mono-product oil economy, various governments have failed to make significant progress in this regard (Economic Affairs, 2012). This could be the result of decades of economic mismanagement that have brought about restricted unbalanced growth, thereby placing Nigeria amongst the poorest nations and causing the GDP per capita to drop to under US\$300 (see Ekpo, 2016). 
Given the present social and economic conditions, the general population of some SSA countries are poorer today than they were 20 years ago - with reports showing about $70 \%$ of the population to be living on less than or on US\$1 a day (National Statistics, 2010). This is to the extent that the US Under Secretary of State, Alan Larson, called for more US assistance in 2003 as follows:

It must be a reform program that is owned by Nigerians. With Nigeria and Angola possible generating US\$150 billion in oil and gas revenue by $2010 \ldots$ we really do think these revenues could be a driver for national economic development. But, frankly, it's not going to happen unless the patterns of the past - including mismanagement and rent seeking - change. [Reform is important because] the more it's seen that Nigeria's oil wealth is helping to improve the capacity of its citizens to participate in the global economy, that it is improving health and educational standards, the better it's going to be for Nigeria and for the United States that wants to have a strong, forward-looking economic partnership [with the West African powerhouse] (Nigeria Monthly Magazine, 2003, p.34).

On its part, the approach of the Nigerian government towards anti-poverty policies have been full of macroeconomic challenges of the years (Bello, 2005, cited in Vanguard, 2005, p.17; Adeoye, 2005 cited in Punch, 2005, p.21), especially in terms of policy implementation, monitoring, and evaluation. These incapacities have led to numerous incidences of employee underperformance and redundancies in the manufacturing sector.

\subsubsection{Employee Performance and Redundancies}

None of the Nigerian sectors' wages have kept up with the abnormally high cost of living, except for a few in the banking and oil sectors (Economist, 2013). A more worrisome incident is the issue of firm collapses, which births terrible consequences. While firm owners lose capital, job losses also come with daunting socio-economic consequences. Economic Affairs (2012) stated that statistics on unemployment are reflections of the realities of underperformance in the sector, and especially in garment \& textiles as well as the Steel sub-sectors. As the report highlights:

- Dozens of garment and textile manufacturers alone folded up in 2007 in Nigeria for a loss of over 4,000 jobs. 
- The Oshogbo Steel Rolling Company (OSRC) made about 1,000 staff redundant.

- Thousands of employees of the Delta Steel Company (DSC) were made redundant in 2005 .

Furthermore, beyond the fear of losing their job, which can obviously affect employees' performance, more harrowing experiences are the issues of 'job fit', 'job suitability', and underemployment, which go a long way towards explaining employee performance (Goulet and Singh, 2002).

In a submission at a recent Lions Day Celebration in Nigeria, the Managing Director and Chief Executive of Omega Bank Plc, Segun Agbetuyi, affirmed that studies have pointed out that one out of every two Nigerians lives in squalor, with basic health services or no access to portable water (Punch, 2003). In a similar assessment of the level of infrastructural development in Africa, using its Infrastructure Index in 2004, the UN Economic Commission for Africa's (UNECA) Economic Report on Africa ranked Nigeria $28^{\text {th }}$ out of 30 African countries (UNECA, 2004). Similarly, according to the UN Conference on Trade and Development (UNCTAD), the number of internet users in Nigeria rose to 17 per 10,000 people in 2002 from 10 per 10,000 people in 2001. Although this represented a substantial increase, the 2002 level was still low compared with 628 in South Africa and 427 in Togo (UNCTAD, 2003). However, according to a statistical report for 2013 to 2019, internet users are gradually increasing in Nigeria.

Another major challenge to development and performance in Nigeria lies in the area of access to power. Adequate energy is an important factor in social and economic development, production processes, development processes, and the population's overall quality of life. Regrettably, the availability of basic infrastructure falls short of demand in Nigeria (World Bank, 2010). In a bid to combat electricity challenges, most firms have had to employ alternative mechanisms, such as opting for gas, petrol, or diesel-powered generators, which cost roughly three times more than grid-sourced electricity. Firms report that power costs as much as $7 \%$ of their revenue. Incidentally, the high cost of power finds its way into the cost of production, thereby raising general prices and the quality of products, creating a vicious cycle (The Report Nigeria, 2010). 
Many firms in Nigeria are constantly in distress simply because none of these infrastructural requirements are available in Nigeria. Good roads, water, and electricity in the case of a developing country like Nigeria are the infrastructure facilities that must be in place before any business or economy can prosper..

\subsubsection{Summary}

The Nigerian manufacturing sector has been underperforming in the past decade with numerous firms in the sector operating at less than $30 \%$ of initially installed capacity. Despite various industrial transformation programmes initiated by the government to boost manufacturing outputs, most firms in this sector do not seem to have made any significant progress in response. Reasons for this underperformance is arguably due to the misalignment between 'externally-driven' policies and the 'internal processes' within the individual firms of various sizes.

By investigating where the challenges lie and how to tackle this misalignment of environmental factors (external and internal) this study resorts to the strategic management literature drawing upon sample of 32 manufacturing firms and interrogating their respective strategy formulation and implementation. Internal influences were conceptualised in light of competence, commitment, and coordination (i.e. the 3Cs) framework proposed by Jha and Iyer (2007) in the case of construction firms in India to the discourse of strategy, corporate entrepreneurship and manufacturing sector performance in Nigeria. This is in a bid to develop a framework that would enable a better understanding of the strategy formulation, strategy implementation, and performance of the sector. The framework taken from

the construction sector serves as an appropriate tool for exploring the performance of the Nigerian manufacturing sector. 


\section{CHAPTER TWO LITERATURE REVIEW}

In this chapter, the focus is on the literature of corporate entrepreneurship. It defines components of strategic management and then discusses a model of the $3 \mathrm{Cs}$, business environment, and organisational performance, which is the key to success or failure.

\subsection{Corporate Entrepreneurship}

Corporate entrepreneurship (CE) is a process that encourages formulating and implementing new ideas that will add value to an organisation and the customers that buy its product (Minniti and Moren, 2010). It involves creating new systems, resources or processes to produce new goods or service at profit or taking advantage of discovering new markets or entering into a market (Aminu, 2011). According to Abrams (2012) and Chinonye (2013), CE can be defined as an enterprising individual's commitment to taking risks, creating new ideas, pursuing lucrative opportunities, and starting new businesses so as to make money through the implementation of the new plans. Some authors believe that $\mathrm{CE}$ is associated with innovation, exploiting ideas, processing to produce new goods, commencing new organisations, services, and resources, and taking risks, which result in entrepreneurs' wealth, firms' success, and customers' satisfaction (George et al., 2016).

An entrepreneur is an individual who coordinates or manages a business and takes all the risk (Roth, 2014). Entrepreneurs formulate business models, employees, and resources and are responsible for their performance, which determines the success or failure of the sector (Minniti and Moren, 2010). Individual entrepreneur and mobility are more innovative and creative with new ideas (Agarwal et al., 2004), a critical source of new knowledge and experience that impact firm performance (Ioannou, 2010; Campbell et al., 2012) and influence the growth and success of the business (Klepper, 2001; Klepper and Thompson, 2010).

The three components of CE are innovation, proactiveness, and risk-taking (McDougall and Oviatt, 2000). The components of attitude toward entrepreneurship are instrumental, opportunity costs, and experiential (i.e. when someone personally sacrifices finances in order to incur an entrepreneurial venture) (Botsaris and 
Vamvaka, 2016). According to Biniari (2012), the CE context is part of its contagion, institutionalisation, and rationalisation.

Corporate entrepreneurs are not only pervasive and important but also perform well economically. CE businesses are the backbone of the global economy (MENA Businesses Report, 2011). Entrepreneurship and small businesses contribute to both national and economic development (Dugguh, 2013). Organisations and national economies can only be successfully transformed through institutional entrepreneurship (Hu et al., 2016). CE and successful businesses provide employment opportunities, poverty reduction, a competitive environment, economic growth, and investment (Osbourne, 2009). Amma Ajayi, the managing director of Swiss Biostadt Limited, stated that the promotion of enterprises leads to income generation, independent wealth, economic benefits, and entrepreneurial development (Nwaoguji, 2016). This require countries to be motivated and committed to strengthening entrepreneurship by investing in growth and development and providing assistance for entrepreneurs to start up a new business (Jung-Wan and Tai, 2010). George et al. (2016) found that the level of CE firms in developing economies was relatively low compared to developed economies due to poverty and social fracture. The concept of entrepreneurship has been studied from psychological and economic perspectives. For example, economic terms like 'difference in profitability' and 'sales growth' are used to measure CE activities (Wiguna and Manzilati, 2014).

Nwankwo and Richards (2004) highlighted the ways in which strategy formulation varies by culture, as there are limited situated understandings of how $\mathrm{CE}$ contextually unfolds in many developing economies. Strategy formulation and CE are fundamental to a firm's overall culture and contribute to their competitive advantage (Mohamad et al., 2011). In an emerging market, most products failed because local cultures were not put into consideration (Khanna and Palepu, 2010). Livermore (2011) pointed to cultural conflict as a major source of setback in CE and concluded that effective performance and success depend very much on finding the right balance in (i) setting strategy and (ii) operating the business designing the organisation.

The entrepreneurship sociological approach is when an entrepreneurial activity is determined by the social context, which has effects on individual characters (Wiguna and Manzilati, 2014). Dess et al. (2003) identified the critical roles and social exchanges that constitute the CE process, as well as the dynamic 
interplay with institutional contexts (the social exchange approach). The authors argued that a CE strategy that is lacking a sufficient level of social embeddedness is bound to fail. Bhardwaj and Sushil (2012) stated that entrepreneurship is a dynamic form of social and economic behaviour. Financial resources, business plans, and participation in social networks influence entrepreneurial coordination (Vuong, Do and Vuong, 2016). Corruption has a negative effect on entrepreneurship (Dutta and Sobel, 2016).

However, this research revealed the cultural and social positions guiding, as well as constraining, the $\mathrm{CE}$ ecosystem and implications for the development (or underdevelopment) of the manufacturing sector in Nigeria. This approach advocates for greater emphasis on the internal environment of $\mathrm{CE}$ as a way to fully understand what underpins entrepreneurial outcomes' 'performance' (Bhardwaj and Sushil, 2012). The internal environment contributes to or influences the success of CE. CE add value to organisations by increasing firms' performance with regard to the moderating effect of the dynamic forces shaping new trends in the environment (Mohamad et al., 2011). Essentially, treatment of CE configurations - how they are embedded in specific environments and/or impact organisational performance continues to raise tensions and contestations in contemporary strategy discourse (Feldman and Pentland, 2003; Bradford, 2007). When businesses operate in volatile, dynamic, and turbulent environments, the effective usage of CE results in the negative performance of organisations (Ireland, Kuratko and Morris, 2006).

Consequently, entrepreneurs need to seek alternative business strategies to sustain growth and success, and CE is the process of creating such alternative new business strategies in an organisation through new products, ideas, and risk-taking to do so (Sarkissian, 2014). 'Corporate entrepreneurship is considered as a process within an existing organisation referring to the development of a specific behaviour that deviates from the customary way of doing business' (Natasa, Zdravko and Goran, 2010).

\subsubsection{Strategy Formulation and CE}

There are theories and published studies by authors on the effect of: CE orientation on strategy (e.g. Suci, 2009; Ozdemirci, 2011). Corporate entrepreneurship combines the advantage seeking of strategic management with opportunity seeking, which is an element of entrepreneurship. Strategic types (choices) have a strong 
relationship with CE and organisational effectiveness (Ingram et al., 2016). Ingram et al then concluded that strategic management is vital to the $\mathrm{CE}$ concept for the development of all kinds of businesses operating in today's dynamic environment. The strategy literature has identified three types of CE: (a) corporate venturing or intrapreneurship; (b) a typology associated with the renewal or transformation of organisational systems; and (c) tasks that redefine the monotonous in a way that changes the 'rules of competition' (Saints, 2009).

$\mathrm{CE}$ evolved from strategic management subjects (McDougall and Oviatt, 2000). Strategic management and CE are related to each other in three ways: (1) Intrapreneurship is when, in some cases, $\mathrm{CE}$ creates a new business in an organisation. (2) When business profits are increasing through a combination of new resources, this is called strategic renewal. That is, businesses pay more attention to the development of products or changes in marketing. (3) A company can be transformed to be new and completely different from its competitors through the reconfiguration of company resources into innovations that lead to competitive advantages and better organisational performance (Hana, 2013).

Strategy, or strategic management, and CE's emphasis on economies is different from one country to another (Shinkle and Kriauciunas, 2012). Although scholars have made significant contributions to $\mathrm{CE}$, research has paid little attention to $\mathrm{CE}$, strategy formulation, and manufacturing sector performance in developing countries like Nigeria. These differences determine the operation of organisations and their performances (Ingram et al., 2016). The implications are far-reaching especially when the study is placed alongside the understanding that solutions to problems of $\mathrm{CE}$ in Nigeria will have to be sought from within the paradigms creating the problems. This angle of inquiry is novel, opening new sites of knowledge. Therefore, this study is focused more on CE strategy formulation (the 3Cs and business environment) and organisational performance, which are the key determinants of the survival and success/failure of an organisation.

\subsection{Performance and Assessment}

Performance is when entrepreneurs use their resources to reach their targets and objectives or goals (Zott and Huy, 2007). The level of business performance is evaluated by finances, management, organisation (Santos, Caetano and Curral, 2013), market performance (Wang at el., 2004), productivity, efficiency, and 
effectiveness (Baron, Franklin and Hmieleski, 2013). Organisational performance and $\mathrm{CE}$ are determined by customer relationship management (Qian and $\mathrm{Xu}, 2007$ ), customer satisfaction and loyalty (Vuong, 2016), and service-oriented architecture (Panian and Croati, 2007) when both objective and subjective measures are used (Liu and $\mathrm{Fu}, 2011)$. Using objective measures that are financial without considering subjective measures has some limitations. According to Antoncic and Hisrich (2003), the performance scale should be based on both financial and non-financial measures, not on Miles and Snow's strategy types. Meanwhile, in contrast, Miles and Snow's typology of strategy choices is related to the organisational performance scale (Ingram et al., 2016) in which the level of business performance is evaluated by strategy choices (Tang and Tang, 2012).

Return on sale, return on equity, return on assets, profitability, sales growth, and so on are measures used to assess performance. Revenues and market shares are used to determine new product success (Wiguna and Manzilati, 2014). Some researchers believe that organisational competitiveness, i.e. rating the competitiveness of an organisation compared with other firms, is used to assess performance (Ingram et al., 2016). In this age of a volatile, dynamic, and turbulent business environment, initial sales tend to take longer because of the complex processes involved (Schoonhoven, Eisenhardt and Lyman, 1990). Assembling different types of resources is associated with the possibility of a first sale (Brush, Glazewski and Hew, 2008), but ambitions influence the achievement of sales (Bosma, Schutjens and Stam, 2009). Slavee and Drnovesek (2012) stated that when the economic size expands, an entrepreneur is successful. For example, Bill Gates procured software from a firm that now runs about $90 \%$ of the world's computers, which increases human productivity. Failure means that an entrepreneur spent $\$ 60$ on production yet sold it for $\$ 40$.

Empirical evidence has shown that entrepreneurs' perseverance and selfefficacy (Santos, Caetano and Curral, 2013), early planning (Vuong and Napier, 2015), experience (Dimov, 2010), resources, the process, past experience, and the business environment (Kessler and Frank, 2009) are the determining factors of venture emergence and better performance. Small business success and entrepreneurship have a strong relationship, and, in some cases, a small business grows large if effectively managed; all businesses start with new ideals, risk-taking, new values, and passionate entrepreneurs (Chinonye, 2013). Increasing risks to start 
a new business and unexpected challenges might complicate the entrepreneurial process and affect its performance (Santos, Caetano and Curral, 2013; Huang and Knight, 2015).

The literature on performance assessment seems to be complex, as the researchers used ambiguous scales to measure organisational performance. Therefore, this study suggests that the literature did not provide a framework useful for assessing organisational performance. This research believes that organisational performance is the key to the success or failure of any business. For instance, failure means no improvement in sales/profits, employees, rewards, productions, asset values, and operations compared to previous months or years. In a similar manner, success means an increase in sales/profits, employees, rewards, productions, and assets compared to previous months or years.

In Nigeria, small business employees number between 1-10, and assets should be between 5 million and 50 million naira. According to the National Bureau of Statistics, 97\% of businesses in Nigeria have less than 50 employees, which implies that $97 \%$ of businesses in Nigeria are small; SMEs provide about $50 \%$ of the country's employment, and the industrial production is $50 \%$ (Nwaogji, 2016). Within the first 5 years of SMEs' existence in Nigeria, $60 \%$ die, and within 6 to 10 years, $30 \%$ fail; only $10 \%$ perform well or grow to large businesses (Nwaogji, 2016). In developing economies, lack of infrastructure, insecurity, bad governors, and corruption are the major factors that cause poor CE and poor performance (Dugguh, 2013). However, this paper found that the independent variable 'strategy formulation' and dependent variables of geopolitical and socio-cultural factors (tribalism, religion, and corruption) have effects on the performance of $\mathrm{CE}$ and business development in developing economies like Nigeria.

\subsection{Conventional Models of Strategies and Organisational Performance Nexus}

The conventional models of strategies that have been successful in the past are no longer effective due to fast dynamic competitors and more complex environments (Pun, 2003). No matter how excellent strategies are, they decline eventually (Hamel, 2011) (see Appendix 7). For example, 'scale' can be achieved when organisations have access to the global marketplace and capital. Scale used to be important for multiple organisations simultaneously, but in modern times, it can literally be rented on online businesses like Amazon.com. Products, scale advantages, and processes 
can be lost completely or compromised without protection and IP ownership. It is no longer an advantage because competitors can copy without legal consequences or economic fear.

Researchers have argued that good 'customer service' is important to gain competitive advantage. However, value for money with the latest products and brands has now made it impossible to maintain customer loyalty to a company. Best practices or process improvement were sources of competitive advantage, but they were not permanent, as competitors could adopt and copy them and, in some cases, even be more innovative. Nowadays, there are limits to gaining a competitive advantage due to the outdated existing product mix (i.e. business models and products) because competitors can easily imitate each other's market position, which can have negative effects on organisational performance (McKeown, 2012).

Successful strategies decay overtime (Hamel, 2011). For example, Toyota is a successful organisation and a global market leader. Most successful firms are now failing globally in their performance. Research evidence has shown that firms made mistakes that destroyed and derailed them during the global financial crisis of 20082009. That is, yesterday's strength became the root of today's weakness. Managers believe in what worked for them in the past and, thus, repeat what worked yesterday. This has affected many firms in terms of operation and making profits. For instance, General Motors (GM), a fulfilled company with a long, good history, finally slipped off the track in 2009 (London Business School, 2010). The disaster on Wall Street in 2008-2009 at firms like Merrill Lynch occurred because they were only after making money for their firms (Beer, 2009). Lehman Brothers has been the market leader since 1850 and, in 2007, declared a net profit of $\$ 4.2$ billion before going bankrupt in September 2008 (Birkinshaw, 2010). The global economic crisis of 2008-2009 would not have happened if banks had paid more attention to investments associated with risks; they did not change the way they made decisions, which affected the quality of their decisions (Mulcaster, 2009). Birkinshaw (2010) stated that failure in the work of the whole market system, failure of bank regulations, and failure of macroeconomic policy were the causes of the global financial crisis of 2008-2009. The nature of management style has not been changed for many decades. The management system that occurred before 1930 remains unchanged. The conventional models that have been applied in the particular case of Nigeria have been proven to yield unsatisfactory outcomes (Dauda, Akingbade and Akinlabi, 2010). This is 
largely because attention is frequently directed towards the hard elements, such as design, structure, hierarchies, and so on (that is, the socio-technical systems) of organisations. This is true of both the organisational level and analyses of the national level. Some scholars have stated that 'brick and mortar', such as capital, land, machineries, and factors of production, are no longer major factors for sustainability and corporate growth.

At the expense of the softer side of the organisation, levels of the $3 \mathrm{Cs}$, environmental factors, embedded cultures (which encompass values), and geopolitical and socio-cultural factors (tribes, religion, and corruption) may all suggest possibilities for improving organisational performance approaches to strategy formulation in CE.

Consequently, this study resorts to the 3Cs framework (Jha and Iyer, 2007) as a guide to address the research questions and objectives. Jha and Iyer (2007) stated that the $3 \mathrm{Cs}$ are the main factors of successful construction firms in India. Cost, quality, and schedule are the criteria used to measure performance, which is the key to the success or failure of construction projects. This study explores the theoretical gap created due to lack of sufficient literature on the influence of the business environment, especially in manufacturing sector in Nigeria. Jha and Iyer (2007) neglected the importance and impact of environmental factors in which businesses operate - a point picked up in this study. Therefore, this study explains the effect of environmental factors on stakeholders' $3 \mathrm{Cs}$ (i.e. the $3 \mathrm{Cs}+\mathrm{E}$ ) and $\mathrm{CE}$ performance in their strategy formulation in Nigeria. The thesis uses sales/profits, employees, rewards, productions, and assets as criteria in the determination of the manufacturing firms' performances.

The application of the $3 \mathrm{Cs}+\mathrm{E}$ can be illustrated in Nintendo, an electronic game business that was established in 1975. Sony and Microsoft were threats to Nintendo in the 1990s and 2000s. This reached a stage in which people thought that Nintendo, a traditionally established competitor, would soon go out of business or become bankrupt because of the attacks from Sony and Microsoft (Markides, 2010). Most Nigerian managers are intelligent, competent, and dedicated, yet they still formulate and/or implement unsuccessful strategies, perhaps because outdated strategies are applied in their strategy formulation and implementation or because they fail to understand how or by whom the strategies are inaugurated. 


\subsection{Competence, Commitment, Coordination, and Organisational Performance}

Entrepreneurial competencies are associated with growth and organisational performance (Mitchelmore and Rowley, 2010). Competence has a significant effect on the commitment of staff and organisational performance (Lotunani et al., 2014) For instance, an IT project manager can use specific competencies to get their team members committed (Thamhain, 2013). That is, gaining the credibility, trust, and respect of a team improves its performance and ensures successful projects (Thamhain, 2013). Competent managers will influence a team to become committed to achieving the project goals and maximising performance (Muller and Turner, 2010). They influence team commitment and the better performance of firms (Ahmad and Oranye, 2010). Entrepreneur or employee commitment positively affects team performance and business success (Xu, Zhang and Barkhi, 2010). Commitment and motivation influence the success and better performance of an organisation (Velickovic et al., 2014). An entrepreneur's commitment and creativity have positive effects on business performance and increase entrepreneurial activity (Trevelyan, 2009). An entire organisation can become paralysed due to lack of leadership commitment (Zaleznik, 1989).

According to Chen, Yao, and Kotha (2009), an entrepreneur's commitment has an impact on their coordination or decision-making. Michael, Sebanz, and Knobllcch (2016) stated that coordination creates employee joint-action commitment because it can enhance trust (Mitkidis et al., 2015), a perception of rapport (Miles, Nind and Macrae, 2009), unity (Lakens, 2010), and the impression of a shared goal (Ip et al., 2006). Coordination can also lead to cooperation in social dilemmas (Wiltermuth and Heath, 2009). According to Ulrich (1998), an organisation's most important asset is when competent employees are committed to the organisational goals and visions. Sumner, Block, and Giamartino (2006) and Muller and Turner (2010) stated that lack of project manager commitment and lack of the required skills to coordinate lead to the failure of many industries.

This study supports Jha and Iyer's (2007) view that managerial competencies alone are not enough to build sufficient team commitment in an organisation without coordination. They concluded that the $3 \mathrm{Cs}$ are essential factors to the success and better performance of construction projects. For instance, an organisation having superior performance and gaining competitive achievement is not a matter of luck but a result of the qualities of managers in terms of their $3 \mathrm{Cs}$. Thus, the $3 \mathrm{Cs}$ of 
stakeholders are necessary in order for CE and strategy choices to be successful, which can be associated with the growth and sustainability of all sizes of manufacturing firms.

Although this has been criticised, Sepasgozar, Razkenari, and Barati (2015) stated that the primary reason for bad performance in construction projects is the use of old-generation technologies, and they concluded that the latest or modern technologies improve the projects' performance and solve their problems. Gunduz and Yahya (2015) believed that the sector's work definition, technical capacity, and scope are the main factors that determine the success of construction projects in terms of schedule, cost, and quality. According to Tabish and Jha (2011), successful firms have barriers because they need economy, quality, transparency, efficiency, and fairness. They concluded that compliance with rules and regulations is a major factor that determines the performance of any organisation (Tabish and Jha, 2011).

Their study could have an important impact on Indian construction projects' success perceptions, which are more subjective and difficult to quantify. This study believes that not every project is the same, so measuring tools must be flexible to account for the different projects involved. Hence, measuring tools must account for objective and subjective factors when assessing the performance of construction projects (Hughes, Tippett and Thomas, 2004). Strategic planning and thinking are essential to the financial success and performance of an organisation (Miller and Cardinal, 2017). In strategy formulation, coordination is significant and is the key that matches the organisational structure and its performance (Alvesson et al., 2009). Michael Porter's Model 1987 is an effective tool to determine investment performance based on the business environment when formulating a strategic plan (Osbourne, 2009). This research believes that businesses can be successful if entrepreneurs and employees are competent, committed to the business, coordinated, and make a strategy that fits the environment.

\subsection{Concept of Strategy}

Strategy is primarily an organisational process in which firms share visions, a value system, and culture in order to gain competitive advantages (Casadesus-Masanell and Ricart, 2011). It concerns how to achieve organisational objectives (Johnson, Scholes and Whittington, 2009). Chia (2004) perceived strategy as objectives and goals. Some authors believe that strategy does not lie in the macroanalysis but, rather, in the 
micro-practices of strategising (Whittington 2004). The four significant strategies are: two from outside the organisation, which are environmental opportunities and threats, and two from inside the organisation, weakness and strength, meaning what the organisation can do with its capabilities (Nonaka and Toyama, 2007). The five components of strategy are staging, arenas, vehicles, differentiation, and economic logic, and these components provide solutions as to how to make plans, make returns on business, gain competitive advantages, and meet targets (Hambrick and Fredrickson, 2010). Various authors see strategy as building blocks that comprise service and product design, customer development, market, sector analysis, and information technology to establish a business and sustain its success (Mantere, Schildt and Sillince, 2012).

Porter (2008) viewed strategy as a protection or guide against competitors' threats or as making use of available opportunities to gain competitive advantages where the forces are not strong. Gavetti and Rivkin (2008) considered strategy as emergent, deliberate at the right moment, and how or when analogies are employed with care. The emerging view strategies are actions, not for the future or past but must take place at present, and value added, its determine strategic success than maximisation of profits (Zeleny, 2010). Strategy is a pattern or plan that incorporates policies, goals, and action sequences into a cohesive whole of an organisation (Mintzberg, 2003). Nevertheless, at times, individual staff members often have a pattern that they prefer but which might not align with the opinion and actions of the rest of the people or of some executives in the organisation. Essentially, the strategy process should not be individualistic but collective, as an individualistic one would have a negative effect on the understanding of the strategic process (Weick, 2001).

Strategy is problem solving through the gathering of information (Rumelt, 2011). It means precise action, visionary, and mission statements (Lovallo and Mendonca, 2007). According to Peukert (2003), strategy is science, art, and craft. Meanwhile, Mintzberg (2004) said that strategy relies on experiments and is based on vision, intuition, and insight because it is more craft or art than science. Capability and position are strategic perspectives (Mills, 2009). Strategy is proactive (intended), deliberate, and planned action (Cox, 2006). It is dynamic, partially unplanned, and partially deliberate (Warren, 2011). Wit and Meyer (2004) stated that strategy is a coordinated plan of action taking that makes use of resources in order to achieve long-term objectives and visions. It is also concerned with how to create value and be 
competitive (Porter, 2001). Roberts (2003) stated that strategy is an incorporated set of decision-making, resulting in the better performance of an organisation.

The argument is that the scholars did not emphasis how the best decisions can be made or discuss any particular strategy or decision that could guarantee the success and survival of firms. For instance, a required decision at the corporate level is not the same as a decision at the functional level. In a similar way, a decision made among construction, banking, and manufacturing firms might not be the same. Furthermore, the dominant view in the literature is that strategy is defined as decisions, goals objectives, visions, patterns, and actions. It has a different meaning for different readers. This is complex and can be confusing since they are not the true definition of strategy but are just strategic elements and threads,

\subsubsection{Strategy Typology}

An important strategic management research concerns strategy typology, which represents different strategy theories. Strategy typology is classified according to particular traits and focuses. There was much proposed interest in business-strategy typologies in the 1970s and 1980s (Gummesson, 2002). There have numerous studies on strategy as a whole (Ozcan and Eisenhardt, 2009; Mantere, Schildt and Sillince, 2012). About 40 years ago, Miles and Snow conducted research on strategy types in one of the most global studies on strategy typology (Laugen, Boer and Acur, 2006; Pittino and Visintin, 2009; Hu and Hafsi, 2010). Researchers' findings on strategy choices have also been recognised, most of which have been consistent with Miles and Snow's typology of strategy choices in which entrepreneurs apply or choose a particular strategy that is suitable for a specific business or changes in the environment (Csepeti, 2010; Sidek and Zainol, 2011). Strategy choices contribute to the success of manufacturing industries, unlike in the service and construction industries, where they are unconvincing (Sanchez and Marin, 2005).

There are four strategy typologies in business, as observed by Sidek and Zainol (2011): defenders, analysers, prospectors, and reactors. Therefore, this study suggests the strategic choice that will fit the Nigerian business environment.

Prospectors: refers to a situation in which entrepreneurs develop new products or new markets to meet new market opportunities to gain competitive advantages (Kabanoff and Brown, 2008). When the markets are not in an existence, it affects the entrepreneurial strategy, unlike the firms that are already established. 
According to Sine and Lee (2009), when there are no markets for services and products, this requires entrepreneurs' understanding, and well-managed services and goods will come to an existence. This entrepreneurial strategy has many implications because markets should be created where there was no market before. The authors believed that competent entrepreneurs formulate markets by organising people collectively, challenging the existing firms linked to the markets, and freeing up space for their markets (Webber, Heinze and DeSoucey, 2008). Again, in a situation where the existing markets are inadequate, the new markets are justified (Khaire and Wadhwani, 2010). Entrepreneurs define the boundaries of nascent technology markets' identified strategies like labels, stories, and templates (Santos and Eisenhardt, 2009). Generally, entrepreneurs use strategies to create infrastructure, grow the emergence of new goods, and meet new markets.

Defenders: Unlike with prospectors, this is when entrepreneurs do not produce or create new products/markets but, rather, improve their efficiency and place more focus on their products (Andrews et al., 2009; Pittino, Visintin and Lauto, 2009; Tang and Tang, 2012). They typically maintain the same set of products and customers (Tandon, Sharma and Uma, 2010) and gain competitive advantages through price, quality, and services.

Analysers: These are between prospectors and defenders (Wang, 2008) and depend on the environment in which a business operates. For example, when the environment is stable or slightly less stable, the defenders' strategy type is application, but when the market environment is highly competitive or complex, it might be necessary to seek new market opportunities ('prospectors') or simultaneously improve the quality of products and services ('defenders') (Hassan, 2010). The natures of the opportunities that firms encounter have effects on their entrepreneurial strategies (Chen et al., 2010). Firms face unclear and ambiguous opportunities, customer demand, technologies, features, and products (Benner and Tripsas, 2012). For instance, entrepreneurs often change strategies to fit their business environment (Gavetti and Rivkin, 2007) and pursue growth opportunities. Otherwise, their firms will suffer (Bingham and Eisenhardt, 2011). Experimentation entails deliberately testing a service or product to achieve market fit (Zott and Amit, 2008) and focuses on market share than to emphasises on strategic objectives such as design of business model (Zott and Amit, 2008).

Reactors: these do not use a particular strategy; they will not change their 
course unless there are no alternatives (Mantere, Schildt and Sillince, 2012). Authors have argued that reactors have short-term orientation and depend on the situations they find themselves in, with no clearly defined strategy in place (Aragon-Sanchez and Sanchez-Martin, 2005). This might result in ideas and knowledge becoming ineffective or inefficient and not well-utilised by the firms involved (Klepper and Thompson, 2010). Therefore, firms will underperform because not all profitable opportunities will be exploited (Klepper and Thompson, 2010).

This takes the view that firms should be innovative and produce new goods and markets for growth and success, contrary to the reactors strategy. Entrepreneurs and employees tend to be so immersed in specific tactics involving immediate ideas and plans that they do not step back and analytically consider how they think about strategy choices. As a result of this, industries can go through major downturns, and firms' growth can become flattened out for years, in many cases persistently.

This study will not consider the reactors strategy because it does not seem to be realistic for developing economies in which the business environment changes constantly and is more complex. It is not in accordance with this study's definition of $\mathrm{CE}$, i.e. new ideas, new businesses, and risk-taking. In Nigeria, the internal and external environmental factors and geopolitical and social-cultural factors are not business-friendly. This study believes that the strategy typology theories that are effective and efficient in developed countries might not work in a developing economy like Nigeria. This study is consistent with prior researches (see Gavetti and Rivkin, 2005; Ingram et al., 2016) that highlighted strategy as being about making choices, i.e. about what entrepreneurs or employees choose to do or not to do, as well as about outlining the long- and short-term directions of a company.

\subsubsection{Strategy Formulation}

Strategy formulation involves decision-making and planning that results in organisational goals and achievements (Daft, 2005). It is the combination of performing situation analyses and planning how organisational objectives can be achieved, and it is concurrent with assessment, that is, an objective can be set (Simister, 2009). It is when the appropriate course of action is determined and the organisational purpose is accomplished (Kotelnikvo, 2008).

The strategy formulation process can be referred to as determining where you want to go, where you are now, and how to get there. These three steps must be fitted 
together (Cox, 2006). Burdett (2010) stated that the system, people, structure, and allocation of resources are the key organisational components that influence strategy formulation. Strategy is formulated by emerges or challenges which company deal with, not by analysis based on universal rules (Mintzberg, 2004). According to Hrebiniak (2005), organisational energy, values, and culture are the same with formulation. The three levels of strategic formulation are the functional or departmental level, the business unit level, and the corporate level (Platts, 2002).

Similarity judgments are important to the formulation of business level strategies (Barney and Hesterly, 2012). Core human competence makes accurate judgment a prerequisite for success (Helversen et al., 2014). Similarity judgments can be shown in error, which may result in organisational failure (Todd, 2002). This study believes that similarity judgments are not important in strategy formulation because there is the possibility that the process of making them can be complex when computational resources are limited. Again, decisions might be inconsistent and inaccurate (Mezias and Starbuck, 2003). This thesis suggests that similarity judgment should not be considered important in strategy formulation, as people can make decisions in error or due to bias. This sometimes makes them incompetent and might cause severe damage to their organisation.

\subsubsection{Strategy Implementation}

The final stage in strategic management is the implementation, i.e. how the action is taken (Coulter, 2008). Strategy implementation is the execution of a plan and its administration. Organisations and employees make use of available resources to accomplish strategic results. The most important and difficult part of strategic management is strategy implementation ((Burdett, 2010). Warren (2011) stated that implementation is not a step or an action but a process. Strategy implementation is the process of making use of available resources in order to achieve strategic results (Castaneda, 2005). It is the assembling of technology, human resources, and suppliers in a way that configures them sustainability and is unique (Barney and Hesterly, 2012). Application, organisation, and interpretation are the three activities involved in strategy implementation (Nonaka and Toyama, 2007). It starts when information flows in the right direction in an organisation and clarifies decisions (Neilson, Martin and Powers, 2008). The essential ingredients of strategy implementation are the organisational structure, style of leadership, budgeting, 
information system, key managers' assignments, resources, control, and reward systems (Hiles, 2007). Strategy implementation fails when enterprises disregard information flows and correct decisions and focus on structural reorganisation instead (Nonaka and Toyama, 2007).

Implementation strategy literature can be confusing (Blahova and Knapkova, 2011). There is no evidence on how it can be successful because of lack of linkage, which implies that all organisational activities and resources are rowing in different directions. All the ambiguous management activities, such as direction, innovation, communication, resources, leadership, control process and reward, are covered in the implementation process (Holmes 2006). Since the entire management function is more than the scope of this study, this research is focused on factors that can contribute to successful strategy implementation.

\subsubsection{Strategic Management and Dynamic Environments}

The two phrases of strategic management are strategy formulation and implementation, designed in such a way to achieve organisational objectives (Surbh, 2015). Strategy formulation and implementation are described as reformative, unlimited, ongoing activities and continuous reassessment (Markides, 2008); interdependent (Clausewitz, 2006); not sequential but must occur simultaneously (Rankin, 2004); and a repetitive learning cycle rather than a linear progression towards a defined destination (McGraw, 2006). According to Mulcaster (2009), 11 forces - such as adding value, politics, time, holistic effects, perception, opposing forces, style, incentives, learning capabilities, opportunity cost, and risk - should be incorporated into the strategy formulation and implementation processes.

If a strategy is formulated, but not effectively implemented, it will fail, and organisational success will be eluded. Scholars have shown that many organisations underperform or collapse because of poor implementation, not poor strategy (Simister, 2009). Strategy implementation is more difficult than strategy formulation (Blahova and Knapkova, 2011). The most important and difficult part of strategy management is its implementation. An excellently formulated strategy will fail if its implementation is not properly done (Blahova and Knapkova, 2011). If the execution is not carefully planned, the strategy goals or objectives will be difficult to attain (Hrebinik, 2005). There is evidence of brilliant strategy formulation going awry due to substandard execution efforts (Davenport, 2007). Despite the fact that 
implementation is important to success, it is usually poorly handled by firms because there are faults in the execution that must be negotiated (Blahova and Knapkova, 2011). Even the best strategies fail to produce strategic results because they are unsuccessful when implemented into action. According to Richardson (2005), the framework for strategy formulation and implementation is idiosyncratic and comparatively fragmented. The actions taken by CEOs or entrepreneurs determine the success and strategic results of small or large organisations. From a financial perspective, customers, processes, and innovation are a cycle that can be used in strategy implementation to make a company outperform its competitors (Richardson, 2005). The flow of information, correct decisions, and restructuring are the building blocks that influence entrepreneurs' actions and make them deliver on their intent, as well as put them on the competitive map (Neilson, Martin and Powers, 2008). In some cases, the information available to a manager influences their decisions and actions.

Strategic management is all about the actions and decision-making an enterprise uses to formulate and implement strategies that fit to its environment for superior performance. This dynamic approach to strategy formulation and implementation is due to today's dynamic and turbulent business environment (Nag, Hambrick and Chen, 2007). Strategic management is when an organisation's major goals are formulated and implemented by top management initiative, based on an assessment of the business environment with the available resources (Nag, Hambrick and Chen, 2007) and on employees' understanding of weaknesses and strengths vis-à-vis other firms.

Researchers have contributed to the knowledge of strategy and formulation but have not emphasised how strategy formulation or implementation can be more successful in today's businesses or on how it can be managed in the long term. Again, no emphasis has been made on who should take action or make decisions. This raises a vital question: how do we formulate and implement successful strategies in Nigeria's business environment? One of the objectives of this study is to determine the factors that could contribute to successful strategy formulation and implementation in developing countries such as Nigeria.

In order to address these research questions and achieve the objectives of this study, four independent drivers are deployed - notably competence, commitment, coordination, and environment $(3 \mathrm{Cs}+\mathrm{E})$. One cannot be substituted for another, and 
they cannot be ordered hierarchically. A company will fail if competent and committed people with bad coordination formulate and implement strategies that do not fit the environment in which they operate. Therefore, the performance or success of an organisation is influenced by the four key drivers, i.e. the $3 \mathrm{Cs}+\mathrm{E}$. This research has been conducted in such a way as to find whether the $3 \mathrm{Cs}+\mathrm{E}$ are related to successful CE, strategy formulation, and implementation in the Nigerian manufacturing sector. Each of the key drivers is discussed in the next section.

\subsection{Competence, Commitment, Coordination and Environments (3Cs+E)}

\subsubsection{The Concept of Competence}

This section presents a sample of previous definitions of competence and the definition to be adopted in this study. Competence is the level of expertise through the acquisition of skills. Knowledge and abilities make it possible for people to perform effectively, both within and outside academic contexts (Purdy 2007). Muller and Turner (2010) defined competence as the 'combined set of an individual's knowledge, personal characteristics and abilities used to perform a specific task or activity'. Competence is an individual characteristic, that is causally associated with superior performance in operations (Ivancevich and Matteson, 2006). It is the employee behaviour that helps a company achieve its long-term goals (Incomes Data Services, 2008) as well as an individual mindset for innovation and firm growth (Stockport, 2000; Clardy, 2008). Preferred futures, in accordance with organisational values and purpose, are identified with competence (Bywater, 2007).

Competence has a significant effect on the performances of staff and organisations. The performance of an organisation can be jeopardised if some employees are promoted to the position of project manager because they have technical skills rather than competent managerial skills (Kerzner, 2009). Professional or technical skills are not good enough for business success (Kerzner, 2009). Millions of highly qualified people are forced into doing unsuitable jobs in a world of work that is unfit for modern needs. Attention to detail and the right people are the major ingredients of success (Scott, 2003). Project managers will only be effective and efficient in the discharge of their duty by using the synergy of different competencies, such as (1) the available tools, (2) the structure of the organisation, (3) managing the people, (4) the task to be done, and (5) the environment in which the organisation operates (Kerzner, 2009, p.145). As how to build a successful career in 
management is not taught in formal education programs, academic qualification alone is not the determining factor for potential managers but with their experience and knowledge gained. Brilliant students in school are often slow in learning in the executive suite.

Kotelnikvo (2008) stated that the two categories of competencies are technical and behavioural. Marketing, technology, and integration (in which marketing and technology are combined together) are the three types of competence. That is, technically provide services, products, market new products and new services that add value to the customers, and employees that result in better performance of an organisation (Wang et al., 2004).

Competence is related to the output, minimum expected standard, and performance of an organisation (Whiddett and Hollyford, 2007), as are information sharing, solving problems as a team, and trust (McEvily and Marcus, 2005). Communication skills, customer skills, team skills, people management, and resultsorientation are associated with the framework of organisational competency (Learning and Development Survey, 2007). According to Johnson, Scholes, and Whittington (2006), competencies are the capabilities of an organisation to gain competitive advantages in a given market. Competence is the quality or adequately well qualified person to perform a specific role (Incomes Data Services, 2008).

Core competence can be seen as the capability of an organisation in terms of its benefit to customers, products and market leverage, and difficulty to imitate (Bradford, 2007). Core competencies shape strategic choices to achieve competitive advantages through an organisation's capabilities, available resources, and major value skills (Grant, 2002). According to the competence resources-based theory, core competence is when an organisation's multiple technologies are harmonised (Michael and Philip, 2004). It is when available resources are deployed in such a way as to gain competitive advantages that others cannot copy or imitate (Johnson, Scholes and Whittington, 2006). Core competence is the external assessment of an organisation's activities and what it does better than its competitors; the more appropriate term is distinctive competence (Collis and Montgomery, 2008). Various authors have argued that the conversion of capabilities to competencies is significant to the success of an organisation (Johnson and Scholes, 2002; Boddy, 2005). Entrepreneurial core competence reduces both risks and the ability to implement the entrepreneurship plan (Fayolle and Gailly, 2015). A core competence can be in the 
areas of extraordinary customer service, professional technological know-how, process efficiency, research, and development (Blaha and Roppe, 2009). It is something a company does better than its competitors.

Cultural competence is when stakeholders understand the time needed to formulate and implement new concepts (Plum et al., 2007). It is when an individual learns new ideas and also understands a new cultural environment in order to formulate a new strategy to fit the new culture for organisational survival (Deng and Gibson, 2008). Moreover, it is when an individual or group of people is able to operate successfully in different cultural environments (Torres, Fub and Lehto, 2014). Cultural competence is the application of individual skills and knowledge on traditions, cultural heritage, customs, and organisational performance (Livermore, 2011). According to Jeris et al. (2005), competence is complex and challenging in a cross-cultural and global economy.

Malmstrom, Wincent, and Johansson (2013) measured entrepreneurial competence in terms of (1) strategy competence (vision, planning ahead, and new ideas), (2) commitments (motivation and dedication), (3) organising competence (coordination and control), (4) relationship competence (the ability to influence others), and (5) conceptual competence (decision-making and the ability to weigh risk). Some authors found that entrepreneurial competencies are associated with business success, even when a business environment is dynamic (Man and Lau, 2005). Attributes to CE are skills, knowledge, beliefs, personality, and behaviour, which lead to better performance (Ahmad et al., 2010). In the process of CE, individual personal factors like competence and personality traits have a positive effect on firm performance (Li, 2009).

Entrepreneurial competence is associated with entrepreneurial characteristics and firm performance (Sarwoko, Armanu and Hadiwidjojo, 2013). The entrepreneurial characteristic factors that have effects on business performance are psychological factors (achievement, personality traits, and control), educational factors (Sorensen and Chang, 2006), personal values, work experience, professional support network, education, age (Hisrich, 2011), and internal and external environmental factors (Shane, 2013). Likewise, the two main types of characteristics of entrepreneurs are 'attributes', i.e. religion, age, gender, family influence, and so on, and 'attained', i.e. qualifications (Blackman, 2003). Entrepreneurial competence is the individual characteristic attitudes and behaviours that influence the better 
performance of an entrepreneur (Shane, 2013). It is one's combination of knowledge, skills, and experience with the effective functioning of their career or organisation (Blaha and Roppe, 2009), as well as how personal management and interpersonal relationships influence operational performance and organisational success (Saito, 2008). Boulay (2007) stated that entrepreneurial competence is a valuable intermediation variable that has a strong effect on new businesses. Individual competence uses strategic choices that fit into new business environments. Continuous change in an environment that results in new ideas, practices, and innovations requires change performance by continual improvement of knowledge and skills.

This thesis emphasises individualistic competence because a good machine cannot operate itself; it is people that make it work. This study believes that individualistic competence (i.e. entrepreneurs and employees) is the main contributor to the success of a business or strategy. The literature on competence seems ambiguous and too general because researchers have given it various meanings with different interpretations (containing some general statements about team skills, people management, communication, and so on). They have referred to their work on competence as lying within the confines of technology, resources, competitors, and capacities. No conclusive evidence showed how competence influences CE performance and strategic success in developing economies. Moreover, some researchers limited their studies to organisational competence. This study defines competence as entrepreneurs' or employees' acquired skills and knowledge with experience to do the right thing for the company at the right time through their talents, initiative, and beliefs. This research has been conducted in such a way as to determine whether individualistic competence is related to strategy formulation and CE performance in the Nigerian manufacturing sector.

\subsubsection{Commitment}

Commitment is not pressure from outside but is an internal decision in which emotions and thoughts work together in the same direction (Alatrista and Arrowsmith, 2004). Stakeholders' cooperation is commitment (Griffin and Moorhead, 2007). Commitment can be defined as the involvement and identification of an individual with an organisation or team (Ahmad and Oranye, 2010). Commitment is the ways of changing people's beliefs, that is, to work for what 
would not otherwise be expected (Frank, 2007). Thus, Zahra et al. (2008) found that stronger commitment is the solution to all complexities.

Organisational commitment is when stakeholders are psychologically attached to an organisation (Cooper-Hamik and Viswesvaran, 2005) and is the degree to which staff members experience a sense of belonging to their company (Cheng and Stockdale, 2003). Organisational commitment and team commitment are similar to each other. For example, teams build principles and goals that can be accepted or rejected by their members. Involvements in job-design autonomy and decision-making in the related job are correlated with extra-role behaviours (Pierce, O'Driscoll and Coghlan, 2006). The characteristics of organisational commitment are: (1) a strong desire and belief to remain in the team and (2) willingness to put in extra effort in order to achieve the organisational or team goals and values (Bishop and Scot, 2000; Solinger, Van-Olffen and Roe, 2008). Organisational commitment can be improved through five major guidelines: commitment to human value, guaranteed organisational justice, community practice and communication mission and clarification (Mercuriom, 2015).

Managerial commitments are the actions taken so that an organisation's future course can be bound (Sull and Houlder, 2005). Some scholars conducted research on the relationship between organisational effectiveness and organisational commitment and discovered that commitment increases the effectiveness of an organisation (Ivancevich and Mattenson, 2006). The three mind-sets of employees' commitment characteristics are when employees feel: attached to their organisation emotionally (affective commitment), obligation (for example, staff are employed to work and paid what they are owed) (normative commitment), and that the cost of leaving is too expensive (continuance commitment). Employees may leave if they obtain a better-paying job elsewhere (Stup, 2006; Mercurio, 2015).

Affective commitment has a significant positive correlation with employees' promotion focus (Cooper-Hamik and Viswesvaran, 2005; Jaros, 2007). Affective and normative commitments to a specific person can be developed by relational selfidentity (Johnson and Yang, 2010). The self-identity of individual employees influences the development of continuance commitment (Gagne and Deci, 2005). At varying levels of intensity, staff can be committed to their enterprise/organisation at three different levels (normative, affective, and continuance), which are not mutually exclusive (Meyer and Herscovitch, 2001). Company owners usually value staff that 
feel affective or normative commitment rather than continuance commitment, which may be undesirable (Stup, 2006).

When an organisational strategy is clear and valid, employees' commitment to work is bound to be high (Velickovic et al., 2014). However, it might not be that easy to build commitment (Thamhain, 2013). Top management and/or board of directors projections have also been found to determine the level of employee commitment (Leibner, Mader and Weiss, 2010). Furthermore, while some research (Brown et al., 2007; Beer, 2009) has suggested that employees' commitment and loyalty are an essential element of increased organisational performance and labour productivity, other research (Tsui and $\mathrm{Wu}, 2009$ ) has indicated that employees' commitment is the determining factor of their organisational growth, competitiveness, and higher performance. Further studies have seen it as being associated with problem solving and increased innovation (Velickovic et al., 2014).

Regarding employees with a high level of job satisfaction, less than $60 \%$ have no intention to leave their job or seek a job in another place, regardless of the present leadership practices in their organisation (Land, 2003). About $87 \%$ of employees are likely to stay in their organisation if they are highly committed (Lockwood, 2007). Moreover, committed people are more likely to remain with their company (Matteson, 2001). In Nigeria, though, most Nigerian employees look for better prospects elsewhere, no matter how committed they are. However, the high rate of unemployment and economic predicament in Nigeria might make them less likely to quit their job and cause them to go to further lengths to ensure that their job is safe. Employers make use of this advantage and take their employees for granted, as staff can easily be replaced.

Motivational factors for CE take on different perspectives, including social recognition, financial independence, a sense of achievement, opportunity, and a friendly working environment (Jung-Wan and Tai, 2010). In developed economies, the critical motivators encouraging $\mathrm{CE}$ are freedom and a sense of achievement (Dugguh, 2013). In transitional countries like Kazakhstan, financial independence and social recognition motivate entrepreneurs to start their own businesses (Shih et al., 2009).

The business environment in developing and transitional economies are unfavourable for new business due to lack of government support (Stefanovic, Rankovic and Ptokic, 2011). In developing countries like Nigeria, poor physical and 
social infrastructure continue to pose a challenge for entrepreneurs' commitment and motivation. This research has been conducted in such a way as to discover whether individualistic commitment is related to strategic growth and $\mathrm{CE}$ performance in Nigeria's manufacturing sector.

\subsubsection{Coordination and Control}

Coordination and control in an organisation can be exercised through a centralisation/bureaucracy or decentralisation/democracy system (Gratton, 2004). Coordination and control are meant to accomplish lines of authority, programs, organisational tasks, and communication (Papamichail and Rajaram, 2007). They are key to organisational structure and strategy implementation (Alvesson et al., 2009). The primary aim of any organisation's coordination and control is to achieve a goal, purpose, or mission that requires informal or formal planning processes to be in place. Coordination and control involve activities and resources being put together to achieve a common goal (Luthans, 2011).

According to McNamara (2008), coordination implies giving directions and ensuring that efforts are channelled towards influencing efforts along these lines (Boer, 2010). It has also been reported as a way for employees to act in unison (Naylor, 2003). Pulling these positions together, McNamara (2008) referred to coordination as both the guide for and direction of communication. Control is staffing, giving directions, planning, and organising, all of which are known as managerial functions (Boer, 2010). It is the process through which managers make use of resources efficiently and effectively to achieve organisational objectives (McNamara, 2008) and is associated with formal processes and the structure of organisations (Pettigrew, 2003). No organisation is without coordination, regardless of the advantages and disadvantages associated with the phrase 'centralization and decentralization' (Robbins and Judge, 2007).

In a centralised system, most decisions are made by top management (Koch, 2006). While some scholars (e.g. Bower and Gilbert, 2007) have pointed out that a centralised system or 'top-down' system of coordination will not work and might result in a firm underperforming, others believe that employees feel disenfranchised when a business is managed and controlled from the top or by a single point (Repenning, 2002). Richard's (2003) views were that centralisation methods (i.e. chain of command) motivate employees because they know what is expected of them 
from the organisation. Decentralisation is when the majority of decisions are delegated to employees, and all the departments and operating units or decisions are taken lower in the organisation (Wit and Meyer, 2008).

In this way, coordination, management costs, and communication problems can be minimised. Employees' participation in decision-making reduces their absenteeism, turnover, and grievances and also enhances their morale (Gate, 2007), cooperation, and understanding of the new changes in the organisation, as well as increases their performance (Kotenlnikov, 2008). Employees are more committed and are able to work towards common goal setting (Ivancevich, 2003). Researchers of innovation have suggested that a flat organisational structure plays a major role in success.

The literature on coordination and control seems to have no practical application. It is more theoretical; the scholars' discussions are contradictory, and some of their findings are inconsistent, which might be confusing. For instance, the theories are based or primarily focused on the advantages and disadvantages of centralisation and decentralisation systems in an organisation. Cloke (2002) claimed that a centralisation or bureaucracy system destroys creativity and innovation. Miles and Snow (2003) studied the classification scheme and stated how hierarchy systematically causes innovative firms to be fast-growing and competitive. In most cases, centralisation or bureaucracy promotes corruption in an organisation, and this affects organisational success and performance (Aidt et al., 2008). In contrast, decentralisation or democracy systems discourage corruption, affecting the success and performance of firms (Robbins, 2000).

Arguably, everyone should know their responsibilities within a company. For example, employees should know that they are not the boss, should not expect to be treated in the same way as their boss, and should not want to behave like a boss. Thus, it does not make sense to brush them aside or conceal them. In organisational coordination, employees cannot make all the decisions. Likewise, a firm's owners or top management cannot make all the decisions. This means that no organisation can be completely decentralised or completely centralised in order to avoid total lack of coordination and control.

Ultimately, a successful organisation practices, either directly or indirectly, both a centralisation and a decentralisation system. Overall, this study has been conducted in such a way as to determine whether coordination (centralisation and 
decentralisation) is related to strategic growth and CE performance in the Nigerian manufacturing sector.

\subsubsection{Strategic Management and Coordination}

Strategy management is all about the long-term decisions taken by an organisation with the aim of gaining competitive advantages. The management concepts use different terms like change management, environmental management, management accounting, customer relation management, value-based management, quality management, and knowledge management (Kaplan and Norton, 2006). These kinds of management exist at different levels, such as executive management, middle management, and low management, of an organisation (Johansson, 2003). However, there has been a significant increase in research on management coordination, control, and strategy in recent years (Anderson, 2007). Accordingly, research on management coordination and strategy has grown. The classification schemes of Miles and Snow (2003) have had a considerable effect on the relationship between the design and use of management coordination systems and organisational strategies.

Nowadays, series of research have been conducted on strategic choices and management control systems. The primary aim of management is to control or coordinate the activity of the organisation to achieve its goals or targets (Bosch and Cook, 2015). Strategy is a theme guiding and coordinating plans in order to gain competitive advantages; it is not a road map but a compass (Giuseppe, 2009). Business strategy has considerable impact on management design, control, and coordination (Miles and Snow, 2003). A balanced strategic management system is meant to achieve the long-term objectives of an organisation through the competence and commitment of entrepreneurs. That is, a well implemented management model leads to the top-level performance of a competitive business (Klepper and Thompson, 2010). Plans, management control, and coordination systems are more determined by managerial methods, personal interests, and experiences than an alignment with strategy (Langfield-Smith, 2005). To avoid complexity, the different management terms will not be considered, but understanding management is important. Therefore, it is necessary to have a common understanding of management.

Research into strategy, coordination, and control has been based on 
contingency theory, other strategic typologies, and other elements of management coordination. The right coordination models, whether centralisation, decentralisation, or both, are the main concern of this thesis, particularly those that are most likely to contribute to strategy formulation success in Nigeria. This study believes that competent, committed people will likely choose the right models of coordination that will lead to strategic results. Hence, this study examined the impact of the $3 \mathrm{Cs}$ on strategy formulation and implementation, since the literature did not emphasise this. The quality of decision-making or coordination is always determined by the quality of people. Leadership operations or professional skills, communication skills, and interpersonal skills are factors that might affect decision-making in an organisation (DuBrin, 2012).

\subsubsection{Environmental Factors and Strategy}

Businesses operate in both the internal and external environments, which influence performance and are the key to the success or failure of firms (Capon, 2009). It is important to know that internal and external factors can work together and influence each other to have an effect on business operations. Businesses supply services and goods to the environment and also receive resources from that same environment (Tinsley, 2002). Macro- and microenvironmental analyses can identify the policy options and direction of a strategy (Noh et al., 2011).

\section{External Factors}

The external environment is the unpredictable force outside an organisation that is beyond the organisation's control. It can constrain firms from functioning effectively and properly. The international, regional, and national levels may be associated with external environmental forces (Perrott, 2008). According to Sull (2009), turbulent environmental times bring threats and opportunities. Organisations evaluate these surrounding opportunities and threats by looking externally (Zinkin, 2008). The macroenvironment includes political, technological, economic, and social factors that have effects on the entire economy rather than just the performance of organisations (Palese and Crane, 2002). It consists of social unrest, interest rates, consumer income, foreign exchange rates, inflation, unemployment rates, and interest rates. The microenvironment includes demand and supply, distribution chains, competitors' strengths, and the number of competitors. 
Political factors include social unrest, rules and regulations, laws, wars, government policies, and trade barriers. Social factors are related to social relationships in the general society that affect business operations, such as consumer preferences, environmental movements, and changes in fashions or seasonal cloths.

Technological factors include innovations, some of which can have positive or negative effects on businesses. They can pose existential threats to businesses (e.g. internet streaming challenging the DVD rental business) or can increase performance, success, and profit margins, such as with automated production and computer software.

\section{Internal Factors}

Organisations can have control over the internal environmental issues in which they operate. The stakeholders deem what is appropriate by modifying or adjusting the internal factors. For instance, organisational weaknesses and strengths are internally assessed and analysed (Zinkin, 2008). Capabilities and resources are composed of an internal environment in which an organisation assesses, analyses, and identifies its weaknesses and strengths (Boddy, 2005). The internal environment includes new equipment, staff attitudes, work force, and strategies (Stiegele, 2008). The framework assumes that strategic stances and actions matter and that an organisational method to scan and assess the environment relative to internal performance is a necessary function. For instance, environmental scans include benchmarking strengths, weaknesses, and opportunities, threat analyses, and a balanced scorecard (Boulay, 2007).

- Internal Relationships: This all about the smooth function of a company, in which there are good rapports among the stakeholders (employees, employers, and shareholders) and the management enjoys an amount of support from its employees, board of directors, and shareholders.

- Value System: The value system includes organisational norms and culture, whereby everybody has to act within the organisational regulatory framework. Top management usually replaces or changes the value system.

- Mission and Objectives: The mission and objectives can affect business philosophies and different priorities and policies. 
Such external environmental factors as new competitors, substantial changes in technology, and market demand have been accorded more prominence than internal factors. However, it may be that both internal and external factors influence turbulent environments. An organisation might underperform due to internal and external environmental factors (Noh et al., 2011). Environmental factors must be given serious consideration and carefully planned for when doing business because they have impacts on day-to-day business operations.

\subsection{The Environmental Principle}

Many decades ago, the business environment was far more stable, firms rarely made changes, and a consistent approach used to be followed (Tusham and Anderson, 2004). In a stable business environment, search routines are used for information gathering (Wartick and Heugen, 2003), predetermined mental models are often used in managers' strategic choices (Csaszar and Levinthal, 2016), and cultural distance is positively associated with recourses committed (Luo, 2004). It can be observed that today's business environment is turbulent, complex, volatile, and dynamic, making it more difficult for businesses to grow and survive. A business environment in a developed economy is more stable than in a developing economy, which might be the reason why doing business in developed countries is better than doing it in developing countries. The World Bank (2013) and IMF 2014 ranked Nigeria as one of the worst countries to do business in. More sophisticated levels of information processing and analysis are required in the present complex business environment (MORI, 2005). This study will not focus on the stable environment but will emphasise the dynamic business environment.

\subsubsection{The Transition Period: Reorientation and Shock}

Major changes in business environments are often referred to as Schumpeterian shocks or environmental jolts (Barney and Hesterly, 2012). Environmental hazards in emerging markets faced by the majority of firms and institutional consumer government controls are called the market uncertainty, which often distorts businesses (Hoskisson et al., 2000; Park and Luo, 2001). Substantial changes in market supply and demand, new competitor group emergences, and technology changes are the shocks that lead to a high level of company uncertainty (Hartman, 2009). Due to an unstable business environment, many firms find it challenging to 
plan or formulate new strategy changes (Levinthal, 2011). Environmental shocks, or jolts, reshape the opportunities and threats that firms face, thus rendering business strategies ineffective (Allen and Snyder, 2009).

The literature reviews on the relationship between strategy formulation processes, environmental factors, and organisational performance are contradictory. For instance, some authors found that environmental shocks, or jolts, in resource commitment may result in escalated economic exposure to regulatory instabilities and uncompensated resource leakage to local businesses (Luo, 2002), making business strategies ineffective and reshaping the threats and opportunities firms face (Allen and Snyder, 2009). One type of shock is recession, a falling GDP environment (Bank of England, 2009). Again, turbulent environments might influence competitive advantages and innovation processes (Hana, 2013) and facilitate higher levels of performance and organisational survival (McGuire and Dow, 2009).

Moreover, the scholars limited their research on external environmental factors such as market demand, new competitors, new technology, and changes in demand and supply, with little emphasis on the effects of internal environments on CE. This study holds that the two levels of turbulent environments are external and internal factors and that they pose the greatest dangers to developing economies like Nigeria. For instance, employee unrest, irregularities in salary payments, discrimination (tribal and ethnic), corruption, breach of trust (and contract) among stakeholders, and worker strikes are all common occurrences in Nigerian firms.

\subsection{Managing Strategy in a Turbulent Business Environment}

The most important thing in this world is to know the direction in which you are moving, not where you are (Holmes, 2006). Some firms formulate and implement strategies that continue to fit or suit the new changes in their environments, maybe because they are lucky or anticipate correctly (Bower and Gilbert, 2007). In today's business, strategies are outdated (Perrott, 2008). Turbulent and dynamic environments are related to difficulties that might contribute to the failure of strategy formulation or implementation (Wetherly and Otter, 2011). Some authors have suggested certain responses to be made by firms in order for them to survive and grow in a dynamic environment, such as understanding customers, being creative, and collaborative relationships, as discussed below. 


\subsubsection{Understanding Customers}

Proposals should invest in marketing sensibly in order to understand or know new changes in consumers' tastes and changing behaviours during recession (Quelch and Jocz, 2009); enhance business processes using information technology (IT) (Dhar and Sundararajan, 2009); gain new or more customers; develop new products (Frey and Callahan, 2008; Makioka, Biragnet and Booker, 2009); maintain brand equity (Jan-Benedict, Steenkamp and Dekimpe, 2009); deliver better value to customers by adopting supply chains (Sodhi and Tang, 2009); and scan the business environment (Zinkin, 2008). These 'understand your customer' models are not effective enough, which is why most of these firms are underperforming. If not, why the global crisis of 2008-2009 (Cable, 2010)? The global crisis resulted in structural break (Allen and Snyder, 2009). These models seem to be outdated, so this study will determine models that are useful or applicable in today's dynamic business environment, particularly the Nigerian business environment.

\subsubsection{Employees' Input}

Employers are encouraging their staff to be creative in order for them to be able to face the challenges of increasingly dynamic environments, changes in technology, and new competitors (Shalley and Gilson, 2004). According to Shalley, Zhou, and Oldham (2004), employee creativity contributes to the growth, innovation, and effectiveness of an organisation. Creativity could be individual useful ideas when groups of people are working together, as well as novel production (Gratton, 2009). However, this study believes that creativity might be damaging, particularly if it does not suit the environment in which it operates. It seems unrealistic: it is not easy to tell employees that they must be creative because this does not make sense, but it makes sense and is convenient to tell employees that they must come to work at $7.30 \mathrm{am}$. It can be concluded that creativity is not a sufficient condition for creative outcomes in a dynamic environment. Consequently, this study will emphasise the effects of a turbulent business environment on $\mathrm{CE}$ and strategy formulation and implementation.

\subsubsection{Collaborative Relationships and Environments}

Several recent studies have identified many advantages of inter-company collaborations. For instance, organisations that collaborate with each other seem to be more successful than independent firms in terms of developing complex market 
products (Teece, 2006; Vazquez-Brust, Sarkis and Cordeiro, 2014). Collaborative agreement is necessary because a turbulent environment can destroy competencies (Tushman and Anderson, 2004).

However, inter-company routines can be an obstacle to timely joint responses when collaborating firms lack strong relations among themselves, even if their interests remain aligned in the new environment (Gillett et al., 2016). This study believes that independent or collaborative relationships do not guarantee the success or effectiveness of an organisation because size cannot determine success but input quality does. However, this does not mean that collaborative relations are totally condemned; they have their own benefits and might even be necessary in some cases. Kennerley and Neely (2002) found that performance measurement (PM) is an alternative way of developing better strategies and business objectives. Strategies that rely on any particular approach can be dangerous, so multiple approaches (i.e. analytics and creativity) should be used to shape a future that is difficult for competitors to imitate (McKeown, 2012).

Chia (2004) and Whittington (2004) stated that a successful strategy does not draw up a precise analytical plan but, rather, has the ability to adapt to continuous environmental changes. Hartman (2009) argued that during uncertain periods, a rapid and flexible response should be the key strategy. The study argues that no particular or specific strategy can be used to respond to turbulent environmental shocks, as environments change constantly and different strategies might be required. Strategy should be an ongoing activity in order for firms to grow and survive. This implies the capability to be able to react appropriately and quickly to unpredictable environmental situations. This study suggests that competent and committed people with good coordination are more likely to have strategic capacity, make use of available resources to achieve success, and survive aftershocks. One of the aims of this study was to explore how Nigerian firms can become flexible enough to cope with a dynamic environment and a readiness to embrace cultures and respond to changes.

The business environment in Nigeria is a very challenging one and impacts on its low ranking in the World Bank's Doing Business Reports over the years. Notable challenges include fuel scarcities, doctors abandoning the sick in hospitals, consistent labour strikes, unpaid salaries, religious and ethnic conflicts - all of which paralyses businesses. This study identified several issues based on the relationship 
between strategy formulation and the $3 \mathrm{Cs}+\mathrm{E}$. It highlights that businesses can be successful if employees and employers are competent, committed to the business with good coordination, and create strategies that fit the environment.

Although the literature highlights the ways in which strategy formulation varies by culture, there are limited situated understandings of how CE contextually unfolds in many developing economies (Nwankwo and Richards, 2004). Essentially, the treatment of $\mathrm{CE}$ configurations - how they are embedded in specific environments and/or impact organisational performance - continues to raise tensions and contestations in contemporary strategy discourse (Feldman and Pentland, 2003; Bradford, 2007).

This study suggests that successful strategic formulation and implementation can be associated with entrepreneurs' competence, commitment, and coordination and the environment in which they operate (i.e. the $3 \mathrm{Cs}+\mathrm{E}$ ). Meanwhile, stakeholders' (entrepreneurs' or employees') commitment is the willingness to put extra effort into their work to achieve the goals and objectives of their company. Stakeholders' competence refers to the knowledge, experiences, and skills that make use of a reasonable degree of their intelligence in the formulation and implementation of strategies. The coordination system deals with effective coordination, either centralisation or decentralisation. Strategy formulation and implementation must fit into the environment operated in for it to be successful by way of competent and committed stakeholders with good coordination.

\subsection{Summary}

Although the concept of CE has been studied from both psychological and economic perspectives, prior research has devoted limited attention to a holistic examination of $\mathrm{CE}$, strategy formulation, and manufacturing sector performance-and not in the least from a developing country perspective. The literature highlights ways in which strategy formulation varies by culture and social embeddedness but remains rather limited in terms of understanding the situated intersection of CE strategy formulation and how this impacts the manufacturing sector. Concerning the research context of a developing economy like Nigeria, this study builds upon and extends the 3Cs framework from an adjacent sector, i.e. construction, and from an equally emerging context such as India (see Jha and Iyer, 2007). Drawing upon the integration of the $3 \mathrm{Cs}$ in alignment with the environment may be essential to success and better 
organisational/sectoral performance. Indeed, the $3 \mathrm{Cs}+\mathrm{E}$ framework highlights an avenue for investigating the discourse of strategy formulation, $\mathrm{CE}$, and the performance of manufacturing sector in Nigeria. 


\section{CHAPTER THREE}

\section{METHODOLOGY}

This chapter explains the methods and procedures used in the study. The research philosophy guiding the study was the interpretative phenomenological analysis (IPA), which is a science that discusses phenomena, or the appearance of things, as lived experiences (Howell, 2013). The chapter is structured around explanations of the research design, discussion of the IPA approach and why it was adopted and provides some insight into the population from which the sample of firms were drawn. The chapter also explains the sampling technique alongside the research instrument, research quality, negotiation of access to research participants, and other challenges associated with fieldwork in the research context.

According to Howell (2013), methodology is a comprehensible set of methods that complement each other and can be used to achieve research aims and objectives. Qualitative and quantitative processes are the two broadly recognised methods used in conducting research, though they might overlap each other (Creswell, 2013). Methodology covers research design, sample size, collection of data, the study population, the sampling technique, research instruments, and limitations (Creswell, 2013), as well as principles and theoretical methods on which the framework and techniques are centred (Holloway, 2005).

\subsection{Research Design}

A logical structure of inquiry combines the research objectives, empirical data, research questions, and conclusions together (Yin, 2003). Bartunek (2007) described research design as the entire set of issues, from the research questions to the writing of the narrative. Research is a logical process of gathering data and analysing information in order to contribute to the existing knowledge. Designs are equated with research methods, which are the reviews (systematic review and literature review).

Researchers use different types of methods (quantitative and qualitative), but the majority of studies prefer quantitative research, that is, testing hypotheses in regard to the typology for empirical validation (Muaz, 2013). Quantitative research entails field experiments and surveys, which are also related to empirical positivist research, but it is not applicable to this study because it is often said to be 
inappropriate in association with social research (Lyons and Coyle, 2007). However, qualitative research is non-experimental and adopts IPA within context; thus, it is applicable to this research (Lyons and Coyle, 2007). Resources available to the researchers usually affect the choice of questionnaire type (Given, 2008). Furthermore, people might be reluctant to complete a questionnaire, as they may think that it is inappropriate to give confidential or sensitive information to a stranger. Likewise, they may have reservations about the way the information may be used (Lyons and Coyle, 2007).

Qualitative research covers natural sciences, with social science as the method of enquiry, i.e. it examines how and why decisions are made. The aims and objectives of qualitative research are associated with the project design (Charmaz, 2006). In research design, the sample selection strategy is very important. As such, this thesis was designed to gain the background information in order to establish the study priority and develop the research questions. Research design is necessary for effective and efficient research. For instance, it minimises expenditure and saves time with the maximum required information and data reliability. A researcher uses their time and research structure effectively so that their study is carefully planned from the introduction to the conclusion. This study makes use of all available data from the interviews and documentations in the data analysis. Therefore, the study design developed the framework to investigate the links between entrepreneurship, strategy formulation, manufacturing firm performance, and other fields like the $3 \mathrm{Cs}$ framework and techniques, from the philosophical and theoretical positions to its limitations.

This study adopted a descriptive, contextual, and exploratory study design because descriptive and exploratory designs work together to discover theoretical differences as well as organise ideas. An exploratory method allows the researcher to contribute to the knowledge of the study by discovering new ideas of a phenomenon (Howell, 2013). Contextual research is based on particular occurrences in naturalistic settings (Punch, 2013). A naturalistic setting is a situation in which real life cannot be controlled and is, in some cases, called a field setting. Research done by an inquiry should not be manipulated (Smith, 2011). The fieldwork was conducted in manufacturing firms, so the respondents should have been able to respond naturally, without manipulation, about the performance of their organisation. The IPA 
approach was used for collecting data in this qualitative research; it described the data so as to gain better knowledge of the manufacturing firms in Nigeria.

\subsection{Research Philosophy}

The research philosophy adopted for this study was the interpretive phenomenological analysis (IPA) because it enables people the opportunity to provide insights into, and to make sense of, phenomena in a particular context (Gill, 2014). It influences open-ended dialogue between the researcher and the researched, thereby leading to new knowledge (Gill, 2014). Therefore, adopting the IPA approach in a qualitative research study reiterates the fact that its main objective and essence are to explore the 'lived experiences' of the research participants and allow them to narrate the research findings through their 'lived experiences' (Clarke 2010). As such, this thesis discusses the historical background of phenomenology as both a theory and a qualitative research approach, an approach that has transitioned into an interpretative analytical practice. It is bottom up in that the researcher generates codes from data to develop new or contribute to existing theories rather than hypothesised theories. IPA recognises that interpretative is people sense making organism in which researcher makes sense of the participants of what happened to them (Muaz, 2013). It is an approach that has been used in many different fields, including business organisation, health psychology, and sexuality (Smith, 2011).

Based on the above, the IPA assumption underlines this thesis through interpretivism and phenomenological analysis. In this study, the IPA approach was developed to guide the design in conducting qualitative research in the investigated area (Smith, 2011). The researcher adopted an IPA framework to collect data through in-depth interviews and analyse the data of manufacturing firms and their performance. The researcher interviewed the participants, who offered meaningful insight into the study, and made sense of the participants' experiences (individual perceptions or accounts of an object). The researcher analysed the respondents' sense-making and their perceptions of what they experienced in detail. Therefore, the researcher used the IPA method to collect data from the in-depth interviews to build up theories and provide more understanding of the people's experiences. 


\subsubsection{Phenomenological Research}

A phenomenological approach is concerned with individuals' subjectivity and knowledge and researchers' interpretations and perceptions. Phenomenology 'provides a deep understanding of a phenomenon as experienced by several individuals' (Creswell, 2007, p.62). This research approach effectively makes use of individuals' experiences and opinions from their perceptions, thus challenging structural or normative assumptions. Furthermore, the interpretive dimension of phenomenological research is used as the support or challenge policy, basis for practical theory, and action.

The phenomenological concept is one of the most important aspects of qualitative research and was used to make sense of the respondents' experiences by eliciting their own meanings of their experiences of being stakeholders of their firms. Creswell (2007) stated that individuals' exceptional experiences in a particular situation are referred to as phenomenological research, 'thus exploring not what is (reality), but what it is preconceived to be'. Phenomenological research contributes to building new theories, adjusts to new findings, collects data more naturally, and understands people's meanings. It is focused on the subjectivity of reality and shows how people view the world around them (Willis, 2007).

Streubert and Capenter (1999) said that descriptive phenomenology encourages breadth, depth, and richness of respondents' existing perceptions of experiences. This study used a phenomenological research approach to investigate manufacturing firms in Nigeria. Thus, it is systematic to investigate the phenomena, critical, and is suitable to participants' perceptions of the business environment and entrepreneurship performances. The researcher interpreted the participants' experiences, stories, and facts and examined the phenomena through the subjectivity of the participants. In a phenomenological investigation, there is always reductive phenomenology, in which the researcher avoids personal biases, presumptions, and postulations in order to avoid allowing their beliefs to affect the description phenomenon of the inquiry (Creswell, 2007). This paper compares and contrasts descriptions of the phenomena without the interruption of the interviewees in order for new concepts to develop.

Reeves and Hedberg (2003, p.32) argued that the 'interpretivist paradigm stresses the need to put analysis in context' from the participants' subjective experiences. It is subjective in the sense that it relies on meaning, oriented in an 
interview approach. Smith (2011) suggested that interpretivism is the way to conduct research and to gain knowledge. Smith (2009) argued that interpretive approaches give the research greater scope to address issues of influence and impact, and to ask questions such as 'why' and 'how' particular research phenomenon are created. Gill (2014) stated that no theories are correct or incorrect, but their quality should be determined by the researcher's interest in the study areas. Casadevall and Fang (2008) suggested that interpretivism is the meaning and knowledge, the deeds of interpretation. Knowledge is not objective; it is not dependent on how people reason and think. According to Myers (2013), interpretive research is an approach to reality through social constructions by shared meaning and language. Interpretive paradigms are underlined by observation, meaning that they interpret information about events by drawing inferences (Gill, 2014). They try to understand phenomena through people's meanings. Thus, the reality of inquiry of this study was adopted through a subjective, or interactional, position.

\subsection{Sampling Procedure}

Consistent with the qualitative orientation of the study, a non-probability sampling procedure was deemed appropriate. Two types of sampling techniques are mentioned in this study: the non-random sampling method, which uses certain criteria to select participants, and the random sampling method, in which any participant or respondent has a chance to be selected. This study used the non-random sampling technique because this could give better results due to the nature of the research objectives. For example, participants that had knowledge in the area of investigation were selected, as they could offer the researcher more meaningful new insights on the study topic. It is based on individual meaning and who has experienced the phenomenon in question rather than on general hypothesis statements.

A sample for quantitative research is usually larger than that of qualitative research because a qualitative sample will arrive to a stage in which the data collected will reach diminishing returns, i.e. the data collected lead to no more new information. Therefore, it becomes unnecessary to collect more data than needed, since too many samples might become repetitive (Ritchie et al., 2003). Qualitative research is primarily based on meaning rather than on generalising hypothesised assertions (Crouch and McKenzie, 2006). Quantitative studies have many more samples because they are not labour intensive, unlike qualitative research in which it 
is not practical to analyse more samples than necessary (Mason, 2010). The major priority of this study was to collect enough data to answer the research questions and achieve the objectives, and it was able to do so.

Participants in this study were selected from the directories of key institutional agencies, such as the Federal Ministry of Industries (FMI), the Nigerian Export Promotion Council (NEPC), and the Manufacturer's Association of Nigeria (MAN) key custodians of corporate enterprise data in Nigeria (see Onyeonoru, 2003; Madichie and Nkamnebe, 2010; Obembe, Olaniyi and Soetan, 2016). The rationale for tapping into the MAN database was that the database is the main source of Nigerian business listing in the sector of interest.

In his seminal study on the impact of globalisation on the industrial performance in the country Onyeonoru (2003) drew extensively from this database. According to the MAN manual, the chosen areas have the greatest concentration of manufacturing firms. For various reasons, however, most of the manufacturing firms had shut down in the investigated geopolitical zones.

The research was conducted in Nigeria, a country consisting of six geopolitical zones South West, South East, South, North Central, North West, and North East, four of which were included in the sample based upon the relative peace in those areas at the time of data collection (the North East and North West were avoided for security reasons). The sampled firms in the South West were from the Lagos, Ibadan, Sango Otta, Ile Ife, and Oyo townships. For the South East, the towns sampled from were Onitsha and Nnewi. Benin, Warri, and Sapele were sampled in the South. In the North Central, the Jos and Ilorin towns were sampled. These cities were purposely selected because they housed viable manufacturing firms, and these firms were chosen because they were among the most viable firms the researcher had access to. For each of the sampled 32 viable manufacturing firms one interview per firm with one senior management staff was conducted (see Appendix 1).

\subsection{Guidelines for Saturation and Sample Size}

A sample is comprised of one or more individuals, groups of people, documents, events, and scenes (Bowen, 2008). The acceptance quality for qualitative and quantitative studies is determined by applicability, neutrality of evidence, truthvalue, and consistency (Frambach, van der Vleuten and Durning, 2013). Quantitative research usually generalises findings; as a result, it encourages large sample sizes for 
better quality and validity. However, in qualitative research, the sample size is smaller, but the relevance and quality of the samples are more important (O'Reilly and Parker, 2012). The high quality of qualitative research should constitute quality guidelines that are value-laid (Hammersley, 2007) and should be standard, with a fixed set of quality and approach (O'Reilly and Parker, 2012). The quality of qualitative research depends on dependability, credibility, and conformability. This study applied Tracy's eight criteria for qualitative research: worthy topic, rich rigor, sincerity, credibility, resonates with readers, meaningful coherence, makes a significant contribution to the field, and is ethical (Tracy, 2010). Furthermore, four factors were used to assess the quality of the research, i.e. the methods used, the research problems, the research findings, and the analysis (Merriam, 2002).

The quality of qualitative research is determined by the data saturation, as failure to reach data saturation affects the quality and validity of the research conducted (Walker, 2012). Data saturation is necessary in qualitative research, as it shows that the collected samples are adequate and valid (Francis et al., 2010). According to Tracy (2010) and Bruce (2007), the encompass rich data, descriptive data to be collected as part of the quality of a qualitative research is associated with the concept of data saturation'. Gibson and Brown (2009) stated that the notion of data saturation has its origins in building up theories by analysing the data collected rather than creating a hypothesis. The term data saturation is rooted in theoretical saturation, which is referred to as collecting, gathering, and analysing data until no more new insights are observed. In theory building, the researcher continues to collect data until the data are saturated, i.e. no new useful information or no new knowledge is arising through the data being collected.

Various authors have criticised the idea of data collection being saturated as problematic in many ways (Bruce, 2007; Bowen, 2008, Francis et al., 2010). For instance, O'Reilly and Parker (2012) stated that the concept of data saturation has been generalised though it should not be. They suggested that data saturation as a yardstick to determine sample size is inappropriate in conversational analysis. Guest et al. (2006) said that there is no evidence in the literature as to how to estimate sample size to reach data saturation or how to determine data saturation. The meaning of data saturation is confusing in qualitative research. Some scholars believe that data saturation does not exist (Wray et al., 2007) and that complete saturation is not achievable (Corbin and Strauss, 2008). 
Some authors have argued that it is difficult to be sure or confident that no new insights will surface if a further number of individuals, groups of people, and documents are sampled (Bowen, 2008; O'Reilly and Parker, 2012). This is because peoples are unique in terms of their thoughts and perceptions (Bowen, 2008; Francis et al., 2010; O’Reilly and Parker, 2012). Guest et al. (2006) conducted 60 interviews and reported that they reached data saturation after analysing 12 interviews; thus, the remaining 48 interviews were a waste of times and resources. If more data than required are collected in the process of reaching saturation, this might lead to waste of resources and time (Francis et al., 2010). This study used a larger sample than needed to be on the safe side, as it is better to have more than enough than to have an insufficient number of samples; good research quality is the priority.

Mason (2010) studied non-random samples of $560 \mathrm{PhD}$ theses that used qualitative approaches as the method of data collection and found that the mean sample size was 31. Francis et al. (2010) interrogated 18 published papers and discovered that 15 of the 18 papers claimed to have reached data saturation. Therefore, there was no evidence of any new information, findings, themes, or ideas in the data. They concluded that ideas or claims that data are saturated are not clear, and how this can be achieved in the context of the research is not known (Bowen, 2008). Consequently, to associate the quality of interviews with data saturation is not convincing and cannot be used as a guideline to estimate sample size. Some scholars have provided guidelines regarding the number of participants that will be enough to reach data saturation, as follows:

In qualitative research, 12 is arguably considered a minimum sample number that can give useful results (Guest et al., 2006). Francis et al (2010) claimed that a range of 13 to 15 interviews may lead to data saturation. According to Charmaz (2006), anything within 5 to 25 participants are recommended, Ritchie et al (2003) said that less than 50 respondents, and nothing less than 20 interviews are also recommended (Green and Thorogood, 2009), Guest et al, Bertaux stated that 15 minimum samples are required. Creswell (2013) said that the range is between 20 and 60 samples. Adler and Adler (2011) stated that the number of qualitative interviews necessary to conduct and complete a research project is between 12 and 60 and that the mean is 30. Furthermore, Gbadamosi (2009) used purposive and snowball sampling in his study of low-income consumers' reactions to lowinvolvement products. According to him, 'one focus group and 30 in depth 
interviews on the subject matter were conducted with low-income women in Salford, Northwest England (Gbadamosi, 2009). Morse (2013) suggested that sample size should depend on the qualitative approach used. For instance, for a phenomenological study, a minimum of 6 samples is sufficient for useful interpretations and meaningful themes. This study agrees with Morse's (2013) view that the sample size should depend on the nature of the study (the aims and objectives and the research title). Moreover, researchers might stop the collection and/or analysis of data in the hope that they have reached the saturation stage, which might not be true of the situation and may lead to counterproductive research results. There are different results as to the number of samples required to achieve data saturation, which is confusing. Since different authors recommend different sample sizes, this is not convincing.

Guest et al. (2006) advised that the number of participants recommended in the literature might not be sufficient enough to justify the findings and analysis. Saturation has varied meanings and limited transparency (O'Reilly and Parker, 2012). Data saturation cannot be the same in all qualitative research approaches like a deductive design. Various authors have suggested different figures. There is no agreed upon formula or sample size for reaching data saturation, and little or nothing has been discussed about depth analysis. Data saturation seems to be flawed because nobody can be sure whether new insights or information have emerged.

Francis et al. (2010) proposed the $10+3$ formula to establish data saturation. Though the formula is not generally agreed upon, this study preferred to apply it to obtain its sample size because it appears reasonable and practicable. Therefore, this study started with 10 interviews; 3 more interviews followed, and so on, until the data collected were sufficient enough (i.e. saturated) for the study objectives and to answer the research questions. Based on these observations, this study conducted 32 in-depth interviews in Nigerian firms that met the inclusion criteria. The 32 samples were consistent with certain authors' samples, as discussed earlier.

Time is another constraint for sample size in qualitative research. Some researchers have found that time spent or taken when collecting data in the field influences the quality of the research (Merriam, 2002; Frambach et al., 2013). According to Corbin and Strauss (2008), conducting five or six interviews within one hour is not likely to be enough to reach saturation. In a similar manner, if interviewing respondents for 10 minutes, it would take 10 hours to interview 60 
respondents during fieldwork. Nevertheless, a 10-minute interview would hardly draw sufficient data or information from a participant, unlike when a respondent is interviewed for an hour (which would take 10 hours to interview 10 respondents). The depth of analysis should also be a focus in data saturation that is determined by the number of samples and time.

Each respondent was interviewed for about an hour. There were 32 respondents in all, and it took about 30 hours to complete all the interviews across the chosen geopolitical zones in Nigeria. This shows that this is time consuming, and at times, it might not be easy to manage. Likewise, the data collected might be difficult to analyse, as a 10-minute interview could take around 1 or 2 hours to transcribe (Online Student Support Services, 2013). However, this method can generate richer data than any other research technique, which is the priority of this study.

\subsection{Data Collection Method}

Data are the collection of factual materials commonly accepted in the scientific community as necessary to validate research findings (Baskarada, 2014). The qualitative data approach is the best to research on human learning (Henning, Van Rensburg and Smit, 2004; Denzin and Lincoln, 2011). Data can be generated from previous literature, surveys, experiments, interviews, and observations (Peersman, 2014). Adler (2011) used a similar approach in his exploration of organisational strategy and performance management. According to him, 'the interview data were complemented by various archival data, including financial statements, internal performance reports, and business publication news items. All of these served to help corroborate and, at times, provide opportunities for further elaboration of the interview data' (Adler, 2011, p.257). All 32 firms visited granted access and audience for the interviews to be conducted with them. The target respondent for the study was one management staff from each of the 32 firms. An interview guide was prepared to solicit responses from the respondents, and the interview sessions were audio recorded while a note-taking officer was present in each of the sessions.

\subsection{Research Instruments}

There are different ways by which data are collected in qualitative research, including interviews, documentation, and observations. Nevertheless, interviews are 
the most suitable and common method used in social science research (Punch, 2013). This study explored individual face-to-face interviews and documentation to collect data on manufacturing firms in Nigeria.

\subsubsection{The Interviews}

Qualitative interview research provides a deeper understanding of social phenomena, unlike the quantitative questionnaire method. An interview is a conversation between the researcher and the respondents in which the former asks questions in order to obtain relevant information from the latter. This study designed its interview in such a way that the questions asked yielded suitable information about the studied phenomenon. The questions were able to answer the research questions; likewise, they addressed the research objective and contributed to the knowledge. The questions were open-ended questions, i.e. sensitive, neutral, and understandable more than yes and no questions. According to Legard and Ward (2003), the three types of interview techniques that researchers usually engage in are telephone interviews, focus group interviews, and individual face-to-face interviews:

\section{Telephone Interviews}

Telephone interview are good for obtaining information rapidly. This does not determine the quality of information, which is the priority of the study. Therefore, telephone interviews were not ideal for this study due to its sensitivity and nature, as a telephone interview would be relatively short in conversation and not every company has telephone facilities in Nigeria. There is also the probability that respondents might have felt that they were being imposed upon or dislike the intrusion into their private lives. Moreover, the interviews might not have been possible due to lack of network in some factories or low battery in the phones on hand, since mobile phones are commonly used by both firms and individuals. Since there would have been no direct access to the respondents, they might have been reluctant to open up to somebody they had never seen or met before.

\section{Focus Group Interviews}

Focus group interviews are a qualitative technique of data collection obtained through less structured interview methods for social science research, albeit with alternative techniques. Some authors believe that focus groups encourage 
respondents to interact with each other and give them an opportunity for instant feedback or clarification about their opinion, with the contribution to other group members (Harding 2013). In a 'group interview, people can develop new ideas they would not have thought about on their own' (Gill et al., 2008, p.293).

For the nature of this study, it was not appropriate to adopt group interviews because some important information might have been confidential and not for everybody in the group to know; some members might not have wanted to be quoted. Furthermore, if respondents are not happy with one another, they might not be able to discuss their opinions or feelings openly. The more vocal respondents may not allow others the chance to contribute to the in-group discussion, even if they have better ideas. Some firms did not have enough staff at work, which made it difficult to arrange group interviews as it would affect their business activities. Furthermore, it might have been difficult to record the interview if multiple respondents' speech overlapped, since this would make it impossible to know who was speaking at a particular time (Gill et al. 2008). Additionally, it might have been impossible to collect the required participants at the same time for the group interviews (Morse, 2008).

\section{Individual Face-to-face Interviews}

Individual face-to-face interviews were the most valuable tool for data collection regarding the nature of this study. This approach yields more reliable and valid qualitative data. This study used in-depth interviews to collect data through face-toface verbal communication between the researcher and the respondents. The study adopted questions that were well-framed for proper data collection, and the respondents were free to express their own experiences, impressions, and opinions (Gill 2014). The firms visited held the interviews in a recommended suitable room or office. The researcher interviewed the respondents to obtain in-depth information on the topic area that covered meanings and facts, from which their responses could be further investigated. This allowed the respondents to express their feelings in their own words and native languages. Using this method, the researcher could probe further or ask follow-up questions. According to Creswell (2013), there are three main techniques of collecting data in individual face-to-face interviews including structured, semi-structured, and unstructured interviews. 
Structured interviews are commonly used in quantitative questionnaire research, in which the verbal questions are predetermined and inflexible, with no opportunity for follow-up questions to respond to anything that deserves more explanation. This technique is not efficient when depth is required because the participants' responses are limited since is deliberately limits what the respondent can talk about - this having been decided in advance by the investigator. Therefore, this approach is not suitable for in-depth interviews.

Unstructured interviews consist of open questions. This allows the researcher and the respondents to brainstorm on the study area. The questions are flexible, i.e. not predetermined and not standard. In some cases, the researcher and the respondents determine the direction of the interviews, which makes it possible for the researcher to quiz the respondents more deeply on specific issues as necessary. Unstructured interviews are a richer source for exploring people's inner feelings and attitudes than any other data collection technique, such as quantitative questionnaire research (Creswell, 2013).

Structured and unstructured interviews are features of semi-structured interviews, which contain open and closed questions. Semi-structured interviews have something in common with the advantages of both interview techniques. They consist of important questions that help describe the area of study to be discovered and also make the researcher or respondents diverge so as to pursue an idea in more detail (Legard, Keegan and Ward, 2003).

The researcher used the same set of questions as guidance for all the participants to respond for consistency reasons. This study used semi-structure interview methods to collection data through in-depth interviews rather than structured or unstructured interviews. Conducting semi-structure interviews means to submerge oneself in the content of interaction. It establish rapport with the respondents, follow the respondents' concerns or interest, greater flexibility of coverage and allows the interview to go into novel areas, and it tends to produce richer data.

The physical presence of the researcher and their operation within the cultural context had a positive impact on the research process. The researcher usually started the interview with simple and straightforward questions like 'What is your name?', 'What is your organisation's name?', Can you tell the researcher about your products?', and so on. The questions were then made to be more difficult, e.g. 'Who 
drives the vision within your organisation?' and 'Can you shed light on what the concepts 'competence' and 'commitment' mean for your organisation?' The next questions might have been about the respondents' personal experiences with their organisation in the last five years in terms of performance or operation. This was to make the participants more confident and comfortable. Rich data were generated as the interview subsequently developed further.

The researcher asked the respondents about their social demographic characteristics, which included their religious affiliation, gender, tribe, qualifications, age, salary, position, ethnicity, and their organisation's name, indices of socioeconomic characteristics, and status. The basis for requesting this information was to assess the manpower of the organisations and the firms' maturity levels in adopting strategies. The interview questions investigated the organisations' achievements in terms of performance and on which factors and/or causes the realisation of this performance depended. The questions also explored the strategies they adopted to make their businesses grow and the difficulties they were facing. Also investigated were the natures and interrelationships of stakeholders' $3 \mathrm{Cs}$ in the organisations in which they operated. Another question concerned the respondents' perspectives on the turbulent business environment. Furthermore, asked what an organisation could do to survive and grow in this complex business environment. The study attempted to interpret the respondents' experiences and the work around them.

Some scholars have stated that interviews have some disadvantages, e.g. the responses might not be valid due to incomplete or false information provided by the subjects. Probably the interviewee might falsify their actual beliefs and or not saying the truth (Turner, 2010). This could have been possible due to social undesirable norms in Nigeria in a situation where the interviewees were concerned about issues related to bribery, corruption, and tribal and religious discrimination/wars. For this reason, the interviewees might have been more concerned with responding the right way than with disclosing their true mindsets or behaviours. Therefore, the researcher was more focused on the important, relevant stories of the respondents from which they derived their own accounts rather than on clarifying whether the resulting text was true or false. Mutual understanding between the interviewer and the respondents was achieved through the negotiation of meanings. The researcher tried as much as possible to follow these guidelines for each interview: 
- Gain access to the company and make an arrangement with each respondent for a suitable time and date.

- Find a meeting point for each interview as agreed by the company and make sure that it is conducive for the interview.

- Prepare a tape recorder with a new battery and test it before the interview.

To start each interview, six considerations were evaluated with the corporation of the respondents as follows:

1) The researcher introduced himself and thanked the respondent for their time and for agreeing to be part of the study.

2) The researcher explained the purpose of the interview to the respondent and ensured that they were aware of the purpose of the study.

3) The researcher called the attention of the respondent to the letter of introduction and consent of the participant (see Appendix 1).

4) The researcher explained that the interview was in-depth (see Appendix 2).

5) The researcher asked permission to tape record the interview.

6) The appointment time and date had to be at the respondent's convenience for full and maximum cooperation.

During the course of each interview, another six considerations had to be in place, notably:

1) The questions were asked in such a way that they answered the research questions, but the researcher avoided irrelevant questions.

2) The researcher made sure that the questions asked were simple, clear, and not difficult to understand.

3) The respondent was not interrupted and spoke freely to give honest answers.

4) The researcher ensured the possibility of easily moving back and forth between the questions due to the likelihood that the respondent might deviate from the study area.

5) The questions asked were flexible and followed a logical sequence.

6) The researcher always encouraged the respondent to continue talking by indicating interest, e.g. by nodding his head and so on. 
After the interviews, four actions needed to be taken on-board, as follows:

1. The researcher transcribed notes into a word-processed document

2. The researcher went through the transcriptions, grouped similar topics into categories, and made note of new ideas.

3. The interviews were transcribed after each interview.

4. The data were organised to produce findings after analysis.

\subsection{Company Documentation}

Documentary analysis is a secondary data collection method that can be used by researchers on their own or with other sources of the study. In social research, documentary analysis is a technique used to collect data and is an essential tool and important scheme of triangulation (Gribbs, 2002). Transactional, financial, memorandum, business letters, business reports, corporate mission statements, policies on formal strategy, human resource management (HRM) strategies, and private correspondence among staff are a few examples of company documents. It should be noted that most of these documents are usually kept in company archives. The information from company documentation varies from personal to wideaudience and depends on the functions in the life of the organisation (Adler, 2011). The researcher was cautious of these types of information in this study.

Western social science uses the documentary analysis method as an important source of raw data and a medium of storage for gathered data (Bryman, 2012). It is considered a preferred method of research on marketing and consumers of menthol cigarettes (Anderson, 2011). Furthermore, European and American social scientists have often considered administrative and official documents as a preferred method of data collection since the mid-1900s (see Dalton, 1959). Oakes (2003) used this method to collect data in his study on the sociology of religious tracts and pamphlets. This method was used on profitability from organisational records and as data collection on employee absenteeism, both of which were used to generate statistical measures (see Barnes et al. 1995)

The research questions and objectives must determine the choice of documents, that is, to look for only documents that are relevant to the study for data collection. Therefore, various company documents brought perceptions to the understanding of the $3 \mathrm{Cs}$ and the firms' backgrounds. They certainly provided 
insight into the respondents' attitudes and behaviours in the research. It was important to gain approval and assistance from management staff in order to access the documents. The director of personnel gave permission for access to some sensitive organisational documents that the researcher might have needed. During the fieldwork, the researcher was assigned limited time to make use of the libraries and other reference centres. These documents obviously helped the researcher learn more about the firms' organisational structures, training programmes, performance records, stakeholders, cultures, and images. These documents revealed the stakeholders' behaviours and attitudes and also brought fresh insights to the understanding of organisational performance.

Documentation was used when writing the firms' histories and profiles and further supported the interviewees' responses. Hence, company documents were used as another means of collecting secondary data through direct information, which added to the quality of the research. This study used the documentation approach of contemporary data of events in the firms to obtain information about the performances and historical processes of the firms. The data collected were more comprehensive in coverage than that obtained from the interviews. Some of the interviewees were limited in their knowledge of the history of their company, probably because of the number of years spent in the company. Once the documentation data were collected, the researcher did not necessarily devote resources and time to collecting certain categories of data through the interviews. Therefore, access to detailed information through documents can make the research work better.

The documents were used to verify the firms' names mentioned during the interviews and correct spellings and titles. Interviews that were contradictory to the information from the documents signalled a need for further inquiry into the study area. Thus, the documents were used to corroborate information from the interviews. As the qualitative research methods were flexible, the documentary analysis could be used to amend the original research questions and other areas. Some documents were used to write about the firms' histories and their most recent changes. The author presented suggestions for the changed objectives and processes in conference presentations and offered them to the researcher. These were useful to complement the interviews that had already been conducted. 
In some situations, the gatekeepers would not allow access to certain sensitive documents for personal, security, and political reasons (Gummesson, 2002; Cole, 2004). The organisational information might be used for ulterior motives, especially by competitors who might use it for their own selfish motive of improving their own business at the detriment of another. At times, some documentation might be one-sided and the information inaccurate, incomplete, or subject to bias, which might affect the quality of the data collected, as these are not likely to be true representative descriptions of life at the company or organisation. Therefore, company documents must be evaluated, interpreted, vetted, and triangulated with interviews so as to make the information valuable. As such, any information that appeared irrelevant to the study or any duplicated documents were not used.

\subsection{Gaining Access to Organisations}

Gaining access to the research field is a major challenge of successful research, especially when the research topic is sensitive (Johl and Renganathan, 2010). Indepth interviews of respective fieldwork require a lot of money and time (Patton, 2002; Shenton and Hayter, 2004; Okumus et al., 2007). Some organisations will not welcome researchers that are not part of them (i.e. outsiders), particularly if the researchers ask questions that are uncomfortable or sensitive to them (Okumus et al., 2007). Moreover, organisations might not see merit in academic studies (Wasserman and Jeffrey, 2007). Researchers may be denied access because the organisation believes that the study will not add value to it and see it as a disturbance (Coleman, 1996). Gaining access to the research field might be difficult due to lack of time of large profit firms, as their managements believe that time is money. Therefore, Easterby-Smith, Thorpe, and Jackson (2008) suggested that questionnaires are more feasible compared to other methods like interviews and observations. Various authors have acknowledged the importance of obtaining access, but little has been done to address the issues and problems facing this. Gaining access to the research field should be taken seriously, as it is more than just 'getting in' to obtain information. However, the quality of access determines the quality of information available for data collection (Altamira, 2003). According to Okumus et al. (2007), the two main types of access are formal and informal access, as discussed below. 


\subsubsection{Formal Access}

Researchers can obtain access through a formal way, in which access can be granted through an agreement between the researchers and the company on terms and conditions. That is, the rules and regulations of the company must be obeyed. In the formal approach, respondents usually keep to the date and time of the meeting so as to give a good image of their company. In this method, the respondents are motivated and cooperate to participate in the study (Oppenheim, 2000). The legitimate access encourages the respondents to not be biased in their responses. Formal communication can be through formal telephone calls or a letter with an official letterhead used to gain access and fix interview appointments.

In this study, letters were given to the firms' managements requesting access to their organisations. The university letterhead was used with a hand-written signature and personally addressed as approved by the team of supervisors (see Appendix 2). The research requirements and proposal were also outlined in the letter to provide a good impression of the research project in order for the respondents to be more cooperative and pay more attention to the researcher. This was in accordance with Rogelberg (2004).

Indeed, Johl and Renganathan (2010) obtained firms' phone numbers, emails, and postal addresses from the list of top 100 firms in Malaysia. Calls were made to gain access to their studied firms and also to identify suitable participants to answer the research questions. Suitable participants were recommended by the firms' public relations officers (PROs) in accordance to their knowledge. A letter was also sent to the corporations through e-mail and asked for their participation and stated the aim of the study. In a similar manner, the researcher of this study obtained the contact details of manufacturing firms in Nigeria from the MAN and FMI directories, since they are the main sources of business lists of manufacturing firms.

The addresses of the firms were found in the directories, but out of 32 firms visited, only 8 had working telephone numbers. Only 5 of them picked up their phones after the lines were tried about 6 times, while 2 of them called back because they saw the researcher's missed calls. Thus, those who picked up their calls were notified about the research project, wanted to talk to the human resources or public relationship manager, and were told to call back because he was not available at the time of the call. After many attempts, there was no positive response: it was either 
they did not pick up the calls, or the phone did not go through. These were disappointing, frustrating, and hopeless.

Cover letters were sent out to the respondents in an e-mail clearly stating the study's aims and objectives and requesting the informed consent of participants, following the ethical approval processes of the researcher's home institutionnotably, the University of East London's research ethics approval procedures of February 2016. Much of the mail did not go through, and the few that went through received no reply. For these reasons, the researcher took the time to personally visit the firms in order to gain access, since the postage system in Nigeria is not guaranteed. During the visit, the researcher met with the firms' receptionists and left the letters with them by hand. The University of East London official letterhead was used and designed properly, as this is a useful way to gain access that can lead to responses, as ascertained by Rogelberg (2004). The letter was made simple, just one page. Time and resources were also minimised so that the organisations or respondents would not be discouraged from the study.

This corresponds to Feldman et al.'s (2003) view that an introduction letter must not be complex; otherwise, gaining access will not be successful. The researcher made it clear that anonymity and confidentiality would be protected if there was need for it (Gill et al., 2008) and that findings would not be linked to the respondents unless permitted to do so (Bell, 2005). This study observed that, for the nature of this study, the existing literature was not suitable for a formal approach of gaining access in developing countries like Nigeria. It was more difficult to obtain access than anticipated. Accordingly, the researcher attempted an informal strategy to gain access.

\subsubsection{Informal Access}

Informal communication includes e-mails, telephone calls to familiar people, and informal letters, and there is no need for formal appointments (Johl and Renganathan, 2010). Personal access is a situation whereby the researcher gains access through the influence of people they know within the organisation (e.g. managers, executives, and individuals). It is even possible that the researcher might be the company's employee or that the researcher and participants are friends before the fieldwork. In this way, the researcher's access will be granted easily (Johl and Renganathan, 2010). 
Access is granted through individual relationships (rapport) when there is collaboration between an organisation and a researcher with good understanding. Access by individual relationships might take several years of preparation, depending on the researcher's requirements (Feldman et al., 2003). The researcher and the respondents might not take the interview seriously since it is informal. In the process, they might decide to cancel the meeting at the last minute. At times, the respondents might not turn up for the meeting at the agreed date and time. Sometimes, information collected is based on trust, since most of the respondents are the researcher's colleagues and volunteered to be interviewed for cooperation reasons.

In this study, the researcher obtained access through influence and connections. For instance, as requested by the researcher, a letter was sent by a senator (name withheld) to some of the firms' chairmen, stating that the bearer should be allowed access in order to conduct research. If not for this influence, some of the information that the researcher had access to might not have been obtained in certain cases. Additionally, governors of certain states in Nigeria made phone calls on behalf of the researcher to the supposed sampled firms; on a few occasions, emails were sent from government officials to the firms. In this situation, the researcher was sent back to those firms to see the management for assistance because they had been instructed. In these ways, the researcher was able to conduct successful interviews with the participants' full cooperation.

According to Ericsson and Kovalainen (2008), researchers must take notes during interviews, and tape recording is necessary in order to be more focused and to concentrate on listening. Therefore, the researcher took notes and also recorded the interviews so as to capture a rich set of evidence. Before the meetings, the researcher asked permission to record the interviews; about $50 \%$ of the respondents did not want to be recorded for reasons best known to them. Some of the participants warned that the recorded interviews should not be released to the press. Regarding ethical issues, the researcher assured the respondents and firms visited of the anonymity and confidentiality of the data protection, in which participants might not be identified directly when writing the thesis. Likewise, the information collected was not misused, and moral responsibilities were maintained towards the participants (see Appendixes 2 and 3).

However, most of the firms visited were favourably disposed towards the research and permitted that anonymity might not be necessary, which was the reason 
for the disclosure of their personal and company identities. Most of the recorded interviews could not be used due to overriding noise from office window airconditioning units, magnetic vibrations, and noise from the generators used to power the firms' factories . Therefore, the researcher employed three people to help with the notetaking during the interviews. The researcher also took a few notes but was more focused and concentrated on the interview. After each interview, the team compared and contrasted their notes and finally made comprehensive notes. Although this approach may have been more expensive, it made the study more reliable, saved time, and reduced stress.

\subsection{Data Analysis}

This study is about human learning and used in-depth interviews and documentation techniques as its data collection methods. Data must preserve the context of collection and be true and interpretative; otherwise, it is useless. The collected data and the data analysis were used to answer the research questions and envisage the forthcoming events and the fact that data determine the quality of research.

The direct interaction and phenomenon of the study was derived from the attempt of interpretive researchers. The interviewees might have had different meanings or different experience of different parts of reality. The analysis started as soon as the first data were collected. When all the data were collected, the actual data analysis occurred. The social perception idea of differences in the meaning reflects, directly or indirectly, the differences in people's behaviours and responses. Hence, in the analysis of the data collected, this study took these differences into consideration by assessing or developing an understanding of them. After the interview, the qualitative interviews were turned to qualitative data; this was maintained in the data analysis.

The 32 interviews were used for the analysis of the theoretical understanding of the strategy (i.e. the 3Cs and the business environment), which then reflected the performance challenges. Moreover, whether the geopolitical and socio-cultural issues identified conceptually constituted the critical tasks of entrepreneurships was also examined. The study also analysed the status quo and ways of detecting and improving the business performance of the enterprises in the study sample. Responses from the interviewees generated further areas of inquiry, with both managerial and policy implications. Data transcription and emerging themes were 
teased out of the Atlas.ti software and guided by inductive coding developed based on the research objectives of the study. The reports were presented thematically with the use of network figures.

\subsection{Challenges and Mitigation Strategies}

This study found that the problems associated with fieldwork had negative effects on the quality of the interviews conducted in Nigeria. It is possible that some errors or biases occurred in the interviews, which might affect the reliability of the research. According to Robson (2002), for example, the employees and organisations were not prepared to do additional unpaid activities. Most of the workers were overstressed; some of them had not even received their salaries, and many had been made redundant. According to a respondent, since the access was through their boss, they thought the head office sent the researcher to monitor them, and they did not want to lose their jobs. Moreover, they responded in ways that they thought their bosses wanted them to respond in.

The participants might not have known how important or sensitive the study was, so they might have provided information that was not relevant to the study. To them, the interviews were for an academic purpose. Dillman (2000) stated that some sincere answers from respondents might not be socially acceptable. However, they might have discussed their responses with their colleagues, so the responses given would be adulterated. Information in company documents is not always true and may have been either corrupted or tampered with without the researcher's knowledge. For instance, some firms' financial year accounts may have been tampered with to reduce the taxes to be paid or to give the public a good impression of the firms.

Fieldwork in Nigeria is stressful and frustrating. The firms visited are spread across four geopolitical zones of Nigeria, and the majority are on the outskirts of the towns. It was very difficult to get public transport; crowds wait for hours at bus stops and taxi stands before they can get public transport. Nigerian employees live with this kind of situation every time they go to work. At times, the researcher spent an entire day travelling on the road before arriving to the organisation. For this reason, the researcher used a private car, but it did not make a difference. For instance, there was a day when a bridge collapsed, and the researcher could not do fieldwork for almost one week because traffic could not move. 


\subsection{Summary}

This study adopted qualitative research methods (in-depth interviews and documentary analysis) to collect data. It used semi-structured interviews because they are the most suitable for this type of research (i.e. social science) (Gill, 2014). Structured interviews would have been too rigid to capture the necessary information from the respondents, while unstructured interviews would have been too loose and unfocused for the interviewer. The one-to-one interview technique provided in-depth information pertaining to the respondents' viewpoints and experiences of the study area. Thirty-two interviews were conducted in thirty-two firms across four geopolitical zones in Nigeria. Influence and connections facilitated access to the respondents and firms, which is contrary to certain scholars' views that well-written letters, time, and resources will encourage access.

Obtaining the data was very stressful for the field officers employed for the work; it took four months to complete the fieldwork. The researcher transcribed the recordings into a word-processed document through a transcription specialist. The documents were then grouped into emerging themes and guided by inductive coding developed based on the research objectives of the study using Atlas.ti software. The reports were presented thematically with the use of network figures. 


\section{CHAPTER FOUR}

\section{DATA ANALYSIS}

This chapter presents the data and discussions of the results. The first part of the data deals with the personal data of the respondents, including gender, age, educational status, religious affiliation, marital status, and state of origin. One respondent each was selected from the 32 firms visited in the 4 geopolitical zones of the country. The second set of issues to be discussed is comprised of the effect of the 3 Cs (i.e. entrepreneurs' and/or employees' capability) on the performance of manufacturing firms in the country and also sheds light on the effect of geopolitical and sociocultural influences on the firms. This chapter also discusses the effect of the immediate environment on firm performance. It ends with a discussion on the performance with a model derived from the study. The data collected are grouped below according to the nature of business:

1. Auto and auto part manufacturing firms;

2. Food, water, and beverages;

3. Plastic and nylon industries;

4. Chemical and paint industries;

5. Building industries;

6. Iron and steel industries;

7. Household industries.

These sub-sectors of the Nigerian manufacturing sector are discussed thematically in the following sections.

\subsection{Auto and Auto Part Manufacturing Firms}

There are two manufacturing firms under this category, and both are located in the South Eastern states of Nigeria. The cases of Innoson Vehicle and the Ibeto Group are highlighted (see Table 4.1). Interestingly, both firms seem to be located not just in the same South East region but, more importantly, in the same town - i.e. Nnewi.

Table 4.1 Auto and Auto Parts Manufacturing Firms

\begin{tabular}{|l|l|l|l|l|}
\hline S/N & Company Name & $\begin{array}{l}\text { Nature of } \\
\text { Business }\end{array}$ & Town/ City & Region \\
\hline
\end{tabular}




\begin{tabular}{|l|l|l|l|l|}
\hline 1 & $\begin{array}{l}\text { Innoson Vehicle } \\
\text { Manufacturing } \\
\text { Company Limited }\end{array}$ & $\begin{array}{l}\text { Auto and auto } \\
\text { parts } \\
\text { manufacturing }\end{array}$ & Nnewi & South East \\
\hline 2 & $\begin{array}{l}\text { Ibeto Group Union } \\
\text { Auto Parts } \\
\text { Manufacturing }\end{array}$ & $\begin{array}{l}\text { Auto parts } \\
\text { manufacturing } \\
\text { Company }\end{array}$ & Nnewi & South East \\
\hline
\end{tabular}

\subsubsection{Innoson Vehicle Manufacturing Company Limited}

Innoson Vehicle Manufacturing Company Limited, located in Nnewi, Anambra State, is an African automobile manufacturing brand. It has different models of buses - such as a five-sitter called Fox (1.5 litre engine), Umu (2 litre engine), and Uzo (mini-bus) - and about 400 employees, the majority of which are casual workers. The organisation has been operating for the past 10 years. Seventy percent of the input materials used are imported to Nigeria from Europe, while the rest are produced locally. The company's mission is to design and manufacture cheap, affordable, and durable vehicles for Africans. Its vision is to make Africans prefer its automobile brand over others so as to eradicate or reduce imported used and new automobiles to Africa.

The general manager was interviewed. $\mathrm{He}$ is in the administration department, a university graduate who was employed by the company through professional merit. The management staff are recruited through a recruiting firm, but the factory workers are usually casual workers. These casual workers are trained on the job with no formal education and then retained as permanent workers. The general manager had worked in another firm before coming to the present firm. $\mathrm{He}$ found the work in the present place more tasking and demanding than that of the initial one. The firm's relationship with the environment has been very cordial; it performs many corporate social responsibilities, among which is the provision of tap water at the wall outside the factory, which people in the neighbourhoods use for their domestic use. The relationship has been very cordial from inception, to the extent that the manager said 'we employ their children that are school dropouts as our casual workers'. 
There have been significant positive changes in the firm in that output has increased significantly. The firm has moved from one type of vehicle to several different types. Negative changes have also occurred, such as a sales drop because of an increase in the cost of their products. A car previously sold at 2.5 million naira now sells for 6 million naira because of an increase in foreign exchange; most of the vehicle parts are imported. Foreign exchange has been made available to people that are well known or close to the corridor of power, as it is known the firms cannot function without forex, and this has been a big challenge to the firm's operation. In addition, Nigeria's currency has highly depreciated to obtain the required money to buy forex, and imported cars are cheaper than those manufactured in the firm, which is contrary to the company's vision and mission. To clear the imported goods and transport them from the port to a warehouse is another issue that has affected the firm's operation and performance.

The problems facing the company are not because the stakeholders are incompetent, lack commitment, or have bad coordination but because of higher exchange rates, the unavailability of forex, the depreciation of Nigeria's currency, and the fact that locally made vehicles are cheaper than imported ones, which encourages low patronage. Unlike other manufacturing firms, manufacturing vehicles is capital intensive. It is impossible to obtain a loan, and if you eventually get one, the interest rate is about $30 \%$. This is very high compared to developed countries, in which the interest rate is about $0.5 \%$. Most firms that are performing well are those that have access to foreign loans to run their businesses; this has little effect on the depreciation of Nigeria's currency. Policymakers in Nigeria are a major problem for the manufacturing firms. Worldwide, only Nigeria that has multiple foreign exchange rates. For instance, there is the CBN's official exchange rate, but banks have different rates, the international rate is not the same, and the parallel market has its own rates and it's the most common among all. If entrepreneurs have Nigerian currency (naira), these multiple rates make it difficult for them to know how much they have, which results in bad decisions, faulty vision, and entrepreneurial predicaments.

It is the Nigerian policymakers that are incompetent, lack commitment, or have bad coordination due to geopolitical and socio-cultural (i.e. tribalism, religion, and corruption) influences in the system. The interconnections between the $3 \mathrm{Cs}$ of the company's stakeholders make positive impacts on the company's progress. 
Otherwise, the company would have been moribund by now, like some others. Most of the stakeholders promote the image of the company to other business associates. In the company, the 3Cs work together. The degree to which entrepreneurial activities are executed in Nigeria can only be fascinating if the external business environment is conducive.

Employees are motivated and committed when they are rewarded for their hard work and increase output productivity. However, when sales drop and there is a reduction in profits, this affects employees' commitment to the firm. 'No increment in the sales and profits, because of recession in the country'. The training and workshops held both within and outside the firm are enough for the level at which the firm is operating. The form of control mechanism is that employees in the firm have supervisors in their entire unit, and there is a quality control manager who ultimately supervises all the supervisors. The decision-making style is such that before decisions are made, all the unit heads come together to brainstorm and come up with the decision.

The sales growth of the company over a five-year period has reduced compared to what it used to be. The success of every business depends on how its product can penetrate the market. The reverse of business success is business failure, and there are key factors that creep up in entrepreneurial performance for either success or failure. In Nigeria, this company is one of the organisations that demonstrates best practice in terms of CE.

\subsubsection{Ibeto Group (Union Auto Parts Manufacturing Company)}

Ibeto Group is a specialised auto parts manufacturing firm of wide range dedicated to accessories such as batteries for cars, motorcycles, and trucks. It also manufactures other auto parts accessories, like car wheel covers, PVC fittings, blade fans, front grills, rear lights, auto lamps, and other plastic products. The company also produces brake shoe kits, brake pads and linings, clutch facings, clutch fibres, and so on. The organisation commissions integrated auto spare parts with its accessories and was the lead acid battery manufacturing plant in 1998. There has been high demand for the company's products since 1991. It has customers in African, European, and Asian countries. It is one of the most diversified, largest, and financially strong firms in Nigeria, dating back to 1976 . 
The founder of Ibeto Group (Union Auto Parts) is Mr. C. M. Ibeto, an entrepreneur with an outstanding public reputation and a patron to large, recognised associations. For instance, he served as the president of the Mine Chamber of Commerce and Industry in Anambra State from 1994 to 1998. He has over 25 years of experience in the Nigerian real sectors. His employees are highly committed to attaining set plans, objectives, and goals for the firm. The company has a competitive advantage because of its consistent corporate philosophy and culture of excellence, well-trained work force, and encouragement of employee involvement in decisionmaking and ideas. The team spirit of the work force contributes to the success of the business. It is an ideal modern manufacturing firm with highly experienced, knowledgeable, and skilled staff, which leads to unique performance.

The human resource manager (HRM) has been working with the company for 24 years and was recruited through professional merit. The company has over 240 workers and has been in operation for the past 30 years. The factory workers are usually casual workers that are trained and then retained as permanent workers. According to the HRM 'good policy' is the major factor that contributes to the company's success, i.e. staff development and training, productive and skilled personnel with experience, and consistency and sincerity in determination to achieve targets and deliver promises so that the sector can contribute to the development of society. The staff and local community have a very good relationship. For instance, the firm supplies drinkable water to the local community because there is no potable water in the area. According to this respondent, 'the relationship has been cordial since inception'.

There have been gradual changes within the organisation that came because of an inflow of cheap fake batteries that flooded the market. The effects of the change were a drop in staff strength from over 1,500 to 250 and the closure of some sections. Another problem is that the company produces its own water to use in the factory, which generates about $70 \%$ of the electricity it uses and is highly costly. The company spends millions of naira on diesel every month to power the generator. The government cannot provide infrastructure yet collects multiple taxes. The company's performance and profit have drastically reduced over the last five years. Last year the company operated at a great loss, with no sign of hope in the future. The majority of its well-trained, competent staff have been sacked because it cannot afford to pay 
salaries anymore due to circumstances beyond its control. Workers' salaries are also delayed, which has affected their commitment.

Decision-making has been affected due to the aforementioned factors, as well. Before the economic problems in the country, the control team, which constitutes part of the management, inspected the factory three times a week as a measure of control, but now this occurs only once a week. Decisions are made by meeting with all department heads, and whatever is agreed upon is final. The staff are motivated by several things, among which are an annual increase in their salaries, a listening ear from the management - which gives them a sense of belonging - and, most importantly, a health scheme for the staff and their household, as well as the provision of incentives. The staff become discouraged if their payments are not encouraging.

The management has knowledge of the benefits and importance of the $3 \mathrm{Cs}$ because they can help the firm grow and gain competitive advantages. Thus, the company's stakeholders are competent and committed to the firm, and their work and coordination is not bad. However, the cause of their problems is because the government does not support industries to grow and survive, competent staff become incompetent, and in a similar manner, committed people lose interest. When this happens, people become confused, which might affect strategy and performance. Geopolitical and socio-cultural influences (e.g. tribalism, religion, and corruption) have no impact whatsoever on the business. It was once believed that geopolitical and socio-cultural influences caused Nigerian firms' bad operation and performance.

According to him, Nigeria has about 170 million people. The Nigerian president, in his own wisdom, appointed one man, Mr. Fasola (a lawyer), to be the Minister of work, housing, and power (three portfolios), knowing well that these three are the most challenging infrastructures in Nigeria. He was convinced that he would not do well because the job is too much and not in line with his profession and many others like that. 'The percentage of the business growth is less than $0 \%$ (negative growth)'. According to him, a firm is successful when it is making profits and growing, and successful firms learn from their failure. The key factors that creep up in entrepreneurial performance and success are market surveys and producing for consumers' tastes at value for money. 


\subsection{Food and Beverages}

The next sub-section concerns food, water, and beverages, in which 10 firms are categorised (see Table 4.2) for the highest and largest representation of the 32 firms sampled in this study (3 firms each from the South and North Central regions and 4 firms from the South West).

Table 4.2 Food \& Beverages

\begin{tabular}{|c|c|c|c|c|}
\hline $\mathbf{S} / \mathbf{N}$ & Name of Company & Nature of Business & Town & Region \\
\hline 1 & Guinness Nigeria & $\begin{array}{l}\text { Beer and beverage } \\
\text { drinks }\end{array}$ & Benin & $\begin{array}{l}\text { South } \\
\text { South }\end{array}$ \\
\hline 2 & Fan Milk Plc & $\begin{array}{l}\text { Ice cream, yoghurt, } \\
\text { etc. }\end{array}$ & Benin & $\begin{array}{l}\text { South } \\
\text { South }\end{array}$ \\
\hline 3 & $\begin{array}{l}\text { Notre Dame Industrial Company } \\
\text { Limited }\end{array}$ & $\begin{array}{l}\text { Bottled, table, and } \\
\text { sachet water }\end{array}$ & Benin & $\begin{array}{l}\text { South } \\
\text { South }\end{array}$ \\
\hline 4 & Vicky Table Water & Table water & Ibadan & $\begin{array}{l}\text { South } \\
\text { West }\end{array}$ \\
\hline 5 & International Breweries Plc & $\begin{array}{l}\text { Beer and beverage } \\
\text { drinks }\end{array}$ & Ilesa & $\begin{array}{l}\text { South } \\
\text { West }\end{array}$ \\
\hline 6 & $\begin{array}{l}\text { Nigerian Bottling Company } \\
\text { Limited }\end{array}$ & $\begin{array}{l}\text { Non-alcoholic } \\
\text { beverages }\end{array}$ & Asejire & $\begin{array}{l}\text { South } \\
\text { West }\end{array}$ \\
\hline 7 & Grand Cereals and Oil Mills & $\begin{array}{l}\text { Vegetable oil and } \\
\text { cereals }\end{array}$ & Jos & $\begin{array}{l}\text { North } \\
\text { Central }\end{array}$ \\
\hline 8 & NASCO Group of Company & $\begin{array}{l}\text { Biscuits and } \\
\text { confections }\end{array}$ & Jos & $\begin{array}{l}\text { North } \\
\text { Central }\end{array}$ \\
\hline 9 & Dangote Flour Mill & Flour & Ilorin & $\begin{array}{l}\text { North } \\
\text { Central }\end{array}$ \\
\hline 10 & Multi Bond Venture & $\begin{array}{l}\text { Bottled water and } \\
\text { beverages }\end{array}$ & Awe & $\begin{array}{l}\text { South } \\
\text { West }\end{array}$ \\
\hline 7 & Grand Cereals and Oil Mills & $\begin{array}{l}\text { Vegetable oil and } \\
\text { cereals }\end{array}$ & Jos & $\begin{array}{l}\text { North } \\
\text { Central }\end{array}$ \\
\hline 8 & NASCO Group of Firms & $\begin{array}{l}\text { Biscuits and } \\
\text { confectionaries }\end{array}$ & Jos & $\begin{array}{l}\text { North } \\
\text { Central }\end{array}$ \\
\hline 9 & Dangote Flour Mills & Flour & Ilorin & $\begin{array}{l}\text { North } \\
\text { Central }\end{array}$ \\
\hline
\end{tabular}




\begin{tabular}{|l|l|l|l|l|}
\hline 10 & Multi Bond Venture & $\begin{array}{l}\text { Bottled water and } \\
\text { beverages }\end{array}$ & Awe & $\begin{array}{l}\text { South } \\
\text { West }\end{array}$ \\
\hline
\end{tabular}

\subsubsection{Guinness Nigeria Plc}

Guinness Nigeria Plc is a subsidiary of Diageo Plc from the UK and was incorporated in 1962. It built breweries in Lagos and Benin City in 1974 and in Ogba in 1982. Nigeria is the only sector that has the potential to produce 15-mhl beers and does Total Beverage Alcohol (TBA). It is a fast-growing market with challenges. This Nigerian brewery was the first to operate outside the UK and Ireland, and it manufactures alcoholic drinks such as Harp Larger Beer, Guinness Extra Smooth, Foreign Extra Stout, Dubic Extra Lager, Orijin, and Satzenbrau. It also produces non-alcoholic chilled drinks as meal i.e. Malta Guinness and Malta Guinness Low Sugar. Guinness Nigeria Plc is the third largest market of Guinness products in the world. Nigeria produces 4.5 to 4.8 million hectolitres of different Guinness brands yearly for both export and local markets. The company has about 300 employees, including the casual workers.

The company's strategy is that it invests a lot in staff training and development, consistently improves its business operations, and makes use of the latest technology in a cost-efficient manner. These investments have contributed to its growth production and sales volume. Engineering technicians maintain the company's machines and equipment by cleaning them and are also responsible for their operation. This results in reliable quality demand, reducing the cost of operations and the equipment required to increase volume. The engineering technicians report to the production services engineer. Staff can contribute to all improvement initiatives or can give new ideas in their department for their personal training and development. The company goals are that there should be continuous improvement in customer satisfaction, employee skills, and overall brewery plant performance.

The interview was conducted with the manager of the company in an operation department. He worked in a different place before joining the Nigerian brewery, which is far better than his previous employer in all aspects. The business is more difficult and complex due to the existence of many competitors and the high cost of production. There have been many negative changes in the organisation due to a drastic drop in sales for economic reasons, which has led to a reduction in the 
firm's net profit. Many private, public, and foreign firms in Nigeria find it difficult to pay workers' salaries due to massive Nigerian currency devaluation, inflation, and recession. In most states, workers are owed six to eight months of salaries arrears. If the firm's stakeholders were not competent, committed to the company's cause, with good strategic coordination and control, the company might have been off the market by now. The new idea of the Orijin drink was from the employees and started marketing in 2013. Additionally, non-alcoholic drinks like Malta Guinness were launched in 1990 for those that do not drink alcohol for religious or personal reasons, and Malta Guinness Low Sugar was produced for people that do not consume sugar for medical (or other) reasons. These contributions of stakeholders led to the expansion of the company's products, since it encourages new ideas and suggestions and strategic decisions are usually approved by the board of directors before implementation.

According to the respondent, interconnections between stakeholders' $3 \mathrm{Cs}$ are important to the success of the strategic formulation and implementation of the organisation. Geopolitical and socio-cultural influences (i.e. tribalism, religion, and corruption) are constraints on the national economy and business growth, so this should not be encouraged, he said. The firms that demonstrate the best strategic practices in terms of CE in Nigeria are Nigerian Breweries, MTN, and Globacom.

\subsubsection{Fan Milk Plc}

This company is in Benin, Edo State, Nigeria, and is engaged in the manufacturing and distribution of dairy products, milk, and yoghurt. The company's mission is to strive towards world-class standards and to be the best manufacturer and marketer of healthy and safe dairy food products at an affordable price for its customers. It has about 150 employees and was established about 15 years ago. One of the most senior managers in Fan Milk Plc is a university graduate who got his job through a recruiting firm and had never worked elsewhere before. The management staff are also recruited through the same recruiting firm. Only the factory workers are recruited on a daily basis when they come to the gate of the factory, and they are paid daily.

The management monitors employee performance, and decision-making is centralised. The employees are motivated through regularity in salary payments and are also paid overtime. The staff undergo different training and workshops, and their 
training and experience is sufficient enough to provide the required services for the firm. Some of the raw materials are imported from Denmark, while about $65 \%$ are local input materials. There has been a significant negative change in this firm over the last five years that occurred suddenly because of the present economic recession and unpredictable financial market. This had effects on its risk management and financial statements and caused underperformance. Additionally, sales reduce daily, and profits diminish every year. The company’s profit after taxes in 2010 was $\$ 514$, $834,000.00$, equivalent to $\$ 2,626,704.00$, and in 2013 , the profit after taxes was $\$ 173,921,000.00$, equivalent to $\$ 887,352.04$ (Company Annual Report and Accounts, 2014).

The $3 \mathrm{Cs}$ in this firm are the backbone of its enterprise development because they will improve the entrepreneurial performance, according to the respondent. However, most, if not all, Nigerian workers are uncommitted to their organisation or work because they are frustrated with no hope due to the hardships they are facing. For example, the minimum wage is $\$ 47.36$, and a bag of rice is about $\$ 52.63$ as of the time of data collection, and the workers still need to pay their children's school fees, house rent, transport, and many other things. Yet, employers do not want their workers to steal or receive bribes. Again, because of high rate of unemployment in Nigeria, majority of the employees were family and friends without considering their commitment or competence. All these factors have negative effects on entrepreneurial performance, but this is common in public organisations. Although this is not applicable to the management staff of Fan Milk, the casual workers are not exonerated from the above example.

The staff at Fan Milk staff put in quite a lot of effort into their work to improve the business performance. However, such effort were not rewarded as anticipated due to negative and challenging external environment. The message from this firm was that business failure is not the reverse of success - and Nigerian Breweries is a success story as far as Corporate Entrepreneurship is concerned.

\subsubsection{Notre Dame Industrial Company Limited}

This company manufactures and distributes bottled, table, and sachet water. The production manager at this firm is Kelly Fine, a university graduate, who has been at the company for four years. The company has been in existence for 15 years and has about 70 employees. There have been large negative changes over the last three years 
which happened suddenly because of the recent economic recession. 'The sales dropped drastically, customers complained that they don't have money as before, and things are too expensive'.

There is an inverse relationship between the price of raw materials and the quantity demanded. The staff are monitored and supervised through unannounced visitation by the management to the working place, and decisions are made centrally. The aspects that motivate the staff are the frequency and regularity of their salary payments and payments of their overtime allowances. If their salaries were paid but not their overtime, they would not be happy. It is commonly held that employee experience and training are not enough for better performance without commitment. An area in which the firm needs to improve is that there is the need for more competent, committed hands and more expansion of the company.

Moreover, according to the respondent, interconnections between stakeholders' 3Cs attributes are the major principles for the firm's sustainability. They are strongly related in the sense that anybody with these concepts will have the spirit of being self-employed with new ideas. Geopolitical and socio-cultural influences (i.e. tribalism, religion, and corruption) do not exist in this business because success is its priority and concern. Geopolitical and socio-cultural influences are commonly experienced in public and government organisations in terms of inequalities on employment, promotions, and awards or inflated contracts, leading to impediments in entrepreneurial growth due to lack of public accountability and Nigeria's economic recession. Success in a business sense is the ability to meet people's desires or needs. Business failure is not the reverse of business success. The key factors that creep up in performance or success are the motivation received and the access to funds for the business.

\subsubsection{Vicky Table Water}

This company produces both pure and bottled water. It has about 30 workers and has been in operation in the last 5 years. Sakariyahu Serimot Oyindamola works for Vicky Table Water as a company accountant; she has secondary school certificates. The company has been facing terrible challenges due to the economic recession. There is no money in the country, so people are suffering, salaries are not paid, and the customers do not buy water to drink as they did before and seek other means. Another problem is that the cost of production is very high due to inflation, which 
also affects the company's sales. The company owner makes all the major decisions, but staff can influence his decision in some cases. Prompt payment of salaries and incentives are what motivate the staff.

Interconnections between stakeholders' 3Cs are attributes for the growth and development of any business. This company has the problem of an epileptic power supply, and this is causing a low rate of productivity and negatively affecting its performance. Geopolitical and socio-cultural influences (i.e. tribalism, religion, and corruption) do not affect the business because the company does not discriminate in any form. Generally, though, the workers are depressed. The high rate of unemployment makes them feel hopeless, and, thus, they have low esteem, which the government is not doing anything about.

\subsubsection{International Breweries Plc}

International Breweries Plc produces Castle Lager, Castle Milk Stout, Trophy Lager, Trophy Black, Grand Malt, Voltic Water, Redd Hero, and Beta Malt drinks. The company was founded by Dr Lawrence Omole in 1971 and started production in 1978 with an installation capacity of 200,000 hectolitres. In 1982, the capacity increased to 500,000 hectolitres due to a demand increase for the products. In 2016, the company had 529 staff and 556 in 2017 . The headquarters and production facility address is Omi-Asoro, Ilesha, Osun State, and the other branches are in Ilorin, Lagos, and Ibadan. This makes the re-distribution of the products to other parts of Nigeria easier.

It became a public liability company, listed on the Nigeria Stock Exchange, in 1994. Brauhaase International Management (GMBH) provides technical services as agreed by them, and SABMiller from BGI Castel has been in charge of the operational management control since 2012. Meanwhile, International Breweries Plc is a subsidiary of the Warsteniner Group of Germany, which owns a share of $72.03 \%$. In 2008, the company formulated and implemented a successful turnaround strategy by generating money from Nigeria's capital market and selling shares to 1.6 million people at 87 kobo per share. The money generated was reinvested into the newer brands and organisation. In 2008, the major shareholders sold their majority shares to Castel Group. In 2012, Castel Group formed a strategic alliance with SABMiller Plc in which ABInbev was the new owner. These large investments resulted in the significant transformation of the organisation, improved its 
performance and growth, and raised profitability. An interview was conducted with the company's human resource manager, who has been working with the company for the past nine years. The company is a large-scale business with over 200 employees. It employs many people from the local community, which serves as social corporate responsibility and gives the firm a good relationship with the community.

There has been a progressive change in this company over the years based on a strategic plan. For example, 'foreigners were invited to invest in the business which brought dollars and pound sterling into the business, make them have strong financial base. IT control systems, standard operating procedures, performance management systems, leader standard work', and so on are used to monitor the activities of workers. The business relies on stakeholders' 3Cs to survive and prosper because it believes that these have been working for their survival. There are no geopolitical effects on the business, but there are socio-cultural influences (i.e. religion and corruption) on the business to a great extent, especially regarding religious dynamics on alcohol consumption. Sales have also dropped as compared to previous years as a result of inflation, not paying workers' salaries, and making people see drinking as a luxury. Over the last five years, the performance and productivity of the company has improved greatly, but it still needs to do more concerning innovation so as to improve the output of its workers.

\subsubsection{Nigerian Bottling Company Limited}

This company produces, sells, and distributes non-alcoholic beverages - including the trademark brands of Coca-Cola, Zero Coca-Cola, Diet Coca-Cola and local brands such as Five Alive, Eva, Schweppes, and Limca - to customers that are registered with it and is one of the largest industries in Nigeria. Moreover, its corporate social responsibility is one of the best. The company's priority is to produce the best quality products and to produce more new, varied products for Nigerian consumers. The company is performing well because of its contribution to the quality of life of the community. It also pays attention to what is necessary for both the business and its customers.

It has headquarters in Switzerland and a premium listing in cities like New York, London, and Athens' stock exchanges. In Nigeria, the company is located in Asejire, Oyo State, and was founded 1951. 
One of the company's HR coordinators in the human resources department was interviewed and has been working for the company for the past 22 years; he was employed on a professional merit basis. This is not the first place he has worked. Of all the places that he has worked, he has always been managing the human aspects and operations. The company has over 200 employees. This is a global firm that needs no introduction but is very conscious of its operating environment in terms of pollution control and giving back to the society, i.e. corporate social responsibility (CSR). Its relationship with the local communities is cordial. The application of all local, national, and international laws in its operations and execution of CSR is in alignment with the host communities.

There have been changes in the firm over the last five years that are progressive in nature. The information is available at the click of a mouse, and its operations are transparency. Internal control champions check on the staff and production process quarterly to monitor people's work, and decisions are made centrally in the firm. The main causes of staff motivation and commitment in this organisation are its welfare programmes and competitive salary, while the main cause of staff not being motivated or committed is that they are neglected during times of personal challenge. The training and experience that the employees have are enough for them.

Stakeholders' 3Cs and foreign connections contribute to the firm's success and good returns on investments through competitive performance. Without international influence, the $3 \mathrm{Cs}$ might be enough in Nigeria due to the turbulent external environment. There are no impacts of geopolitical and socio-cultural issues on this business because the operations are based on acceptable international practices and policies, but there are socio-cultural impacts on it to a great extent, especially on health grounds that the drinks have too much sugar. Business success is the attainment of visions and goals. Business failure is not the reverse of business success. The key factors that creep up in the company's performance concern sticking to its vision. There are organisations that demonstrate best practice in terms of CE in Nigeria in manufacturing and food and beverages.

\subsubsection{Grand Cereals and Oil Mills}

Grand Cereals Limited (GCL) produces and markets a variety of food for human and animal consumption. The company uses local raw materials to manufacture its 
products, with leading brands such as vegetables, cereals, oils, and many others. The company was incorporated in 1983 with the aim of manufacturing baking flour from imported wheat as the raw material. It had to change its operation strategy and production objective when the Nigerian government placed a ban on the importation of its major raw material (wheat), though. For instance, UACN Plc became the major shareholder of GCL in 1997, and this is added to the subsidiary of UACN Plc.

The firm is steadfastly engaged in the benefit and improvement of agricultural-based industrial activities. GCL's three product units are: (i) Oil millthis is used to process soya beans, cotton seeds, groundnuts, and palm kernels into high quality cakes, soap stock, deodorized groundnut oil, cotton seed oil, soya oil, and lecithin. The firm can also process pelletised poultry feed and fish, cow, and pig feed, if requested. (ii) Cereal mill - this can process grits and maize into flour; Offa is a by-product and cleans sorghum to be used for industrial purposes. (iii) Animal feed plant - this is capable of processing waste products, i.e. oil mill produces waste (cakes) and cereal mill produce waste (bran), at about 140 tonnes per day. An ultramodern feed plant was created in 2004 to increase the company's feed production capacity to 400 tonnes per day. Its strategic silos have a storage capacity of about 16,000 tones. According to the respondent, the company has the following as its strategy:

1. Core Effectiveness: to be more focused on internal efficiency so as to add value to the customers and company through competence in terms of customer service, operations, marketing efforts, information gathering, and operations.

2. Manufacture of New Products: to develop new products by continuous innovation and to produce new brands that will meet the stakeholders' need for affordable nutritional best products.

3. Working Environment: to make the working environment conducive for the stakeholders, i.e. to respect employees' opinions, openness, and trust and give visionary leadership to individuals who have a view of the company's vision and mission.

4. Distribution and Marketing of Products: to make the product distribution and marketing more effective and efficient by improving the products' penetration, market share, and visibility. 
5. Bad Policy: it is company policy that anything sold in good condition cannot be returned, unless the bad quality or damage is traceable to the company's negligence.

To reduce the rate of damaged products and the bad distribution of such products, the following measures have been put in place:

- Staff are well-trained to do the right thing at all times.

- Raw materials and product packaging must be done in accordance to the international standard.

- Stored goods must be certified and properly placed as prescribed.

- The vehicles that load the products must be road-worthy, i.e. in good condition, and have the correct capacity and meet the GCL standard procedure to carry the products so as not to damage them in transit.

The logistics representative must sign delivery invoices and notes so that the transporter is responsible for any damage that occurs during transit. At the customer depot and MDS outlets, the policy is that any damaged or bad product should not be accepted and should be sent back through the same transporter immediately. Otherwise, it will become the customers' liability if such a damaged product was not rejected and sent back. Only complaints that are due to the negligence of the manufacturer are treated.

The welfare, health, safety, and encouraging working environment of its stakeholders are some of GCL's top priorities. Likewise, the company provides and maintain a healthy, safe atmosphere and minimises hazards/injuries in the working environment for all the staff. To successfully implement this policy, GCL always complies with legislations and works with health and safety consciousness at all levels. This responsibility is vested on the management, which are accountable. Staff are involved and contribute to the safe working environment, so all employees are trained on the potential health and safety and encouraged to be concerned about their health, safety, and so on.

The interview was conducted with Danladi Suleiman, the factory supervisor in the production unit. He has a secondary school certificate and has been working with the company for 10 years. According to him, GCL is a medium-scale business organisation with between 51 to 200 employees. The company has been in existence 
for almost 35 years. The first 29 years of the firm's operation really improved the standard of living of the people in the surrounding environment, unlike in the last five years until present, in which things have not been the same. When asked for the reason, he said inflation due to inconsistent government policy. For instance, the cost of production has increased by $300 \%$, and in the same manner, the cost of living has increased while workers' salaries have not. Even states owed 6 to 9 months of salary arrears, so customers have no money to buy food, pay rent, or pay children's school fees. Sales have drastically reduced, and with no profit, most of the permanent staff are now casual workers. Most manufacturing firms have closed down because they were operating at a loss and could no longer afford to pay salaries, not because their employees were not competent, committed, or had bad coordination or strategy. This was simply because of inflation and the cost of production in Nigeria.

Interconnections between stakeholders' 3 Cs have really helped the company in terms of production and growth, but inflation and the cost of production make the $3 \mathrm{Cs}$ ineffective. Some years back, one of the company's major imported raw materials used in production was banned by the government. It cannot be produced in Nigeria, but no alternative arrangement was made by the government. The means of passing information is through a centralised method. Staff compensation and regular salary payments motivate workers. Work supervision is constantly done in the firm.

The company does not allow geopolitical or socio-cultural influences (i.e. tribalism, religion, and corruption) in its daily activities. In his opinion, the respondent said that geopolitical and socio-cultural influences have affected Nigerian policymakers' performance. For instance, he asked, 'How can you ban raw materials we use in our production without consultation and not available anywhere in Nigeria?' Again, employing their relative or someone of the same religion into a sensitive position in which they do nothing about. Over the last five years, the performance and productivity of the company has not improved due to inflation, cost operations, and inconsistent policies.

\subsubsection{NASCO Group of Firms}

The NASCO Group of Firms' strategy for success is a strong financial base because of the company's diversification of revenue across businesses/products of different groups and geographical areas. The business strategies add value to both the 
customers and organisation. The cost leadership is attained due to the efficiency of the company's procurement and operations. Economies of scale, innovations, geographical reach, and advanced research and development make it possible for the company to transfer reasonable cost savings to its customers. Therefore, it produces high quality products with an affordable price to the customers. The future strategy is that the company will continue to: increase its manufacturing capacity, commit to international best practice, strengthen its market presence, deliver consistent growth and sustainable profitability, improve employees' international exposure and skill base, and invest in research and technology.

The respondent is one of the marketing managers and has been working as a marketer for six years now. His recruitment was based on professional merit. The company produces biscuits and confections. NASCO has over 200 workers. There have been positive changes in this company that happened suddenly because large number of customers patronise its goods. The company is effective and efficient because its products sell quickly. Experts in the field are usually invited for proper supervision. Information is passed through a centralised method; the top management make strategic decisions concerning acquisitions, capital investments, and whether to shut down or expand operations. The main causes of staff motivation and commitment in the organisation are that they are receiving good salaries and bonuses. The main cause of staff being not motivated or committed is a poor salary scheme due to recession and inflation in the town. No matter how big of salary they receive, it is never enough, which affects everybody.

Without a doubt, interconnections between stakeholders' 3Cs contribute to the firm's performance when aiming to achieve its business vision and mission. A challenge the firm experiences is the non-availability of foreign exchange to import the raw materials needed, and this is a concern as it can bring about stoutness in performance. The company is free from geopolitical and socio-cultural influences (i.e. tribalism, religion, and corruption). The firm audits its account every three months to guard against any form of corruption or envisaged fraud. There are no strong effects of tribalism, religion, or corruption in the company. The company's performance has improved immensely. Success from a business sense is defined by the achievement of action within a specified period of time or within specified parameters. 


\subsubsection{Dangote Flour Mills}

The company produces and markets branded flour, which is comprised of bread, semolina, confections, and wheat offal (bran). The company imports most of its raw material (hard red wine Wheat) from America to Kano and Ilorin. It was a subsidiary of its group parent company, Dangote Industries Limited (DIL), which started its operation in 1999 and is one of the most successful conglomerates. As a strategic decision, DIL incorporated Dangote Flour Mills in 2006 so as to unbundle its various operations. During the organisational restructuring, all the assets and liabilities belonging to the flour division of DIL were transferred to Dangote Flour Mills. At the start of the business, the installed capacity was 500 MT per day. An additional three flour mills were established in Ilorin, Calabar, Kano in the years 2005, 2001, and 2000, respectively, with an installation capacity of 500 MT per day. Therefore, the total installed capacity is about 5000 MT per day. Dangote Flour Mill's subsidiaries are Dangote Pasta Limited, Dangote Noodles Limited, and Dangote Agro Sacks Limited.

The company's environmental administrator is in the administration department; he is a university graduate who has been working for the past five years. He started as a casual employee and was later promoted to the permanent staff. Dangote Flour Mill has over 200 staff and many casual workers. Over the last five years, there have been significant changes in the company. It has three branches; the Tiger branch is operating at loss, and the Kashra branch has closed down completely. The other branches are functioning well and supplying the customers.

Daily supervision of the workers' activities is done through departmental supervisors, who in turn report to their unit heads. The management's decisionmaking process is in a centralised form. Staff members are motivated through the payment of leave bonuses and extension hour bonuses, salary increments, and training outside and within for management and mostly technical staff. If the staff were not motivated, production would be affected, and the company could become run down. Staff members need to be introduced to contemporary techniques through training so that the company can remain at the top. Additionally, the firm needs improvement in all areas and departments, especially in handling of the machines.

The company is aware of the importance of the interconnections between stakeholders' 3 Cs to the success of the firm, which is why experts are brought from outside to train the workers and groom the casual workers to be more competent 
since they already have experience from being casual workers. It is important to note that geopolitical and socio-cultural influences have negative impacts on the business, especially tribal and religious wars, which can shut down the factory for weeks. This has affected the company's operation and performance (and resulted in the loss of life and property). Many of the factories in the North are paralysed due to continuous terrorist activities. In the last five years in this organisation, the sales growth has been significant, assets have increased, the number of staff has increased, and there has been a little increase in the net profit.

\subsubsection{Multi Bond Venture, Awe, Oyo}

This company manufactures bottled water and beverages and has over 60 employees. It has been in existence for about 15 years. The cordiality of the company with its local communities is good in terms of corporate social responsibility. There has been a significant negative change in the company over the last five years. The generator is run constantly, and fuel has tripled in price. This change has influenced the daily work through a decrease in the number of shifts from four to two. The experience and training of employees is not enough for the production capacity of a firm. Therefore, employees should be subjected to various types of training in order for them to improve and, in turn, improve the firm's output. In the organisation, control mechanisms for the daily work are achieved through report submissions. The decision-making process of this organisation is in a centralised form. What causes the staff to be motivated and committed is job security and the constant payment of their monthly salaries. Staff are not motivated when there is no salary or no increase in salary.

Stakeholders' 3Cs are key aspects needed for an organisation to grow effectively. If these three components are not involved, the work may not be completed to the expectations. The effects of geopolitical and socio-cultural influences are not applicable in this organisation. However, due to the high rate of corruption and poverty in the country, the growth and development of industries are multifaceted. For the last five-year period, the organisation's performance and net profit have reduced drastically. The company's production manager started working with the company less than two years ago. He was recruited through a daily advertisement. This is not his first appointment. The only differences between his 
former and current employers are ethnic differences and proximity to his family members.

\subsection{The Plastic and Nylon Industries}

In this category, seven manufacturing firms were captured (see Table 4.3) in this sector, fairly distributed across the geopolitical zones - three from the South West, two from the South East, and one each from the South and North Central regions.

Table 4.3 The Plastic and Nylon Industries

\begin{tabular}{|l|l|l|l|l|}
\hline S/N & Name of Company & $\begin{array}{l}\text { Nature } \\
\text { Business }\end{array}$ & Town & Region \\
\hline 1. & Louis Carter Industries Limited & $\begin{array}{l}\text { Industrial plastic } \\
\text { wares }\end{array}$ & Nnewi & $\begin{array}{l}\text { South } \\
\text { East }\end{array}$ \\
\hline 2 & Sunny Tex Poly Industries & Polythene nylon & Onitsha & $\begin{array}{l}\text { South } \\
\text { East }\end{array}$ \\
\hline 3 & I.C. MASCOT Nigeria Limited & Plastic & $\begin{array}{l}\text { Benin } \\
\text { City }\end{array}$ & South \\
\hline 4 & $\begin{array}{l}\text { Altak Industries Limited } \\
\text { and wares }\end{array}$ & Plastic goods & Ibadan & $\begin{array}{l}\text { South } \\
\text { West }\end{array}$ \\
\hline 5 & Tee Key Venture & Sango & $\begin{array}{l}\text { South } \\
\text { Otta }\end{array}$ & West \\
\hline 6 & $\begin{array}{l}\text { Crown Park, polythene, and Plastic } \\
\text { bottle }\end{array}$ & Plastic bottles & Lagos & $\begin{array}{l}\text { South } \\
\text { West }\end{array}$ \\
\hline 7 & Citico Plastic Industrial Limited & Plastic & Ilorin & $\begin{array}{l}\text { North } \\
\text { Central }\end{array}$ \\
\hline
\end{tabular}

\subsubsection{Louis Carter Industries Limited}

Louis Carter Industries Limited is located at 9 Emma Okafor Street, Akaboukwu, Uruagu, Nnewi, Anambra State, Nigeria. It is a successful manufacturer of local and exported domestic and industrial plastic wares like shopping bags and ladies' hair attachments, as well as battery castings. The company is a large-scale business enterprise with 150 employees and has been in existence for over 15 years. It has been performing social corporate responsibility in the area of water supply, which 
has influenced its good relationship with the local communities. The relationship is still working today.

Festus Chukwumalu is the production manager; he has university degrees and has been working for the company for the past 14 years. He obtained the job through a friend. This is not his first appointment. The differences between his first and present appointments are that there is better exposure, higher pay, and less stringent working conditions. There have been significant, gradual negative changes in the company because of the economic issues the country is facing. These negative changes include a reduction in production units from 6 units to 2 units, a reduction in the number of staff from about 350 workers to about 50 workers, and a reduction in daily activities, mainly due to inadequate funding. In the company, daily activities are always supervised with regular, thorough monitoring. The decision-making of the company is in a centralised form. The staff are motivated through a good relationship with the management, regular salary payments, and immediate payments for extra time worked. The staff are not motivated in the areas of promptness in salary payments and non-increments of staff salaries.

The employees' experience and training are enough for the capacity of the firm. Good government policies that favour industries and financial assistance to resuscitate the closed-down department are needed. 'Staff are not committed anymore due to lack of job security. How can one be committed to the organisation or work when workers are retrenched every day, company is collapsing, salaries are not regular and loss of hope?' People are working harder than ever before because they want progress for the company in order to retain their jobs, considering the high rate of unemployment in Nigeria. Most competent staff have been made redundant, and there is no more training due to a lack of resources and logistics. The company still needs to work on the mindset of the workers to ensure continual commitment. The problem with the company is not within the organisation but is external, so it has nothing to do with the stakeholders. The $3 \mathrm{Cs}$ concepts can be associated with entrepreneurial growth, but external factors like bad government policies, which result in a lack of funds and recession, are major factors that are associated with entrepreneurial underperformance, of which the firm is victim to.

There is no way that geopolitical and socio-cultural dynamics have a negative effect on stakeholders' 3Cs in this firm, but in government settings, this happens all the time, especially in recruitment. For instance, when people challenged President 
Buhari because his cabinet was not performing, he publicly responded that he employed those he trusted and had known for a long time. These should not be the criteria; the 3Cs should be the yardstick for employment. Although this has no direct link with this firm, it indirectly makes the 3 Cs not work well in any firm. The sales growth of the company over the last five-year period has been reduced compared to what it used to be. Success in every business depends on growth, staff strength, and regular increments in staff remuneration. Staff training is one of the factors that creep up in entrepreneurial performance (success). Business failure is the reverse of its success. One of the organisations that demonstrate best practice in terms of $\mathrm{CE}$ in Nigeria is the Chikason Group of Firms, a production and manufacturing company located in the South East region of Nigeria.

\subsubsection{Sunny Tex Poly Industries}

The chief executive officer (CEO) is a university graduate who worked for a polythene nylon factory in the North before he started his own industry (i.e. Sunny Tex Poly Industries). He started this business because his former employer could no longer afford to pay salaries, and with no jobs elsewhere, things were very bad. 'It is not easy to be an entrepreneur in Nigeria, everything is tough', he said. He had no access to financing from banks, but he borrowed money from friends and relatives and bought some raw materials on credit. He made some monthly contributions to start his new business out of frustration and determination. The factory has 20 workers. There have been significant changes since he started this factory, although it has been gradually progressing. He is now considering employing about nine more factory workers because the work is too much for the staff.

The CEO makes the final decisions after listening to contributions from the staff. Likewise, he monitors the activities of the factory through frequent checking and overall checking of the finished products, although employees can use their initiative if there is need. The staff are motivated when they receive their salaries on time, and they are paid bonuses on weekends. Staff training is not enough for any organisation to progress; they must be willing to put more effort and determination into achieving the goals and targets set by the firm. The company still needs money to buy a blowing machine so as to improve its performance and growth. The stakeholders' $3 \mathrm{Cs}$ are enough for the organisation to progress. This concept is related to the entrepreneurial performance of the organisation because it will make the 
organisation grow. Geopolitical and socio-cultural influences (i.e. tribalism, religion, and corruption) are not applicable in the company, but tribal wars (IPOD) and Fulani herdsmen killings have adverse effects on manufacturing firms and their operations and performances.

The CEO defined success as the more fixed assets, the more the quality of staff; the more production, the more market and profit. The key factors that creep up in entrepreneurial performance (success) are the organisation's total dedication, commitment, and capability. The reverse of any successful business is its failure. Chidibest Auxido Investment is the best CE in Nigeria.

\subsubsection{IC MASCOT Nigeria Limited, Benin City}

The company manufactures plastic and has about 130 workers; it was established about 15 years ago. There has been a great negative change in the company over the last five years, which happened suddenly due to the present economic recession. It affected the firm so much that there has been a reduction in daily profit. There is serious supervision of every unit by the company's management. The decisionmaking is centralised. Prompt payment of their salaries is what motivates the staff, and if the salaries are not paid when due, this could cause a lot of problems in terms of performance.

Susan is a manager in I.C. MASCOT Nigeria Limited, Benin City; she is a university graduate and has been working for the company for the past 10 years. She obtained her job through an advertisement placement. This company is her second employer. She changed her job because of family relocation, not because the present job is better than the former one. She does not see any interconnections between stakeholders' 3Cs. According to her, everybody knows each other's capacity, so the competent staff will supervise, monitor, and guide the less competent ones. Naturally, everybody is committed and hardworking because nobody is ready to lose their job since there are no jobs elsewhere. Geopolitical and socio-cultural influences (i.e. tribalism, religion, and corruption) affect every sector in Nigeria. For example, Nigeria is in recession due to the corruption of the people in positions of authority, the rate of unemployment is very high, and the few that have jobs cannot even survive on their salaries. As a result of this, the majority of firms have closed down completely. 
Success is the ability to train people on how to develop a business idea and, in the long run, to turn it into a business opportunity. The respondent does not agree that business failure is the reverse of business success because something that fails today can rise up tomorrow.

\subsubsection{Altak Industries Limited}

Altak Industries Limited manufactures plastic goods and wares and markets them locally as well as exports them. This firm was established in 1990 and is located in KM 8, Old Lagos Road, New Garage, Challenge, Ibadan, Oyo State. The company was the first to produce a plastic chair called 'Monobloc' in 1991, introduced the 'Tossa' chair, and also produced the first plastic table in Nigeria in 1993. The factory produces over 50 different furniture types, such as loungers, tables, chairs, stools, school furniture, and so on. It's commitment to innovation and the use of new technology makes it the market leader. It is unique in the field of plastic manufacturing, making its products difficult for other competitors to imitate, which is the secret of its success.

Art manufacturing machines are used to produce plastic furniture, and the company's highest quality machines and injection moulds are imported from Europe and Taiwan. Altak works together with mould suppliers from Europe in the design and implementation of the plastic furniture. This, coupled with experience and commitment since 1991, has led to the company maximising its production and manufacturing capabilities. The company's major customers are state governments like Ondo, Adamawa Ogun, and Lagos in the sale of plastic school furniture, and firms like Nigerian Breweries, MTN, Seven Up Plc, and Nigeria Bottling Company Plc use these plastic chairs as souvenirs for their customers. Quality, innovative, and unique visions are the focus and priority. The mission is to create and design innovative solutions to add value to the stakeholders, with a commitment to quality.

Abiola Mary has been the site supervisor for the past five years. Her employment was based on merit. The company has about 50 workers. According to her, there have been significant changes over the last three years. 'There are complaints about the current Nigeria economic recession and this has caused the reduction in demand for the products, reduction in profit, and cost of production is very high', she said. Supervision is performed throughout the firm constantly, and the staff are motivated by the prompt payment of their salaries. 
The stakeholders' 3Cs make a positive impact on the company's progress. Most of them promote the image of the company to other business associates. In the company, the 3Cs work together. There are no geopolitical or socio-cultural effects on the business - they all believe that they are one Nigeria - but the negative impacts of geopolitical and socio-cultural influences (i.e. tribalism, religion, and corruption) on the business are large. An example of this is 'the government rationing dollars to sectors where their directors or their relative are close to the corridors of power and other sectors could not get dollars to import their raw materials for their production'. The company's sales over a three-year period have reduced compared to what they used to be. The success of any business is the ability to continue for a long period of time and be able to make normal profits. Business failure is not the opposite of business success. Additionally, there are key factors that creep up in entrepreneurial performance for either success or failure.

\subsubsection{Tee Key Venture}

Tee Key Venture is a company that has been manufacturing polythene for the past 5 years and has about 19 workers, including casual workers. Olayiwola Olatunde is the director of the company. The director makes all the decisions, formulates the strategy, and implements it with the staff. Everybody adheres strictly to their time schedule so that they can make time for other personal things. What causes staff not to be motivated or committed is working overtime without pay. Employee experience, training, and commitment increase the production capacity of firms. Tee Key Venture staff members are exposed to training, and this, coupled with their experience on the job, has increased performance and productivity, though not up to expectation due to lack of funds and inability to access funds to buy machinery and required materials, since things are costly.

Interconnections between stakeholders' 3Cs are significant to effective business operation and success. However, in this firm, it is important that competent and committed workers are able to use the machines in different capacities so as to produce different outputs. Therefore, the use of the machines depends on the operators' skills and knowledge acquired on the job rather than through academic certification. Most of the jobs here are automated.

Geopolitical and socio-cultural factors (i.e. tribalism, religion, and corruption) do not have any negative influence within this organisation. However, 
banks are not ready to assist or loan to entrepreneurships that are small scaled in capacity because they may not have commensurable collateral and the cost of transaction is on the higher side. This has been the major obstacle to the growth of Tee Key Venture, and electricity is a challenge, too. The obstacle does not occur because the stakeholders are not competent or committed; it is purely on financial problems and a poor electricity supply. In the last three years, the company's performance and production within its capacity has improved in terms of sales growth, return on sales, return on assets, and operating profits. When any business fails, that is the reverse of its success. Factors that hinder the success of any entrepreneurial firm are electricity failure and economic instability. Organisations that best practice CE in Nigeria are nylon and plastic Producers.

\subsubsection{Crown Park, Polythene, and Plastic Bottles}

Crown Park is a relatively large-scale business with over 100 workers. It started operation about 18 years ago, manufacturing plastic bottles. Raji Adeoba has been the general manager of the company for the past 14 years. In the last five years, there have been significant negative changes in the company due to the country's bad economic situation that industries and individuals are experiencing. The board of directors makes the firm's major strategic decisions, such as market decisions, the expansions of operations, change of management team, and so on. Supervisors in all units oversee staff performance. Staff members are motivated through the payment of leave bonuses, extension hour bonuses, and increments of salary, and they will not be committed to their jobs if the salaries are not paid when due. They are trained both outside and within management to acquire skills and more knowledge about their work.

Interconnections between stakeholders' $3 \mathrm{Cs}$ have a positive impact on the firm. There are no effects of geopolitical and socio-cultural influences on the company, but inequality due to tribalism and religion sparks extensive social unrest and undermines entrepreneurship and business growth.

\subsubsection{Citico Plastic Industrial Limited}

Citico Plastic Industrial Limited manufactures plastic products. The firm is a largescale business with over 100 employees and has been in existence for the past 15 years. Dara Lawal, a university graduate and the company's marketing manager, has 
been working for the company for the past eight years. Over the last five years, there have been no significant changes in the company. The management's decisionmaking process is a centralised form. Staff members are motivated through the payment of leave bonuses, extension hour bonuses, and increments of salary, training outside and within for management and mostly technical staff. Moreover, there is a need for improvement in the company's production and safety management. There is a supervisor in each unit of the company who steadily supervises the production.

The interconnections between stakeholders' 3Cs have an impact on the successful operation of the sector and gain high profits. In Citico Plastic Industrial Limited, people are groomed from casual workers. These concepts are believed to be working well, and customers are accepting the company's products. Geopolitical and socio-cultural influences (i.e. tribalism, religion, and corruption) have no impact on the production performance of the company. However, the absence of infrastructure is a great challenge to entrepreneurship in Nigeria because entrepreneurs have to build their factories, generate amenities like electricity and water, construct roads that lead to the factories, and provide security. This makes the cost of production very high when coupled with inflation and other aspects, making it difficult for consumers of the product, unlike in developed countries where all these facilities are provided by the government through the use of taxpayers' money. In the last five years, the sales growth, return on assets, return on sales, and operating profits have increased slightly. Increased sales and lack of consumer complaints are factors influencing the success of the company.

\subsection{Chemical and Paint Industries}

There are four firms under this category, as listed below in Table 4.4 two from the South-South region and one each from the South West and North Central regions..

Table 4.4 Chemical and Paint Industries

\begin{tabular}{|l|l|l|l|l|}
\hline S/N & Name of Company & Nature of Business & Town & Region \\
\hline 1 & Kings Paints Company & Paints & $\begin{array}{l}\text { Benin/ } \\
\text { Edo }\end{array}$ & $\begin{array}{l}\text { South } \\
\text { South }\end{array}$ \\
\hline 2 & Anyi Solid Chemical Industries & Paints & $\begin{array}{l}\text { Sapele/ } \\
\text { Delta }\end{array}$ & $\begin{array}{l}\text { South } \\
\text { South }\end{array}$ \\
\hline
\end{tabular}




\begin{tabular}{|l|l|l|l|l|}
\hline 3 & Bond Chemical Industry & Pharmaceutical & Awe & $\begin{array}{l}\text { South } \\
\text { West }\end{array}$ \\
\hline 4 & Wangtok Enterprises & Agro-Chemicals & Ilorin & $\begin{array}{l}\text { North } \\
\text { Central }\end{array}$ \\
\hline
\end{tabular}

\subsubsection{Kings Paints Company, Benin City}

King Paints manufactures varieties of paints, selling and distributing them to its customers; these paints are used for home decorating and protective coating for surfaces. The two types of paints the company produces are water-thinned paints and turpentine-thinned paints. The turpentine-thinned paints are used for hard surfaces like timber, while the water-thinning paints - popularly referred to as emulsions - are for interior walls and ceilings, it could be in form of glossy texture. The major materials used in producing paints are pigments, binders, solvents, and additives, some of which are imported; few are available locally. The company has about 50 staff and has been in operation for about 15 years. The firm responds to and produces what people lack in the environment. The relationship has always been cordial.

Sunday Bade, the manager, was interviewed, and he responded that he was employed on professional merit. He worked with a similar company before joining the present firm and left his former job for a better salary and better service conditions. The company's challenges are that it takes a long time to produce paints and more time to meet customers' orders. He further stated that the cost of production is very high, so the cost of products is relatively high. This leads to low patronage because few customers can afford to buy them. He denied that these challenges are due to stakeholders' incompetency, lack of commitment, or bad strategic coordination. According to him, $55 \%$ of the input materials are locally sourced, and the company imports about $45 \%$ of the raw materials used in manufacturing its products. Manufacturers experience a lot of delay from the clearing of the consignment due to unnecessary bureaucracy, and most things are done manually at the port. According to the respondent, normally, goods that are cleared in developed countries within seven days might take three to four months to be cleared in Nigeria, depending. He told a story regarding his experience at the port:

When it was time for them to clear their goods at Lagos port, and bill of lading indicated that good should be cleared at the Lagos port, for 
several months they could not locate the whereabouts of their goods, until they were told that their good has been diverted to Port-Harcourt port due to over congestion at Lagos port, this took over 6 months to clear. To take this good to the factory there were series of delay due to bad road and government agencies asking for different kinds of papers from the drivers exploiting money from them, all these factors raise business cost in an already high environmental cost and also result to highly delay of activities. Even some local inputs are expensive and scarce. Delays and high cost of operation are challenges to the production.

This is the corruption and infrastructural problems that are badly affecting the manufacturing industries in Nigeria. If the $3 \mathrm{Cs}$ are working perfectly within the company, the external environment might not make this visible. This is the essence of the narration above.

The workers are depressed and frustrated, daily revenue is reducing drastically, the company cannot increase salaries if it does not make the required profits. Though the workers are competent, they can do practically nothing in this situation, and even their coordination can be destabilised. In the respondent's opinion, you can have new ideas only when things are in order, that is, when strategic and operational decisions are translated into action at a normal time, which will result in better performance and business growth. The respondent also believes that the 3Cs concepts are the major determinants of firm growth and also enhance $\mathrm{CE}$, but the obstacles might be the complex external environmental factors. The factor that creeps up in entrepreneurial performance is the frequent updating of the employees' knowledge through training, workshops, etc. Geopolitical and sociocultural influences (i.e. tribalism, religion, and corruption) have no effects on the $3 \mathrm{Cs}$ and their operation. Business success is the ability to achieve the vision and mission of a firm. Business failure is when a firm cannot achieve its aim or performs below expectations. The organisations that demonstrate best practice are the Nigerian telecommunication industries. 


\subsubsection{Anyi Solid Chemical Industries (Paint)}

The Anyi Solid Chemical Industries (Paint) company manufactures different kinds of paints. It was established about 17 years ago and has about 25 employees. Ifeanyi Ukor is the production manager and a university graduate. He has worked for the company for the last 15 years and obtained this job through a familial relationship. There has been significant progressive change in the organisation over the last five years. The firm has employed more staff and made more sales. It gives instruction from time to time as a form of monitoring the work in the factory and makes decision centrally. The workers are well-motivated and committed because the company pays them good, regular salaries and also gives them Christmas packages every December period. The employees' training is good for the work, but it will never be enough. The organisation still needs to buy more modern machines so as to improve its productivity.

Interconnections between stakeholders' $3 \mathrm{Cs}$ are necessary for the firm to grow and to add value to the organisation and customers who buy the products. Geopolitical and socio-cultural influences (i.e. tribalism, religion, and corruption) have negative effect on business operations. For instance, inequality (Igbos and Christians claim that they have been marginalised) has caused far-reaching social unrest in many ways in Nigeria, menacing the development of businesses and entrepreneurships. Success means making more profits, paying better salaries to staff, and making customers happy. Any organisation's performance that can be rated $80 \%$ or more is successful. The respondent reiterated that business failure is the opposite of business success. There is one industry in Enugu that has best practice in terms of CE that is also into paint-making and has one of the bestselling paints in Nigeria.

\subsubsection{Bond Chemical Industry, Oyo}

Bond Chemical Industry is a pharmaceutical company, a manufacturer of medicines and vaccines. In 1976, it was first traded as a retail outlet for pharmaceutical products. The factory's headquarters is situated in 22A, Alafia Street, Mushin, Lagos, Nigeria, and the branch is located in Adesakin Layout, off Iwo Road, Awe, Oyo State. The company's brand, structure, workforce, and equipment size have greatly increased by almost five times compared to when it first started. It has about 
200 employees. The company's relationship with local communities is cordial because it provides some social amenities for them, although there are complaints about air pollution and the noise from the heavy machinery, which are not healthy for the communities.

The company's accountant, a university graduate, was employed through professional merit. The company recruits its management staff through a recruiting firm and also gives regular training to its casual workers in order for them to become more capable in carrying out their duties. There has been a progressive change in the company over the last seven years. The changes reflect an increase in sales of its output, and the company is growing and performing well. Recently, the Nigerian economic has been in recession, but this has not really affected the sales too much because people still fall sick, especially in Nigeria where health and safety are not priorities. The company provides training and updates the staff on a regular basis. It also pays salaries regularly, unlike some firms that can no longer pay their workers' salaries. This has made its staff more committed to their jobs. Staff are free to suggest new ideas for the improvement of production, marketing, and so on, which has made the company more effective and efficient in its performance. The form of control mechanism is that there are supervisors in each unit and a quality control manager who ultimately supervises all the supervisors and passes relevant information to the managing directors, who then pass the information to the board of directors for the final decision and approval. Everybody is proud and happy to work for the firm.

The company faces challenges that are beyond its capabilities. There a many fake drugs manufactured locally and even imported in large quantities from abroad. This has damaged the lives of many people due to their ignorance because these fake drugs are much cheaper. Although much has been done in this area and the government is fighting against fake drugs, there are still many around. The worst challenge that affects this company is the security issue. As the company takes security, health, and safety seriously, it invests a lot into security, and the staff are well trained on these aspects.

In 2015, armed men whom the workers thought were company cleaners kidnapped the chairman of the company, Adebowale Omotoso. They requested an unavoidable ransom from the chairman's family and threatened to kill him if the ransom was not paid before the deadline. At this stage, the only options available 
were to either save the life of the chairman and allow the company to collapse, or vice versa. The company payed the money (though not enough), the chairman was released, and the company is now in serious debt and everything is paralysed. In this situation, stakeholders' 3Cs could not save the company from the myriad of problems. However, it is the respondent's belief that the interconnections between stakeholders' 3Cs played fundamental roles in the company's success before 2015. There are no geopolitical and socio-cultural effects on stakeholders. There are no forms of discrimination in the establishment. In most cases, geopolitical and sociocultural influences have negative effect on stakeholders' performances in public organisations. Bond Chemical Industry is one of the organisations that demonstrate best practice in terms of CE in Nigeria.

\subsubsection{Wangtok Enterprises}

The production manager of Wangtok Enterprises has been working for the company for the past seven years. The firm manufactures agrochemicals. It is a large-scale business organisation with over 40 workers and was established about 10 years ago. The mechanism of control is primarily through supervision. The means of passing information is through a centralised method. Staff compensation and constant salary payments help a lot in motivating workers. There is a need to expand by acquiring new production machines to increase production, and its strategic marketing needs to be improved in order to promote the company. The company's challenge is the unavailability of facilities and resources. Any organisation that has stakeholders who are competent, committed, and well-coordinated is more likely to be at a competitive advantage. Since Wangtok Enterprises is a very small organisation, these 3 Cs might not be very effective because the firm is less complex and easy to operate, the market is not large, and it has a normal routine and practice.

Geopolitical and socio-cultural influences (i.e. tribalism, religion, and corruption) can affect small-scale businesses. When there is ethnic and religious violence, all business activities will be paralysed. The rate at which customers spend has reduced drastically. When the government removed its fuel subsidy, industries suffered for it. Over the last five years, the performance and productivity of the company has improved. Customer satisfaction is paramount for any organisation to progress. The organisation that has the best practice CE in Nigeria is the service sector. 


\subsection{The Building Materials Sector}

This section highlights the data on the production of building materials (Table 4.5), in which five firms are represented in the investigated sample.

Table 4.5 The Building Materials Sector

\begin{tabular}{|l|l|l|l|l|}
\hline S/N & Name of Company & Nature of Business & Town & Region \\
\hline 1 & Hentsco Group of Company & Building materials & Sapele & $\begin{array}{l}\text { South } \\
\text { South }\end{array}$ \\
\hline 2 & $\begin{array}{l}\text { Highland Aluminium } \\
\text { Company }\end{array}$ & Aluminium products & Lagos & South West \\
\hline 3 & Spring Aluminium & Aluminium products & Asejire & South West \\
\hline 4 & $\begin{array}{l}\text { Holdent International } \\
\text { Limited }\end{array}$ & $\begin{array}{l}\text { Aluminium, hygiene } \\
\text { products and } \\
\text { cosmetics }\end{array}$ & Ota & South west \\
\hline 5 & $\begin{array}{l}\text { Success Business Link } \\
\text { Building and } \\
\text { construction materials }\end{array}$ & Abraka & $\begin{array}{l}\text { South } \\
\text { South }\end{array}$ \\
\hline
\end{tabular}

\subsubsection{Hentsco Group of Company, Sapele}

Henry is the manager of the Hentsco Group of Company. He has been working with the company for the past seven years and obtained his job through a recruiting firm. This job is not his first job; he changed his job because of better pay. The company manufactures building materials with about 70 workers, including casual workers that are always on daily job and daily pay. The firm has been in existence for the past 15 years. The company is experiencing an unusual sudden negative change due to the national economic recession. The production and sales are diminishing daily. Before, there were 200 workers, including the casual workers, but because of the present situation, the work force has been reduced to 25 , as the company can no longer afford to pay salaries. The management supervises the work routinely, and annual inspections are performed. Decision-making is centralised. Regular promotions and the payment of salaries on time are what motivate the staff to do well and perform to expectations. Restriction of staff freedom is the main cause for employees to be unmotivated. The employees' experience and training are enough for the firm to 
grow. What is needed now is the creation of more branches and government policies that can promote industries.

Interconnections between stakeholders' $3 \mathrm{Cs}$ are factors that can determine entrepreneurial performance. These concepts are related to entrepreneurial performance in the sense that they create passion for being self-employed. One of the major aspects constraining entrepreneurship and restricting business growth in Nigeria is the geopolitical and socio-cultural influence (i.e. tribalism, religion, and corruption) of corruption through the misappropriation of resources, lack of public accountability, and infrastructural deficit. Business success is the achievement acquired through any business idea discovered. Business failure is not the reverse of business success because if anything fails today, it may succeed later; the business owner will learn from their failures or past mistakes. Key factors can creep up in entrepreneurial performance when the external business environment is friendly.

\subsubsection{Highland Aluminium Company}

Highland Aluminium Company is a large-scale enterprise with about 200 employees. It has been in existence for the past 15 years. The company produces aluminium products that it believes are of better quality than those of competitors. For instance, it uses superior 'stucco' to engrave the surface of the sheets, making them stronger and last longer. The Standards Organisation of Nigeria (SON) sets minimum standard roofing sheets to be $0.40 \mathrm{~mm}$, so Highland Aluminium's products do not go below the SON's standards.

The respondent has been working for the company for the past five years. There have been drastic changes in the production process of the company over the years due to an increase in the cost of production that affected the firm negatively. Information is passed to workers through a centralised method. Salary payments at the due date, the implementation of allowances, and proper treatment motivate the staff to work effectively. Delays in salaries and a lack of motivation from the board of directors make staff not as productive and effective as expected.

Interconnections between stakeholders' $3 \mathrm{Cs}$ make industries thrive and survive. Geopolitical and socio-cultural influences (i.e. tribalism, religion, and corruption) are factors that work against entrepreneurships. The problem with the firm is not that its workers are incompetent or lack commitment but that the company's important strategic decisions and operations are slow to be implemented 
due to an erratic power supply. In many cases, the diesel to power generator might not be available due to scarcity, which constrains organisational achievements.

\subsubsection{Spring Aluminium, Asejire, Oyo}

This company is located in KM 23, Ibadan/Ife expressway, Asejire, Oyo State, Nigeria. The total number of employees is less than 50. The company was established in 2006. It manufactures aluminium roofing sheets, aluminium coils, claddings, and flashings of different colours, shapes, and gauges. Aloba is the managing director; she is a university graduate. the company recruits casual workers who learn on the job. Some of them are experts now even though they do not have formal education. The company is a small-scale business with 5 to 50 employees. The relationship of the company with its immediate local communities is cordial. The firm bought a transformer for them to transmit electricity when the old one was damaged.

There have been significant gradual changes in the company over the last five

years because of the retrenchment of staff due to the economic situation of the country. The company could no longer afford to pay salaries, there was no foreign exchange to buy input imported materials, and an increase in the cost of input local materials and a drop in the sales affected the daily profits. Activities are monitored through the use of visual display units (CCTV). The company's management disseminates information in a centralised form. Staff are motivated through the daily provision of lunch and salary yearly salary increases. The employees' experience and training are enough for the better performance of the firm. The company is friendly with the local communities and arranges and pays for local security men to protect the communities and the factory. It also donates transformers to the communities.

In the last five years, the performance and productivity of the company have reduced greatly due to lack of infrastructure. There was an instance when the fluctuation of electricity damaged the company's machinery beyond repair, and it took almost six months before it could be replaced. During this period, the company was on standstill. An organisation that demonstrates best practice in terms of $\mathrm{CE}$ in Nigeria is poultry farming, which is performing wonderfully. 


\subsubsection{Holdent International Limited}

Holdent International Limited, a manufacturer and marketer of aluminium, hygiene products, and cosmetics, became a limited liability company ('PLC') in 1999. It has a joint venture with Indonesian technical support together with an engagement of Nigerian management skills and investments, and in so doing, has created some of the best-enduring Nigerian brands. Its vision is to manufacture top quality and affordable products to Nigerian consumers and to provide enough to fill the gap created due to the ban on imported aluminium and cosmetics. The factory address is Plot 111, Ikorodu Industry Layout, Ikorodu Lagos. The registered office address is 88A Ojo Lane, off HFP Way, Dolphin Estate Ikoyi Lagos.

Ikechukwu Moses is the company's production manager; he is a university graduate and has been working for company for the past nine years. He was employed with the company on professional merit. The company is a large-scale business firm with over 50 employees and has been in existence for the past 15 years. The company maintains a cordial relationship with the local communities by providing drinking water for them. Over the last five years, to 2017, there were significant negative changes in the company that called for re-studying of the market and changes in the firm's strategy to increase sales, which eventually brought about a massive increase of sales. There is no work supervision, and decisions are made in a decentralised form. Staff members are motivated through the organisation's commitment to improving their welfare. Staff are not motivated when salaries are not paid regularly.

The production manager does not believe in interconnections between stakeholders' 3Cs. To him, it is academic: before you obtain a job, you sign an agreement on what you should do and not do and have already committed yourself; also, salaries motivate staff. The coordination system is a natural phenomenon that is the firms' ways of doing thing and is cultural. Before someone is employed, the management has to be sure that they are competent, that is, they should know what and what not to do in their work or profession.

Geopolitical and socio-cultural influences (i.e. tribalism, religion, and corruption) can affect entrepreneurial performance. The company spends millions of naira every year to repair the road that leads to their factory in order to ease its business operations and for public use because the Nigerian government's budgeted money to 
repair and maintain the roads was used for different things or shared among corrupt politicians. The culture of corruption and inconsistent policies adversely affect national economic activities and entrepreneurial performance. Success in a business sense is an increase in sales and value creation. Business failure is the reverse of business success. Proactive entrepreneurial behaviour is used by optimising risk in the firm and is turned to opportunity.

\subsubsection{Success Business Link, Warri}

This company's address is Sapele-Abraka Old Road, Abraka, Ethiope East, Delta. The company produces blocks, concrete, and building and construction materials. Ogbodu Obed is the production manager of the firm; he does not have any formal education and is 55 years old, with 10 years of experience. The company has over 15 workers. And has been operating for about 15 years. The firm is located in a central business district (CBD) in which there is an availability of materials.

There has been significant progressive change in the sales of its products over the years because of the quality of the products, which have the correct mixing proportions. This change has affected the company's daily sales. Quality control managers supervise the water, sand, and cement ratios during production to meet the standard point. Quality control is done so that sub-standard materials are not used at any point in time; this is the form of supervision strategy employed by the firm. The decision-making is centralised. Regularity in staff salaries, the granting of loans, and incentives given to staff members in any festive period are forms of motivation for them; they refused to be motivated if there are irregularities in their salaries and excess workload. The training and experience that the workers have here are not enough but still sufficient for the capacity of work. In the case of expansion, there is the need for the training and retraining of staff so as to give them the latest updates in production and marketing strategies.

Interconnections between stakeholders' 3Cs help businesses to grow progressively and sustainably. No firm or establishment can experience progress without observing the $3 \mathrm{Cs}$, i.e. foundation for any entrepreneur. Geopolitical and socio-cultural influences (i.e. tribalism, religion, and corruption) help to grow the business. For example, the respondent stated that 'we sell most of our products (blocks and concretes) by connection and influence through people you know (relative or religious) or on settlement issues'. Business success is the ability to meet 
consumers' expectations and to take risks. Business failure is not the reverse of business success, in the respondent's opinion. The key factors that creep up in performance are the availability of funds and materials.

\subsection{Iron and Steel Sector}

Two firms, both from the South West region of the country, were sampled in the iron and steel category, as shown in Table 4.6.

Table 4.6 Iron and Steel Sector

\begin{tabular}{|l|l|l|l|l|}
\hline S/N & Name of Company & Nature of Business & Town & Region \\
\hline 1 & $\begin{array}{l}\text { Iron and Steel Nigeria } \\
\text { Limited }\end{array}$ & Carbon steel billets & Ile Ife & South West \\
\hline 2 & Sumo Steel & Iron and steel & Ota & South West \\
\hline
\end{tabular}

\subsubsection{Iron and Steel Nigeria Limited}

This is an industry that manufactures carbon steel billets, steel and iron gates, doors for blast furnaces and steel mills and produces all different types of iron rods, such as $12 \mathrm{~mm}, 20 \mathrm{~mm}$, and $30 \mathrm{~mm}$ rods. The company employs people with skill and experience in the steel industry. It has about 100 workers, including casual workers. Founded in 2009, the firm is situated in Ile Ife, Osun State and 40 Parklane Lagos, Nigeria.

Stephen Glory is the company's accountant; he has a university degree and has been working in the Ife steel industry for the past five years. He left his former employer, an Indian man, because that company folded and the employer never paid his salary and did not care. The firm does not have a very good relationship with its local communities because people complain about the noise and air pollution caused by the smoke from its machines. The people also believe that the trucks damage their roads. However, the majority of the company's employees are from these local communities, which has led to a reduction in the rate of unemployment in the area.

There has been a great change over the last five years. The work is now more tedious than it was before when the production was very minimal. Supervision is done daily by factory supervisors, and there is proper recordkeeping and inventory control. The top management makes all decisions. Staff in the organisation are not motivated and lack commitment because the management does not take care of them 
and is only after making profits and saving costs. The people working here are always looking for adverts in the daily newspaper to find alternative jobs elsewhere because they believe that the business owners are exploiters. The employees still need a lot of training for better performance in order for success to be recorded so that the company can do better.

Interconnections between stakeholders' $3 \mathrm{Cs}$ are very crucial to any establishment, especially those in the manufacturing sector, but most of the workers in this company are not competent and few are committed. This is why the company is not growing well, coupled with bad government policies. There is no vivid evidence that shows whether geopolitical and socio-cultural influences have affected the organisation, but it is certain that the company is taking advantages of the high rate of unemployment in the country. Thousands of people graduate every year without a job, and they are redundant. Even when they know that employers are not paying salaries, they will apply for the jobs, which makes the employers abuse and treat the workers without respect. According to the respondent, he left his former job because salaries were not paid, but he is experiencing the same problem in his new job.

\subsubsection{Sumo Steel, Ota}

Sumo Steel was established over 22 years ago and is a large-scale firm with over 200 employees. Adebayo Adekunle was first employed about 20 years ago; now, he is the company's human relations manager. He secured his job through a recruiting firm. He left his former job for better pay and job security. Over the last five years, the company has not been doing well, as there have been significant negative changes. The changes happened suddenly because the firm could not afford to buy imported materials due to the high price of the exchange rate, the devaluation of Nigerian currency and inflation, and the expense of local materials.

The top management makes all decisions for the company but encourages new useful ideas. Staff are motivated and more committed when incentives are paid regularly and are not motivated when their salaries are not paid when due. The employees' experience and training are not sufficient enough for the firm's capacity development. According to the respondent, there is a need to improve the technical aspects of the company. 
Interconnections between stakeholders' $3 \mathrm{Cs}$ are needed for the firm to grow and become profitable, but external forces make it seem as if the $3 \mathrm{Cs}$ are inefficient. The firm does not experience any geopolitical effects, but there are socio-cultural impacts on the business to a great extent. For instance, Nigeria is an importedproducts nation that does not encourage manufacturers to produce locally finished goods; the government does not have a good policy in place to promote industry. The sales growth of the company over a five-year period decreased compared to what it used to be. Success in every business depends on the acceptability of the company's products by the consumers and whether the company is not creating any shortage.

\subsection{Household Industries}

Two firms were sampled under the household industries sub-category of the manufacturing sector, as highlighted in Table 4.7. Both firms are from diverse regions of the country - the South West (Yinka Oba Foam in Ilesa) and the South East (Divine Grace in Onitsha).

\section{Table 4.7 Household Industries}

\begin{tabular}{|l|l|l|l|l|}
\hline S/N & Name of Company & Nature of Business & Town & Region \\
\hline 1 & $\begin{array}{l}\text { Yinka Oba Foam Nigeria } \\
\text { Limited }\end{array}$ & $\begin{array}{l}\text { Mattresses, pillows, } \\
\text { cushions, and sheets }\end{array}$ & Ilesa & South West \\
\hline 2 & $\begin{array}{l}\text { Divine Grace Business } \\
\text { Enterprises }\end{array}$ & Shoe soles & Onitsha & South East \\
\hline
\end{tabular}

\subsubsection{Yinka Oba Foam Nigeria Limited}

Yinka Oba Foams is a family company established in 1979. Located in Kilometre 4 Ijebu-Jesa Road, Ilesha, Osun State, the company manufactures affordable, good quality foams, such as mattresses, pillows, cushions, and sheets. It produces both ordinary and customised products to customers' specifications, which can be purchased at various local stores. The company has been doing well because its products are of international standard. The employees' experience and commitment are the major contributing factors to the company's recorded success.

Alhaji Jubri Abdul is the general manager who was interviewed. He is a university graduate who has been working for past 15 years with the firm and was 
employed on professional merit. Yinka Oba Foam Nigeria Limited is a large-scale enterprise with over 200 employees. It has been in existence for over 25 years. The organisation is environmentally friendly till date, since some of the employees' children have benefitted from employment from the company. There is regular supervision of work in this organisation. Over the last five years, the performance and productivity of the company has improved greatly due to commitment, hard work, capability, and the availability of raw materials. However, power is generated through a generator, which has increased the cost of production. Since 2015, this has been another story entirely, since raw material prices have gone up greatly due to exchange rates, inflation, and the depreciation of Nigerian currency. This has negatively affected the business. The organisation was progressing positively until 2015, when the country's economy became bad as a result of different government policies. This affects production greatly because almost all the company's raw materials are imported.

The mode of disseminating information is through a centralised method. The chairman makes all the decisions. Prompt salary payment is what motivates the staff to perform well. Most of the business owners do not believe in any motivational steps. Training and retraining of staff are needed, but the organisation lacks enough resources to train workers outside the country for contemporary technological exposure. The company engages only in in-house training now.

The company's 3Cs have contributed positively to the little growth that has been achieved, but there are not enough resources and facilities to function at full capacity. There are no geopolitical and socio-cultural influences on the factory but gaining access to foreign exchange to buy imported materials is difficult. The CBN makes foreign exchange available to religious pilgrims that buy dollars at a favourable rate for holy trips to Rome and Mecca and to people that pay their children's school fees abroad. Banks use currency control techniques to become rich. For instance, they buy dollars from the $\mathrm{CBN}$ at a cheap rate and then sell them to smugglers (black market) at a very high rate to make a large profit effortlessly. Meanwhile, the entrepreneurs and businesses suffer for it, as this is undermining the development and performance of enterprises. 


\subsubsection{Divine Grace Business Enterprises}

Ifeanyi Eze is the managing director (MD) of Divine Grace Business Enterprises and a university graduate. Since 2009, Divine Grace has been in an operation manufacturing shoe soles. The respondent started as an apprentice and was promoted to full-time staff and went on training before he became the MD of the company. The company is a small business with less than 10 employees.

There have been significant changes in the company since 2014, such as a drastic decrease in patronage, as most Nigerians prefer to buy imported shoes than locally made shoes. The government has not done much in this area. Most of the customers are low income people, like state government workers, and most have not received their salaries for the past five months. Things are expensive, so even if they receive salaries, they can no longer afford to buy the shoes anymore. Furthermore, the company is producing far below its capability, which has led to low performance.

The company still needs to import a few items for its production from abroad but cannot afford the foreign exchange and increase in import tariffs since it is on the small scale. The problems with the company are not due to incompetence, lack of commitment, or bad coordination but because of the issue explained earlier. The staff have the skills, knowledge, and experience to perform, and everybody is committed for economic reasons. The firm had been doing very well before the negative situations in Nigeria. The problems are external, not within the company. When there is hope, staff are motivated and committed so as to receive a good salary when due. Interconnections between stakeholders' $3 \mathrm{Cs}$ are necessary for good results in production and sales, with the support of the government. Geopolitical and sociocultural influences (i.e. tribalism, religion, and corruption) do not have impacts within the company. However, they generally affect some industries, especially when government policies favour one industry due to a personal relationship with the government and collapse other industries. This makes entrepreneurships much less likely to succeed.

\subsection{Competence, Commitment, Coordination (3Cs) and Performance}

The data collected was imported into Atlas.ti software and guided by inductive coding, and themes were developed based on the objectives of the study, as shown in Figures 1, 2, and 3. Likewise Figure 4 shows the effect of environmental issues on 
the 3Cs, and Figures 5 and 6 show the positive and negative factors of performance. According to the respondents, the training and retraining of workers, coupled with other factors highlighted in Figure 1 (especially the management team and technical staff working directly with production), has provided valuable insights into the elements of competence.

Most of the respondents stated that the employees are committed because of different kinds of conditions that make them perform very well and do their best. There are many other responses in Figure 2 on the contribution of commitment to the strategy formulation process. The study found that apart from the salary paid to the workers, there are many other incentives that the employees enjoy. For example:

"Our staff are being motivated in several ways among which are increase in their salaries, giving of incentives, giving audience to employees complaints and suggestions which enhances their sense of belonging. And most importantly the effecting health scheme for the staff and their household. Our firm makes decision centrally. Our workers perform excellently because they have good and regular salaries. We also give them gift during December period".

\section{Figure 1 Competence's contribution to the strategy formulation process}

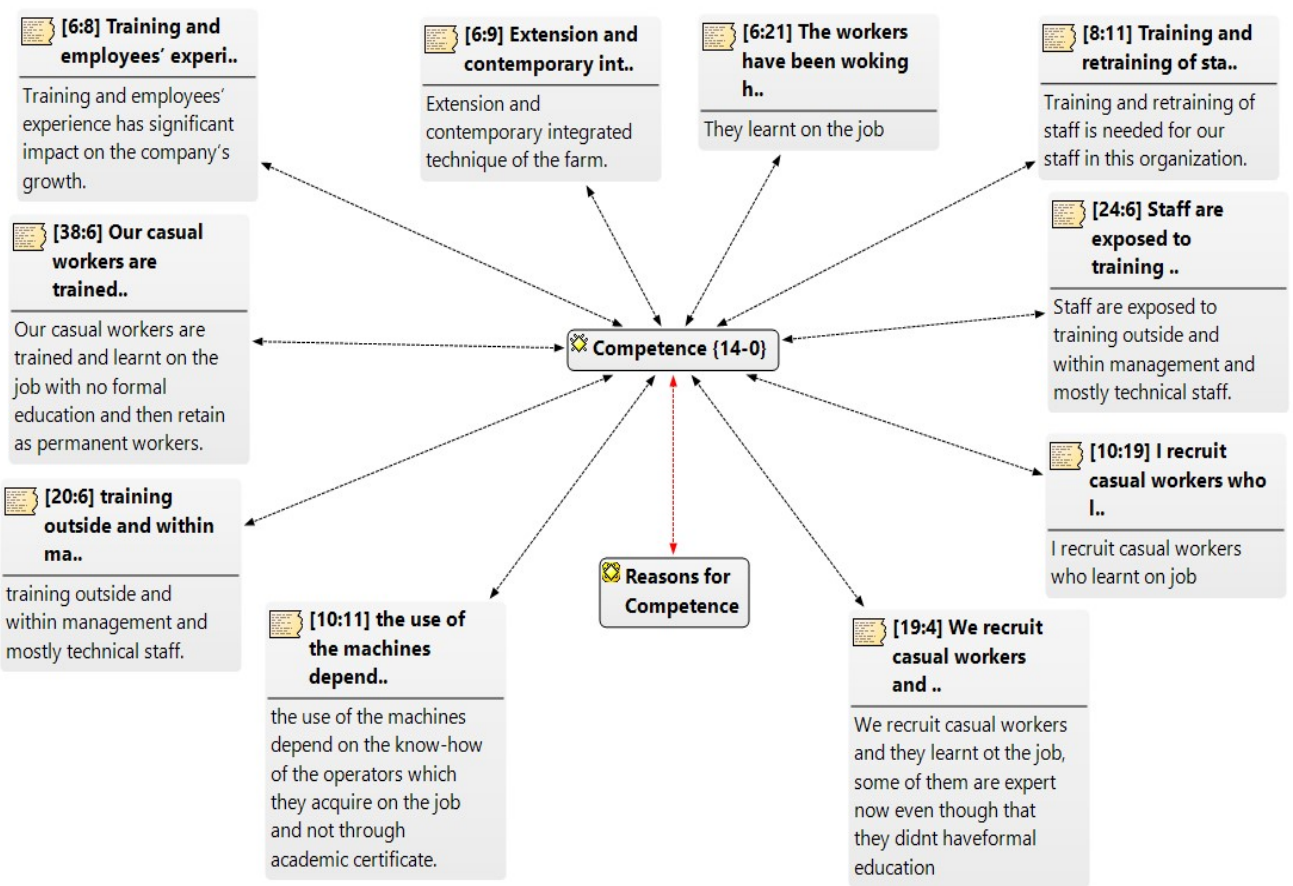

Source: Fieldwork, 2017 
Figure 2. Commitment's contribution to the strategy formulation process

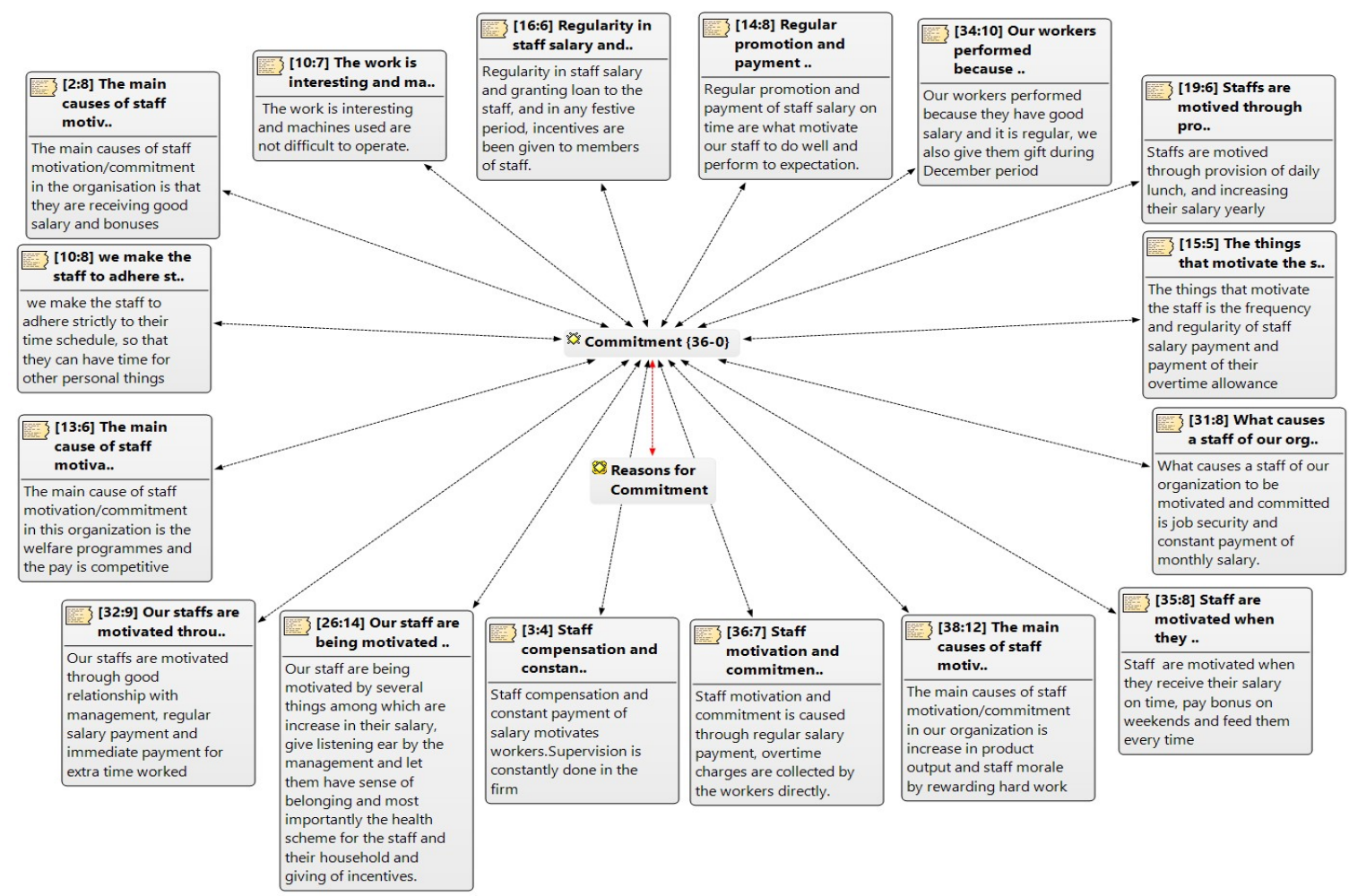

Source: Fieldwork, 2017

Different coordination tools are employed by the firms as presented in Figure 3, which include the use of technology like CCTV, unscheduled surprise visitations, and supervision of all kinds. Figure 4 shows the effect of environmental issues (i.e. geopolitical and socio-cultural influences) on stakeholders' 3Cs. Performance was measured with different parameters like sales growth, assets, company outputs, and income growth rates in terms of profits/losses for a period of five years. The study revealed that the majority of the firms within this period had negative experiences in terms of these aspects. Some firms went through difficult times due to incessant infrastructure failure, geopolitical and socio-cultural influences. Figures 5 and 6 also provide insights into positive and negative forms of performance, which are key to the failure or success of firms. 
Figure 3 Coordination's contribution to the strategy formulation process

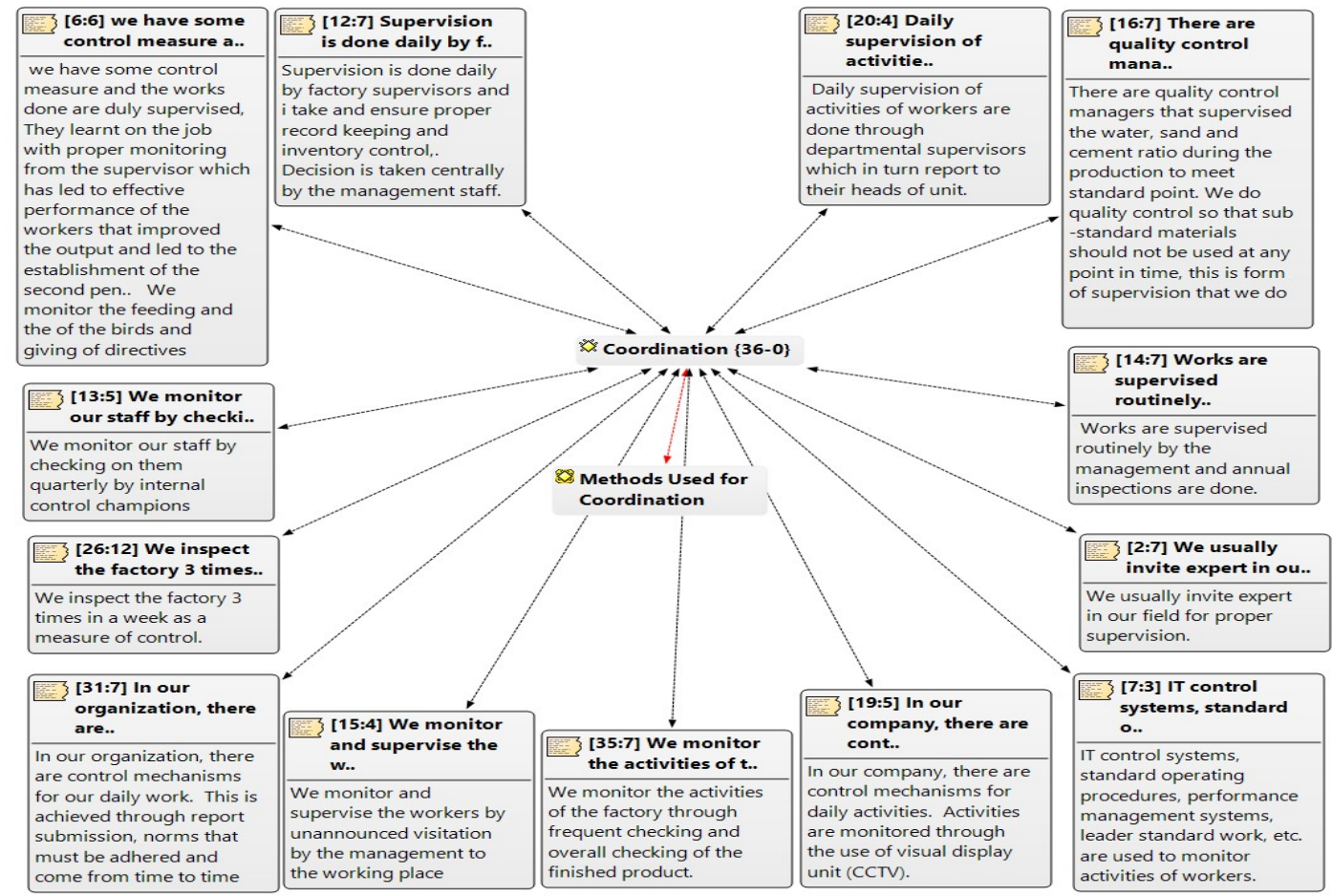

Source: Fieldwork 2017 
Figure 4 Effects of environmental (geopolitical and socio-cultural) issues

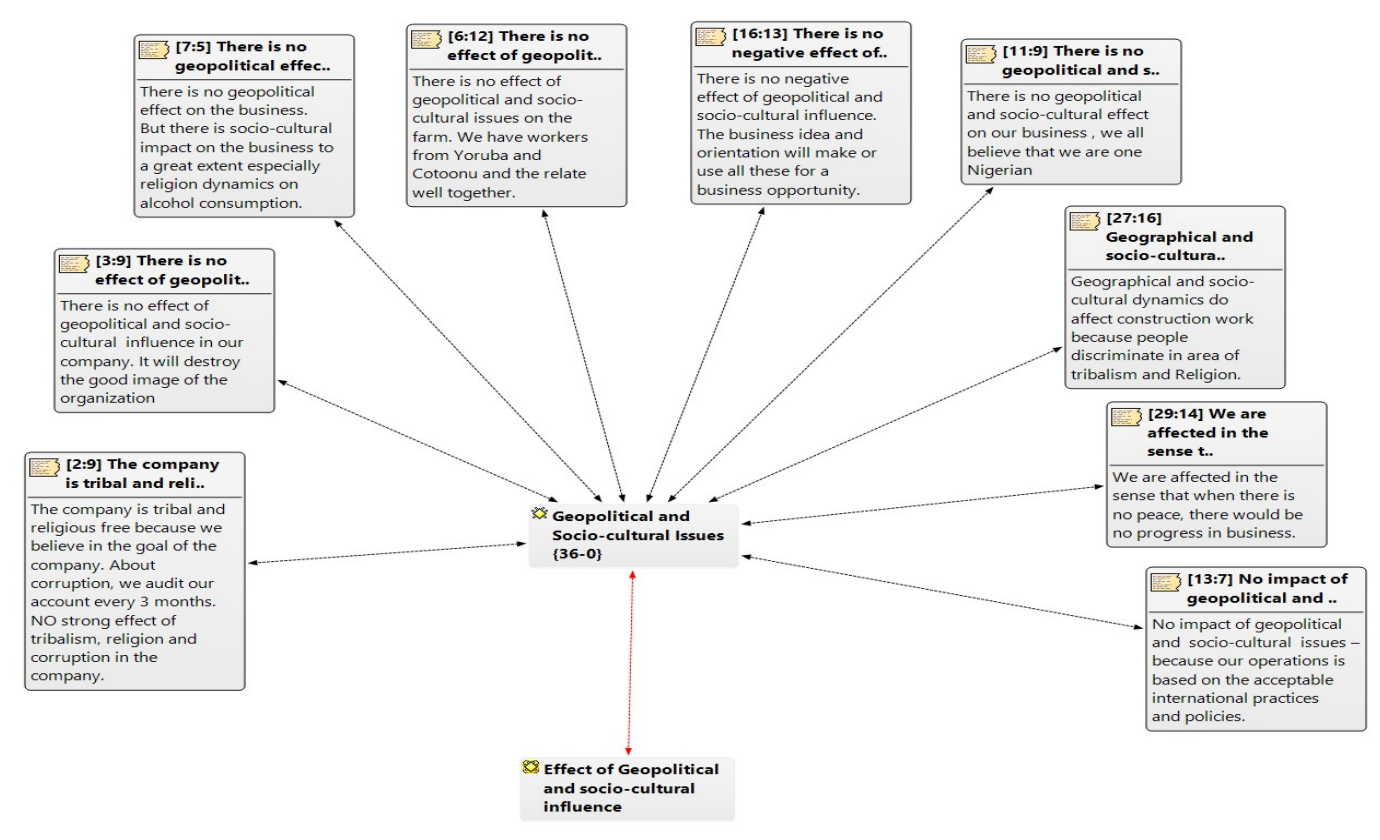

Source: Fieldwork 2017 
Figure 5 Negative factors of performance

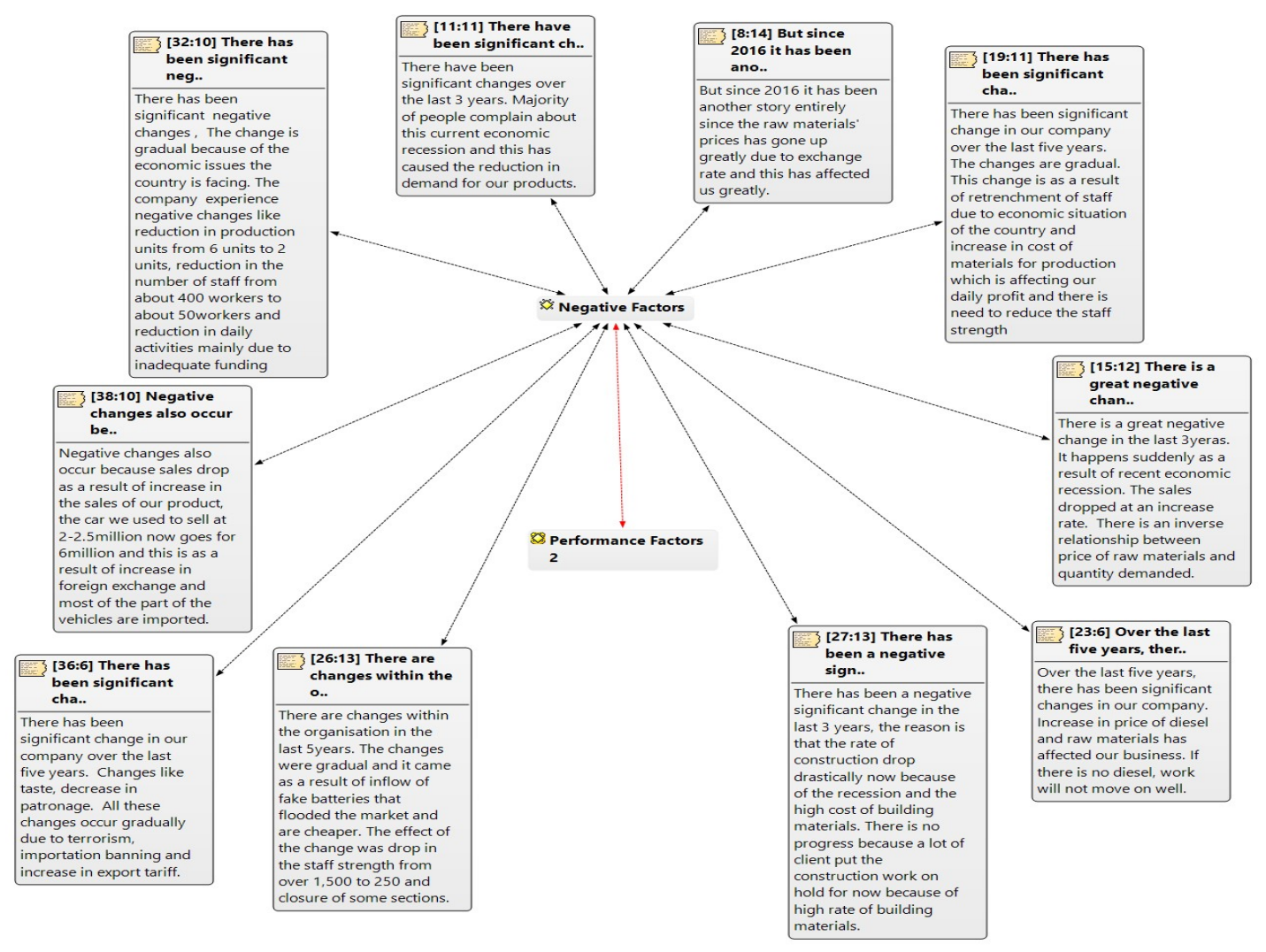

Source: Fieldwork, 2017 
Figure 6 Positive factors of performance

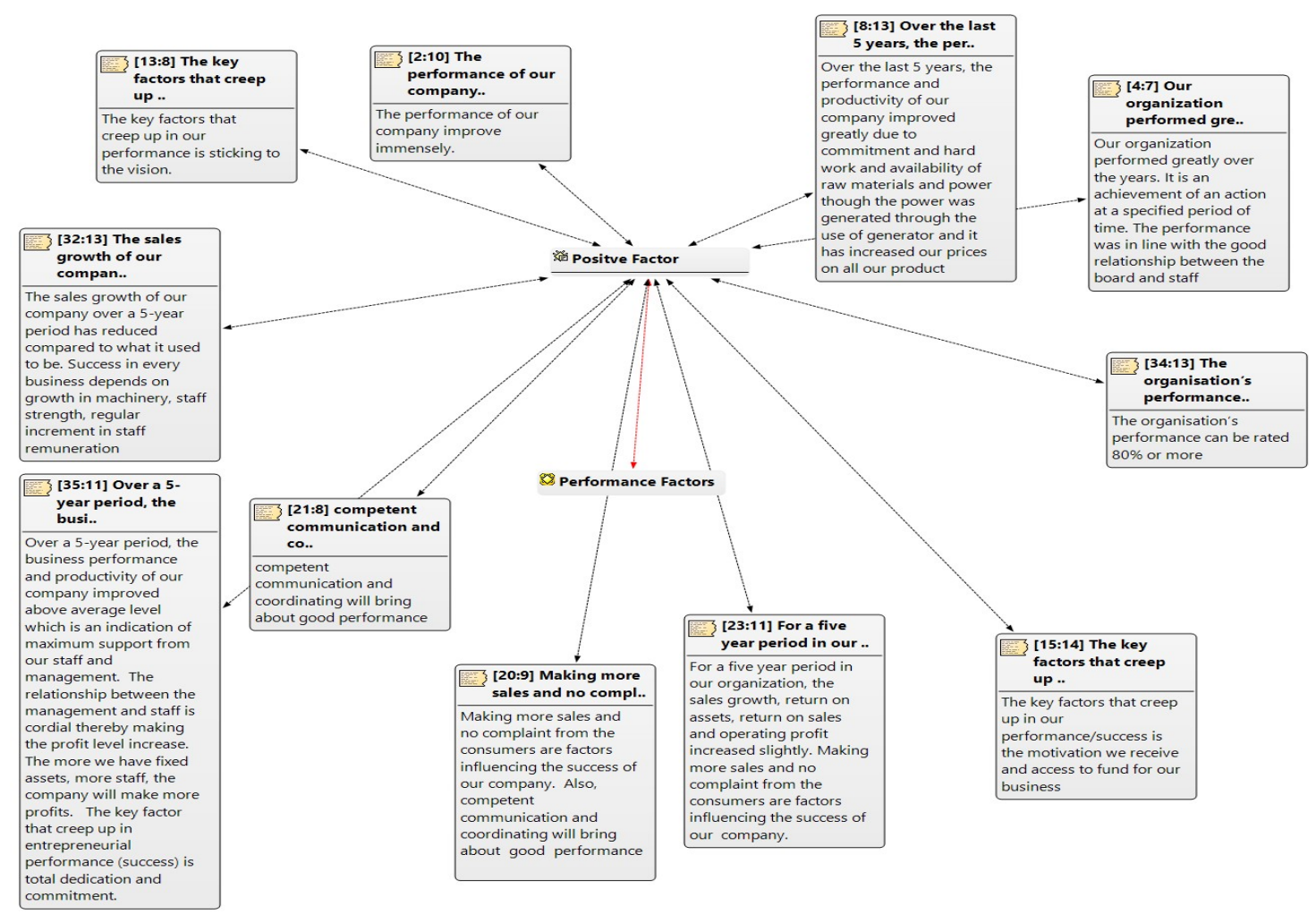

Source: Fieldwork, 2017

\subsection{Summary}

This chapter displayed the raw data captured in the field and was arranged based on the categories of the sampled firms. Most of the respondents interviewed believed that the poor performance of the sector is not due to stakeholders' lack of commitment, incompetence, or bad coordination but has more to do with external environmental factors that clearly beyond their control. The external environmental factors (i.e. geopolitical and social-cultural) tend to pose problems across all firms investigated, whether related to tribal issues, religion, and corruption or to the lack of political will. Most of the firms also indicated that the dynamic external environmental factors (i.e. exchange rates, inflation, lack of access to finances, inefficient infrastructure, unregulated imports, criminality, and violence) have had a negative impact on CE (see Appendix 11). 


\section{CHAPTER FIVE DISCUSSION}

This chapter discusses concerns the socio-demographic characteristics of the respondents. Table 5.1 shows the distribution of the respondents by background information and also provides a descriptive summary of the socio-demographic characteristics of respondents, i.e. age, education level, religious affiliation, gender, marital status, position, and organisation name, all of which are indices of socioeconomic characteristics and status. All respondents were in the age range of 20-60 years, and most were from the Southern regions of the country, notably, the South West, South East and South, which are predominantly Christian enclaves. Although religion is a very sensitive issue in Nigeria and is often not included in census figures, there is a general belief that Christianity dominates in the South where this data was collected, while Islam is the dominant religion in the North.

In terms of marital status, it is worth pointing out that most respondents (28 out of 32) were married, and 26 were male while the remaining 6 were female. Furthermore, the fact that most respondents $(83 \%)$ were male while the remaining 6 respondents (17\%) were female justifies the British Council's statement (2012 cited in Akinbami and Aransiola, 2015) that nearly 6 million young women and men enter the labour market each year but only $10 \%$ are able to secure a job in the formal sector, 1/3 of which are women. 
Table 5.1 Socio-Demographic Characteristics of Respondents

\begin{tabular}{|c|c|c|c|c|c|c|c|c|c|c|c|c|c|}
\hline \multirow[t]{2}{*}{ Region } & \multirow[t]{2}{*}{ State } & \multicolumn{4}{|c|}{ Age (in years) } & \multicolumn{2}{|c|}{ Education Level } & \multicolumn{2}{|c|}{ Religion } & \multicolumn{2}{|c|}{ Gender } & \multicolumn{2}{|c|}{ Marital Status } \\
\hline & & 20- & 30- & 40- & $50-$ & Secondary & Tertiary & Islam & Christianity & Male & Female & Single & Married \\
\hline \multirow{5}{*}{$\begin{array}{l}\text { South } \\
\text { West }\end{array}$} & & 29 & 39 & 49 & 60 & & & & & & & & \\
\hline & Оуо & 1 & 2 & 1 & 2 & 0 & 4 & 1 & 3 & 5 & 1 & 0 & 6 \\
\hline & Osun & 0 & 2 & 2 & 2 & 0 & 4 & 1 & 4 & 4 & 0 & 1 & 4 \\
\hline & Ogun & 0 & 2 & 2 & 0 & 0 & 3 & 1 & 3 & 2 & 2 & 1 & 2 \\
\hline & Lagos & 0 & 0 & 2 & 0 & 0 & 3 & 1 & 2 & 3 & 0 & 0 & 3 \\
\hline South & Anambra & 0 & 1 & 0 & 1 & 2 & 3 & 0 & 3 & 2 & 0 & 0 & 2 \\
\hline \multicolumn{14}{|l|}{ East } \\
\hline \multirow{2}{*}{ South } & Edo & 0 & 1 & 0 & 1 & 0 & 3 & 0 & 2 & 2 & 1 & 1 & 3 \\
\hline & Delta & 1 & 1 & 0 & 1 & 0 & 3 & 1 & 3 & 3 & 1 & 0 & 3 \\
\hline North & Plateau & 0 & 1 & 2 & 1 & 1 & 4 & 1 & 2 & 4 & 0 & 0 & 3 \\
\hline Central & Kwara & 0 & 0 & 1 & 2 & 1 & 1 & 2 & 2 & 1 & 1 & 1 & 2 \\
\hline TOTAL & & 2 & 10 & 10 & 10 & 4 & 28 & 8 & 24 & 26 & 6 & 4 & 28 \\
\hline
\end{tabular}




\subsection{Competence, Commitment, and Coordination}

\section{Employers' and Employees' Competence}

Employees' competence is an internal factor that has contributed a great deal to the success of most firms sampled within the study. This study measured competence from the academic qualifications and experiences of the respondents and the recruitment processes, as shown in Figure 5.1. The educational status of the respondents reflected that the majority have a high level of education; this was evident from the fact that they completed tertiary education. This was the reason they were part of the management teams of their respective firms.

However, two of the respondents in the South East and two in the North Central had only secondary education; these are the set that were recruited as casual workers and then trained before rising through the ranks to the management level. This training acquired was expected to affect their ability to effectively manage the firms. Competence focuses on the effective and efficient utilisation of human resources through recruitment, management, and providing direction for firms' success. It implies that the ability and capacity of workers are major determinants of good business performance (Opatha, 2010). Furthermore, based on the requirements of a firm, competence is a major factor responsible for deciding the relevant workforce. Apart from the formal or informal training that most workers possess, the study revealed that most of the workers were usually trained and retrained by the entrepreneurs to suit the purpose of the firms, normally to enhance the capacity of the workers to achieve the firms' objectives. There is no gainsaying that the ability and capacity of workers have major effects on their performance.

The recruitment process, according to the study as shown in Figure 1, showed that the majority of the management staff were recruited on professional merit, which means that they had the necessary qualifications and were suitable for the job. Furthermore, the majority of the technical staff were recruited as casual workers and then trained and retrained until they learnt on the job and became experts. Mondy and Neo (2005) noted that in keeping abreast with these situations, management pay more attention to the recruitment and retention of employees, specifically by ensuring that the 
employees are highly qualified and will make tremendous contributions to the business' success.

Similarly, professional trainings that are industry-relevant have major effects on the performance of firms. This is because these professionals, who are usually of managerial cadre, make decisions that are germane to the success of the firms. From the study's findings, it was discovered that most entrepreneurs try to minimise costs with regard to labourers and employees in order to maximise their profits. Therefore, most entrepreneurs have a strong preference for casual workers; these workers are usually temporary in nature and learn on the job. Incidentally, some of these temporary workers are eventually recruited into the mainstream of most of the firms. It was observed that in some of the firms, the absorption of casual workers is not the usual practice.

The study corroborates Farnham (2015) that recruitment is sensitive to the determination of business performance. This is because the recruitment process goes a long way towards determining the labour quality and output of a firm. Therefore,

effective recruitment will not only enhance firm performance but will equally assist human resources to perform exceptionally. Thus, firms should make conscious efforts to monitor the selection process of their human resources to ensure that the right sets of individuals are being absorbed. Therefore, this study is in agreement with Man et al. (2008) that entrepreneurial competencies significantly influence business success.

\section{Employers' and Employees' Commitment}

Following the selection of personnel to drive production activities within an organisation is the issue of commitment. The implication of this is that if a person qualifies for a job but lacks the commitment or passion required to drive the job, this will lower the worker's productivity. In addition, an uncommitted worker may pose a potential threat to any organisation because such a worker may be more than willing to switch jobs with ease or become infectious to other workers, affecting the firm's performance. According to the majority of the respondents, commitment has helped their firms perform very well. This shows that commitment is one of the major aspects that must be demonstrated in any manufacturing firm to have good results. 
This is done to further make the employees do their best. In view of the foregoing, this study was able to identify motivation as a major factor ensuring the commitment of workers in an organisation. Worker motivation can emerge in various categories, which include the early and regular payment of staff salaries, moderate work hours, adequate compensation for overtime, productivity-based promotion, the implementation of policies to cater for staff welfare like health care and lunch provision, the payment of special bonuses, and good working conditions.

These motivational tactics are germane to the successes recorded in the study, as shown in Figure 5.2. As such, this study is in agreement with Zayas-Ortizet et al. (2015), who postulated that a highly motivated human resources department significantly distinguishes one company from another. It is a key element in achieving the strategic goals of a company. Ivancevich et al. (2006) agreed that human capital is vital to organisational success. Therefore, these authors concluded that apart from the quality of human resources dictating performance, staff enthusiasm facilitated by motivation is an impulse to achieving organisations' objectives with the highest effectiveness. It should be noted that employees who experience high satisfaction tend to be more committed to pro-social behaviours, as well (Schappe, 1998; Murphy et al., 2002).

\section{Firms' Coordination}

This study established the importance of managerial control and coordination in the interaction of strategy formulation and implementation and explained the performance experienced amongst the firms at the internal level. Moreover, coordination can be used as a means to communicate directions and guide the behavioural patterns of employees. If there is no proper coordination in an organisation, the aims and objectives will not be achieved. It was observed that all the firms were very serious regarding the issue of coordination. Practical supervision was performed throughout the units constantly in all the firms. There were also clear indications that coordination is also germane to the existence and performance of the firms. Some of the firms had supervisors within the

firm that see to the company's day-to-day activities. For some, it was the quality control staff who made sure that work is done properly from time to time. These different 
measures of coordination have assisted in making the workers conscious of the tasks and targets ahead of them.

The study showed that most of the firms employed various levels and types of control measures to achieve effective coordination. These measures entailed a range of activities, such as continuous monitoring, daily recordkeeping, and stock assessments through supervisors who report to unit heads. In addition, some other control processes included the existence of internal control mechanisms, monthly to quarterly reviews, IT control systems, quality control mechanisms, inspections, and ad-hoc check-ups. The importance of these control mechanisms have resulted in effective coordination, which has had a continuing effect on production output as well as on overall business performance. These coordinative mechanisms are ensured because privately-owned firms are usually geared towards making profits, as these profits will guarantee their sustenance in business. Therefore, most entrepreneurs implement a proper monitoring system to avoid compromising on quality, quantity, and profit.

These findings are consistent with the assertion of Zanini and Migueles (2013) who argued that coordination has links to trust and performance. Coordination produces performance because it creates the trust needed for achieving performance through proper and adequate interactions between management and employees. This is consistent with the literature review results in Chapter Two that the interaction of different components in and outside an organisation is what coordination actually represents.

Internally, coordination is setting rules and standards based on cooperation; externally, coordination is fostering relationships and interest aggregation. Following the information provided by the respondents, the activities of the firms in terms of coordination have facilitated friendly interactions with their immediate internal environments. Likewise, there have been various benefits to their immediate environments given from the existence of the firms.

About $96 \%$ of the respondents said that stakeholders' 3Cs contribute greatly to the success of the manufacturing sector and better CE performance, which is consistent with the literature review results in Chapter Two that stated that the $3 \mathrm{Cs}$ are the key factors for the successful performance of construction firms (Jha and Lyer, 2007). 
According to Michael et al. (2016), competence and commitment are created perfectly through good coordination.

From the foregoing, it can be assumed that internal and controllable activities, such as the 3Cs (which are within the purview of entrepreneurs), account for positive feedback in most businesses in Nigeria. However, the case is completely different when examining the external environment's effects on business performance in Nigeria. Firms generally do not have any measure of control over the external factors. Irrespective of the planning mechanism via the $3 \mathrm{Cs}$, there will be continuing effects on business performance from external factors because such activities are beyond them.

\subsection{Mitigating Role of the External Environmental}

Foreign exchange rates, inflation rates, poverty, unregulated imports, insufficient funds, infrastructure deficits, socio-cultural influences, violence, and criminality are the major factors of the turbulent external environmental in Nigeria, as discussed below.

\section{Foreign Exchange Rate}

The study found that manufacturing firms in Nigeria use both local and foreign raw materials to produce finished products. At times, the imported input might be up to $70 \%$ raw materials, and the firms need to buy foreign exchange to be able to purchase some of these raw materials. According to some respondents, the challenges facing the firms are that the foreign exchange is scarce or unavailable to all but a few people that are close to or associated with the government of the day, even though the exchange rate is not suitable for their businesses because it is on the high side.

The respondents pointed out that Nigeria has different levels of the rate. For example, the exchange rate for religious pilgrims is not the same as the one to pay for the school fees of children studying abroad, and there are different rates for importers and exporters. Unlike other countries, Nigeria has fluctuating exchange rates (see Tables

\section{2 and 5.3).}

\section{Table 5.2 Exchange Rates}

\begin{tabular}{|l|l|l|l|}
\hline Year & Exchange agent & Dollar & Naira rate \\
\hline 2016 & CBN (Central Bank of Nigeria) & 1 & 196 \\
\hline 2017 & CBN & 1 & 305 \\
\hline
\end{tabular}




\begin{tabular}{|l|l|l|l|}
\hline 2017 & Interbank & 1 & 315 \\
\hline 2017 & BDC (Bureau de Change) & 1 & 385 \\
\hline 2017 & Parallel/ street market & 1 & 465 \\
\hline $2017-2019$ & *CBN (for investors and exporters) & 1 & 360 \\
\hline
\end{tabular}

Source: ABOKIFX, NIFEX (2017) and XE Currency Converter (2019)

*Not always available

Table 5.3 Exchange Rate

\begin{tabular}{|l|l|l|l|}
\hline Years & $\mathbf{1 9 9 5}$ & $\mathbf{1 9 9 7}$ & $\mathbf{1 9 9 8}$ \\
\hline 1 US Dollar CBN rate & 17.3 Naira & 21.9 Naira & 21.9 Naira \\
\hline 1 US Dollar AFEM rate & 81.0 Naira & 81.6 Naira & 83.8 Naira \\
\hline Differences in Naira & 63.7 & 59.7 & 61.9 \\
\hline
\end{tabular}

Source: CBN Statistical Bulletin (2002)

The multiple exchange rates not only lead to cash problems for entrepreneurs but also to fraud and corruption, which affects their strategy planning and entrepreneurship. For instance, in 2017, government officials and their friends would buy dollars at the CBN for the official rate of 305 naira and then sell them at the parallel rate of 465 naira to make millions of dollars effortlessly. Even the banks do the same 'round-tripping', the respondents said. In a similar manner, in the late 90 s, the story was the same. Therefore, the foreign exchange rate is one of the factors that affects the price of importation and cost of production and makes the manufacturing sector poor.

\section{Inflation Rate}

Less than two years ago, Nigeria's inflation rate more than doubled from $9.0 \%$ in 2015 to $18.72 \%$ (NBS, 2017). In a similar manner, economic growth was at $6.2 \%$ GDP in 2014 but decreased to $2.8 \%$ GDP in 2015 (NBS, 2017) as a result of a sharp increase in organisational and individual expenses like foodstuffs, which became unaffordable. Transportation problems, such as when the price of fuel increased from 86.5 naira/litre to 145 naira/litre, increases in the irregular electricity tariff from $13.5 / \mathrm{KW} / \mathrm{H}$ to $25.6 \mathrm{KW} / \mathrm{H}$, which can damage industrial machines, and the devaluation of the naira 
from 197 naira/\$ to 305 naira/\$ official rate (Nigeria Economy, 2016). In 2017, Nigeria was in recession, which greatly affected the national economy and businesses operations (CBN, 2016). This has been a great challenge to manufacturing firms in terms of their decision-making and strategy formulation and implementation, as well as their sales.

\section{Consumer Spending}

Nigeria has the largest population in Africa, so it should be a prime market for international and local retailers to target its over 170 million people as buyers of manufactured goods (The Report Nigeria, 2013). Due to human power and its resources, Nigeria became the largest market in Africa (The Report Nigeria, 2013). However, as a result of high inflation and poverty rates, consumers could no longer afford to buy the manufactured products because they did not have money as before. For example, employers in both public and private organisations owe salaries for months or even a year, and most firms are running at loss. Staff are depressed, and most of the firms are making their employees redundant (see Appendix 8):

The governor of Ondo State, Rotimi Akeredolu, has called on all civil servants in the state to sacrifice the outstanding salaries owed to them by the immediate past government. He said government workers must be prepared to pay the sacrifices of waiving their salaries as part of their own contributions to the economic development of the state. NAIJ.com gathered that the Ondo state governor has paid three months salaries of February, March and April in 2017. It was also gathered that the fresh government has paid one out of the six months arrears owed the workers by the past governor of the state Olusegun Mimiko (Nationwide 2018).

Those who receive salaries have collapsed wages caused by price inflation and the massive devaluation of Nigeria's currency. According to Issa Aremu, General Sectary of the National Union of Textile Garment Workers, in 1981, the minimum wage was 125 naira per month, equivalent to $\$ 240.00$. When Nigeria had no inflation, businesses were growing, salaries were paid when due, and better education was free. In 2017, over half of the Nigerian population received less than the minimum wage of 18,000 naira per 
month, which is not regular and equivalent to just $\$ 45.00$. Parents have to pay school fees, and a bag of rice is $\$ 12,000$ (equivalent to \$39.00). The high rate of unemployment also plays a major role, as there are many people who do not have a job at all and no benefits or support elsewhere. Unemployment increased from $13.4 \%$ in 2004 to 59.1\% in the South West and 77.1\% in the North East in 2012 (NBS, 2014). Moreover, 4.07 million Nigerians lost their jobs between January 2017 and September 2017 (NBS Report, 2017). According to a UN Human Development Report (2009), about $85 \%$ of Nigeria's population is living on less than $\$ 2.00$, and over 120 million Nigerians are poor (Oxfam International, 2016). This has created poverty among the old and young people of Nigeria. Thus, the respondents confirmed that the high rate of poverty has resulted in sales dropping drastically, which affects the entrepreneurship, profits, and performance of firms.

\section{Unregulated Imports}

Businesspersons in Nigeria struggle to obtain foreign exchange to import their input raw materials, and they still face huge challenges at the seaports due to Nigeria's unregulated imports policy, like high tariffs and inferior imported products flooding the market. A firm's respondent narrated a situation in which it took their company over six months to clear its imported materials from the port, which caused delays in delivering its responsibilities. In 2017, News Agency Nigeria (2017) stated that some containers were stolen from ports and nothing was done. Additionally, local input raw materials are not always available, and the obtainable ones are inflated, making most manufacturing firms lose money or, in some cases, close down.

\section{Access to Finance}

Entrepreneurs do not have access to finances. Many of them have good ideas and are ready to take risks, produce new products, and expand their business but cannot translate their strategic priorities and operation decisions into action due to the lack of sufficient funds. This has resulted in a major challenge to entrepreneurial growth and the manufacturing sector's sustainability. Some of the respondents said that they borrowed money locally, obtained supplier credits, or made monthly contributions to start their 
businesses because they could not afford to get bank loans due to the high interest rate of about $28 \%$. Commercial lending is not committed to the growth and success of entrepreneurship and business. For instance, commercial banks loans to firms reduced from $7.5 \%$ in 2003 to $1.0 \%$ in 2006 and then to $0.14 \%$ in 2012 (International Financial Corporation, 2014) Furthermore, investment (annual variation) reduced drastically from $13.4 \%$ in 2014 to $1.3 \%$ in 2015 (CBN, 2016; NBS, 2016). Therefore, many entrepreneurs have no means of saving and do not have money to start their businesses or make their businesses grow. As such, many people with good strategies, visions, and business ideas cannot strive. This study found that the manufacturing firms that are not moribund, though making little profit compared to before, are those that have some foreign shareholders, invested in dollars, or used their international connections to obtain loans at an interest rate of $0.25 \%$. Once again, the Nigerian banks have multiple interest rates, unlike those of developed countries (see Appendix 9), which has a negative effect on $\mathrm{CE}$ and business practices in Nigeria.

\section{Weak Infrastructure}

The United Nation Industry Development (UNIDO) (2008) revealed that over $60 \%$ of respondents cited physical infrastructure as a major problem facing manufacturers in Nigeria. This study also discovered that infrastructure deficits are a challenge facing industries in Nigeria. To start a business, entrepreneurs must have enough money to finance their own electricity, construct the roads to their factories, and provide water supply to the factories. These add ridiculously to the cost of production, resulting in a reduction of the firm's profits and increased overhead costs and sales costs so that the consumers can no longer afford to buy.

\section{Inefficient Transport Infrastructure}

The developed countries' roads are almost 100\% motorable (good roads). In Nigeria, according to Federal Road Safety (2017), when travelling from Jos to Abuja, there are 1,700 potholes, causing trailers that carry products to navigate non-existent roads and causing much delay. A journey that is supposed to take 2 to 5 hours might take 24 hours or cause accidents. Nigeria has $25 \%$ of the total accidents in Africa and was 'ranked 192 of road accident of 193 world nations' due to bad roads (WHO, 2014). About 45\% of 
tomatoes transported from farms to markets were wasted in 2011 due to the inefficient transportation system (The Report Nigeria, 2012; NBS, 2013). Inefficient transport increases the cost of production between 7-10\% (Nigeria Transport Infrastructure, 2015). Boeh and Beamish's (2011) research revealed that an hour delay on business travel will reduce a company's profits by $8 \%$. The majority of respondents said that Nigeria's poor roads are a massive challenge for industries' performance and operations.

\section{Inadequate Power Supply}

South Africa has a population of over 45 million people and a grid electricity power generation of about 30,000 megawatts (30,000MW). Nigeria has over 170 million people yet has a grid electricity power generation of less than 4,000 megawatts (4,000MW) (Nigeria Magazine, 2014). Out of 189 surveyed countries, Nigeria was number 187 regarding the ease of getting electricity (Doing Business Database, 2015). A survey conducted by the Manufacturers Association of Nigeria (MAN) found that $85 \%$ of manufacturing firms used standby generators to run their businesses; about $50 \%$ had a minimum of 3 generators to supply the electricity, and about $20 \%$ relied on their power generators and used national grid electric generation as a backup due to damages to their equipment and machinery as a result of continuous fluctuations in the power supply. The cost of power supply through diesel generators is over $30 \%$ of the overhead cost of manufacturing firms (MAN, 2002). This shows that Nigeria has poor electricity compared to developed countries, so firms have to generate their own electricity by using generators, buying diesel, maintaining and servicing the generators, and employing people to be in charge of the generators. Large firms build their own power plants, often at an excessively high cost. According to the respondents, the inadequate power supply increases production costs and affects both the production and sales.

\section{Violence and Criminality}

These high levels of unemployment and poverty and the feeling of hopelessness among citizens are associated with serious violence and crimes such as armed robbery, terrorist activities, and kidnapping (Dugguh, 2013). These occur due to lack of adequate security, which contributes to the already sky-high operating cost of doing business in Nigeria 
(IMF, 2016). Nigeria is ranked high among the most corrupt countries globally (Transparent International, 2012). According to some of the respondents, armed robbery, terrorist activities, and kidnapping are negatively affecting the operation of entrepreneurship and business growth. Other respondents claimed that the government's inconsistent and bad policies, like multiple taxes, multiple foreign exchange rates, bureaucracy, corruption, and inequalities that lead to tribal and religious wars, are associated with the predicament of business growth and the national economy.

\section{Corporate Social Responsibility}

This study revealed that environmental factors can be either negative or positive (see Figure 4). The positive environmental factors were further classified into interpersonal relationships, corporate social responsibility, and unemployment reduction. It was observed that most firms had very good and cordial relationships with their local communities as a result of the different kinds of programmes put in place by the firms, including the provision of potable drinking and domestic water, the installation of electrical transformers, the contribution of money to hire security agents in their locality, and the reduction of unemployment in the area.

The firms also employed some of their children/wards who are school dropouts as casual workers. These aspects helped in the protection of the firms and good patronage for their goods within the communities and beyond, thereby improving their performance. Thus, the majority of the firms attributed good interpersonal relationships to their local communities, which has given them good yield in terms of their performance. On the other hand, some respondents reported that their firms had negative impacts on the communities as a result of air pollution and noise from the factory machines. Therefore, in spite of the corporate social responsibility of giving back to the community, the firms still did not have a good relationship with the communities because of their poor safety measures.

\subsection{Geopolitical and Socio-Cultural Influences on the 3C's}

This study established that there were little to no effects of geopolitical and sociocultural influences on the stakeholders' 3 Cs within their firms. The majority of the firms 
are located in their indigenous areas, although there are socio-cultural issues externally that can have effects on the strategic configurations. For instance, one respondent reported that: 'There is no geopolitical effect on the business but there is socio-cultural impact on the breweries business to a great extent especially religion dynamics and its impact on alcohol consumption'. Some of the respondents believed that Nigeria has the highest number of holidays in the world, i.e. Christian, Muslim, and civil work free days, which costs firms billions of naira every year. The government's bad policies of the removal of its fuel subsidy and inequalities have definitely caused violence like tribal wars, which have negative impacts on consumer spending, sales and profits, production activities, operations, and entrepreneurial performance.

Furthermore, some of the respondents said that Nigeria's policymakers are not competent, lack commitment, and have bad coordination due to geopolitical and sociocultural influences. They provided the example of the position of Minister of Power, Housing, and Work being given to one person who is a lawyer by profession, although it is well known that power and transportation are major challenges to industries and individuals in Nigeria. Moreover, all security chiefs are Hausa Muslims from the northern part of Nigeria where the president comes from.

Infrastructural bottlenecks are part of the factors that are working against the industries. The money allocated for infrastructure in the budget was removed for different things that benefit the administration. Former President Obasanjo spent $\$ 10$ billion on electricity without results (Doing Business Database, 2015). According to the respondents, the people in authority are there to enrich themselves, and the interests of industries and individuals are not their priority. About three quarters of the respondents said that infrastructure inefficiencies result in firms' idle capacity.

It was observed from the respondents that there have been reductions in sales growth, assets, and income growth because of these external factors. Upon further enquiry, the researcher found that these external factors were major reasons for the closure of most manufacturing firms in Nigeria (see Table 5.4). Specifically, the study revealed that issues such as political factors, socio-cultural factors, infrastructuraltechnological factors, and economic factors have had continuous and far-reaching effects in setting the climate for business success or failure within the Nigerian economy. 
The study also revealed that within the political terrain of Nigeria, problems such as instability and lack of continuity in government policies, as well as the lopsided structure of government activities, have accounted for poor business performance. For instance, while previous governments had no issues or policies against outsourcing raw materials, Nigeria's Local Content Bill frowns on this and strongly encourages the usage of local raw materials (see Madichie, 2011). The geographical breakdown of the firms during the period is highlighted in Table 5.4, which displays the number of firm closures in the investigated geopolitical zones in the country, ranging from 46 in the South-South to an astronomical 225 in the South-West.

In order to further discourage the importation of raw materials, the government hiked tariffs on imports, thus making it more difficult to outsource. Additionally, most entrepreneurs have a preference for either outsourcing or a mix of both local and outsourcing.

\section{Table 5.4 Firm Closures by Geopolitical Zone (Ranked by Number of Closures)}

\begin{tabular}{|l|l|}
\hline Geopolitical zone & Number of firm closures/collapses \\
\hline $\begin{array}{l}\text { South-West area, comprised of the Oyo, Ogun, } \\
\text { Osun, Ondo, Ekiti, Kogi, and Kwara states. }\end{array}$ & 225 firms closed down. \\
\hline $\begin{array}{l}\text { Lagos zone, covering Ikeja, Apapa, Ikorodu, and } \\
\text { other industrial divisions in the so-called 'Centre } \\
\text { of Excellence'. }\end{array}$ & $\begin{array}{l}214 \text { manufacturing firms closed } \\
\text { down. }\end{array}$ \\
\hline $\begin{array}{l}\text { South-East zone. } \\
\text { sorthern zone, covering the Kano and Kaduna }\end{array}$ & 176 collapses. \\
\hline $\begin{array}{l}\text { South-South zone, consisting of the Rivers, } \\
\text { Cross River, and Akwa Ibom states. }\end{array}$ & 46 closures. \\
\hline
\end{tabular}

Source: Adapted from Oyelola et al. (2013, pp.207-208)

Incidentally, these tariffs find their ways into the cost and quality of production, thereby increasing the cost of products. Invariably, this reduces the expected performance of businesses in terms of returns on investments. 
Furthermore, entrepreneurs have to build their factories, generate amenities like electricity and water, construct roads that lead to their factories, and provide security. These aspects make the cost of production very high, coupled with inflation and so on. Incidentally, this has equally increased production costs and in turn the selling cost, encouraging sharp practices among entrepreneurs with regard to maximising profits at all costs. In addition, factors such as corruption and religious inclinations are part of the socio-cultural issues impeding business performance in Nigeria. Among all other external determinants of business performance in Nigeria are changes in taste and economic policies. However, in recent times, the hallmark of complaints among business owners and entrepreneurs has concerned the issue of economic recession. The economic recession, which has brought about inflation and exchange rate volatility, has made business in Nigeria a herculean task. For instance, given the import-dependent nature of the Nigerian economy, the exchange rate volatility has influenced the rising prices of products within the economy.

These price changes have equally led to an increase in the cost of raw materials, thereby increasing the rates of locally produced goods. For example, the cost of power supply through diesel generators has increased by $30 \%$ or more (MAN, 2002), commercial loans have interest rates of about 30\% (NTI, 2015), inefficient transport increases the cost of production by $7-10 \%$, (NTI ,2015), and a five hour/month delay of travel reduces profits by 35\% (Boeh and Beamish, 2011) - all of which result in an increase in the cost of production of about $103 \%$ or more with corruption, exchange rates, and other aspects. One of the respondents even said that the cost of production has increased by $300 \%$ compared to the last 3 years.

The research also found that almost all the firms visited were highly underperforming, which is consistent with the negative findings of manufacturing firms in Chapter One. For instance, according to the respondents, their firms were no longer making profits, and some said that their firms could no longer afford to pay salaries. According to a respondent from Ibeto Group, the company's staff strength had been reduced from 1,500 to 250. Another said that many units have been shut down; one of the respondents also shared their firm's experience of having to change from three shifts of duty to two shifts. Of the few firms that seemed to still be doing well, the profit 
making had dropped drastically. For example, International Breweries' profit after taxation in 2016 was about 2.652 billion naira compared to 2017 when the profit declared was about 1.03 billion naira (Annual Report and Financial Statement, 2017), and Nigeria Guinness' profit after taxation in 2015 was 3.4 billion naira, while its profit after taxation in 2016 was 1.2 billion naira (Income Statement, 2016). About $90 \%$ of the respondents interviewed lamented that the problems with the manufacturing firms were not because their stakeholders were incompetent, lacked commitment, or had bad coordination but rather because of external forces like multiple exchange rates, recession, high inflation rates, high poverty rates, unregulated imports policies, infrastructure deficits, geopolitical and social-cultural influences. One respondent was of the view that Nigeria's external environmental factors can make competent people, committed employees, good coordination, and procedures much less effective and less efficient, which has contributed to the underperformance of entrepreneurship in firms' strategy formulation.

This study also discovered that firms like International Breweries Plc and Nigerian Bottling, among others, that seemed to be performing very well (though not to expectations) had a strong financial base because foreigners were invited to invest in the business, which brought dollars and pounds sterling into the businesses. According to a respondent, 'foreign connections contribute to their firm success and good return on their investment through competitive performance'. For instance, they have access to foreign bank loans with interest of about $0.5 \%$ or foreign debt and so on.

\subsection{Summary}

There is limited doubt that if the external environment does not engineer a favourable business climate through supportive policies and infrastructure, internal efforts to drive business performance will yield lopsided results. Thus, in order to achieve positive results in business performance, a complement of internal and external factors must be harmonised. This study found that the $3 \mathrm{Cs}$ are major factors that sustain the top-level performance of strategy formulation, $\mathrm{CE}$, and manufacturing sector, which is consistent with the literature review in Chapter Two. The 3Cs are the vehicles that actualise the sustainability of entrepreneurship and enterprise growth. 
Regrettably, external environmental forces have not allowed stakeholders the opportunities to make use of their job commitment, skills, knowledge, and acquired experiences in order to achieve their company's objectives, vision, and strategic goals. Moreover, the enterprises' strategy formulation is ineffective, and decision-making is impeded due to the complex and turbulent external business environment. Therefore, the following conclusions were drawn from the study:

- External environmental factors make stakeholders' 3Cs less effective in terms of strategy formulation and contribute significantly to the underperformance of manufacturing firms in Nigeria.

- External environmental factors are constraints to $\mathrm{CE}$, strategy formulation, and firms' performance.

- Geopolitical and socio-cultural influences are associated with complex and turbulent external business environmental factors in Nigeria.

- Geopolitical and socio-cultural influences include foreign exchange, inflation rate, consumer spending, unregulated imports, access to finances, inefficient infrastructure, tribal and religious violence, and corruption

In conclusion, the external business environment (political, social, technological, economic, and legal) has negatively affected almost all the visited firms, which in turn has affected the firms' performances. Many are struggling to survive, and one has almost become moribund. Thus, from the findings, the contribution of this study is that if the external environment is not favourable, a company will not perform well or at all, no matter the level of internal contribution of the 3 Cs. 


\section{CHAPTER SIX}

\section{CONCLUSIONS}

This study uncovered the relationship between the outcomes and research objectives with reference to the research questions by examining the data using interpretative phenomenology. The researcher made allowance for new insights or opportunities that might have emerged throughout the analysis in order to strengthen the research findings and conclusions. Interviews and the documentary analysis approach were used to gain an advantage, as they provided a variety of perspectives and insights.

The study also examined the data and patterns. When there was conflicting evidence, the researcher probed more deeply into where the perceptions were conflicting and identified the source of contradiction. Generally, the findings are considered to be reliable and valid. When other evidence collaborated one data type, this increased confidence in the findings (Rothbauer, 2008). Finally, the analytical responses to the original 'why' and 'how' research questions were treated with evidence in all cases.

This thesis developed a better understanding of the connection between corporate entrepreneurship, strategy formulation, and organisational performance in the Nigerian manufacturing sector. It also investigated the effect of internal entrepreneurial processed such as competence, commitment, co-ordination (3Cs) of firms in the sector, and their interactions with the external environment within which they operate. This is with a view to understanding how these interactions impacted upon organisational performance. This final chapter commences with a discussion of methodological issues such as reliability and validity. This is followed by highlights of key contributions of the study towards ensuring improvements in the Nigerian manufacturing sector. Finally, some limitations of the study are acknowledged, reflected upon and areas for future research exploration highlighted. 


\subsection{Validity and Reliability}

Threats to research reliability and validity can never be eliminated completely, so this study tried to minimise these threats as much as possible by applying the measures stated by Cohen et al. (2007), though it was not limited to the following points:

- The appropriate methodology and characteristics of the study were taken into account.

- The study adopted the most suitable sampling method.

- The study selected an appropriate time scale.

- The respondents were not put under pressure in any way during the interviews.

As Babbie (2010, p.158) once pointed out, "reliability is a concern every time a single observer is the source of data, because we have no certain guard against the impact of that observer's subjectivity." In most cases, reliability is always associated with subjectivity, and there is possibility that reliability might be compromised (Wilson, 2010). Reliability was also borne in mind during data collection. Reliability is when relevant information is obtained from articles, journals, and company documents written by firms' stakeholders. Therefore, original copies of these documents were used as primary sources, and many of the people who prepared the documents were interviewed. This increased the knowledge about the organisational context in which the interviews were conducted. Responses from the participants that could not be justified and that were unconvincing or suspected of being biased were ignored.

Validity of research can be explained as the extent to which the requirements of the scientific research method have been followed during the process of generating research findings. According to Oliver (2010), validity is very important for all types of research. Corroboration of the objective reality and knowledge validated the research. Interpretative analysis is a way of accessing knowledge that improves the strengths and features of the interpretations. Based on this definition, the study considered social construction to be a knowledge that is created by conflicting interpretations and staff negotiating amongst themselves and creating dialogue. As such, interpretative analysis must portray the organisational objective realities without prior assumptions. 
The respondents and the researcher shared the same knowledge about social and political upbringing and, in some cases, shared the language of the region in which the firms were situated. This provided opportunities for insightful exchange and common ground so as to allow for understanding and good interactions that produce/ provide richer data. The knowledge shared was regulated so as to avoid the respondents from being taken for granted. The effective use of the information obtained showed the credibility of the research and encouraged participants to provide more details during the discussions. The study's interpretation and analysis provided new insights into the role of external environmental factors on strategic formulation, $\mathrm{CE}$, and the performance of the Nigerian manufacturing sector.

\subsection{Contributions to Knowledge}

Essentially, the study sought to establish whether the interactions of the $3 \mathrm{Cs}$ within the context of a turbulent environment can bring about successful enterprise performance. This integrated view is novel, with both theoretical and practical implications. To extend the theoretical impact of this study, the 3Cs framework of Jha and Iyer (2007) was built upon and extended to the discourse of strategy and CE performance. The contextual insights provided added to enriching and extending the literature and, thus, responded to the now-dominant notion that 'context is everything' when assessing both variability in strategy discourse and the viability of strategy-in-use.

From a practical standpoint, the study sought to expand the array of tools available to managers, as well as their strategic horizons in relation to integrating the dimensions of strategy formulation and strategy implementation. According to Noble (1999, p.131), 'the commander' model is closest to the traditional strategy literature in its focus on centralised direction from the CEO to guide the firm's strategy. He also pointed out that 'it is clear that well-conceived strategies have little value unless they are effectively implemented' (Noble, 1999, p.132). In addition, the study responded to the call for continuous monitoring of the environment in which strategy formulation takes place so that enterprises are more firmly positioned in their catchment markets (Craven et al., 2008). 
A deeper understanding of both systems is significant for the analysis and design of $3 \mathrm{Cs}$ control systems within organisations. In investigating organisations in distinctive locations and environments, certain insights were gained. For example, by comparing and contrasting the interactions of strategies with environmental factors and the organisations' successes or failures, this study ferreted out this relationship through several variables, i.e. stakeholder commitment and competence, forms of coordination, environmental and organisational adaptation, and firm performances. Better understanding of these relationships is likely to be beneficial to managers as they seek more effective ways to grow and sustain their businesses.

Overall, this study has provided a clearer understanding of the relationship between strategy and firm performance-a critical determinant of business success and/or failure in Nigeria (Dauda, Akingbade and Akinlabi, 2010). Likewise, it has uncovered the relationship between geopolitical and socio-cultural influences (tribalism, religion, and corruption) on stakeholder's 3Cs as well as their influences on entrepreneurial performance. It can be postulated that stakeholders' four key drivers are the $3 \mathrm{Cs}+\mathrm{E}$, which together lie at the heart of performance and the success of strategic configurations in CE. It is also believed that this research has revealed the hybrid and ambivalent positions guiding, as well as constraining, the $\mathrm{CE}$ ecosystem and implications for the development (or underdevelopment) of the CE sector in Nigeria.

The implications are likely to be far-reaching, especially when the question is placed alongside the understanding that solutions to problems of the CE in Nigeria will have to be sought from within the paradigms creating the problems. This angle of inquiry is novel, with possibilities for opening new sites of knowledge.

\section{Competence}

The concept of competence has previously been defined as innovations, achievements, competitive advantages, resources, capabilities, and organisational success. Therefore, the combinations of knowledge, attitudes, and skills are conceptualising competencies. This thesis has shown that external environmental factors (i.e. geopolitical and sociocultural) have negative effects on the stakeholders' competencies in the strategy formulation process, which is a pioneering study. 


\section{Commitment}

The literature review examined commitment, particularly employees' commitment to job involvement, management, supervisor teams, and professions. This thesis was limited to the analysis of individual's commitment to their organisations. The findings were consistent with the evidence from the literature review undertaken. For instance, good working conditions, regular salary payments, and morale boost employees' commitment to their firms and spur them to do their best. From the analysis and findings of the study, it was evident that committed stakeholders contribute to better firm/ organisational performance. The literature placed more emphasis on staff commitment, but this study is based on the stakeholders' (i.e. employers' and employees') commitment to their organisations. This study found that external business environment influences (i.e. geopolitical and socio-cultural) such as tribalism, religion, and corruption, among other factors, affect stakeholders' commitment to their firms.

\section{Coordination and Control}

The relationship between coordination and strategy formulation is inconclusive. It is a question of balancing the potential merits and demerits of the decentralisation and centralisation systems that firms operate. For example, some authors support the centralisation system, as they believe it makes coordination activities easier. Other authors disagree because it might result in slow response to change, which has negative effects on individual performance. In a similar manner, some scholars believe that the decentralisation system influences employees' commitment to the organisation and improves their performance, while others are against it because of problems concerning linking of responsibility. Previous studies have found that coordination and control can be facilitated by organisational structure or/and firm size, with larger firms having a highly decentralised strategy formulation processes.

However, this thesis discovered that in developing countries like Nigeria, external environmental factors have serious effects on the organisational coordination and control of both decentralisation and centralisation systems. Most stakeholders are subject to geopolitical and socio-cultural influences, such as social alienation, 
corruption, as well as ethnic and tribal sentiments, all of which undermine organisational performance not only in the manufacturing sector but more broadly.

\section{Environmental Factors}

The external environment includes such attributes as shifts in technology, emergence of new competitors, substantial changes in supply and demand markets, as well as economics and institutional control by the government. In the course of this study most of these attributes were found to have impacted on the internal environment within which firms in the Nigerian manufacturing operate. To varying degrees across the 32 firms, there were mentions of challenges ranging from lack of accountability, to unpaid salaries, staff retrenchment/ redundancies and firm closures. This mismatch between the internal and external environment were bound to contribute to the poor performance of the sector as a whole.

To extend the theoretical impact of this study, the 3Cs framework of Jha and Iyer (2007) was appropriated and mapped against Ulrich's (1998) study on 'Intellectual Capital $=$ Competence $\mathrm{x}$ Commitment' in order to inform the discourse on the strategy and CE performance of the manufacturing sector in Nigeria.

\subsection{Limitations of the Research and Future Research Directions}

Despite the insights unravelled in this study, there are certain limitations that could form the basis for follow-on studies into the performance of the Nigerian manufacturing sector.

First, and foremost, the research objectives could be broadened to provide new insights into the relationship of $\mathrm{CE}$, strategy formulation, and organisational performance. It is important to know that the study area should develop a new approach for discovering whether $\mathrm{CE}$ and strategy formulation are relevant and significant to organisational performance.

Second, it is arguable that in order to upgrade or build a successful organisational strategy to fit the challenging environment, further research could explore the theoretical development on behavioural $\mathrm{CE}$ and the $3 \mathrm{Cs}$ framework undertaken in the current study. This would require inquiry into the utility of the concepts associated with the model or 
phenomenon before there could be profound advocacy for new research models or phenomena.

Third, the CE and strategy formulation requirements vary from one region to another because of geopolitical and social-cultural differences, so the argument concerning the generalisation of the study cannot the extended beyond manufacturing firms in the selected four regions in Nigeria. Therefore, further analysis of CE, strategy formulation, and organisational performance in the different six geopolitical zones, using a variety of languages, is needed for the argument to be generalised.

Fourth, the research was conducted only on manufacturing firms, which means that insights from the service sectors as well as the Oil \& Gas sectors may have been missed in the study. This calls for future research into some form of comparative analysis. It is possible that strategy of the manufacturing firms will be the same internalised and interpreted with oil or service sectors and especially the banking sector.

Fifth, the degree of generalisation need to be treated with caution, as only firms in the manufacturing sector were sampled. It can be argued that enterprises in other sectors face similar external environmental constraints but may well respond differently by making reasonable adjustments to their $3 \mathrm{Cs}$. Perhaps the ability to do this may well be sector specific.

Sixth, restricting the interviews to only a few respondents within the investigated firms may serve to exclude the views of other employees as to how their organisations have been managing the interactions of their internal 3Cs with the turbulent environment within which they operate. Furthermore, the evidence in this study was based on the model of entrepreneur and employee performance without considering the employee ownership performance. Employee ownership concerns major shareholders or owners as well as employees. It might be more productive, profitable, and committed than others. As such, this study believes that in order to arrive at a more critical perspective, further research on employee ownership is necessary. A similar concern could be raised in terms of business location influences, which could suffer from an error of judgment. For example, two firms with all factors of similar, may have different levels of performance due to their location. 
Looking back at the literature, it is worth recalling that Collier (2000) argued that the transaction costs faced by African manufacturers are atypically high because manufacturing firms are intensive users of services that are particularly expensive in Africa. The same argument goes for the location issues e.g. same organisational form based in the Southeast vis-à-vis North Central.

\subsection{Recommendations}

The Nigerian manufacturing sector faces complex environmental challenges, which may be further complicated by weak responses from internal strategy formulation and/or implementation by firms and especially those in the manufacturing sector. The major causes of these environmental problems are the government's inconsistent and dislocation policies. The turbulence in Nigeria's business environment is associated with shareholders' incompetence and lack of commitment, which results in badly coordinated systems, the failure of $\mathrm{CE}$, and makes it difficult to formulate and implement successful strategies.

Entrepreneurs and company owners should first discover whether they can still function despite the dynamic business environment. To deliver on environmental objectives, invest in long-term solutions, and have business confidence, these environmental problems (geopolitical and social-cultural) must be resolved. Businesses should build continuity into their organisation in order to operate successfully amid the environmental crisis. For example, there should be continual updates of training exercises and workshops for both casual and permanent staff for company sustainability.

In order for firms to meet their objectives, certain measures need to be in place to serve as checks and balances throughout the operating period. Such measures, if properly managed, would ensure effective the "coordination" on the part of the management and increased levels of "commitment and competence" of employees, thereby enhancing firm performance.

In all these, however, the business environment needs to be enabling, as there is nothing organisations can achieve without government support, no matter how competent, committed, entrepreneurial and strategic organisations might be. Appropriate regulations and legislation should be in place to protect these organisations from an 
unsettled external environment that would enable the internal processes of these firms to respond positively. For example, the fight against corrupt practices should be intensified in all sectors of the economy and restrictive practices that stifle access to resources eased. The government should also provide adequate security, and necessary infrastructural facilities, such as good roads and uninterrupted electricity, which most of these firms are reliant upon. Firms, on their part, should engage in productive relationships with suppliers that allow extended credit time periods and customers who allow short payment periods. 


\section{REFERENCES}

Aaron, J. 2000. Growth and institutions: A review of the evidence. The World Bank Research Observer, 15(1), 99-135

Abrams, R., 2012. Entrepreneurship: A real world approach. Hands-on guide for today's entrepreneur. California: Planning Shop.

Adegbite, E., 2012. Corporate governance regulation in Nigeria. Corporate Governance: The International Journal of Business in Society, 12(2), 257-276.

Adegbite, E., Amaeshi, K. and Amao, O., 2012. The politics of shareholder activism in Nigeria. Journal of Business Ethics, 105(3), 389-402.

Adeoye, S., 2005. The cultural and political set-up of the Nigerian economy. The Economist, p.23.

Adler, P.A. and Adler, P., 2011. The tender cut: Inside the hidden world of self-injury. New York: New York University Press.

Adler, R.W., 2011. Performance management and organisational strategy: How to design systems that meet the needs of confrontation strategy firms. The British Accounting Review, 43(4), 251-263.

Agarwal, R., Echambadi, R., Franco, A.M. and Sarkar, M.B., 2004. Knowledge transfer through inheritance: Spinout generation, development, and survival. Academy of Management Journal, 47(4), 501-522.

Ahmad, N.H., Halim, H.A. and Zainal, S.R.M., 2010. Is entrepreneurial competency the silver bullet for SME success in a developing nation? International Business Management, 4(2), 67-75.

Ahmad, N.H., Ramayah, T., Wilson, C. and Kummerow, L., 2010. Is entrepreneurial competency and business success relationship contingent upon business environment? A study of Malaysian SMEs. International Journal of Entrepreneurial Behaviour \& Research, 16(3), 182-203.

Ahmad, N. and Oranye, N.O., 2010. Empowerment, job satisfaction and organisational commitment: A comparative analysis of nurses working in Malaysia and England'. Journal of Nursing Management, 18(5), 582-591. 
Aidt, T., Dutta, J. and Sena, V., 2008. Governance regimes, corruption and growth: Theory and evidence. Journal of comparative Economics, 3(6), 195-220.

Akinbami Catherine Abiola O. \& Joshua O. Aransiola (2015): Qualitative exploration of cultural practices inhibiting rural women entrepreneurship development in selected communities in Nigeria, Journal of Small Business \& Entrepreneurship, DOI: $10.1080 / 08276331.2015 .1102476$

Alatrista, J. and Arrowsmith, J., 2004. Managing employee commitment in the not-for profit sector. Personnel Review, 33(5/6), 536-548.

Allen, N.J. and Meyer, J.P., 1990. The measurement and antecedents of affective, continuance and normative commitment to the organisation. Journal of Occupational Psychology, 6(3), 1-18.

Allen, R. and Snyder, D., 2009. New thinking on the financial crisis. Critical Perspectives on International Business, 5(1/2), 36-55.

Alvesson, M., Bridgman, T. and Willmott, H., 2009. Critical management studies. Oxford University.

Aminu, A.A., 2011. Entrepreneurship-Theory and practice. Maiduguri: IPTTOUniversity of Maiduguri, Nigeria.

Anderson, S.J., 2011. Marketing of menthol cigarettes and consumer perceptions: a review of tobacco industry document. Tobacco Control, 20(2), 37-43.

Andrews, R., Boyne, G.A., Law, J. and Walker, R.M., 2009. Strategy formulation, strategy content and performance: An empirical analysis. Public Management Review, 11(1), 1-22.

Antoncic, B. and Hisrich, R.D., 2003. Clarifying the intrapreneurship concept. Journal of Small Business and Enterprise Development, 10(1), 2-24.

Aragon-Sanchez, A. and Sanchez-Martin, G., 2005. Strategic orientation, management characteristics and performance: a study of Spanish SMEs. Journal of Small Business Management, 43(3), 287-308.

Awolowo, O., 1947. Path to Nigerian freedom. London: Faber and Faber.

Babbie, E.R., 2010. The practice of social research. Cengage Learning.

Baker, S. and Novack, S., 2014. Capturing the lost dollar: Finding solutions for uncompensated care. National Journal TransUnion, 16(2), 55-70. 
Barnes, D.E., Hanauer, P., Slade, J., Bero, L.A. and Glantz, S.A., 1995. Environmental tobacco smoke. The Brown and Williamson documents. JAMA, 274(3), 248-253.

Barney, J. and Hesterly, W., 2012. Strategic management and competitive advantage: Concepts and cases. 4th ed. New Jersey: Pearson.

Baron, R.A., Franklin, R.J. and Hmieleski, K.M., 2013. Why entrepreneurs often experience low, not high, levels of stress: The joint effects of selection and psychological capital. Journal of Management, 52(6), 199-214

Bartunek, M.J., 2007. Insider and outsider team research: The development of the approach and its meanings. SAGE. Publications: London 19960803971591

Baskarada, S., 2014. Qualitative case studies guidelines. The Qualitative Report, 19(40), $1-25$.

Beer, M., 2009. High commitment high performance: How to build a resilient organisation for sustained advantage. Palgrave Macmillan. ISBN: 978-0-78797228-8

Bell, J., 2005. Doing your research project: A guide for first-time researchers in educations, health and social science. 4th ed. Buckingham: Open University Press.

Bello, I., 2005. Nigerian textile industries. Vanguard Nov 24, p. 25

Benner, J.M. and Tripsas, M., 2012. The influence of prior industry affiliation on framing in nascent industries: The evolution of digital cameras. Strategic Management Entrepreneurship, 33(3), 277-302.

Berg, B.L., 2009. Qualitative research methods for the social sciences. 7th ed. Boston, MA: Education Inc.

Bertaux, D., 1981. From the life-history approach to the transformation of sociological practice. In D. Bertaux, ed., 1970 Biography and society: The life history approach in the social sciences. London: Sage.

Bhardwaj, B.R. and Sushil, M.K., 2012. Internal environment for corporate entrepreneurship. Journal of Chinese Entrepreneurship, 4(1), 70-87. 
Bingham, B.C. and Eisenhardt, M.K., 2011. Rational heuristics: The 'simple rules' that strategists learn from process experience. Strategic Management Journal, 32(13), 1437-1464.

Biniari, M.G., 2012. The emotional embeddedness of corporate entrepreneurship: The case of envy. Entrepreneurship Theory and Practice, 36(1), 141-170.

Birkinshaw, J., 2010. The critical need to reinvent management. Business Strategy Review London Business School, 21(1), 9-31.

Bishop, J.W. and Scott, K.D., 2000. An examination of organisational and team commitment in a self-directed team environment. Journal of Applied Psychology, $8(5), 439-450$.

Blaha, S. and Roppe, D., 2009. The five leadership competencies: Secrets to successful leadership succession $1^{\text {st }}$ Edition. Performance Consulting.

Blackman, A.J., 2003. Entrepreneurs: Interrelationships between their characteristics, values, expectations, management practices and SME performance. School of Business Department of Management Griffith University, Gold Coast Campus. (Submitted in fulfillment of the requirements of the degree of Doctor of Philosophy).

Blahova, M. and Knapkova, A., 2011. Effective strategic action: From formulation to implementation. International Conference on Economics, Business and Management IACS IT Press, Manila. IPEDR.

Boddy, D., 2005. Management: An introduction. 3rd edition. Financial Times/ Prentice Hall. ISBN-10: 027369586X

Boeh, K.K. and Beamish, W.P., 2011. Connecting flights: The time sink that kills profits. Business travel. Harvard Business Review, www.hbr.org

Boer, R., 2010. Flexible organisations: By coordination and control or structure? Capgemini, 16(7), 22-80.

Bosch, F. and Cook, K., 2015. Strength training and coordination: An integrative approach. $1^{\text {st }}$ edition. Uitgevers.

Bosma, N., Schutjens, V. and Stam, E., 2009. Determinants of early-stage entrepreneurial activity in European regions; distinguishing low and high 
ambition entrepreneurship. Making the difference in local, regional and national economies: Frontiers in European entrepreneurship research.

Botsaris, C. and Vamvaka, V., 2016. Attitude toward entrepreneurship: Structure, prediction from behavioral beliefs, and relation to entrepreneurial intention. Journal of the Knowledge Economy, 7(2), 433-460.

Boulay, A.D., 2007. Linking competence change and organisation performance. Ohio State University. USA

Bowen, G.A., 2008. Naturalistic inquiry and the saturation concept: A research note. Qualitative Research, 8(1), 137-152.

Bower, J.L. and Gilbert, C.G., 2007. How managers' everyday decisions create-or destroy-your company's strategy. Harvard Business Review, 85(2), 72-79.

Bradford, J.W., 2007. Competency models and performance management-Getting it right. Altamira Press.

Brenner, B., 2009. The value of increase investment in employee benefits during an economic downturn, Journal of Financial Service Professionals, 63(1), 29-31.

Brown, S., McNabb, R. and Taylor, K., 2007. Firm performance, worker commitment and loyalty. Working Paper. Department of Economics, University of Sheffield.

Bruce, C., 2007. Questions arising about emergency, data collection, and its interaction with analysis in a grounded theory study. International Journal of Qualitative Methods, 6(1), 51-68.

Brush, T., Glazewski, K.D. and Hew, K.F., 2008. Development of an instrument to measure preservice teachers' technology skills, technology beliefs, and technology barriers. Computers in the Schools, 25(1/2), 112-125.

Bryman, A., 2012. Social research methods. Oxford University Press.

Burdett, C., 2010. A practical guide to strategic planning. Anoova.

Bywater, J., 2007. Future-oriented competencies: A framework for job profilers and competency modellers. IRS Employment Review, 879(20)

Cable, V., 2010. The storm: The world economic crisis and what it means. London: Atlantic Books.

Campbell, B.A., Ganco, M., Franco, A. and Agarwal, R., 2012. Who leaves, to go where, and does it matter: Employee mobility, employee entrepreneurship and 
the effects on parent firm performance. Strategic Management Journal, 33(16), 65-87.

Capon, C., 2009. Understanding the business environment. 3rd ed. Trans-Atlantic Publications Ins.

Casadesus-Masanell, R. and Ricart, J.E., 2011. How to design a winning business model. Harvard Business Review, 89, 100-107.

Casadevall, A. and Fang, F.C., 2008. Descriptive science. Infect. Immun, 76, 1543-1553.

Cassell, C. and Symon, G., 2004. Essential guide to qualitative methods in organisational research. Sage.

Castaneda, C., 2005. A practical guide to strategy formulation: A comprehensive resource for the strategic planning team. Anoova.

CBN, 2016. The world economy data: The global conference for Wikimedia and The Economist

CBN, 2010. (Quarterly) Economic report executive summary

CBN, 2002. Nigeria gross domestic products (GDP) economist intelligence unit

Chandler, G.N. and Hanks, S.H., 1994a. Founder competence, the environment, and venture performance. Entrepreneurship Theory and Practice, 18(3), 77-89.

Chandler, G.N. and Hanks, S.H., 1994b. Market attractiveness, resource-based capabilities, venture strategies, and venture performance. Journal of Business Venturing, 9(4), 331-349.

Charmaz, K., 2006. Constructing grounded theory: A practical guide through qualitative analysis. Thousand Oaks: Sage.

Chatterji, A., 2009. Spawned with a silver spoon? Entrepreneurial performance and innovation in the medical device industry. Strategic Management Journal, 30(24), 185-206.

Chen, X. P., Yao, X. and Kotha, S., 2009. Entrepreneur passion and preparedness in business plan presentations: A persuasion analysis of venture capitalists' funding decisions. Academy of Management Journal, 52(1), 199-214.

Chen, E., Katila, R., McDonald, R. and Eisenhardt, K., 2010. Life in the fast lane: Origins of competitive interaction in new vs. established markets. Strategic Management Journal, 31, 1527-1547. 
Cheng, Y. and Stockdale, M.S., 2003. The validity of the three-component model of organisational commitment in a Chinese context. Journal of Vocational Behavior, 62, 465-489.

Chia, R., 2004. Strategy-as-practice: Reflections on the research agenda. European Management Review, 1, 29-34.

Chinonye, L.E., 2013. Entrepreneurship: A conceptual approach. 2nd ed. Lagos: Pumark Nigeria Ltd.

Clardy, A., 2008. The strategic role of human resource development in managing core competencies. Human Resource Development International, 11(2), 183-197.

Clark, A., 2012. ASDA CEO: Reveals online sales increase by $19 \%$ over fourth quarter.

Clarke, V. 2010. Review of the book "Interpretative Phenomenological Analysis: Theory, Method and Research". Psychology Learning \& Teaching, 9(1). 57-56.

Clausewitz, V.C., 2006. Strategy: From formulation to implementation. Anoova.

Cloke, K., 2002. The end of management. Berkeley: University of California Press.

Cobbold, I. and Lawrie, G., 2006. Why less than one third of UK firms achieve strategic success? 2GC Ltd.

Cohen, L. and Manion, L., 1994. Surveys in research methods in education. 4th ed. London: Routledge.

Cohen, L., Manion, L., Morrison, K. and Morrison, R.B., 2007. Research methods in education. Routledge.

Cole, A.G., 2004. Management theory and practice. 6th ed. South-Western.

Coleman, S., 1996. Obstacles and opportunities in access to professional work organisations for long-term fieldwork: The case for Japanese laboratories. Human Organisation, 55, 334-343.

Collier, P., 2006. Economic causes of civil conflict and their implications for policy. New York: Oxford University Press.

Collis, J.D. and Montgomery, A.C., 2008. Competing on resources. Harvard Business Review, 140-150.

Cooper-Hamik, A. and Viswesvaran, C., 2005. The construct of work commitment: Testing an integrative framework. Psychological Bulletin, 131, 241-259. 
Cook, W.C. and Hunsaker, L.P., 2003. Management and organisational behaviour. New York McGraw-Hill.

Corbin, J. and Strauss, A., 2008. Basics of qualitative research: Techniques and procedures for developing grounded theory. London: Sage Publications.

Corporate Nigeria Guide, 2010. Africa Population, IMF Dataset

Coulter, M., 2008. Strategic management in action. 4th ed. Pearson Education International. London

Cox, C., 2006. Strategic planning for dummies. Straightforward guide to business strategy. John Wiley and Sons, Inc. London

Cravens, W.D., Piercy, F.N., Shipp, H.S. and Neeley, J.M., 2008. New organisational forms for competing in highly dynamic environments: The network paradigm. John Wiley and Sons, Inc. London

Creswell, J.W., 2013. Research design: Qualitative, quantitative, and mixed methods approaches. Sage Publications. London

Creswell, J.W., 2007. Qualitative inquiry and research design: Choosing among five approaches. Thousand Oaks: Sage.

Crouch, M. and McKenzie, H., 2006. The logic of small samples in interview based qualitative research. Social Science Information, 45(4), 483-499.

Csaszar, F.A. and Levinthal, D.A., 2016. Mental representation and the discovery of new strategies. Strategic Management Journal, 37, 2021-2049.

Csepeti, A., 2010. Research issues of Miles and Snow strategic typology. Budapest Management Review, 41(11), 15-30.

Daft, R.L., 2005. Strategy formulation and implementation management. 6th ed. AMA.

Daft, R.L., 2002. Organisation theory and design. 5th ed. St Paul: West Publishing Company.

Dalton, M., 1959. Men who manage. New York: Wiley.

Darya, P.G., 2014. Effect of entrepreneurship characteristic, government commitment and business competence on performance of small micro enterprise in Balikpapan. Journal of Business and Management, 16(4), 12-20. 
Dauda, Y., Akingbade, W. and Akinlabi, H., 2010. Strategic management and corporate performance of selected small business enterprises in Lagos metropolis. International Journal of Business Management, 5(11), 97-105.

Davenport, T., 2007. Strategy execution: Avoid the extremes. Harvard Business Review, [e-journal].

David, B., 2007. A core source of competitive advantage: Linking competence change and organisation performance. Ohio

David, F.R., 2013. Strategic management: Concepts and cases: A competitive advantage approach. 14th ed. Boston: Pearson.

Decker, S., 2010. Postcolonial transitions in Africa: Decolonisation in West African and present-day South Africa. Journal of Management Studies, 47(5), 791-813.

Dell, M., 2014. Dell's manufacturing processes: Business Voice

Deng, L. and Gibson, P., 2008. A qualitative evaluation on the role of cultural intelligence in cross - cultural leadership effectiveness. International Journal of Leadership Studies, 3(2), 181-197.

Denzin, N.K. and Lincoln, Y., 2003. Collecting and interpreting qualitative materials. 2nd ed. London: Sage.

Denzin, N.K. and Lincoln, Y.S., 2008. The landscape of qualitative research theories and issues. In: N.K. Denzin and Y.S. Lincoln, eds. The Sage handbook of qualitative research. 2005 London: Sage. pp.1-32.

Denzin, N.K. and Lincoln, Y.S., 2011. Handbook of qualitative research. Thousand Oaks: Sage Publications.

Dess, G.G., Ireland, D.R., Zahra, A.S., Floyd, W.S., Janney, J.J. and Lane, J.P., 2003. Emerging issues in corporate entrepreneurship. Journal of Management, 29(3), 351-378.

Dhar, V. and Sundararajan, A., 2009. Plugging in to transformation. Financial Times, [online] 5 February. Available at: $<$ http://www.ft.com/reports/managingdownturn>

Dhliwayo, S., Van Vuuren, J.J. and Fletcher, L., 2011. The practice of strategic planning and corporate entrepreneurship in South African public firms. Southern Journal of Entrepreneurship, 4(2), 46-47. 
Dillman, D.A., 2000. 'Mail and internet surveys': The tailored design method. 2nd ed. New York: Wiley.

Dimov, D., 2010. Nascent entrepreneurs and venture emergence: Opportunity confidence, human capital, and early planning. Journal of Management Studies, 47(6), 1123-1153.

Doty, D.H., Glick, W.H., Huber, G., 1993. Fit, equifinality, and organisational effectiveness: A test of two configurational theories. Academy of Management Journal, 36(6), 1196-1250.

DuBrin, A.J., 2012. Leadership: Research findings, practice, and skills. Mason, OH: Cengage South-Western.

Dugguh, S.I., 2013. Innovation and business success in Nigeria: From intuition to process management. International Journal of Economics, Commerce and Management, 1(1), 1-8.

Dugguh, S.I., 2013. Entrepreneurship and small business: Strategic approach to alleviating poverty and corruption in Nigeria. GSTF Business Review, 3(1), 5766.

Dutta, N. and Sobel, R., 2016. Does corruption ever help entrepreneurship? Small Business Economics, 47(1), pp.179-199.

Easterby-Smith, M., Thorpe, R. and Jackson, P.R., 2008. Management research. 3rd ed. Sage Publication. London

Economic Affairs, 2012. Africa left behind. Economic affairs, Special Issue 26(4), 2343.

Economic Affairs, 2007. Enterprise solutions to poverty in Africa. Economic Affairs, Special Issue, 27(2), 36-53.

Economic and Financial Crime Commission EFCC, 2009. global corruption perceptions, Country Report index

Ekpo, U. N. (2016). Determinants of private investment in Nigeria: An empirical exploration. Journal of Economics and Sustainable Development, 7(11), 80-92.

Eriksson, P. and Kovalainen, A., 2008. Qualitative methods in business research. SAGE. London 
Erondu, E. and Sharland, A., 2002. Managerial competence in Nigerian firms, an empirical and comparative analysis. Multinational Business Review, 10(2), 129137.

Farnham, D., 2015. Human resource management in context: Strategy, insights and solutions. 4th ed. CIPD - Kogan. London.

Fayolle, A. and Gailly, B., 2015. The impact of entrepreneurship attitudes and intention: Hysteresis and persistence. Journal of Small Business Management, 53(1), 7593.

Federal Ministry of Finance, 2004. Manufacturing sectors and economy. The Observer, 11 November, p. 13

Feldman, M.S. and Pentland, B.T., 2003. Reconceptualizing organisational routines as a source of flexibility and change. Administrative Science Quarterly, 48(1), 94118.

Fafchamps, M. (2001). Networks, communities and markets in Sub-Saharan Africa: Implications for firm growth and investment. Journal of African Economies, 10(suppl_2), 109-142.

Frambach, J., van der Vleuten, C. and Durning, S., 2013. Quality criteria in qualitative and quantitative research. Academic Medicine, 88(4), p.552.

Francis, J.J., Johnston, M., Robertson, C., Glidewell, L., Entwistle, V., Eccles, M.P. and Grimshaw, J.M., 2010. What is an adequate sample size? Operationalizing data saturation for theory-based interview studies. Psychology and Health, 25, 12291245.

Frank, R.H., 2007. Cooperation through emotional commitment, Wiley online library

Frey, C. and Callahan, R., 2008. Innovation strategies for the global recession, online at: http://www.innovationtools.com/Reports

Frey, H.J. and Fontana, 1991. The group interview in social research. The Social Science Journal, 28(2), 175-187.

Gagne, M. and Deci, E.L., 2005. Self-determination theory and work motivation. Journal of Organisational Behavior, 26, 331-362.

Gavetti, G. and Rivkin, J.W., 2005. Strategy making in novel and complex worlds: The power of analogy. Strategic Management Journal, 26, p.8. 
Gavetti, G. and Rivkin, J.W., 2007. On the origin of strategy: action and cognition over time. Organisation Science, 18(3), 420-439.

Garvin, A.D. and Levesque, C.L., 2008. The multiunit enterprise. Harvard Business Review pp. 106-117 www.ca.com/success

Gate, B., 2007. Innovation management policies for large corporations. Cheltenham Edward Elgar.

Gavetti, G. and Rivkin, W.J., 2008. Seek strategy the right way at the right time. Harvard Business Review, 86(1), 22-23.

Gbadamosi, A., 2009. Low-income consumers' reactions to low-involvement products. Marketing Intelligence \& Planning, 27(7), 882-899.

George, G., Kotha, R., Parikn, P., Alnuaimi, T. and Bahaj, A.S., 2016. Social structure, reasonable gain, and entrepreneurship in Africa. Strategic Management Journal, 37(6), 1118-1131.

Gibson, W. and Brown, A., 2009. Working with qualitative data. London: Sage Publications.

Gill, M.J., 2014. The possibilities of phenomenology for organisational research. Organisational Research Methods, 17(2), 118-137.

Gill, P., Stewart, K., Treasure, E. and Chadwick, B., 2008. Methods of data collection in qualitative research: Interviews and focus groups. British Dental Journal, 204(6), 88-94.

Gillett, A., Loader, K., Doherty, B. and Scott, J.M., 2016. A multi-organisational crosssectoral collaboration: empirical evidence from an 'Empty Homes' project. Public Money and Management, 36(1), 15-22.

Given, L.M., 2008. The Sage encyclopedia of qualitative research methods. Los Angeles: Sage Publications.

Glynn, M., 1993. Strategic planning in Nigeria versus the US: A case of anticipating the (next) coup. Academy of Management Executive, 7(3), 82-83.

Gorman, E.G. and Clayton, P., 2005. Qualitative research for the information professional. A practical handbook. 2nd ed. London: Facet Publications. 
Gomez-Mejia, L.R., David, B.B. and Robert, L.C., 2008. Management: People, performance, and change. 3rd ed. McGraw-Hill Irwin, 773 pages, 2008, English, Book; Illustrated, 6 ... Pearson new international edition. New York.

Goulet L.R. and Singh, P., 2002. Career commitment: A reexamination and an extension. Journal of Vocational Behavior, 61(1), 73-91.

Grant, R.B., 2002. Contemporary strategy analysis. 4th ed. Blackwell: Oxford.

Grant, R.M., 2003. Strategic planning in a turbulent environment: Evidence from the oil majors. Strategic Management Journal, 24(6), 491-517.

Gratton, L., 2004. The democratic enterprise. Financial Times Prentice Hall. Harlow

Gratton, L., 2009. 'The time is ripe for fresh ideas': Managing in a downturn series. Financial Times, [online] Available at: http://www.ft.com/reports/managingdownturn

Green, J. and Thorogood, N., 2009. Qualitative methods for health research. 2nd edition. Thousand Oaks: Sage.

Gibbs, G., 2002. Qualitative data analysis: Explorations with Nvivo. Open University Press. Buckingham.

Griffin, W.R. and Moorhead, G., 2007. Organisational behavior: Managing people and organisations. $9^{\text {th }}$ edition. Cengage Learning. USA

Guest, G., Bunce, A. and Johnson, L., 2006. How many interviews are enough? An experiment with data Saturation and variability. Field Methods, 18(1), 59-82.

Gummesson, E., 2002. Qualitative methods in management research. 2nd edition. Sage. London.

Gunduz, M. and Yahya, A.M.A., 2015. Analysis of project success factors in construction industry. Journal of Technology and Economic Development of Economy. 64 (October), 55-62

Hambrick, C.D. and Fredrickson, W.J., 2010. Are you sure you have a strategy? Academy of Management Executive, 13(4), 51-62.

Hamel, G., 2011. Management is the least efficient activity in your organisation. Harvard Business Review (5), 50-60.

Hammersley, M., 2007. The issue of quality in qualitative research. International Journal of Research and Method in Education, 30(3), 287-305. 
Hana, U., 2013. Competitive advantage achievement through innovation and knowledge. Journal of Competitiveness, 5(1), 82-96.

Harding, J., 2013. Qualitative data analysis from start to finish. London: Sage Publishers.

Hartman, N., 2009. 'Sure ways to tackle uncertainty in tough times': Managing in a downturn series. Financial Times, [online] Available at: $<$ http://www.ft.com/reports/managingdownturn>

Helversen, V.B., Karlsson, L., Rasch, B. and Rieskamp, J., 2014. Neural substrates of similarity and rule-based strategies in judgment. Frontiers in Human Neuroscience, 8(809), 147-158.

Henning, E., Van Rensburg, W. and Smit, B., 2004. Finding your way in qualitative research. Van Schaik. Pretoria.

Hertzberg, F., 2003. One more time: How do you motivate employees? Harvard Business Review on motivating people. Boston: Harvard Business School Press.

Hiles A., 2007. The definitive handbook of business continuity management. 2nd ed. John Wiley \& Sons. Chichester, England.

Hisrich, R.D., 2011. Entrepreneurship. McGraw-Hill Education. New York

Holloway, I., 2005. Qualitative research in health care. London: McGraw-Hill Education.

Holmes, W.O., 2006. Profiting from knowledge: Planning, decision-making and implementation tools. Wiley: New York.

Hoskisson, R.E., Eden, L., Lau, C.M. and Wright, M., 2000. Strategy in emerging economies.. Academy of Management Journal, 43(3), 249-267.

Howell, K.E., 2013. Introduction to the philosophy of methodology. London: Sage Publications.

Hrebiniak, G.L., 2005. Making strategy work: Leading effective execution and change. Wharton School Publishing. Upper Saddle River Huselid MA, Becker BE

Huang, L. and Knight, A., 2015. Resources and relationships in entrepreneurship: An exchange theory of the development and effects of the entrepreneur-investor relationship. Academy of Management Review, 2(4), 79-91. 
Hu, H. and Hafsi, T., 2010. Strategic change in a shifting institutional context. Journal of Change Management, 10(3), 293-313.

Hughes, W.S., Tippett, D.D. and Thomas, K.W., 2004. Measuring project success in the construction industry. Engineering Management Journal, 16(3), 31-37.

Human Resources Magazine, 2013. Line managers. HRM, p.17.

IBM, 2014. Capitalizing on complexity: Insights from the Global Chief Executive Office Study.

Igwe, P. A., Madichie, N. O., \& Newbery, R. 2019. Determinants of livelihood choices and artisanal entrepreneurship in Nigeria. International Journal of Entrepreneurial Behavior \& Research, 25(4), 674-697.

Igwe, P.A., Newbery, R., Amoncar, N., White, G.R. and Madichie, N. 2019. Keeping it in the family: Exploring Igbo ethnic entrepreneurial behaviour in Nigeria. International Journal of Entrepreneurial Behavior \& Research, DOI: https://doi.org/10.1108/IJEBR-12-2017-0492

Iles, P., Chuai, X. and Preece, D.A., 2010. Talent Management and HRM in multinational firms in Beijing: Definitions, differences and drivers. Journal of World Business, 46(2), 58-63.

Imas, L.G. and Rist R.C., 2009. The road to results: Designing and conducting effective development evaluations. World Bank Publications. Washington, DC: World Bank. http://documents.worldbank.org/

IMF, 2014. 'Africa Economy', The world fact book 2011. Cameroun

Incomes Data Services, 2008. Competency frameworks. HR studies, 865. London: IDS.

Ingram, T., Krasnicka, T., Wronka-Pospiech, M., Gtod, G. and Gtod, W., 2016. Relationships between Miles and Snow strategic types and organisational performance in Polish production firms. Journal of Management and Business Administration. Central Europe, 24(1), 17-45.

Ioannou, I., 2010. The impact of different types of spinoffs on firm survival: Evidence from the US automobile industry 1890-1986. London Business School Working Paper. 
Ip, G.W., Chiu, C. and Wan, C., 2006. Birds of a feather and birds flocking together: Physical versus behavioral cues may lead to trait-versus goal-based group perception. Journal of Personality and Social Psychology, 90(3), 368-381.

Ireland, R.D., Kuratko, D.F. and Morris, M.H., 2006. A health audit for corporate entrepreneurship: Innovation at all levels. Journal of Business Strategy, 27(1), 10-17.

Ivancevich, J.M., Konopaske, R. and Matteson, M.T., 2006. Organisational behaviour and management. 5th edition. New York: McGraw-Hill International.

Ivancevich, J.M., 2003. Human resource management. 9th edition. McGraw-Hill College. New York.

Ivancevich, J.M. and Matteson, M.T., 2006. Organisational behaviour and management. 5th edition. New York: McGraw-Hill International.

Jan-Benedict, E., Steenkamp, M. and Dekimpe, M., 2009. Marketing strategies for fastmoving consumer goods. Managing in a downturn series. Financial Times, [online] Available at: <www.ft.com/reports/managingdownturn $>$

Jaros, S.J., 2007. Measurement issues in the Meyer and Allen (1984) model of organisational commitment. Paper presented at the annual meeting of the Academy of Management, Philadelphia.

Jeris, L., Isopahkala, U., Winterton, J. and Anthony, K., 2005. The competence debate: An international dialogue on a 'fuzzy' concept. In: Proceedings of the annual conference of the Academy of Human Resource Development -- 2005. Este Parks, Co.: Academy of Human Resource Development.

Jha, K.N. and Iyer, K.C., 2007. Project management: Commitment, competence, coordination and the iron triangle. International Journal of Project Management, 25(5), 527-540.

Johl, K.S. and Renganathan, S., 2010. Strategies for gaining access in doing fieldwork: Reflection of two researchers. The Electronic Journal of Business Research Methods, 8(1), 42-50.

Johnson, G. and Scholes, K., 2002. Exploring corporate strategy. 6th ed. Harlow: Financial Times/Prentice Hall. 
Johnson, R.E. and Yang, C.H., 2010. Commitment and motivation at work: The relevance of employee identity and regulatory focus. Academic of Management Review, 35(2), 233-350.

Johnson, G., Scholes, K. and Whittington, R., 2006. Exploring corporate strategy. FT: Prentice Hall. New Jersey.

Johnson, G., Scholes, K. and Whittington, R., 2009. Fundamentals of strategy. Prentice Hall. New Jersey.

Jung-Wan, L. and Tai, S.W., 2010. Management and sustainable development. World Journal of Entrepreneurship, 6(2), pp.61-75.

Kabanoff, B. and Brown, S., 2008. Knowledge structures of prospectors, analyzers, and defenders: Content, structure, stability, and performance. Strategic Management Journal, 29(2), pp.149-171.

Kannadhasan, M. and Nandagopal, R., 2010. The influence of business strategy on the performance of automotive industry in India. Smart Journal of Business Management Studies, 6(1), pp.42-49.

Kaplan, R.S. and Norton, D.P., 2006. Transforming the balanced scorecard from performance measurement to strategic management: Part 1. Accounting Horizons, 15(1), pp.87-104.

Kennerley, M. and Neely, A., 2002. A framework of the factors affecting the evolution of performance measurement systems. International Journal of Operations and Production Management, 22(3), pp.1222-1245.

Kerzner, H., 2009. Project management: A systems approach to planning, scheduling and controlling. 10th edition. New Jersey: John Wiley \& Sons, Inc.

Kessler, A. and Frank, H., 2009. Nascent entrepreneurship in a longitudinal perspective. The impact of person, environment, resources and the founding process on the decision to start business activities. International Small Business Journal, 27(6), pp.720-742.

Kent, J.L., 2010. Psychedelic information theory: Shamanism in the age of reason, Chapter 04, 'Limits of Human Perception'. PIT Press 
Khaire. M. and Wadhwani, R., 2010. Changing landscapes: The construction of meaning and value in a new market - Modern Indian art. Academy of Management Journal, 53(6), pp.1281-1304.

Khanna, T. and Palepu, K.G., 2010. Winning in emerging markets: A roadmap for strategy and execution. Boston: Harvard Business Press.

Klepper, S., 2001. Employee startups in high-tech industries and corporate change. Oxford University Press, 10(10), pp.639-654.

Klepper, S. and Thompson, P., 2010. Disagreements and intra-industry spinoffs, International Journal of Industrial Organisation, 28(5), pp.526-538.

Koch, R., 2006. Guide to strategy: How to create and deliver a winning strategy. 3rd edition. FT Prentice Hall. New Jersey

Kotelnikov, V., 2008. Flat Organisational Structure: Empowering People and Making Faster Decisions. [online] Available at: <www.1000ventures.com>

Lakens, D., 2010. Movement synchrony and perceived entitativity. Journal of Experimental Social Psychology, 46(5), pp.701-708.

Land, D., 2003. Identifying strategic leadership practice motivators of non-profit employee retention. DM dissertation. University of Phoenix.

Langfield-Smith, K., 2005. What do we know about management control system and strategy? In: C.S. Chapman, ed. Controlling strategy. Oxford: Oxford University Press.

Latif, D.A., 2002. Model for teaching the management skills component of managerial effectiveness to Pharmacy Student Review, 377.

Laugen, B.T., Boer, H. and Acur, N., 2006. The new product development improvement motives and practices of Miles and Snow's prospectors, analyzers and defenders. Creativity \& Innovation Management, 15(1), pp.85-95.

Legard, R.K. and Ward, K., 2003. In-depth interviews. Qualitative research practice. A guide for social science students and researchers. London: Sage Publications.

Leibner, J., Mader, G. and Weiss, A., 2010. The power of strategic commitment: Achieving extraordinary results through total alignment and engagement. AMACOM. New York 
Levinthal, D.A., 2011. A behavioral approach to strategy-What's the alternative? Strategic Management Journal, 32(13), pp.1517-1523.

Li, X., 2009. Entrepreneurial competencies as an entrepreneurial distinctive: An examination of the competency approach in defining entrepreneurs. Dissertations and Theses Collection PhD. Singapore Management University.

Liu, B. and Fu, Z., 2011. Relationship between strategic orientation and organisational performance in born global: A critical review. International Journal of Business and Management, 6(3), pp.109-115.

Livermore, D.A., 2011. The cultural intelligence difference. New York: AMACOM.

Lockwood, N.R., 2007. Leveraging employee engagement for competitive advantage: HR's strategic role. HR Magazine, pp.1-11.

Lotunani, A., Idrus, S.M., Afnan, E. and Setiawan, M., 2014. The effect of competence on commitment, performance and satisfaction with reward as a moderating variable (A study on designing work plans in Kendari City Government, Southeast Sulawesi). International Journal of Business and Management Invention, 3(21), pp.18-25.

Lovallo, D. and Mendonca, L., 2007. Strategy's strategist: An interview with Richard Rumelt. The McKinsey Quarterly, 4, pp.56-67.

Lowe, R.A. and Ziedonis, A.A., 2006. Overoptimism and the performance of entrepreneurial firms. Management Science, 52(2), pp.173-186.

Luo, Y., 2004. Building a strong foothold in an emerging market: A link between resource commitment and environment conditions. Journal of Management Studies, 41(5), pp.749-773.

Luthans, F., 2011. Organisational behavior. 12th edition. New York: McGraw-Hill.

Lyons, E. and Coyle, A., 2007. Analysing qualitative data in psychology. SAGE Publication. London

Madichie, N. 2011. "Made-in" Nigeria or "owned-by" Ireland? Country-of-origin cues and the narratives of Guinness consumption in London. Management Decision, 49(10), 1612-1622. 
Madichie, N. and Nkamnebe, A.D., 2010. Micro-credit for microenterprises? A study of women 'petty' traders in Eastern Nigeria. Gender in Management: An International Journal, 25(4), pp.301-319.

Madichie, N. O., Mpofu, K., \& Kolo, J. (2017). Entrepreneurship development in Africa: Insights from Nigeria's and Zimbabwe's telecoms. In Entrepreneurship in Africa (pp. 172-208). BRILL.

Malmstrom , M., Wincent, J. and Johansson, J., 2013. Managing competence acquisition and financial performance: An empirical study of how small firms use competence acquisition strategies. Journal of Engineering and Technology Management, 30(4), pp.327-349.

Man, T.W.Y., 2001. 'Entrepreneurial competencies and the performance of small and medium enterprises in Hong Kong services sector'. Unpublished doctoral thesis. Hong Kong Polytechnic University.

Man, T.W.Y. and Lau, T., 2005. The context of entrepreneurship in Hong Kong: An investigation through the patterns of entrepreneurial competencies in contrasting industrial environments. Journal of Small Business and Enterprise Development, 12(4), pp.67-92.

Man, T.W.Y., Lau, T. and Snape, E., 2008. Entrepreneurial competencies and the performance of small and medium enterprises: An investigation through a framework of competitiveness. Journal of Small Business \& Entrepreneurship, 21(3), pp.257-276.

Manufacturers Association of Nigeria (MAN 2002) - Membership profile available from: www.manufacturernigeria.org

Mantere, S., Schildt, H.A. and Sillince, J.A., 2012. Reversal of strategic change. Academy of Management Journal, 55(1), pp.173-196.

Mason, M., 2010. 'Sample Size and Saturation in PhD Studies Using Qualitative Interviews,' in: Forum Qualitative Sozialforschung / Forum: Qualitative Social Research. 8, pp.44-58.

Matteson, D.B., 2001. 'Trucks Involved in Fatal Accident': National truck statistics. Published by University of Michigan, Transportation research Institution.

Markides, C., 2010. Innovating globally. Business Strategy Review. 3(2), pp.4-9. 
Markides, C., 2008. Game-changing strategy: How to create new market space in established industries by breaking the rules. Jossey-Bass. San Francisco. CA. US

Makioka, H., Biragnet, J.P. and Booker, M., 2009. Learning from recession, the Japanese way. Businessweek, p.18.

McDougall, P.P. and Oviatt, B.M., 2000. International entrepreneurship: The intersection of two research paths. Academy of Management Journal, 43(5), pp.189-208.

McEvily, B. and Marcus, A., 2005. Embedded ties and the acquisition of competitive capabilities. Strategic Management Journal, 26(8), pp.1033-1055.

McGraw, H., 2006. Strategic management: Creating effective organisational designs. [online] Available at: <http://management.uta.edu/bgoodman>

McGuire, J. and Dow, S., 2009. Japanese keiretsu: Past, present, future. Asia Pacific Journal of Management, 26(2), pp.333-351.

McKeown, M., 2012. Why Plan B matters most, 30 March 2012, Management Today

McNamara, C., 2008. Management function of coordination and control: Overview of basic methods. SAGE Publication. London

Mercurio, Z.A., 2015. Affective commitment as a core essence of organisational commitment: An integrative literature review. Human Resource Development Review, 14(4), pp.389-414.

Merriam, S., 2002. Qualitative research in practice: Examples for discussion and analysis. California: John Wiley \& Sons.

Meyer, J.P. and Herscovitch, L., 2001. Commitment in the workplace: Toward a general model. Human Resource Management Review, 11, pp.299-326.

Meyer, J.P., Stanley, D., Herscovich, L. and Topolnytsky, L., 2002. Affective, continuance, and normative commitment to the organisation: A meta-analysis of antecedents, correlates, and consequences. Journal of Vocational Behavior, 6(1), pp.20-52.

Mezias, M.T. and Starbuck, H.W., 2003. Planning for productivity. Harvard Business Review, 8(3), pp.21-45.

Michael, J., Sebanz, N. and Knoblich, G., 2016. Observing joint action: Coordination creates commitment. Cognition, 157, pp.106-113. 
Michael, L.T. and Philip, A., 2004. Managing strategic innovation and change. Oxford University Press. UK

Miles, L.K., Nind, L.K. and Macrae, C.N., 2009. The rhythm of rapport: Interpersonal synchrony and social perception. Journal of Experimental Social Psychology, 45(3), pp.585-589.

Miles, R.E. and Snow, C.C., 2003. Organisational strategy, structure and process. Stanford University Press. Redwood City, California

Miles R.E. and Snow, C.C., 1978. Organisational strategy, structure and process. New York: McGraw-Hill.

Miller, C.C. and Cardinal, L.B., 2017. Strategic planning and firm performance: A synthesis of more than two decades of research. Academy of Management Journal, 37(6), pp.1649-1665.

Mills, J., 2009. Strategic management: How effective is your strategy realisation? Harvard Business Review, 13(4), pp.14-29.

Mintzberg, H., 2004. Managers, not MBAs: A hard look at the soft practice of managing and management development. Oakland, CA 94612 U.S.A.

Mintzberg, H., 2003. The strategy process: Concepts, contexts, cases Oakland, CA 94612 U.S.A.

Minniti, M. and Moren, L., 2010. Entrepreneurial types and economic growth. Journal of Business Venturing, 25(3), pp.305-314.

Mitchelmore, S. and Rowley, J., 2010. Entrepreneurial competencies: A literature review and development agenda. International Journal of Entrepreneurial Behavior and Research, 16(2), pp.92-111.

Mitkidis, P., McGraw, J.J., Roepstorff, A. and Wallot, S., 2015. Building trust: Heart rate synchrony and arousal during joint action increased by public goods game. Physiology \& Behavior, 14(9), pp.101-106.

Mohamad, O., Ramayah, T., Puspowarsito, H., Natalisa, D. and Saerang, D.P.E., 2011. Corporate entrepreneurship and firm performance: The role of business environment as a moderator (dagger). IUP Journal of Management Research, 10(3), pp.7-27. 
Mondy, W. and Neo, R., 2005. Administración de recursos humanos. 9th edition. Pearson Education. London, England

MORI, 2005. Awareness and uptake of environmental services: research among SMEs and journalists. London: MORI.

Morse, J.M., 2008. Styles of collaboration in qualitative inquiry. Qualitative Health Research, 18(1), pp.3-4.

Morse, J.M., 2013. Readme first for a user's guide to qualitative methods. 3rd edition. Thousand Oaks: Sage Publications.

Muaz, J.M., 2013. Practical guidelines for conducting research. Summarizing good research Practical in line with the DCED Standard.

Mulcaster, W.R., 2009. Three strategic frameworks. Business Strategy Series, 10(1), pp.68-75.

Muller, R. and Turner, R., 2010. Leadership competency profiles of successful project managers. International Journal of Project Management, 28(5), pp.437-448.

Murphy, G., Athanasou, J. and King, N., 2002. Job satisfaction and organisational citizenship behavior: A study of Australian human-service professional. Journal of Managerial Psychology, 17(4), pp.287-297.

Myers, M.D., 2013. Qualitative research in business \& management. 2nd edition. London: Sage Publications.

Nag, R., Hambrick, D.C. and Chen, M.J., 2007. What is strategic management, really? Inductive derivation of a consensus definition of the field. Strategic Management Journal, 26(9), pp.935-955.

Natasa, R., Zdravko, Z. and Goran, K., 2010. Learning Environment - Framework for Successful Corporate Entrepreneurship. An Enterprise Odyssey. International Conference Proceeding Zagreb. eJournal: Periodical

National Statistics, 2008. Labour force survey, Incomes Data Services

National Statistics, 2010. Labour force survey Oxford Business Group

Naylor, J., 2003. Management. 2nd edition. Prentice Hall. New Jersey

Neilson, L.G., Martin, L.K. and Powers, E., 2008. The secrets to successful strategy execution. Harvard Business Review, pp.61-70. 
Noble, C.H., 1999. The eclectic roots of strategy implementation research. Journal of Business Research, [e-journal] 45(2), pp.119-134. doi:10.1016/s01482963(97)00231-2.

Noh, W.J., Kwon, D.Y., Yoon, J.S. and Hwang I.J., 2011. Internal and external environmental factors affecting the performance of hospital-based home nursing care. International Nursing Review, 58(2), pp.263-269.

Nonaka, I. and Toyama, R., 2007. Strategic management as distributed practical wisdom. Oxford University Press. Oxford, England, UK

Nooraie, M., 2008. Decision magnitude of impact decision and strategic decision magnitude of impact and strategic decision-making process output. Management Decision, 46(4), pp.640-655.

NPC, 2009. Nigeria: National Economic Empowerment Development Strategy (NEEDS2). National Planning Commission Abuja.

NPC, 2011. Nigeria Vision 20:2020: Economic Transformation Blueprint. National Planning Commission Abuja.

Nwaoguji, C., 2016. Why Nigeria's 17m SMEs struggle to survive. The Sun Nigeria, [online] Available at: www.sonline-com.cdn.ampproject.org

Nwankwo, S., 2011. Imagining Africa in the global economy. Thunderbird International Business Review, 53(1), pp.3-8.

Nwankwo, S. and Richards, D., 2004. Institutional paradigm and the management of transitions: A sub-Sahara African perspective. International Journal of Social Economics, 31(1/2), pp.111-130.

Nwankwo, S., 1997. State and market partnership for development: A review of development strategy for sub-Saharan Africa. The Review of Policy Issues, 3(4), pp.3-23.

Oakes, G., 2003. Max Weber on value rationality and value spheres: Critical remarks. Journal of Classical Sociology, 3(1), pp.27-45.

Obembe, O.B., Olaniyi, C.O. and Soetan, R.O., 2016. Managerial ownership and performance of listed non-financial firms in Nigeria. International Journal of Business and Emerging Markets, 8(4), pp.446-461. 
Okonjo-Iweala, N., 2014. 3,000 ghost workers were discovered on payroll. Nigerian Tribune https://www.premiumtimesng.com/.../156647-okonjo-iweala-sendsghost-workers-icp... Mar 13, 2014

Okpara, J., 2011. Factors constraining the growth and survival of SMEs in Nigeria: Implications for poverty alleviation. Management Research Review, 34(2), pp.156-171.

Okumus, F. Altinay, L. and Roper, A., 2007. Gaining access for research: Reflections from experience. Annals of Tourism Research, 34(1), pp.7-26.

Oliver, V., 2010. 301 smart answers to tough business etiquette questions. New York: Skyhorse Publishing.

Olamade, O.O., 2011. ICT for business environment scanning: A study of the manufacturing industry in south-western Nigeria. Lambert Academic Publishing. Germany

Onyeonoru, I., 2003. Globalisation and industrial performance in Nigeria. Africa Development: A Quarterly Journal of CODESRIA, 28(3/4), pp.36-66.

Opatha, H.H.D.N.P., 2010. Personal Quality, Colombo: Department of Human Resource Management, University of Sri Jayewardenepura

Oppenheim, A.N., 2000. Questionnaire design, interviewing and attitude measurement. London: Continuum International.

O’Reilly, M. and Parker, N., 2012. Unsatisfactory saturation: A critical exploration of the notion of saturated sample sizes in qualitative research. Qualitative Research Journal, 6(1), pp.1-8.

Osbourne, W., 2009. Small business success: The roles planning, location, and government play in the entrepreneurship development. Dissertations Publishing. New Jersey

Osuagwu, L., 2002. Entrepreneurship in a developing economy: Empirical evidence from Nigeria business organisations. International Journal of Entrepreneurship, 6, pp.19-32.

Oyelola, O.T., Ajiboshin, I.O., Raimi, L. and Raheem, S., 2013. Entrepreneurship for sustainable economic growth in Nigeria. Journal of Sustainable Development Studies, 2(2), pp.197-215. 
Ozcan, P. and Eisenhardt, K., 2009. Origin of alliance portfolios: Entrepreneurs, network strategies, and firm performance. Academy of Management Journal, 52(2), pp.246-279.

Ozdemirci, A., 2011. Corporate entrepreneurship and strategy process: A performancebased research on Istanbul market. The proceedings of 7th International Strategic Management Conference. Procedia - Social and Behavioral Sciences, 24(2011), pp.611-626.

Palese, M. and Crane, T.Y., 2002. Building an integrated issue management process as a source of sustainable competitive advantage. Journal of Public Affairs, 2(4), pp.284-292.

Panian, Z. and Croati, T., 2007. How to make business intelligence actionable through service-oriented architectures. WSEAS Transactions on Business and Economics, 5(5), pp.210-221.

Papamichail, K.N. and Rajaram, V., 2007. A framework for assessing best practice in decision making. $29^{\text {th }}$ International Decision Sciences Institute Conference, Bangkok. February 11-15, 2019 ACM International Conference on Web Search and Data Mining (WSDM), 12th. ...... Mandarin Oriental Hotel, Bangkok, Thailand. http://www.gels.asia/

Park, S.H. and Luo, Y., 2001. Strategic alignment and performance of market-seeking MNCs in China. Strategic Management Journal, 22(2), pp.141-156.

Patton, M.Q., 2002. Qualitative research and evaluation methods. 3rd edition. Thousand Oaks: Sage Publications.

Peersman, G., 2014. Overview: Data collection and analysis methods in impact evaluation, methodological briefs: Impact evaluation 10, UNICEF Office of Research, Florence.

Perrott, E.B., 2008. Managing strategy in turbulent environments. Journal of General Management, 33(3), pp.79-102.

Pettigrew, A.M., 2003. Handbook of strategy management and organisations. Sage. London 
Peukert, H., 2003. The missing chapter in Schumpeter's the theory of economic development. In: J.A. Schumpeter and J. Backhaus, eds. 2003. Norwell: Kluwer Academic Publishers. pp.221-231.

Phan, P., Wright M., Ucbasaran, D. and Tan, W., 2009. Corporate entrepreneurship: Current research and future directions. Journal of Business Venturing, 2(4), pp. 198.

Platts, K., 2002. The centre for strategy and performance. Cambridge University. Cambridge

Plum, E., Achen, B., Draeby, I. and Jensen, I., 2007. Cultural competence: A concept for bridging and benefiting from cultural difference. Copenhagen: Borsen Forlag.

Pierce, J.L., O’Driscoll, M.P. and Coghlan, A.M., 2006. 'The psychology of ownership': Working environment structure, organisational commitment, and citizenship behaviors. Group and Organisation Management, 31(3), pp.388-416.

Pierce, J.L., O’Driscoll, M.P. and Coghlan A.M., 2004. Work environment structure and psychological ownership: The mediating effects of control. Journal of Social Psychology, 144(50). pp.88-96

Pittino, D. and Visintin, F., 2009. Innovation and strategic types of family SMEs: A test and extension of Miles and Snow's configurational model. Journal of Enterprising Culture, 17(3), pp.257-295.

Pittino, D., Visintin, F. and Lauto, G., 2009. A configurational analysis of the antecedents of entrepreneurial orientation. European Management Journal, 35(2), pp.224-237.

Porter, M., 2001. Strategy and internet. Harvard Business Review, 41(21), pp.45-63.

Porter, E.M., 2008. The five competitive forces that shape strategy. Harvard Business Review, 86(1), pp.76-93.

Pun, K.F., 2003. A synergy model for strategic planning in manufacturing enterprises. The West Indian Journal of Engineering, 2(6), pp.29-43.

Punch, K.F., 2013. Introduction to social research: Qualitative and quantitative approaches. Sage Publications. London

Purdy, G., 2007. Competence management: Understanding it and implementing it. Tycom 
Qian, F. and $\mathrm{Xu}, \mathrm{L} ., 2$ 2007. Improving customer satisfaction by the expert system using artificial neural networks. WSEAS Transactions on Business and Economics, 4(10), pp.147-151.

Quelch, J. and Jocz, K., 2009. How to market in a downturn. Harvard Business Review, 87(4), pp.52-62.

Qzdemirci, A., 2011. Corporate entrepreneurship and strategy process: A performancebased research on Istanbul market. $7^{\text {th }}$ edition. Elsevier. Edinburgh, London

Ramo, I.G., 2009. The impact of social and emotional competencies on effectiveness of Spanish executives. Journal of Management Development, 28(9), pp.771-793

Rankin, N., 2004. The new prescription for performance: The eleventh competency benchmarking survey. Competency and emotional intelligence benchmarking supplement 2004. London: IRS.

Reed, D., 1996. Structural adjustment, the environment, and sustainable development. London: Earthscan Publication Ltd.

Reeves, T.C. and Hedberg, J.C., 2003. Interactive learning system evaluation. Englewood Cliffs: Educational Technology Publications.

Renganathan, S., 2005. 'The use of English as a social practice: A study of Malaysian ESL students'. Unpublished doctoral thesis. King's College University of London.

Repenning, N., 2002. A simulation-base approach to understanding the dynamics of innovation implementation. Organisation Science, 13(2), pp.109-127.

Richardson, J., 2005. The business model: An integrative framework for strategic execution. Working Paper Series. Social Science Research Network. SSRN Electronic Journal DOI: 10.2139/ssrn.932998

Ritchie, J., Lewis, J. and Elam, G., 2003. Designing and selecting samples. Qualitative research practice. A guide for social science students and researchers. Thousand Oaks: Sage.

Robinson, M.A., 2010. Work sampling: Methodological advances and new applications. Human Factors and Ergonomics in Manufacturing \& Service Industries, [ejournal] 20(1), pp.42-60 
Robbins, P., 2000. The rotten institution: Corruption in natural resources management. Political Geography, 19, pp.423-443.

Robins, S. and Coulter, M., 2005. Management. 7th edition. New Jersey: Prentice Hall Inc.

Robbins, S.F. and Judge, T.A., 2007. Organisational behaviour. 12th edition. Pearson Education. London, England

Robson, C., 2002. Real world research. 2nd edition. Oxford: Blackwell.

Robson, L., 2005. Countries of the world: Nigeria. Evans Brothers. Ibadan Nigeria

Rogelberg, G.S., 2004. Handbook of research methods in industrial and organisational psychology. Blackwell. Oxford England

Roberts, K., 2003. What strategic investments should you make during a recession to gain competitive advantage in the recovery? Strategy and Leadership, 31(4), pp.31-39.

Roberts, C.P., 2011. Two who made a difference. The Washington Times June 2 2011, p.34.

Roth, S., 2014. Booties, bounties, business models: A map to the next red oceans. International Journal of Entrepreneurship and Small Business, 22(4), pp.439448.

Rothbauer, P., 2008. Triangulation. The Encyclopedia of Qualitative Research Methods. Sage Publications London

Rumelt, R.P., 2011. Good strategy/Bad strategy. Crown Business. Midtown Manhattan

Saints, R.P., 2009. Entrepreneurial orientation, dynamic capabilities and the management and its impact on performance. Application Management Journal, 7(2), pp.38-52

Saito, M., 2008. 'Relationship Management Competence and Organisational Performance'. Encyclopedia of healthcare information systems. Waseda. Japan

Sanchez, A. and Marin, S., 2005. Strategic typology and performance. Australian Journal of Business and Management Research, 1(4), pp.40-51.

Santos, S.C., Caetano, A. and Curral, L., 2013. Psychosocial aspects of entrepreneurial potential. Journal of Small Business \& Entrepreneurship, 26(6), pp.661-685. 
Santos, F. and Eisenhardt, K., 2009. Constructing markets and shaping boundaries: Entrepreneurial agency in nascent field. Academy of Management Journal, 52(4), pp.643-671.

Sanusi, L.S., 2010. Growth prospects for the Nigerian economy. Convocation lecture delivered at the Igbinedion University, Okada, Edo State, Nigeria. Unpublished

Sarkissian, A., 2014. The relationship Between Corporate Entrepreneurship and Strategic Management, Strategic Management Journal. Chron.com 20(5) DOI: 10.1002/(SICI)1097-0266

Sarwoko, E., Armanu, S. and Hadiwidjojo, D., 2013. Entrepreneurial characteristics and competency as determinants of business performance in SMEs. Journal of Business and Management, 7(3), pp.31-38.

Saunders, K.N.M., Lewis, P. and Thornhill, 2015. Research methods for business students. 7th edition. Pearson. New Jersey

Sawyer, O., Ebrahimi, B. and Thobodeaux, P., 2000. Executive environmental scanning, information source utilisation, and firm performance: The case of Nigeria. Journal of Applied Management Studies, 9(1), pp.95-115.

Scarlett, K., 2008. What is engagement? Institute for employment studies. [online] Available at: http://www.employment-srtudy.co.uk

Schappe, S. P. (1998). The influence of job satisfaction, organizational commitment, and fairness perceptions on organizational citizenship behavior. The Journal of Psychology: Interdisciplinary and Applied, 132(3), pp. 277-290. http://dx.doi.org/10.1080/00223989809599167

Schoonhoven, C.B., Eisenhardt, K.M. and Lyman, K., 1990. Speeding products to market: Waiting time to first product introduction in new firms. Administrative Science Quarterly, 35(1), pp.177-207.

Scott, K., 2003. Company turnaround: Managing downturn. Growing Business Journal, July-August 2003 Issue 4, p.18.

Sepasgozar, E.M.S., Razkenari, A.M. and Barati, K., 2015. The importance of new technology for delay mitigation in construction projects. American Journal of Civil Engineering and Architecture, 3(1), pp.15-20. 
Shalley, C.E. and Gilson, L.L., 2004. What leaders need to know: A review of social and contextual factors that can foster or hinder creativity. Leadership Quarterly, 15, pp.33-35.

Shalley, C.E., Zhou, J. and Oldman, G.R., 2004. The effects of personal and contextual characteristic on creativity: Where should we go from here? Journal of Management, 30(14), pp.933-958.

Shane, S., 2013. The genetics of entrepreneurial performance. International Small Business Journal, 31(5), pp.473-495

Shenhar, A.J. and Dvir, D., 2007. Reinventing project management - The diamond approach to successful growth and innovation. Brighton, Massachusetts USA: Harvard Business School Press.

Shenton, A. and Hayter, S., 2004. Strategies for gaining access to organisations and informants in qualitative studies. Education for Information, 21(8), pp.223-231.

Shih, M.L., Lin, S., Hsiao, S. H., Huang, L.M., Chiu, C. and Chen K.Y., 2009. The study of the correlation among personality traits, leadership competence and organisational performance. Wseas Transactions on Business and Economics, 1(6), pp.11-20.

Shinkle, G.A. and Kriauciunas, A.P., 2012. The impact of current and founding institutions on strength of competitive aspirations in transition economies. Strategic Management Journal, 33(4), pp.448-458.

Sidek, S. and Zainol, F.A., 2011. Assessing strategic typology and business performance: Empirical evidence in small construction industry in Malaysia. Franklin Watts. New York

Simister, P., 2009. An introduction to business strategy. Why strategy is important? Blackwell, Oxford.

Sine, W. and Lee, B., 2009. Tilting at windmills? The environmental movement and the emergence of the U.S. wind energy sector. Administrative Science Quarterly, 54(1), pp.123-155

Slavee, A. and Drnovesek, M., 2012. A perspective on scale development in entrepreneurship research. Economic and Business Review, 14(1), pp.39-62. 
Smith A.J., Flower, P. and Larkin, M., 2009. Interpretative phenomenological analysis: Theory, methods and research. London: Sage.

Smith, J.A., 2011. Evaluating the contribution of interpretative phenomenological analysis. Health Psychology Review, 5(1), pp.9-27

Solinger, O.N., Van Olffen, W. and Roe, R.A., 2008. Beyond the three-component model of organisational commitment. Journal of Applied Psychology.93(1), pp.70-83.

Sorensen, J.B. and Chang, P.M.Y., 2006. Determinants of Successful Entrepreneurship: A Review of the Recent Literature, MIT Sloan School of Management.

Stefanovic, I., Rankovic, L. and Ptokic, S., 2011. Entrepreneurs' motivational factors: Empirical evidence from Serbia. Serbian Journal of Management, 6(1), pp.7383.

Stewad, J.W.H., Carland, I.C., Carland, I.W., Watson, W.E. and Sweo, R., 2003. Entrepreneurial Dispositions and goal orientations: A comparative exploration of United State and Russian entrepreneurs. Journal of Small Business Management, 41(1), pp.27-46.

Stiegele, F.R., 2008. Business environment: A combination of political, economic, social, and technology (PEST) forces. Edward Elgar. Cheltenham

Stockport, G.J., 2000. Developing skills in strategic transformation. European Journal of Innovation Management, 3(1), pp.45-52.

Streubert, H. and Carpenter, D., 1999. Qualitative research in nursing: Advancing the humanistic perspective. 2nd edition. Philadelphia: Lippincott Williams and Wilkins.

Stup, E.R., 2006. Human Resource Management and Dairy Employee. Pennsylvania State University. Economics Bulletin 31(1), pp.208-217

Suci, P.R., 2009. The effect of entrepreneurial orientation on the management capability and sustainable innovation. Journal of Management and Entrepreneurship, 11(1), pp.46-58.

Sugiarto, 2006. Corporate good governance, firms can improve performance. School of Economics IBII Jakarta, 6(1), pp.34-46. 
Sull, D., 2009. How to thrive in turbulent markets. Harvard Business Review, 87(2), pp.79-88.

Sull, D.N. and Houlder, D., 2005. Do commitments match your convictions? Harvard Business Review 4, p.84.

Sumer, K. and Bayraktar, A.C., 2012. Business strategies and gaps in Porter's typology: A literature review. Journal of Management Research, 4(3), pp.100-119.

Sumner, M., Block, D. and Giamartino, G., 2006. Exploring the linkage between the characteristics of IT project leaders and project success. Information Systems Management, 23(4), pp.43-49.

Surachman, 2007. Influence skill management and business orientation against acceptance rate risk and its impact on small industries product development in Java Tinmur. Journal of Management Application. 12(10), pp.56-67

Suwarsono, M., 2008. Strategic management. 4th edition. School of Economics YKPN Jogyakarta. Indonesia

Tabish, S.Z.S. and Jha, N.K., 2011. Identification and evaluation of success factors for public construction projects. Journal of Construction Management and Economics, 29(8), pp.809-823

Tandon, A., Sharma, R.R.K. and Uma, N.S., 2010. ERP implementation approach in defenders organisations: An empirical study. International Journal of Business Research, 10(2), pp.281-284

Tang, Z. and Tang, J., 2012. Entrepreneurial orientation and SME performance I China's changing environment: The moderating effects of strategies. Asia Pacific Journal of Management, 29(2), pp.409-431.

Teece, D.J., 2006. Technology know-how, organisational capabilities, and strategic management: Business strategy and enterprise development in competitive environment. World Scientific Publishing Co Pte Ltd. Singapore

Tervio, M., 2008. The difference that CEOs make: An assignment model approach. American Economic Review, 98(3), pp.642-668.

Thamhain, H. J., 2013. Building a collaborate climate for multinational projects. Procedia - Social and Behavioral Sciences, 7(4), pp.21-33.

The Report Nigeria, 2013. Bridging the refining gap. Energy and Industry Analysis 
The Report Nigeria, 2010. Nigerian textile industries production, World in Focus. Nigeria.

Tinsley, S., 2002. EMS models for business strategy development. Business Strategy and the Environment, 11, pp.376-390.

Todd, P.M., 2002. 'Heuristic for Decision and Choice'. International encyclopedia of the social and behavioral sciences. Amsterdam

Torres E.N., Fub, X. and Lehto, X., 2014. Examining key drivers of customer delight in a hotel experience: A cross-cultural perspective. International Journal of Hospitality Management, 36, pp.255-262.

Tracy, S., 2010. Qualitative quality: Eight 'big-tent' criteria for excellent qualitative research. Qualitative Inquiry, 16(10), pp.837-851.

Trevelyan, R., 2009. Entrepreneurial attitudes and action in new venture development. The International Journal of Entrepreneurship and Innovation, 10(1), pp.21-32.

Tsui, P. and Wu, D., 2009. Social performance: Overview-Empowerment and engagement. [online] Available at: $<$ European Motivation index.com $>$

Turner, D.W., 2010. Qualitative interview design: A practical guide for novice investigators. The Qualitative Report, 15(3), pp.754-760.

Turri, J., 2016. Knowledge and the norm of assertion: An essay in philosophical science. Cambridge: Open Book Publications.

Tushman, M.L. and Anderson, P., 2004. Managing strategic innovation and change. Oxford University Press. Oxford England

Ulrich, D., 1998. Intellectual capital $=$ Competence $\mathrm{X}$ commitment. MIT Sloan Management Review, 39(2), pp.15-26

United Nation Industry Development, 2010. Infrastructure Deficits UNIDO

Vazquez-Brust, D.A., Sarkis, J. and Cordeiro, J.J., 2014. Collaboration for sustainability and innovation: A role for suitability driven by Global South? London:

Velickovic, V.M., Visnjic, A., Jovic, S.A., Radulovic, O., Sargic, C., Mihajlovic, J. and Mladenovic, J., 2014. Organisational commitment and job satisfaction among nurses in Serbia: A factor analysis. Nursing Outlook, 62(6), pp.415-429. 
Vuong, Q.H. and Napier, N.K., 2015. Acculturation and global mindsponge: An emerging market perspective. International Journal of Intercultural Relations, 49(6), pp.354-367.

Vuong, Q.H., 2016. Survey data on entrepreneurs' subjective plan and perceptions of the likelihood of success. Data in Brief, 6, pp.858-864.

Vuong, Q.H., Do, T.H. and Vuong, T.T., 2016. Resources, experience, and perseverance in entrepreneurs' perceived likelihood of success in an emerging economy. Journal of Innovation and Entrepreneurship, 5(1), pp.1-24.

Walker, J.L., 2012. The use of saturation in qualitative research. Canadian Journal of Cardiovascular Nursing, 22(2), pp.37-46.

Walker, O. and Ruckert, R., 1987. Marketing's role in the implementation of business strategies: A critical review and conceptual framework. Journal of Marketing, 5(1), pp.15-33.

Wang, C.L., 2008. Entrepreneurial orientation, learning orientation, and firm performance. Entrepreneurship: Theory \& Practice, 32(4), pp.635-657.

Wang, Y., Lo, H.P., Chi, R. and Yang, Y., 2004. An integrated framework for customer value and customer relationship-management performance: A customer-based perspective from China. Managing Service Quality, 14(2/3), pp.169-182.

Wang, Y. and Gao, Z., 2013. Corporate entrepreneurship, core competence and market performance. Journal of Business and Management, 7(3), pp.31-38.

Warren, K., 2002. Competitive strategy dynamics. Chichester: Wiley.

Warren, K., 2011. Strategic management dynamics. John Wiley \& Sons, Ltd. Chichester, UK

Wartick, S.L. and Heugens, P., 2003. Future directions for issues management. Corporate Reputation Review, 6(1), pp.7-18.

Wartzman, R., 2009. Working in Japan: Rethinking lifetime employment. Businessweek September 4, 2009

WEF, 2011. African competitiveness report. Geneva: World Economic Forum.

WEF, 2015. Global competitiveness report. Geneva: World Economic Forum.

Weick, K.E., 2001. Sense-making in organisations. Thousand Oaks: Sage Publications. 
Wetherly, P. and Otter, D., 2011. The business environment. 2nd edition. Oxford University Press. Oxford UK

Whiddett, S. and Hollyforde, S., 2007. Competencies toolkit. London: Chartered Institute of Personnel and Development (CIPD).

Whittington, R., 2004. Strategy after modernism: Recovering practice. European Management Review, 1, pp.62-68.

Whittington, R., 2006. What is strategy and does it matter. 2nd ed. Thomson Learning. Stamford

Wiguna, B.A. and Manzilati, A., 2014. Social entrepreneurship and socioentrepreneurship: A study with economic and social perspectives. Procedia Social and Behavioral Sciences, 115(21), pp.12-18.

Wiltermuth, S.S. and Heath, C., 2009. Synchrony and cooperation. Psychological Science, 20(1), pp.1-5.

Willis, J., 2007. Foundations of qualitative research: Interpretive and critical approaches. Thousand Oaks: Sage Publications.

Wilson, J., 2010. Essentials of business research: A guide to doing your research project. Sage Publications. London

Wit, D.B. and Meyer, R., 2004. Strategy: Process, content, context. An international perspective. 3rd edition. Thomson. Stamford

Wit, D. and Meyer, R., 2008. Strategy process, content and context. Thomson Learning. Stamford

World Bank, 2018. Doing Business in Nigeria 2018. International Bank for Reconstruction and Development/The World Bank, Washington DC. Retrieved from:

https://www.doingbusiness.org/content/dam/doingBusiness/media/SubnationalReports/DB_in_Nigeria_2018_w-bookmarks.pdf

World Bank, 2010. International Finance Corporation. Doing Business in Nigeria 2010. Doing Business Subnational. Washington, DC. (C) World Bank. https://openknowledge.worldbank.org/handle/10986/13424 License: CC BY-NCND 3.0 IGO. 
Wray, N., Markovic, M. and Manderson, L., 2007. Researcher saturation: The impact of data triangulation and intensive-research practices on the researcher and qualitative research process. Qualitative Health Research, 17(10), pp.1392-1402.

Xu, X., Zhang, W. and Barkhi, R., 2010. IT infrastructure capabilities and IT project success: A development team perspective. Information Technology and Management, 11(3), pp.123-142.

Zahra, S.A., Hayton, J.C., Neubaum, D.O., Dibrell, C. and Craig, J.B., 2008. Culture of family commitment and strategic flexibility: The moderating effect of stewardship. entrepreneurship theory and practice, 32(6), pp.1035-1054.

Zeleny, M., 2010. Strategy as action from porter to anti-porter. International Journal of Strategy Decision Science, 1(1), pp.1-22.

Yin, R.K., 2003. Applications of case study research. 2nd edition. Thousand Oaks: Sage.

Yin, R.K., 2009. Case study research: Design and methods. 4th edition. Thousand Oaks: Sage.

Zanini, F.T. and Migueles, P.C., 2013. Trust as an element of informal coordination and its relationship with organisational performance. Economia, 14(2), pp.77-87.

Zayas-Ortiz, M., Rosario, E., Marquez, E. and Gruneiro, C.P., 2015. Relationship between organisational commitments and organisational citizenship behavior in a sample of private banking employees. International Journal Sociology and Social Policy, 35(1), pp.91-106.

Zincin, J., 2008. Analysis of firms' internal and external environment vital. Oxford University Press. Oxford UK

Zott, C. and Huy, N.Q., 2007. How entrepreneurs use symbolic management to acquire resources. Administration Science Quarterly, 52(70), pp.70-105.

Zott, C. and Amit, R., 2008. The firm between product market strategy and business model: implication for firm performance. Strategic Management Journal, 29(1), pp.1-29. 
APPENDIXES (1-11)

APPENDIX 1: SAMPLE MANUFACTURING FIRMS

\begin{tabular}{|c|c|c|c|c|}
\hline & Organisation Name & $\begin{array}{l}\text { Number of } \\
\text { Employees }\end{array}$ & City/ State & $\begin{array}{l}\text { Geopolitical } \\
\text { Zone }\end{array}$ \\
\hline 1 & $\begin{array}{l}\text { Innoson Vehicle } \\
\text { Manufacturing Company } \\
\text { Limited }\end{array}$ & $\begin{array}{l}\text { Almost } 400, \\
\text { including casual }\end{array}$ & Nnewi/Anambra & South East \\
\hline 2 & $\begin{array}{l}\text { Ibeto Group (Union Auto } \\
\text { Parts Manufacturing } \\
\text { Company) }\end{array}$ & $\begin{array}{l}\text { Over } 240, \\
\text { including casual }\end{array}$ & Nnewi/Anambra & South East \\
\hline 3 & $\begin{array}{l}\text { Divine Grace Business } \\
\text { Enterprises }\end{array}$ & $\begin{array}{l}\text { Under } 10, \\
\text { including casual }\end{array}$ & Nnewi/Anambra & South East \\
\hline 4 & Sunny Tex Poly Industries & $\begin{array}{l}20 \text {, including } \\
\text { apprentices }\end{array}$ & Onitsha/Anambra & South East \\
\hline 5 & $\begin{array}{l}\text { Anyi Solid Chemical } \\
\text { Industries }\end{array}$ & Over 25 & Sapele/ Delta & South \\
\hline 6 & Guinness Nigeria, Benin & $\begin{array}{l}\text { Over } 300, \\
\text { including casual }\end{array}$ & Benin/ Edo & South South \\
\hline 7 & Fan Milk Plc, Benin City & $\begin{array}{l}\text { 150, including } \\
\text { casual }\end{array}$ & Benin/ Edo & South South \\
\hline 8 & $\begin{array}{l}\text { I.C. MASCOT Nigeria } \\
\text { Limited, Benin City }\end{array}$ & $\begin{array}{l}\text { 130, including } \\
\text { casual }\end{array}$ & Benin/ Edo & South South \\
\hline 9 & $\begin{array}{l}\text { Notre Dame Industrial } \\
\text { Company Limited, Benin } \\
\text { City }\end{array}$ & $\begin{array}{l}70, \text { including } \\
\text { casual }\end{array}$ & Benin/ Edo & South South \\
\hline$\overline{10}$ & $\begin{array}{l}\text { Hentsco Group of } \\
\text { Company, Sapele }\end{array}$ & $\begin{array}{l}\text { About } 70, \\
\text { including casual }\end{array}$ & Sapele/Delta & South South \\
\hline 11 & $\begin{array}{l}\text { Nigerian Bottling } \\
\text { Company Limited }\end{array}$ & $\begin{array}{l}\text { Over } 200, \\
\text { including casual }\end{array}$ & Asejire/Oyo & South West \\
\hline
\end{tabular}




\begin{tabular}{|c|c|c|c|c|}
\hline 12 & $\begin{array}{l}\text { Iron and Steel Nigeria } \\
\text { Limited }\end{array}$ & $\begin{array}{l}\text { About } 100 \text {, } \\
\text { including casual }\end{array}$ & Ile Ife/Osun & South West \\
\hline 13 & Tee Key Venture & $\begin{array}{l}\text { Over } 19, \\
\text { including casual }\end{array}$ & Ibadan/Oyo & South West \\
\hline 14 & $\begin{array}{l}\text { Yinka Oba Foam Nigeria } \\
\text { Limited }\end{array}$ & $\begin{array}{l}\text { Over } 200, \\
\text { including casual }\end{array}$ & Ilesa/Osun & South West \\
\hline 15 & International Breweries Plc & $\begin{array}{l}\text { Over } 556 \\
\text { including casual }\end{array}$ & Ilesa/Osun & South West \\
\hline 16 & $\begin{array}{l}\text { Spring Aluminium, } \\
\text { Asejire, Osun }\end{array}$ & $\begin{array}{l}\text { About } 50, \\
\text { including casual }\end{array}$ & Asejire/Oyo & South West \\
\hline 17 & $\begin{array}{l}\text { Highland Aluminium } \\
\text { Company }\end{array}$ & $\begin{array}{l}\text { About } 200, \\
\text { including casual }\end{array}$ & Ojodu/ Lagos & South West \\
\hline 18 & $\begin{array}{l}\text { Grand Cereals and Oil } \\
\text { Mills }\end{array}$ & $\begin{array}{l}\text { Over } 50, \\
\text { including casual }\end{array}$ & Jos/Plateau & $\begin{array}{l}\text { North } \\
\text { Central }\end{array}$ \\
\hline 19 & $\begin{array}{l}\text { NASCO Group of } \\
\text { Company, Jos }\end{array}$ & $\begin{array}{l}\text { Over 200, } \\
\text { including casual }\end{array}$ & Jos/Plateau & $\begin{array}{l}\text { North } \\
\text { Central }\end{array}$ \\
\hline 20 & $\begin{array}{l}\text { Wangtok Enterprises (Agro } \\
\text { Chemical) }\end{array}$ & $\begin{array}{l}\text { Over } 40, \\
\text { including casual }\end{array}$ & Jos/Plateau & $\begin{array}{l}\text { North } \\
\text { Central }\end{array}$ \\
\hline 21 & $\begin{array}{l}\text { Dangote Flour Mill, Ilorin } \\
\text { Plant }\end{array}$ & $\begin{array}{l}\text { Over } 200, \\
\text { including casual }\end{array}$ & Ilorin/Kwara & $\begin{array}{l}\text { North } \\
\text { Central }\end{array}$ \\
\hline 22 & $\begin{array}{l}\text { Citico Plastic Industrial } \\
\text { Limited }\end{array}$ & $\begin{array}{l}\text { 100, including } \\
\text { casual }\end{array}$ & Ilorin/Kwara & $\begin{array}{l}\text { North } \\
\text { Central }\end{array}$ \\
\hline 23 & $\begin{array}{l}\text { Holdent International } \\
\text { Limited }\end{array}$ & $\begin{array}{l}\text { Over 50, } \\
\text { including casual }\end{array}$ & Ota/Ogun & South West \\
\hline 24 & $\begin{array}{l}\text { Crown Park, polythene, } \\
\text { and Plastic bottle }\end{array}$ & $\begin{array}{l}\text { Over } 100, \\
\text { including casual }\end{array}$ & Lagos & South West \\
\hline$\overline{25}$ & $\begin{array}{l}\text { Bond Chemical Industry, } \\
\text { Oyo }\end{array}$ & $\begin{array}{l}\text { Over 200, } \\
\text { including casual }\end{array}$ & Awe/Oyo & South West \\
\hline 26 & $\begin{array}{l}\text { Multi Bond Venture, Awe, } \\
\text { Oyo }\end{array}$ & $\begin{array}{l}\text { Over } 60, \\
\text { including casual }\end{array}$ & Awe/Oyo & South West \\
\hline
\end{tabular}




\begin{tabular}{|c|c|c|c|c|}
\hline 27 & $\begin{array}{l}\text { Louis Carter Industries } \\
\text { Limited }\end{array}$ & $\begin{array}{l}\text { Over } 150, \\
\text { including casual }\end{array}$ & Nnewi/Anambra & South East \\
\hline 28 & Sumo Steel, Ota & $\begin{array}{l}\text { Over 200, } \\
\text { including casual }\end{array}$ & Ota/Ogun & South West \\
\hline 29 & $\begin{array}{l}\text { Kings Paints Company, } \\
\text { Benin City }\end{array}$ & $\begin{array}{l}\text { Over 50, including } \\
\text { casual }\end{array}$ & Benin/Edo & South \\
\hline 30 & $\begin{array}{l}\text { Success Business Link, } \\
\text { Warri }\end{array}$ & $\begin{array}{l}\text { Over 15, including } \\
\text { casual }\end{array}$ & Abraka & South South \\
\hline 31 & Altak Industries Limited & $\begin{array}{l}\text { Over 50, including } \\
\text { casual }\end{array}$ & Ibadan/Osun & South West \\
\hline 32 & Vicky Table Water & $\begin{array}{l}\text { Over } 30 \text {, including } \\
\text { casual }\end{array}$ & Ibadan/Osun & South West \\
\hline
\end{tabular}




\section{APPENDIX 2: PARTICIPANT INFORMATION SHEET \\ PARTICIPANT INFORMATION SHEET}

Dear Participant

Date:

My name is Segun OMISORE, a doctoral research student at the University of East London. My research involves an investigation of the 'Corporate Entrepreneurship, Strategy- making, and Performance of the Nigerian Manufacturing Sector'.

The purpose of this letter is to provide you with the information that you need to consider in deciding whether to participate in this study, which seeks to establish the situated understandings and explanations of the dynamics of corporate entrepreneurship in Nigeria.

The study seeks to explore how businesses like yours make sense of strategic planning systems with a view to establishing the intensity of effects and causative links with performance outcomes. There are four key objectives driving this study - namely to:

1. To explore whether the process of strategy-formulation in Nigeria is causatively linked to corporate under-performance rather than corporate sustainability enhancement. "ì

2. To establish whether there are any links between competence, commitment and coordination on strategy formulation and implementation at your organisation. 'SI'P'

3. To examine the role of the business environment or climate and how this impacts on

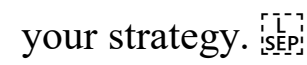

4. To determine your views on the strategic environment in which Nigerian firms operate

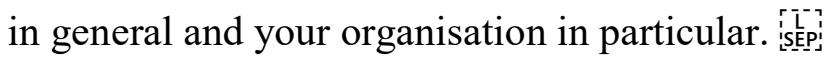

Please note that this study (interview) might take one to two hours of your time. You are also free to withdraw from the interview or not to answer questions at any time, without providing any reasons.

I would also like to reassure you that all information provided in the cause of the interview will be treated in strict confidence and anonymity. For instance, no individual will be identified or exposed, research data or other identifying information will be secured and locked in filing cabinets, and all hardcopy and electronic data will undergo secure disposal. 
If you have any question or concern regarding to this study in which you are being asked to participate, please contact the following persons:

Catherine Fieulleteau, Research Integrity and Ethics Manager, ic sépiaduate School, University of East London, Docklands Campus, London E16 2RD Tel: +44(0)20 8223 6683, Email: researchethics@uel.ac.uk

Professor Sonny Nwankwo, Director of Studies, íspeps School of Business \& Law, University of East London, Docklands Campus, London E16 2RD Tel:

Yours Sincerely, Segun Omisore 


\section{APPENDIX 3: CONSENT OF THE PARTICIPANT \\ CONSENT OF THE PARTICIPANT}

Segun Omisore (Researcher) Email:

Project Title: 'Corporate Entrepreneurship, Strategy-formulation, and

Performance of the Nigerian Manufacturing Sector'

I have gone through the information provided by the researcher stating the purpose, nature, duration, and procedures of the study. These have all been well explained and understood. I am also aware of my freedom to withdraw from the study, seek further clarification in the course of the study.

I am aware and convinced that all information provided by me will remain confidential and anonymous.

I hereby freely and fully consent to take part in the interview without obligation.

I am also aware that it is my right to withdraw from the interview or not to answer questions without having to provide a reason for my decision.

Participant's Printed Name: (optional)

Participant's Signature: (optional)

Investigator's Name:

Investigator's signature:

Date: 


\section{APPENDIX 4: INTERVIEW SCHEDULE INTERVIEW SCHEDULE}

Since the aim of this study is to establish the situated understandings into, and explanations of, the dynamics of corporate entrepreneurship in Nigeria, the themes were categorised in seven broad areas $(A-G)$ and mapped against the research questions (plus an additional outcome on business performance). ${ }^{1}$

\section{A.) Biographical information}

1.) Organisation's Name

2.) Title, Name, and Position

3.) Profession, Department, and Qualifications

4.) Religion, Age, and Marital Status

\section{B.) Job Description}

1.) What kind of job do you do?

2.) How long have you been working?

3.) How do you recruit in this firm/how were you recruited?

4.) Is this your first appointment?

5.) If no, what are differences between your job now and the previous?

\section{C.) Strategy-Formulation in Nigeria}

1.) To what extent would you consider strategy or planning a key element of corporate entrepreneurship in your firm?

2.) Where do the decision-making processes come in within corporate organisations such as yours?

3.) Who drives the vision, ideas, etc. within your organisation?

4.) Are there any organisations that demonstrate best practice in terms of corporate entrepreneurship in Nigeria?

5.) In what sector? What geographical region? Any explanations for this?

\section{D.) Interconnections Between Competence, Commitment, and Coordination (3Cs)}

1.) Do you think those employees' skills, experience, and training/formation enough for the capacity of the firm?

\footnotetext{
${ }^{1}$ Note that this opening statement would not be shared with respondents in order not to lead them to providing anticipated responses and thereby resulting in interview bias.
} 
2.) If no, what are your suggestions?

3.) Is there any kind of supervision or control of work?

4.) If yes, what are the control mechanisms?

5.) What is the style of management in terms of decision-making? (centralisation/decentralisation)

6.) What do you see as the main causes of staff motivation/commitment?

7.) Any area to be improved on within the firm?

8.) Can you shed any light on what the concepts 'competence, commitment, and coordination' mean for your organisation?

9.) Are these concepts related in any way?

10.) Should every organisation seek to integrate these concepts in order to enhance performance?

\section{E.) Role of Environment of Organisations (E)}

1.) How would you define your organisation at the firm level in relation to the general environment it operates in?

2.) Has there been a significant change in your organisation over the last five years? Why?

3.) Did it happen suddenly, or was the change progressive?

4.) How have those changes influenced your daily work?

\section{F). Effect of Geopolitical and Socio-Cultural Influences}

1.) To what extent would geopolitical and socio-cultural dynamics impact upon stakeholder's competence, commitment, coordination?

2.) To what degree would these dimensions moderate the strategic environment in which entrepreneurial practices are executed in Nigeria?

\section{G.) Business Performance and Productivity}

1.) To what extent has the sales growth changed over a five-year period?

2.) To what extent has the company employment rate increased over a five-year period?

3.) To what extent has the return on assets increased over a five-year period?

4.) To what extent has the return on investment increased over a five-year period?

5.) To what extent has the return on sales (ROS) increased over a five-year period? 
6.) To what extent has the operating profit increased over a five-year period?

7.) How do you define success from a business sense?

8.) Is business failure, in your view, the reverse of business success?

9.) Are there any key factors that creep up in business performance- success and /or failure?

10.) Are there any organisations that demonstrate best practice in terms of corporate entrepreneurship in Nigeria?

11.) In what sectors? What geographic region? Any particular explanations for this? 
APPENDIX 5: NIGERIAN ECONOMY DATA

\begin{tabular}{|l|l|l|l|l|l|l|}
\hline & 2012 & 2013 & 2014 & 2015 & 2016 & 2017 \\
\hline Population (in millions) & 165 & 169 & 174 & 179 & 184 & 196 \\
\hline $\begin{array}{l}\text { Economic Growth (GDP, annual } \\
\text { variation in \%) }\end{array}$ & 4.2 & 5.5 & 6.2 & 2.8 & & \\
\hline Unemployment Rate & 7.5 & 7.5 & 7.5 & & & \\
\hline $\begin{array}{l}\text { Inflation Rate (CPI, annual variation in } \\
\text { \%) }\end{array}$ & 12.2 & 8.5 & 8.1 & 9.0 & 12.77 & 17.26 \\
\hline Exchange Rate (vs USD) & 158.8 & 159.2 & 165.2 & 197.9 & 196.5 & 305.1 \\
\hline Current Account (\% USD bn) & 18.9 & 20.1 & 1.3 & -15.4 & & \\
\hline Trade Balance (USD billion) & 40.9 & 43.8 & 21.0 & -6.4 & & \\
\hline Exports (USD billion) & 94.3 & 95.1 & 82.6 & 45.9 & & \\
\hline Imports (USD billion) & 53.4 & 51.4 & 61.6 & 52.3 & & \\
\hline Exports (annual variation in \%) & -2.9 & 0.8 & -13.2 & -44.4 & & \\
\hline Imports (annual variation in \%) & -14.1 & 3.8 & 19.9 & -15.0 & & \\
\hline International Reserves (USD) & 44.2 & 43.6 & 34.5 & 29.1 & & \\
\hline Eternal Debt (\% of GDP) & 1.5 & 1.8 & 1.8 & 2.2 & & \\
\hline Source: CBN (2018) & & & & & & \\
\hline
\end{tabular}

Source: CBN (2018) 
APPENDIX 6: EASE OF DOING BUSINESS RANK IN 2015 AND 2017

\begin{tabular}{|l|l|l|}
\hline & $\begin{array}{l}\text { Doing business rank in } \\
2015\end{array}$ & $\begin{array}{l}\text { Doing business rank in } \\
2017\end{array}$ \\
\hline Nigeria & 170 & 138 \\
\hline Indian & 142 & 155 \\
\hline Kenya & 136 & 116 \\
\hline South Africa & 43 & 131 \\
\hline United Kingdom & 8 & 16 \\
\hline
\end{tabular}

Source: Doing Business Database (2017) 
APPENDIX 7: CONVENTIONAL MODELS OF STRATEGIES

\begin{tabular}{|c|c|c|}
\hline Scholars & Strategies proposed & Variables/outcomes \\
\hline Ansoff (1965) & $\begin{array}{ll}\text { - } & \text { Market Development } \\
\text { - } & \text { Diversification } \\
\text { - } & \text { Product Development } \\
\text { - } & \text { Market Penetration }\end{array}$ & $\begin{array}{l}\text { Growth from existing and new } \\
\text { products and new markets }\end{array}$ \\
\hline $\begin{array}{l}\text { Hofer and Schendel } \\
\text { (1978) }\end{array}$ & $\begin{array}{ll}\text { - } & \text { Growth } \\
\text { - } & \text { Profit } \\
\text { - } & \text { Asset Reduction } \\
\text { - } & \text { Turnaround } \\
\text { - } & \text { Share Increasing } \\
\text { - } & \text { Market Concentration }\end{array}$ & $\begin{array}{l}\text { Stage of the } \\
\text { competitive position, evolution } \\
\text { of products/markets }\end{array}$ \\
\hline Porter (1980) & $\begin{array}{ll}\text { - } & \text { Differentiation } \\
\text { - } & \text { Focus-Cost }\end{array}$ & $\begin{array}{l}\text { Strategic strength, scope, and } \\
\text { competitiveness }\end{array}$ \\
\hline Mintzberg (1988) & $\begin{array}{ll}\text { - } & \text { Price Differentiation } \\
\text { - } & \text { Image Differentiation } \\
\text { - } & \text { Support Differentiation } \\
\text { - } & \text { Quality Differentiation } \\
\text { - } & \text { Design Differentiation }\end{array}$ & Differentiation and scope \\
\hline Michael Porter & $\begin{array}{ll}\text { - } & \text { Cost Leadership } \\
\text { - } & \text { Differentiation } \\
\text { - } & \text { Focus-Cost } \\
\text { - } & \text { Focus-Differentiation }\end{array}$ & Competitive advantage \\
\hline Ward et al. (1996) & $\begin{array}{ll}\text { - } & \text { Cost Leadership } \\
\text { - } & \text { Niche Differentiation } \\
\text { - } & \text { Broad Market } \\
\text { - } & \text { Lean Competitiveness } \\
\text { - } & \text { Differentiation }\end{array}$ & $\begin{array}{l}\text { Innovation, products, R\&D, and } \\
\text { market scope. Focus on quality, } \\
\text { price, and asset parsimony }\end{array}$ \\
\hline Hitt et al. (2007) & 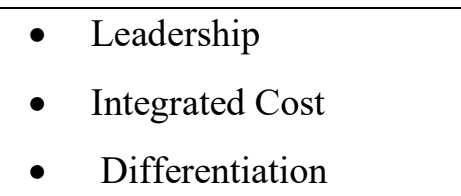 & $\begin{array}{l}\text { Strategic strength, scope, and } \\
\text { competitiveness }\end{array}$ \\
\hline Douglas and Rhee & - Integrated Marketer & Market scope, marketing tactics, \\
\hline
\end{tabular}




\begin{tabular}{|c|c|c|}
\hline (1989) & $\begin{array}{ll}\text { - } & \text { Low Quality } \\
\text { - } & \text { Innovation } \\
\text { - } & \text { Broad Liner } \\
\text { - } & \text { Synergist }\end{array}$ & $\begin{array}{l}\text { business synergy (17 strategy } \\
\text { variables) }\end{array}$ \\
\hline Huang (2001) & $\begin{array}{ll}\text { - } & \text { Stuck in the Middle } \\
\text { - } & \text { Innovation } \\
\text { - } & \text { Cost Leadership }\end{array}$ & About eight strategic statements \\
\hline Hambrick (1983) & $\begin{array}{ll}\text { - } & \text { Broad Based } \\
\text { - } & \text { Asser Conscious Focusers } \\
\text { - } & \text { Cost Leadership } \\
\text { - } & \text { Asset Conscious Followers } \\
\text { - } & \text { Differentiation } \\
\text { - } & \text { Prospectors } \\
\text { - } & \text { High Quality Gendarme }\end{array}$ & $\begin{array}{l}\text { Strategic position and choice } \\
\text { attributes for aggressive markers } \\
\text { of complex and disciplined } \\
\text { capital goods markers }\end{array}$ \\
\hline $\begin{array}{l}\text { Powers and Hahn } \\
\text { (2004) }\end{array}$ & $\begin{array}{l}\text { - } \text { Customer Service Diff. } \\
\text { - } \text { Cost Leadership } \\
\text { - } \text { General Differentiation } \\
\text { - } \text { Stuck in the Middle }\end{array}$ & 26 competitive methods \\
\hline Buzell et al. (1975) & $\begin{array}{ll} & \text { Holding } \\
\text { - } & \text { Building } \\
\text { - } & \text { Harvesting }\end{array}$ & Market share goals \\
\hline $\begin{array}{l}\text { Utterback and } \\
\text { Abernathy (1975) }\end{array}$ & $\begin{array}{ll}\text { - } & \text { Sales Maximising } \\
\text { - } & \text { Performance Maximising } \\
\text { - } & \text { Cost Minimising }\end{array}$ & Innovation process and products \\
\hline $\begin{array}{l}\text { Venkatraman } \\
\text { (1989) }\end{array}$ & $\begin{array}{ll}\text { - } & \text { Futurity } \\
\text { - } & \text { Riskiness } \\
\text { - } & \text { Defensiveness } \\
\text { - } & \text { Pro-Activeness } \\
\text { - } & \text { Analysis } \\
\text { - } & \text { Aggressiveness }\end{array}$ & Orientation strategy \\
\hline Wright el al. (1992) & $\begin{array}{ll}\text { - } & \text { Low Cost Differentiation } \\
\text { - } & \text { Focus Low Cost }\end{array}$ & Firm strength, size, and scope \\
\hline
\end{tabular}




\begin{tabular}{|c|c|c|}
\hline & $\begin{array}{ll}\text { - } & \text { Differentiation } \\
\text { - } & \text { Focus Differentiation }\end{array}$ & \\
\hline Miller (1988) & $\begin{array}{ll}\text { - } & \text { Cost Leaders } \\
\text { - } & \text { Innovators } \\
\text { - } & \text { Niche Marketers } \\
\text { - } & \text { Marketers }\end{array}$ & $\begin{array}{l}\text { Asset intensity, asset parsimony, } \\
\text { business focus }\end{array}$ \\
\hline Chang et al. (2002) & $\begin{array}{ll}\text { - } & \text { Pre-Emptive/First Mover } \\
\text { - } & \text { Differentiation/Follower } \\
\text { - } & \text { Low Cost/Follower }\end{array}$ & $\begin{array}{l}\text { Timing of entry into the } \\
\text { marketplace. Dimensions of } \\
\text { competitive advantage }\end{array}$ \\
\hline $\begin{array}{l}\text { Robinson and } \\
\text { Pearce (1988) }\end{array}$ & 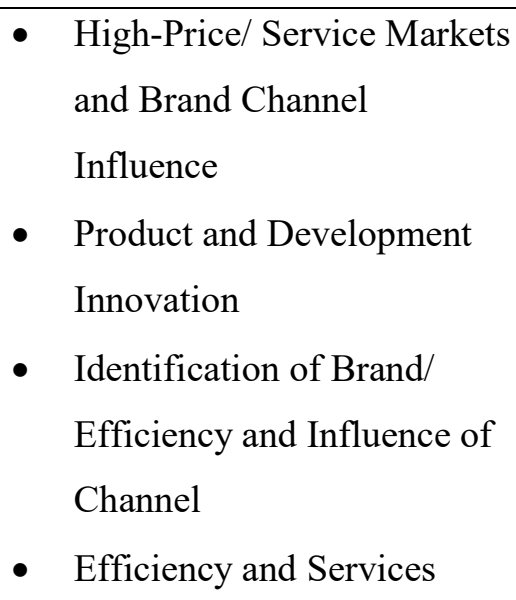 & 27 competitive methods \\
\hline $\begin{array}{l}\text { Galbraith and } \\
\text { Schendel (1983) }\end{array}$ & $\begin{array}{l}\text { - } \text { Growth } \\
\text { - } \text { Maintenance } \\
\text { - } \text { Niche } \\
\text { - Continuity } \\
\text { - Climber } \\
\text { - Cashout } \\
\text { - Niche } \\
\text { - Harvest }\end{array}$ & $\begin{array}{l}\text { Strategy posture and strategy } \\
\text { direction ( } 26 \text { variables) for the } \\
\text { industrial product industry } \\
\text { Strategy posture and strategy } \\
\text { direction ( } 26 \text { variables) for the } \\
\text { consumer goods industry }\end{array}$ \\
\hline $\begin{array}{l}\text { Lillo and Lajara } \\
\text { (2002) }\end{array}$ & $\begin{array}{ll}\text { - } & \text { Differentiation } \\
\text { - } & \text { Aggressive Growth with } \\
\text { - } & \text { Innorrow Special Product } \\
\text { - } & \text { Product Offering }\end{array}$ & $\begin{array}{l}\text { Firm's competitive strategy } \\
\text { described by } 19 \text { variables }\end{array}$ \\
\hline
\end{tabular}




\begin{tabular}{|c|c|c|}
\hline Vesper (1979) & $\begin{array}{ll}\text { - } & \text { Specialisation } \\
\text { - } & \text { Liquidation } \\
\text { - } & \text { Monopolising } \\
\text { - } & \text { Multiplication } \\
\text { - } & \end{array}$ & $\begin{array}{l}\text { Strategic posture-based } \\
\text { flexibility in adapting to the } \\
\text { environment and on superiority }\end{array}$ \\
\hline $\begin{array}{l}\text { Wissema et al. } \\
\text { (1980) }\end{array}$ & $\begin{array}{l}\text { - } \text { Consolidation } \\
\text { - Continuous Growth } \\
\text { - Contraction } \\
\text { - Expansion } \\
\text { - Explosion }\end{array}$ & $\begin{array}{l}\text { Situation of the market and } \\
\text { situation of the company } \\
\text { (possible routes to the desired } \\
\text { strategic position) }\end{array}$ \\
\hline $\begin{array}{l}\text { Thompson and } \\
\text { Strickland (1999) }\end{array}$ & $\begin{array}{l}\text { - } \text { Best Cost Provider } \\
\text { - } \text { Focus } \\
\text { - } \text { Cost Leadership } \\
\text { - } \\
\text { Differentiation }\end{array}$ & Strategic strength and scope \\
\hline Kin and Lim (1988) & $\begin{array}{l}\text { - } \text { Stuck in the Middle } \\
\text { - } \text { Overall Cost Leaders } \\
\text { - } \text { Market Differentiators } \\
\text { - } \\
\text { Product Differentiators }\end{array}$ & 15 strategy variables \\
\hline $\begin{array}{l}\text { Herbert and } \\
\text { Deresky (1987) }\end{array}$ & $\begin{array}{ll}\text { - } & \text { Harvest } \\
\text { - } & \text { Turnaround } \\
\text { - } & \text { Stabilise } \\
\text { - } & \text { Develop }\end{array}$ & Evolution of market/product \\
\hline $\begin{array}{l}\text { Schuler and Jackson } \\
\text { (1987) }\end{array}$ & $\begin{array}{ll}\text { - } & \text { Cost Reduction } \\
\text { - } & \text { Enhancement Quality }\end{array}$ & $\begin{array}{l}\text { Dimensions of competitive } \\
\text { advantage }\end{array}$ \\
\hline $\begin{array}{l}\text { Miles and Cameron } \\
\text { (1982) }\end{array}$ & $\begin{array}{ll}\text { - } & \text { Domain Creation } \\
\text { - } & \text { Domain Defence } \\
\text { - } & \text { Domain Offense }\end{array}$ & Organisational adaptation \\
\hline $\begin{array}{l}\text { Kim and } \\
\text { Mauborgne (1999) }\end{array}$ & - Innovation & Competitive advantage \\
\hline
\end{tabular}

Source: Sumer and Bayraktar (2012) 
APPENDIX 8: BACKLOG OF ALLOWANCES AND SALARIES IN 12 STATES IN NIGERIA

\begin{tabular}{|l|l|}
\hline States & Salaries Arrears \\
\hline Kogi & 15 Months \\
\hline Osun & 12 Months \\
\hline Kwara & 11 Months \\
\hline Bayelsa and Ondo & 7 Months \\
\hline Ekiti, Oyo, and Ogun & 6 Months \\
\hline Benue & 4 Months \\
\hline Nasarawa, Abia, and Imo & 2 Months \\
\hline
\end{tabular}

Source: Ahiuma et al. (2017) 


\section{APPENDIX 9: INTEREST RATES}

CBN (official) Interest rate as of Sep 2018 to date is 14\% (NBS, 2018).

Top 10 Best Bank Interest Rates in Nigeria

\begin{tabular}{|l|l|l|}
\hline Name of Bank & Prime/\% & Maximum/\% \\
\hline (1) First Bank of Nigeria & 20.0 & 28.0 \\
\hline (2) Zenith Bank Nigeria & 20.5 & 31.5 \\
\hline (3) Guaranty Trust Bank & 12.0 & 24.0 \\
\hline (4) Access Bank Nigeria & 14.0 & 30.5 \\
\hline (5) Keystone Bank & 19.0 & 34.0 \\
\hline (6) Ecobank Nigeria & 14.0 & 24.0 \\
\hline (7) Diamond Bank & 20.0 & 30.0 \\
\hline (8) Union Bank & 9.5 & 32.0 \\
\hline (9) Skye Bank & 28.0 & 34.0 \\
\hline (10) Fidelity Bank & 19.0 & 36.0 \\
\hline Sources: Adesanya (2018); Nigeria Gallera (2018) & & \\
\hline
\end{tabular}

Sources: Adesanya (2018); Nigeria Galleria (2018)

Interest Rates in Developed Countries as of Sep 2018

\begin{tabular}{|l|l|}
\hline Developed Countries & Interest Rates/\% \\
\hline United States of America & 2.0 \\
\hline United Kingdom & 0.75 \\
\hline France & 0.00 \\
\hline France & 0.00 \\
\hline Japan & -0.10 \\
\hline
\end{tabular}

Source: Trade Economics (2018) 
APPENDIX 10: RESPONDENTS' NAMES AND DATE VISITED

\begin{tabular}{|c|c|c|c|}
\hline & Organisation Name & Name of Respondent & $\begin{array}{l}\text { Date } \\
\text { Visited }\end{array}$ \\
\hline 1. & $\begin{array}{lr}\text { Innoson } & \text { Vehicle } \\
\text { Manufacturing } & \text { Company } \\
\text { Limited } & \end{array}$ & $\begin{array}{lll}\text { Onusogu } & \text { Nnamdi } & \text { (General } \\
\text { Manager) } & & \\
\end{array}$ & $01 / 02 / 17$ \\
\hline 2 & $\begin{array}{l}\text { Ibeto Group (Union Auto } \\
\text { Parts } \\
\text { Company) }\end{array}$ & $\begin{array}{ll}\text { Uzoewulu Oliver } & \text { (Human } \\
\text { Resource Manager) } & \end{array}$ & $06 / 02 / 17$ \\
\hline 3 & $\begin{array}{l}\text { Divine Grace } \text { Business } \\
\text { Enterprises }\end{array}$ & Ifeanyi Eze (Managing Director) & $08 / 02 / 17$ \\
\hline 4 & Sunny Tex Poly Industries & $\begin{array}{lll}\text { Sunday } & \text { Anaeme } & \text { (Chief } \\
\text { Executive Officer) } & \end{array}$ & $10 / 02 / 17$ \\
\hline 5 & $\begin{array}{lll}\text { Louis } & \text { Carter } & \text { Industries } \\
\text { Limited } & & \\
\end{array}$ & $\begin{array}{l}\text { Festus Chukwumalu (Production } \\
\text { Manager) }\end{array}$ & $13 / 02 / 17$ \\
\hline 6 & $\begin{array}{l}\text { Anyi Solid } \text { Chemical } \\
\text { Industries }\end{array}$ & \begin{tabular}{|lll} 
Ifeanyi & Ukor & (Production \\
Manager) & & \\
\end{tabular} & $15 / 02 / 17$ \\
\hline 7 & Guinness Nigeria, Benin & Joel Afeovoh (Manager) & $17 / 02 / 17$ \\
\hline 8 & Fan Milk Plc, Benin City & Chucks (Senior Manager) & $20 / 02 / 17$ \\
\hline$\overline{9}$ & $\begin{array}{l}\text { I.C. MASCOT Nigeria } \\
\text { Limited, Benin City }\end{array}$ & Susan (Manager) & $22 / 02 / 17$ \\
\hline$\overline{10}$ & $\begin{array}{l}\text { Notre Dame Industrial } \\
\text { Company Limited, Benin } \\
\text { City }\end{array}$ & $\begin{array}{lll}\text { Kelly Fine } & \text { (Production } \\
\text { Manager) } & & \\
\end{array}$ & $24 / 02 / 17$ \\
\hline 11 & $\begin{array}{l}\text { Hentsco Group of Company, } \\
\text { Sapele }\end{array}$ & Henry (Manager) & $27 / 02 / 17$ \\
\hline 12 & $\begin{array}{l}\text { Kings Paints Company, } \\
\text { Benin City }\end{array}$ & Sunday Bade (Manager) & $01 / 03 / 17$ \\
\hline 13 & $\begin{array}{lll}\text { Success } & \text { Business } & \text { Link, } \\
\text { Warri } & & \\
\end{array}$ & $\begin{array}{lll}\text { Ogbodu } & \text { Obed } & \text { (Production } \\
\text { Manager) } & & \\
\end{array}$ & $03 / 03 / 17$ \\
\hline
\end{tabular}




\begin{tabular}{|c|c|c|c|}
\hline 14 & $\begin{array}{l}\text { Nigerian Bottling Company } \\
\text { Limited }\end{array}$ & $\begin{array}{l}\text { Ganiyu Dada Belo (HR } \\
\text { Coordinator) }\end{array}$ & p7/03/17 \\
\hline 15 & $\begin{array}{l}\text { Ife Iron and Steel Nigeria } \\
\text { Limited }\end{array}$ & Stephen Glory (Accountant) & $10 / 03 / 17$ \\
\hline 16 & Tee Key Venture & $\begin{array}{lll}\text { Olayiwola } & \text { Olatunde } & \text { John } \\
\text { (Director) } & & \\
\end{array}$ & $13 / 03 / 17$ \\
\hline 17 & $\begin{array}{l}\text { Yinka Oba Foam Nigeria } \\
\text { Limited }\end{array}$ & $\begin{array}{l}\text { Alhaji Jubri Abdul (General } \\
\text { Manager) }\end{array}$ & $15 / 03 / 17$ \\
\hline 18 & International Breweries Plc & $\begin{array}{l}\text { Hammed Adenuga, (Human } \\
\text { Resource Manager) }\end{array}$ & $17 / 03 / 17$ \\
\hline 19 & $\begin{array}{l}\text { Spring Aluminum, Asejire, } \\
\text { Osun }\end{array}$ & Aloba (Managing Director) & $20 / 03 / 17$ \\
\hline 20 & Aluminum & $\begin{array}{ll}\text { Victor Akpan } & \text { (Factory } \\
\text { Supervisor) } & \end{array}$ & $22 / 03 / 17$ \\
\hline 21 & $\begin{array}{ll}\text { Holdent } & \text { International } \\
\text { Limited } & \end{array}$ & $\begin{array}{l}\text { Ikechukwu Moses (Production } \\
\text { Manager) }\end{array}$ & $24 / 03 / 17$ \\
\hline 22 & $\begin{array}{l}\text { Crown Park, Polythene, and } \\
\text { Plastic Bottle }\end{array}$ & Raji Adeoba (General Manager) & $27 / 03 / 17$ \\
\hline 23 & $\begin{array}{l}\text { Bond Chemical Industry, } \\
\text { Oyo }\end{array}$ & $\begin{array}{l}\text { Olawoyin } \\
\text { (Accountant) }\end{array}$ & $28 / 03 / 17$ \\
\hline 24 & $\begin{array}{l}\text { Multi Bond Venture, Awe, } \\
\text { Oyo }\end{array}$ & $\begin{array}{lll}\text { Adebayo } & \text { David } & \text { (Production } \\
\text { Manager) } & & \\
\end{array}$ & $29 / 03 / 17$ \\
\hline 25 & Sumo Steel, Ota & $\begin{array}{ll}\text { Adebayo Adekunle (Human } \\
\text { Relations Manager) }\end{array}$ & $31 / 03 / 17$ \\
\hline 26 & Altak Industries Limited & Taiwo Abiola Mary (Supervisor) & $03 / 04 / 17$ \\
\hline 27 & Vicky Table Water & $\begin{array}{lll}\text { Sakariyahu } & \text { S. } & \text { Oyindamola } \\
\text { (Accountant) } & & \end{array}$ & $05 / 04 / 17$ \\
\hline 28 & $\begin{array}{l}\text { Wangtok Enterprises (Agro } \\
\text { Chemical) }\end{array}$ & \begin{tabular}{|lr} 
Mohammed & \multicolumn{2}{c}{ Abubakar } \\
(Production & Manager)
\end{tabular} & $12 / 04 / 17$ \\
\hline
\end{tabular}




\begin{tabular}{|l|l|lr|l|} 
& & \multicolumn{2}{|l|}{ Central } & \\
\hline 29 & Grand Cereals and Oil Mills & $\begin{array}{l}\text { Danladi Suleiman (Factory } \\
\text { Supervisor) }\end{array}$ & 17/04/17 \\
\hline 30 & $\begin{array}{l}\text { NASCO Group of Company, } \\
\text { Jos }\end{array}$ & $\begin{array}{l}\text { Anonymous } \\
\text { Manager) }\end{array}$ & (Marketing & 05/05/17 \\
\hline 31 & $\begin{array}{l}\text { Dangote Flour Mill, Ilorin } \\
\text { Plant }\end{array}$ & $\begin{array}{l}\text { Opoola } \\
\text { Administrator) }\end{array}$ & (Environmental & $12 / 05 / 17$ \\
\hline 32 & $\begin{array}{l}\text { Citico Plastic Industrial } \\
\text { Limited }\end{array}$ & $\begin{array}{l}\text { Dara Lawal (Marketing } \\
\text { Manager) }\end{array}$ & \\
\hline
\end{tabular}




\section{APPENDIX 11: EXTERNAL ENVIRONMENTAL ISSUES \\ External environmental issues that undermine the $3 \mathrm{Cs}, \mathrm{CE}$, strategy, and organisational performance}

\begin{tabular}{|c|c|c|}
\hline Organisation Names & Findings (External Environmental Issues) & Themes \\
\hline 4.1 Innoson Vehicle & $\begin{array}{l}\text { Multiple and non-availability of foreign exchange, } \\
\text { high cost of production, imported cars are cheaper }\end{array}$ & $\begin{array}{l}\text { Exchange Rate, } \\
\text { Unregulated } \\
\text { Importations }\end{array}$ \\
\hline 4.2 Ibeto Group & $\begin{array}{l}\text { Inflow of fake batteries and cheaper, multiple } \\
\text { taxes, } \\
\text { unstable policy }\end{array}$ & Policy instability \\
\hline 4.3 Guinness Nigeria & $\begin{array}{l}\text { Economic reasons, Nigerian currency devaluation, } \\
\text { inflation, poverty }\end{array}$ & Inflation Rate \\
\hline 4.4 Fan Milk Plc & $\begin{array}{l}\text { Economic recession and unpredictable financial } \\
\text { markets }\end{array}$ & $\begin{array}{l}\text { Access to } \\
\text { Finances }\end{array}$ \\
\hline 4.6 Vicky Table & $\begin{array}{l}\text { Economic recession, cost of production, and } \\
\text { inflation }\end{array}$ & $\begin{array}{l}\text { Infrastructure } \\
\text { Deficits }\end{array}$ \\
\hline 4.7 Breweries Plc & Inflation, not paying salaries, drink as a luxury & $\begin{array}{l}\text { Consumer } \\
\text { Spending }\end{array}$ \\
\hline 4.8 Nigerian Bottling & $\begin{array}{l}\text { On health grounds that the drinks have too much } \\
\text { sugar }\end{array}$ & $\begin{array}{l}\text { Violence and } \\
\text { Criminality }\end{array}$ \\
\hline 4.9 Grand Cereals & $\begin{array}{l}\text { Ban on the importation of their major raw material } \\
\text { (wheat), with no alternative }\end{array}$ & $\begin{array}{l}\text { Inconsistent } \\
\text { Government } \\
\text { Policy }\end{array}$ \\
\hline 4.10 NASCO Group & $\begin{array}{l}\text { Poor salary schemes and salary areas affect } \\
\text { consumers }\end{array}$ & $\begin{array}{l}\text { Consumer } \\
\text { Spending, Access } \\
\text { to Finances }\end{array}$ \\
\hline 4.11 Dangote Four & $\begin{array}{l}\text { Tribal and religion wars that shut down the factory } \\
\text { for weeks }\end{array}$ & $\begin{array}{l}\text { Violence and } \\
\text { Criminality }\end{array}$ \\
\hline 4.12 Multi Bond & $\begin{array}{l}\text { Maintenances of generator sets tripled the cost of } \\
\text { production }\end{array}$ & $\begin{array}{l}\text { Inadequate } \\
\text { Power Supply }\end{array}$ \\
\hline
\end{tabular}




\begin{tabular}{|c|c|c|}
\hline 4.13 Louis Carter & Inadequate funding & $\begin{array}{l}\text { Access to } \\
\text { Finances } \\
\text { Inflation Rate }\end{array}$ \\
\hline 4.14 Sunny Tex & $\begin{array}{l}\text { Multiple interest rate, tribal war (IPOD), } \\
\text { and Fulani herdsmen killing }\end{array}$ & $\begin{array}{l}\text { Access to } \\
\text { Finances } \\
\text { Violence and } \\
\text { Criminality }\end{array}$ \\
\hline 4.15 I.C. MASCOT & Economic recession, multiple interest rates & \\
\hline 4.16 Altak Industries & Rationing dollars to sectors, poverty & $\begin{array}{l}\text { Socio-Cultural } \\
\text { Influences and } \\
\text { Consumer } \\
\text { Spending }\end{array}$ \\
\hline 4.17 Tee Key Venture & Financial problems and poor electricity supply & $\begin{array}{l}\text { Exchange rate, } \\
\text { Inflation, } \\
\text { Infrastructure } \\
\text { Deficits }\end{array}$ \\
\hline 4.18 Crown Park & $\begin{array}{l}\text { Inequality due to tribalism and religious sparks } \\
\text { extensive social unrest }\end{array}$ & $\begin{array}{l}\text { Geopolitical and } \\
\text { Socio-cultural } \\
\text { Influences }\end{array}$ \\
\hline 4.19 Citico Plastic & Lack of security and properties & $\begin{array}{l}\text { Violence and } \\
\text { Criminality }\end{array}$ \\
\hline 4.20 Kings Paints & $\begin{array}{l}\text { Delay from the clearing of the consignment, } \\
\text { corruption }\end{array}$ & $\begin{array}{l}\text { Inefficient } \\
\text { Transport, } \\
\text { Unregulated } \\
\text { Importations, and } \\
\text { Socio-Cultural } \\
\text { Influences }\end{array}$ \\
\hline 4.21 Anyi Solid & Inequality, social unrest & $\begin{array}{l}\text { Geopolitical and } \\
\text { Socio-Cultural } \\
\text { Influences }\end{array}$ \\
\hline 4.22 Bond Chemical & Security issues; chairman was kidnapped & $\begin{array}{l}\text { Violence and } \\
\text { Criminality }\end{array}$ \\
\hline 4.23 Wangtok & Removal of fuel subsidy and non-availability & Consumer \\
\hline
\end{tabular}




\begin{tabular}{|c|c|c|}
\hline & of facilities and resources & $\begin{array}{l}\text { Spending, Access } \\
\text { to Finances }\end{array}$ \\
\hline 4.24 Hentsco Group & Economic recession & $\begin{array}{l}\text { Inflation Rate, } \\
\text { Multiple exchange } \\
\text { rate and Consumer } \\
\text { Spending, }\end{array}$ \\
\hline 4.25 Highland & High cost of production & $\begin{array}{l}\text { Inflation Rate, } \\
\text { Infrastructure } \\
\text { Deficits, Violence } \\
\text { and } \\
\text { Criminality, } \\
\text { Consumer } \\
\text { Spending }\end{array}$ \\
\hline 4.26 Spring & $\begin{array}{l}\text { Electricity damage the company's machinery } \\
\text { beyond } \\
\text { repair, high cost of input local materials }\end{array}$ & $\begin{array}{l}\text { Infrastructure } \\
\text { Deficits, } \\
\text { Inflation Rate }\end{array}$ \\
\hline $\begin{array}{l}\text { 4.27 Holdent } \\
\text { Aluminium }\end{array}$ & Corruption and inconsistent policies & $\begin{array}{l}\text { Socio-Cultural } \\
\text { Influences }\end{array}$ \\
\hline 4.28 Success Business & High cost of production & \\
\hline 4.29 Iron and Steel & $\begin{array}{l}\text { Staff in the organisation are not motivated and lack } \\
\text { commitment; bad government policies }\end{array}$ & $\begin{array}{l}\text { Lack of } \\
\text { Commitment, Bad } \\
\text { Government } \\
\text { Policies }\end{array}$ \\
\hline 4.30 Sumo Steel & $\begin{array}{l}\text { High price of exchange rate, devaluation of } \\
\text { Nigerian currency and inflation, and local materials } \\
\text { are unavoidable }\end{array}$ & $\begin{array}{l}\text { Lack of Raw } \\
\text { Materials } \\
\text { Inflation, } \\
\text { Exchange Rate }\end{array}$ \\
\hline 4. 31 Yinka Oba & $\begin{array}{l}\text { No resources and facilities to function at full } \\
\text { capacity }\end{array}$ & $\begin{array}{l}\text { Exchange Rate, } \\
\text { Access to } \\
\text { Finances, } \\
\text { Infrastructure } \\
\text { Deficits }\end{array}$ \\
\hline
\end{tabular}




\begin{tabular}{|l|l|l|}
\hline 4.32 Divine Grace & Nigerians prefer to buy imported shoes, and & Unregulated \\
government policies favour one industry over & Importations, \\
& others & Socio- \\
& & Cultural \\
& & Influences \\
\hline
\end{tabular}


EXTERNAL AND STRATEGIC DEVELOPMENT SERVICES

vel.ac.uk/qa

Quality Assurance and Enhancement

Approved Documents

The final list of documents reviewed and approved by the Committee is as follows:

\begin{tabular}{|l|l|l|}
\hline Document & Version & Date \\
\hline UREC application form & 2.0 & 15 February 2016 \\
\hline Participant information sheet & 3.0 & 22 February 2016 \\
\hline Consent form & 2.0 & 15 February 2016 \\
\hline Interview schedule & 1.0 & 17 December 2015 \\
\hline
\end{tabular}

Approval is given on the understanding that the UEL Code of Practice in Research is adhered to.

The University will periodically audit a random sample of applications for ethical approval, to ensure that the research study is conducted in compliance with the consent given by the ethics Committee and to the highest standards of rigour and integrity.

Please note, it is your responsibility to retain this letter for your records.

With the Committee's best wishes for the success of this project.

Yours sincerely,

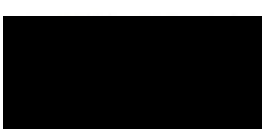

Rosalind Eccles

University Research Ethics Committee (UREC)

UREC Servicing Officer

Email: rescarchethics@uel.ac.uk 
EXTERNAL AND STRATEGIC DEVELOPMENT SERVICES

vel.aciuk ca

Quality Assurance and Enhancement

25 February 2016

Dear Segun

\begin{tabular}{|l|l|}
\hline Project Title: & $\begin{array}{l}\text { The contexts of corporate entrepreneurship and performance } \\
\text { in Nigeria }\end{array}$ \\
\hline $\begin{array}{l}\text { Principal } \\
\text { Investigator: }\end{array}$ & Professor Sonny Nwankwo \\
\hline Researcher: & Segun Omisore \\
\hline Reference Number: & UREC 1516 37 \\
\hline
\end{tabular}

I am writing to confirm the outcome of your application to the University Research Ethics Committee (UREC), which was considered by UREC on Wednesday $20^{\text {th }}$ January 2016.

The decision made by members of the Committee is Approved. The Committee's response is based on the protocol described in the application form and supporting documentation. Your study has received ethical approval from the date of this letter.

Should you wish to make any changes in connection with your research project, this must reported immediately to UREC. A Notification of Amendment form should be submitted for approval, accompanied by any additional or amended documents:

of uk/wwwmedia/schools/qraduate/documents/Notification-of-Amendmentto-Approved-Ethics-App-150115.doc

Any adverse events that occur in connection with this research project must be reported immediately to UREC.

\section{Approved Research Site}

I am pleased to confirm that the approval of the proposed research applies to the following research site.

\begin{tabular}{|l|l|}
\hline Research Site & $\begin{array}{l}\text { Principal Investigator I Local } \\
\text { Collaborator }\end{array}$ \\
\hline Locations in Nigeria agreed with participants & Professor Sonny Nwankwo \\
\hline
\end{tabular}

Dockiands Campus, Uwiversity Way, London E16 2PD

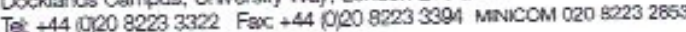
Email: r.carterisurel.ac.uk

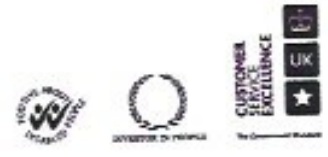


Dear Segun

Application ID: ETH1819-0221

Original application ID: UREC151637

\section{Project title: Corporate Entrepreneurship, Strategy-making, and Performance of the Nigerian Manufacturing Sector}

Lead researcher: Mr Segun Omisore

Your application to Professional Services College Research Ethics Board was considered on the 13th of August 2019.

The decision is: Approved

The Committee's response is based on the protocol described in the application form and supporting documentation.

Your project has received ethical approval for 2 years from the approval date.

If you have any questions regarding this application please contact your supervisor or the secretary for the Professional Services College Research Ethics Board.

Approval has been given for the submitted application only and the research must be conducted accordingly.

Should you wish to make any changes in connection with this research project you must complete

'An application for approval of an amendment to an existing application'.

Approval is given on the understanding that the UEL Code of Practice for Research and the Code of Practice for Research Ethics is adhered to.

Any adverse events or reactions that occur in connection with this research project should be reported using the University's form for Reporting an Adverse/Serious Adverse Event/Reaction.

The University will periodically audit a random sample of approved applications for ethical approval, to ensure that the research projects are conducted in compliance with the consent given by the Research Ethics Committee and to the highest standards of rigour and integrity.

Please note, it is your responsibility to retain this letter for your records. With the Committee's best wishes for the success of the project

Yours sincerely

Fernanda Silva 